Florida International University

FIU Digital Commons

$10-30-2018$

\title{
A Mixed Method Study of Prospective Teachers' Epistemic Beliefs and Web Evaluation Strategies Concerning Hoax Websites
}

Jennifer Coccaro-Pons

jcocc001@fiu.edu

Follow this and additional works at: https://digitalcommons.fiu.edu/etd

Part of the Communication Commons, Computer Sciences Commons, Curriculum and Instruction Commons, Epistemology Commons, Language and Literacy Education Commons, Online and Distance Education Commons, Science and Technology Studies Commons, and the Teacher Education and Professional Development Commons

\section{Recommended Citation}

Coccaro-Pons, Jennifer, "A Mixed Method Study of Prospective Teachers' Epistemic Beliefs and Web Evaluation Strategies Concerning Hoax Websites" (2018). FIU Electronic Theses and Dissertations. 3911. https://digitalcommons.fiu.edu/etd/3911

This work is brought to you for free and open access by the University Graduate School at FIU Digital Commons. It has been accepted for inclusion in FIU Electronic Theses and Dissertations by an authorized administrator of FIU Digital Commons. For more information, please contact dcc@fiu.edu. 


\section{FLORIDA INTERNATIONAL UNIVERSITY}

Miami, Florida

\section{A MIXED METHOD STUDY OF PROSPECTIVE TEACHERS' EPISTEMIC BELIEFS AND WEB EVALUATION STRATEGIES CONCERNING HOAX WEBSITES}

A dissertation submitted in partial fulfillment of the requirements for the degree of DOCTOR OF PHILOSOPHY

in CURRICULUM AND INSTRUCTION

by

Jennifer Coccaro-Pons 
To: Dean Michael R. Heithaus

College of Arts, Science and Education

This dissertation, written by Jennifer Coccaro-Pons, and entitled A Mixed Method Study of Prospective Teachers' Epistemic Beliefs and Web Evaluation Strategies Concerning Hoax Websites, having been approved in respect to style and intellectual content, is referred to you for judgement.

We have read this dissertation and recommend that it be approved.

Flavia Iuspa

Maria Lovett

Sarah Mathews

M. O. Thirunarayanan, Major Professor

Date of Defense: October 30, 2018

The dissertation of Jennifer Coccaro-Pons is approved.

Dean Michael R. Heithaus
College of Arts, Sciences and Education

College of Arts, Sciences and Education

Andrés G. Gil

Vice President for Research and Economic Development and Dean of the University Graduate School

Florida International University, 2018 
(C) Copyright 2018 by Jennifer Coccaro-Pons

All rights reserved. 


\section{DEDICATION}

This dissertation is dedicated to my grandfather Jose M. Meyer, who I promised at an early age that I would someday get a Ph.D., just like him. Even though he is now in heaven with my grandmother, Yolanda Fernandez Meyer, I know that somehow this accomplishment will reach them. I feel that they will be happy to know that I kept my promise. I also dedicate this dissertation to my mother, Dazheyra Meyer Coccaro and father, Luis F. Coccaro, who have lovingly supported all my dreams. 


\section{ACKNOWLEDGMENTS}

I would like to thank, from the bottom of my heart, my parents, Luis F. Coccaro and Dazheyra Meyer Coccaro, as well as my sisters Angy and Dazhe, for always encouraging and believing in me. Also, I know that Tia Angela Cruz (in heaven) will be happy to know that I finally finished what she saw me start so many years ago and of course my mother-in-law, Angela Pons and brother-in-law, Alexander Pons, who I love as a second mom and big brother.

This academic journey would not have been possible without my major professor, Dr. M. O. Thirunarayanan, which I am thankful for always supporting and guiding me. His feedback and meetings throughout the years, enriched my mind and soul. Also, my sincerest appreciation goes to Dr. Sarah Mathews, Dr. Maria Lovett, Dr. Flavia Iuspa and Dr. Eric Dwyer for the time spent in reading this dissertation and providing valuable feedback.

Last but not least, I would like to thank my loving husband, Eugene Pons and my children Sabrina and Nicholas, who are my pride and joy, for always supporting me. I hope that I am able to encourage and motivate them to pursue their academic and personal dreams by always trying to do better than the day before and never giving up. I remember that I told my children at the beginning of this journey that I was going to start working on my dissertation and they thought it meant something related to food. I asked them what they thought it meant and they said, "I think dissertation means a "dessert" that gives you a good "sensation?" Now I can finally say that they were sort of right because it is indeed a sweet sensation to finish it! I will end with thanking God and with my husband's trademark words... little by little, you get to a lot. 


\begin{abstract}
OF THE DISSERTATION
A MIXED METHOD STUDY OF PROSPECTIVE TEACHERS' EPISTEMIC BELIEFS

AND WEB EVALUATION STRATEGIES CONCERNING HOAX WEBSITES
\end{abstract}

by

\author{
Jennifer Coccaro-Pons
}

Florida International University, 2018

Miami, Florida

Professor M. O. Thirunarayanan, Major Professor

Teachers need to be equipped with the tools necessary to evaluate content on the Internet and determine if it is a credible source, or a hoax website since they are expected to instruct and prepare students on how to evaluate the sites which is now a relevant phenomenon. The purpose of the mixed-method study was to obtain an understanding of the web evaluation strategies of prospective teachers regarding the evaluation of hoax websites and how their epistemic beliefs may influence their evaluation. Another aspect of this study was to find out what outcomes resulted from providing guidance, or not to prospective teachers before evaluating the hoax websites.

Seventy-two prospective teachers from undergraduate education courses completed an online questionnaire, where they evaluated four websites (two hoaxes and two credible) and completed questions regarding their epistemic beliefs. Two groups of prospective teachers were selected. Group A was the control group and Group B was the experiment group. Group A simply took the online questionnaire. However, Group B was provided with an overview of a specific web evaluation strategy, the WWWDOT Framework, before taking the online questionnaire. Sixteen participants were 
interviewed. Interestingly, almost half of the participants (48.6\%), trusted at least one of the hoax websites.

The study concluded that teaching the WWWDOT Framework helped to increase the number of people that did not trust the aesthetically appealing hoax website in Group B. Regarding epistemic beliefs, prospective teachers, who displayed feeling-based epistemic beliefs, tended to trust the hoax website that was aesthetically appealing in Group A. The qualitative results provided additional insights and supported the quantitative data. The qualitative research suggests that lateral reading, spending sufficient time to read and evaluate and knowing the definition of a hoax website as being the most important web evaluation strategies displayed by those that did not trust the hoax websites. 


\section{TABLE OFCONTENTS}

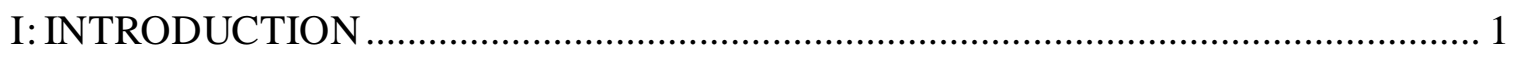

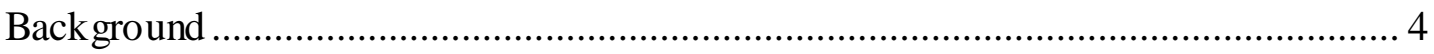

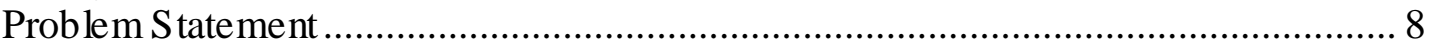

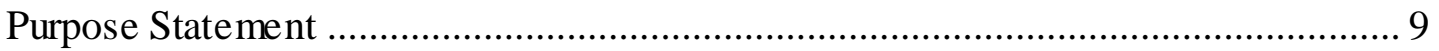

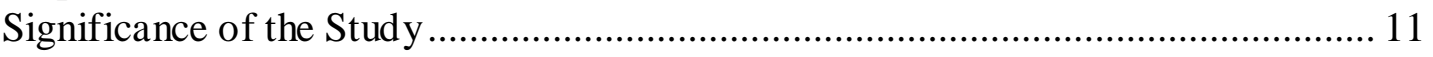

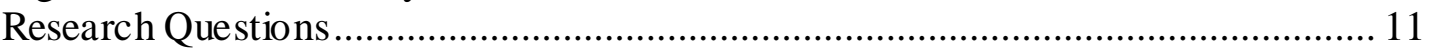

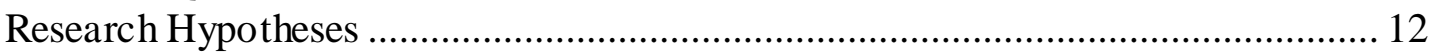

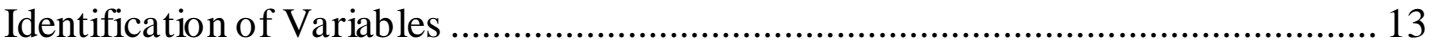

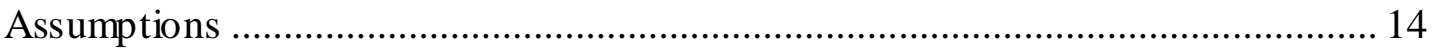

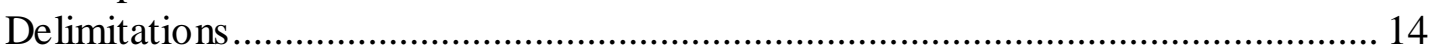

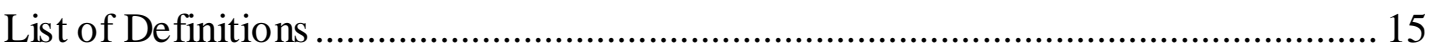

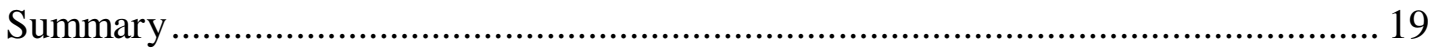

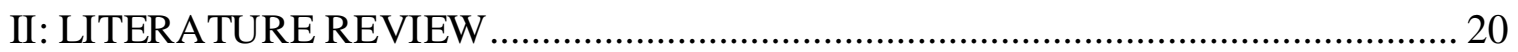

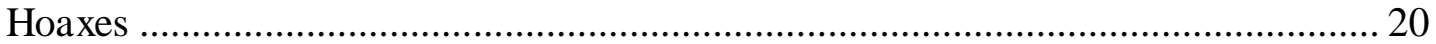

Hoax Websites and Related Fake Sites ................................................................ 30

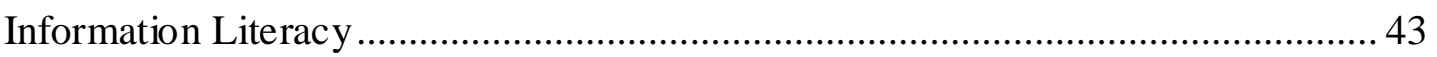

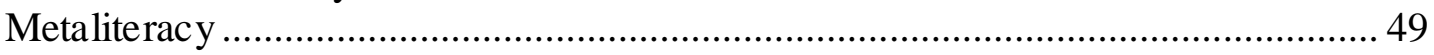

Website/Information Evaluation Criteria and Tools ................................................5

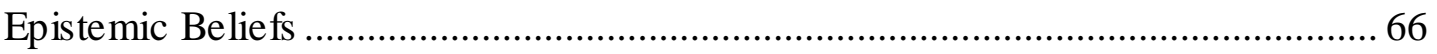

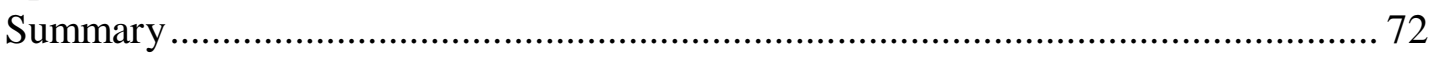

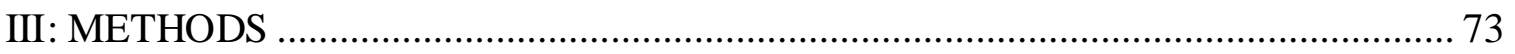

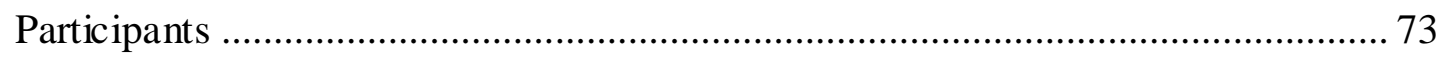

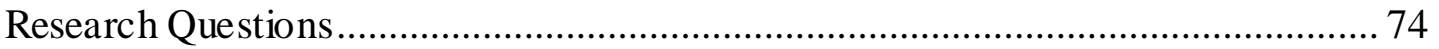

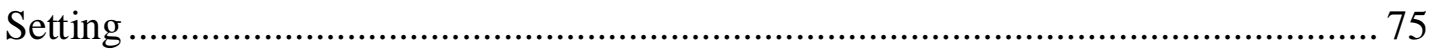

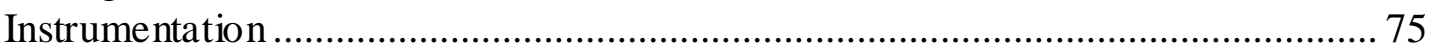

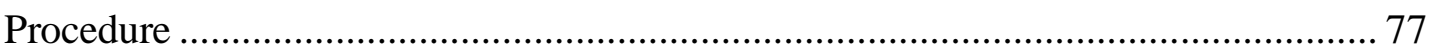

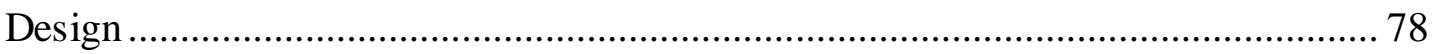

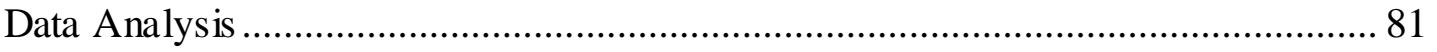

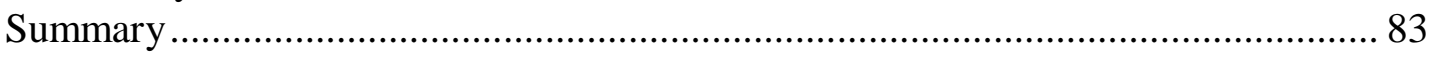

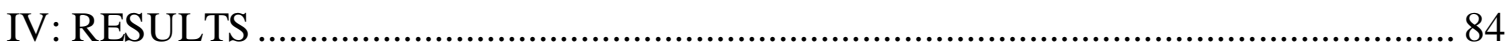

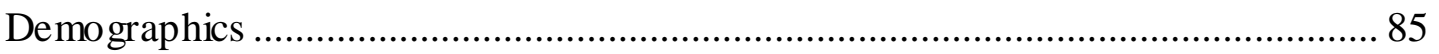

Quantitative Analysis of Questionnaire Data ....................................................... 89

Qualitative Analysis of Interview Data ............................................................. 148

Results for Research Question \#1 ...................................................................... 282

Results for Research Question \#2 ..................................................................... 283

Results for Research Question \#3 ...................................................................... 284 
Summary

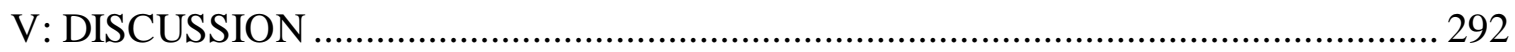

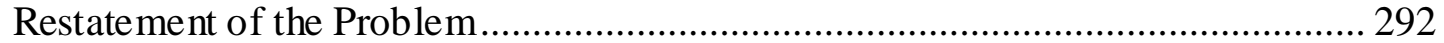

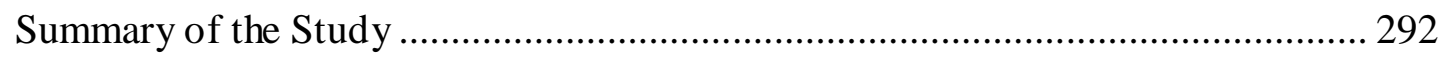

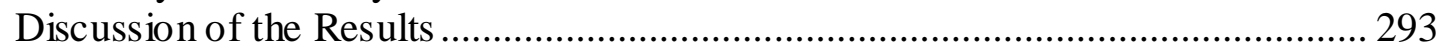

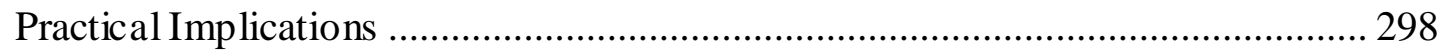

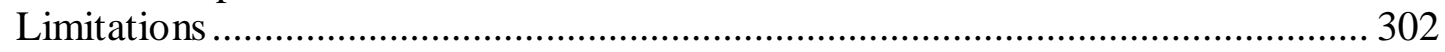

Recommendations for Future Research........................................................ 303

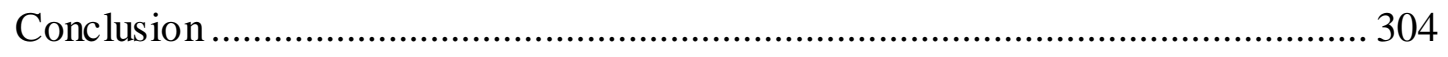

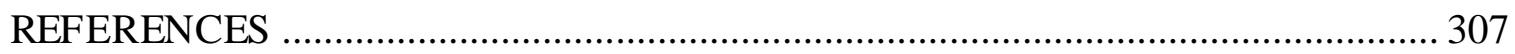

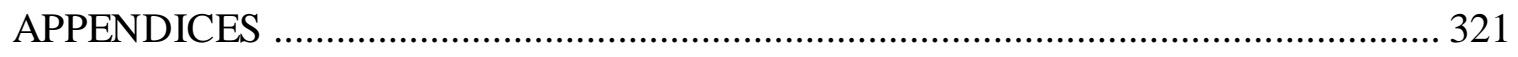

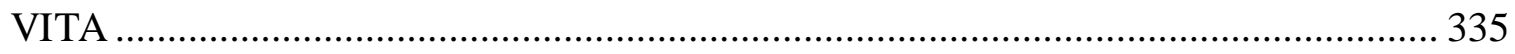




\section{LIST OF TABLES}

TABLE

PAGE

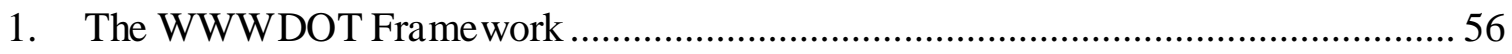

2. Information on University's Undergraduate Population ...................................... 74

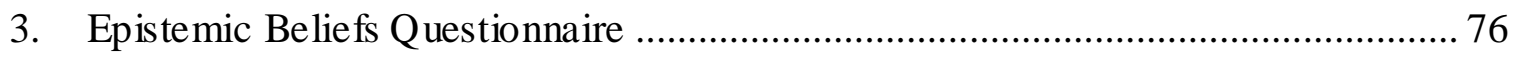

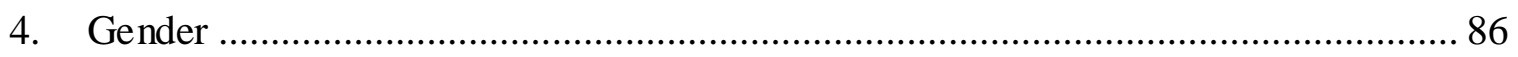

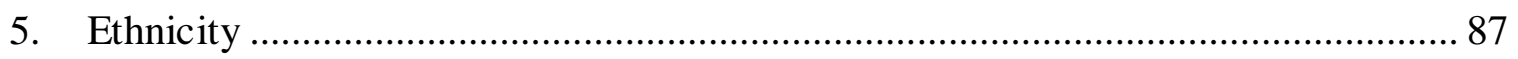

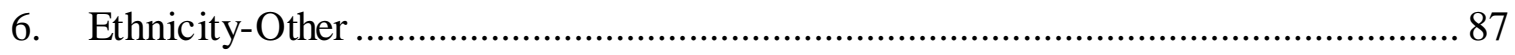

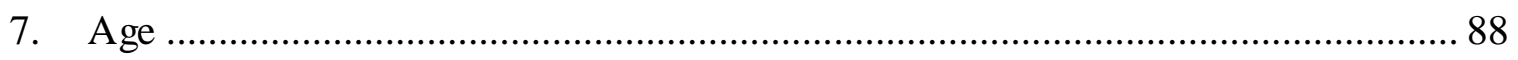

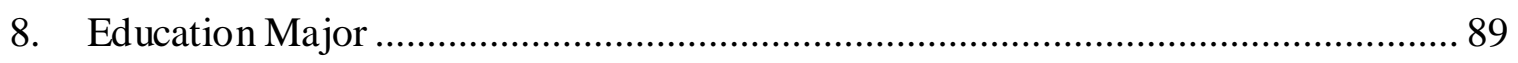

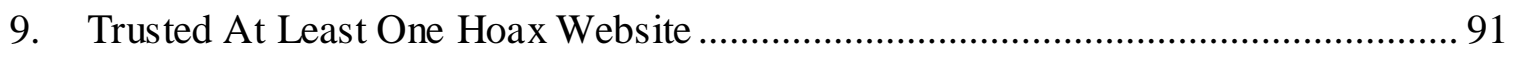

10. DHMO.org Group and Trust Variables ........................................................... 93

11. DHMO.org Aesthetic Appeal and Trust Variables for Total .............................. 96

12. DHMO.org Organization and Trust Variables for Total ..................................... 99

13. DHMO.org Organization and Trust Variables for Group A .............................. 101

14. DHMO.org Visit in the Future and Trust Variables for Total.............................. 104

15. DHMO.org Visit in the Future and Trust Variables for Group B ......................... 106

16. DHMO.org Useful and Trust Variables for Total ......................................... 108

17. DHMO.org Useful and Trust Variables for Group A....................................... 109 
18. DHMO.org Useful and Trust Variables for Group B

19. Frequencies DHMO.org-Open Text for Total.

20. Frequencies DHMO.org-Open Text for Group A

21. Frequencies DHMO.org-Open Text for Group B

22. Tree Octopus Group and Trust Variables

23. Tree Octopus Aesthetic Appeal and Trust Variables for Total

24. Tree Octopus Aesthetic Appeal and Trust Variables for Group A

25. Tree Octopus Organization and Trust Variables for Total

26. Tree Octopus Visit in the Future and Trust Variables for Total

27. Tree Octopus Visit in the Future and Trust Variables for Group A.

28. Tree Octopus Visit in the Future and Trust Variables for Group B 130

29. Tree Octopus Useful and Trust Variables for Total 132

30. Tree Octopus Useful and Trust Variables for Group A

31. Tree Octopus Useful and Trust Variables for Group B.

32. Frequencies Tree Octopus-Open Text for Total 136

33. Frequencies Tree Octopus-Open Text for Group A 138

34. Frequencies Tree Octopus-Open Text for Group B 140

35. Epistemic Beliefs Frequencies 141

36. Epistemic Beliefs Combinations 142 
37. Feeling Epistemic Beliefs

38. Probability Values for Independent Variables and Dependent Variable Trust ....... 146

39. Trusted-Aesthetic Appeal, Not Spending Sufficient Time to Read and Evaluate

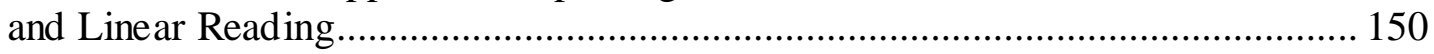

40. Trusted-Not Knowing the Definition of a Hoax Website ......................................... 152

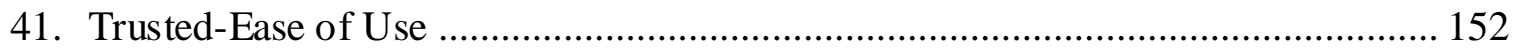

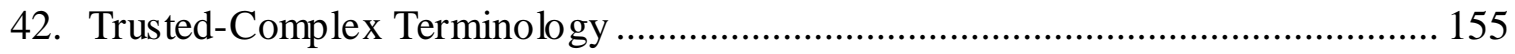

43. Trusted-Knowing the Definition of a Hoax Website ………………………........ 155

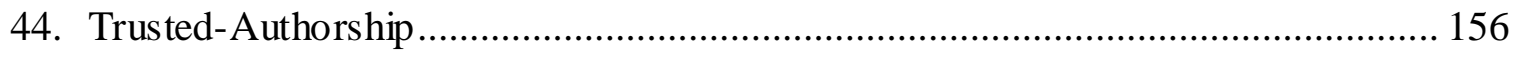

45. Trusted-Not Using WWWDOT Framework …………………………………..... 157

46. Trusted-No Experience Evaluating Websites .......................................................... 158

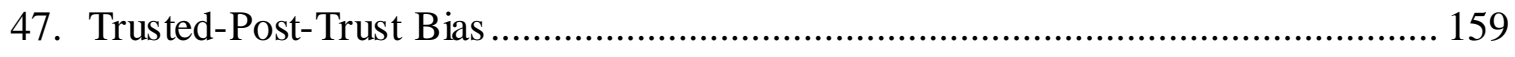

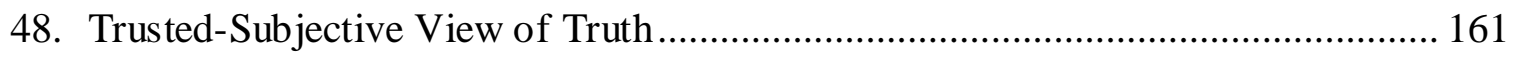

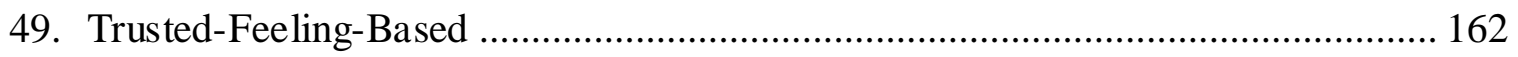

50. Trusted-Empirical View of Knowledge ................................................................ 163

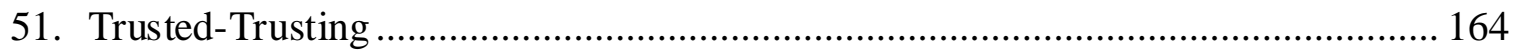

52. Trusted-Being Open-Minded and Aware of Own Bias ......................................... 165

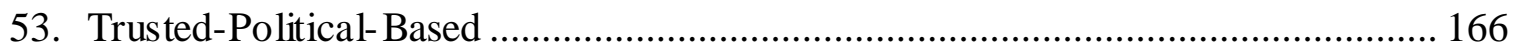

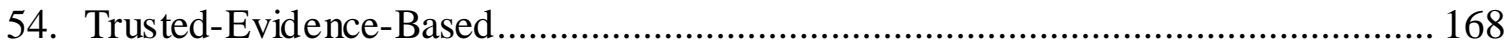

55. Trusted-Combination of Feeling and Evidence …….............................................. 169 
56. Trusted One-Aesthetic Appeal

57. Trusted One-Not Spending Sufficient Time to Read and Evaluate 172

58. Trusted One-Complex Terminology 173

59. Trusted One-Knowing the Definition of a Hoax Website and Poor Design/Layout 174

60. Trusted One-Citations 175

61. Trusted One-Prior Knowledge 176

62. Trusted One-Authorship, Lateral Reading, Linear Reading and Ease of Use 178

63. Trusted One-Not Letting Design Affect Decision to Trust Content 179

64. Trusted One-Making Sense 180

65. Trusted One-Experience Evaluating Websites 182

66. Trusted One-Useful and WWWDOT Framework 183

67. Trusted One-Subjective View of Truth 184

68. Trusted One-Post-Truth Bias 186

69. Trusted One-Being Open-Minded and Aware of Own Bias 188

70. Trusted One-Empirical View of Knowledge 189

71. Trusted One-Evidence-based and Political-Based 190

72. Trusted One-Feeling-Based 193

73. Trusted One-Skeptical and Trusting..... 194

74. Trusted One-Combination of Feeling and Evidence 194 
75. Not Trusted-Lateral Reading 196

76. Not Trusted-Spending Sufficient Time to Read and Evaluate 198

77. Not Trusted-Aesthetic Appeal

78. Not Trusted-Authorship.

79. Not Trusted-Ads/Asking for Money 202

80. Not Trusted-Not Making Sense 204

81. Not Trusted-Ease of Use 205

82. Not Trusted-Knowing the Definition of a Hoax Website and Useful/Applicable .. 206

83. Not Trusted-Prior Knowledge 207

84. Not Trusted-Experience Evaluating Websites 209

85. Not Trusted-Poor Design/Layout 210

86. Not Trusted- Citations 213

87. Not Trusted-Not Knowing the Definition of a Hoax Website 213

88. Not Trusted-WWWDOT Framework 214

89. Not Trusted-Not Letting Design Affect Decision to Trust Content 216

90. Not Trusted-Combination of Feeling and Evidence 218

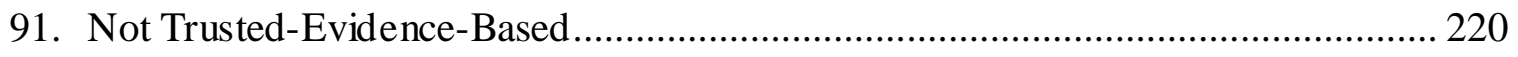

92. Not Trusted-Objective View of Truth 221

93. Not Trusted-Skeptical. 222 
94. Not Trusted-Multidimensional View of Knowledge.

95. Not Trusted-Feeling-Based

96. Not Trusted-Empirical View of Knowledge 225

97. Not Trusted-Being Open-Minded and Aware of Own Bias 225

98. Not Trusted-Post-Truth Bias 227

99. Not Trusted-Political-Based 228

100. Neutral-Aesthetic Appeal 229

101. Neutral-Knowing the Definition of a Hoax Website. 230

102. Neutral-Prior Knowled ge 231

103. Neutral-No Prior Knowledge 232

104. Neutral-Not Making Sense 233

105. Neutral-Not Spending Sufficient Time to Read and Evaluate 233

106. Neutral-Poor Design/Layout 234

107. Neutral-Linear Reading 237

108. Neutral-Authorship. Ads/Asking for Money and Complex Terminology 238

109. Neutral-Not Useful 239

110. Neutral-Lateral Reading and WWWDOT Framework 240

111. Neutral-No Experience Evaluating Websites and Ease of Use 241

112. Neutral-Useful Applicable 
113. Neutral-Evidence-Based

114. Neutral-Combination of Feelings and Evidence 243

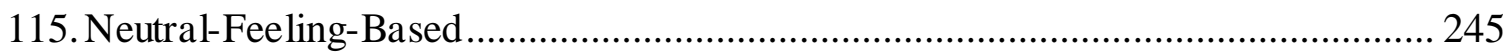

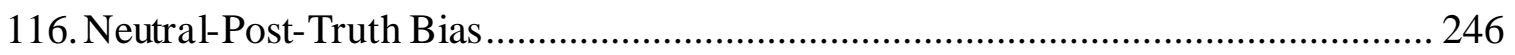

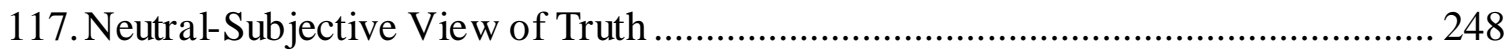

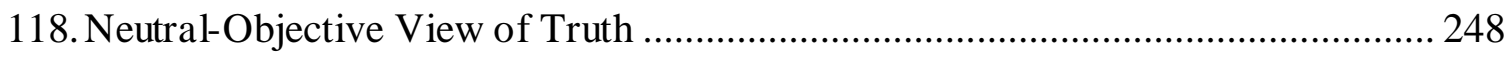

119. Neutral-Multidimensional View of Knowled ge ................................................. 250

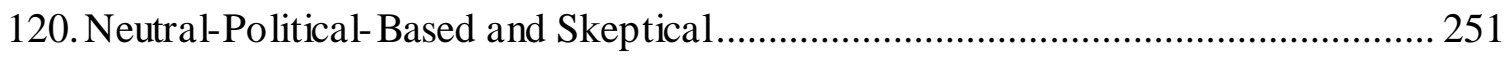

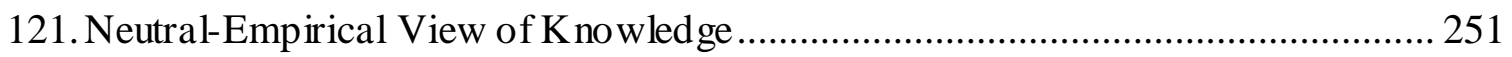




\section{LIST OF FIGURES}

FIGURE

PAGE

1. Tweet on fake news by President Donald J. Trump ................................................ 34

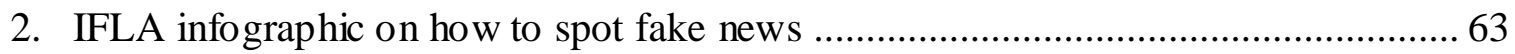

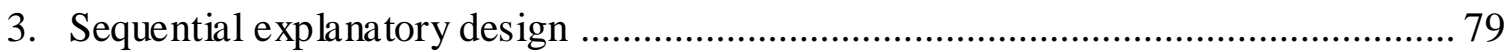

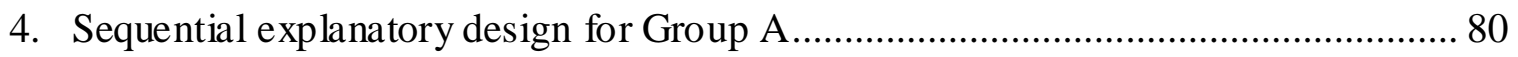

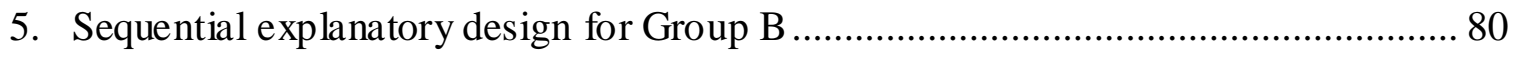

6. Comparison of results between Group A and Group B ....................................... 81

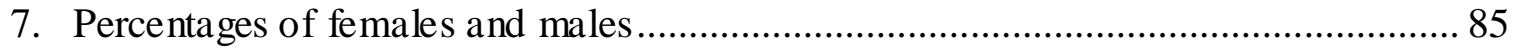

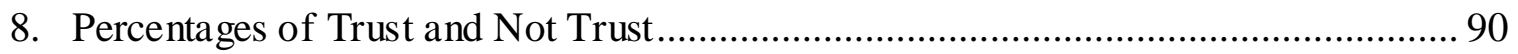

9. Comparison of Group A and Group B with trust variable ..................................... 91

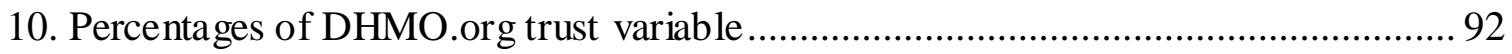

11. Comparison of Group A and Group B with DHMO.org trust variable ..................... 93

12. Percentages of DHMO.org aesthetic appeal .................................................. 95

13. Comparison of DHMO.org aesthetic appeal and trust variable for all participants.... 96

14. Comparison of DHMO.org aesthetic appeal and trust variable for Group A .............97

15. Comparison of DHMO.org aesthetic appeal and trust variable for Group B ............ 98

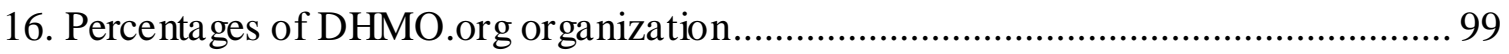

17. Comparison of DHMO.org organization and trust variable for all participants ....... 100

18. Comparison of DHMO.org organization and trust variable for Group A................ 101 
19. Comparison of DHMO.org organization and trust variab le for Group B 102

20. Percentages of DHMO.org visit in the future 103

21. Comparison of DHMO.org visit in the future and trust variable for all participants. 104

22. Comparison of DHMO.org visit in the future and trust variable for Group A 105

23. Comparison of DHMO.org visit in the future and trust variable for Group B 106

24. Percentages of DHMO.org useful. 107

25. Comparison of DHMO.org useful and trust variable for all participants 108

26. Comparison of DHMO.org useful and trust variable for Group A. 109

27. Comparison of DHMO.org useful and trust variable for Group B. 110

28. Comparison of DHMO.org open text and trust variable for all participants 112

29. Comparison of DHMO.org open text and trust variable for Group A. 114

30. Comparison of DHMO.org open text and trust variable for Group B 115

31. Percentages of Tree Octopus trust variable 116

32. Comparison of Tree Octopus trust variables for Group A and Group B 117

33. Percentages of Tree Octopus for aesthetic appeal 118

34. Comparison of Tree Octopus aesthetic appeal and trust variable for all participants

35. Comparison of Tree Octopus aesthetic appeal and trust variable for Group A

36. Comparison of Tree Octopus aesthetic appeal and trust variable for Group B

37. Percentages of Tree Octopus organization. 123 
38. Comparison of Tree Octopus organization and trust variable for all participants ... 124

39. Comparison of Tree Octopus organization and trust variable for Group A ............. 125

40. Comparison of Tree Octopus organization and trust variable for Group B.............. 126

41. Percentages of Tree Octopus visit in the future variable ....................................... 127

42. Comparison of Tree Octopus visit in the future and trust variable for all participants 128

43. Comparison of Tree Octopus visit in the future and trust variable for Group A ...... 129

44. Comparison of Tree Octopus visit in the future and trust variable for Group B ..... 130

45. Percentages for Tree Octopus useful variable ....................................................... 131

46. Comparison of Tree Octopus useful and trust variable for all participants .............. 132

47. Comparison of Tree Octopus useful and trust variable for Group A........................ 133

48. Comparison of Tree Octopus useful and trust variable for Group B........................ 134

49. Comparison of Tree Octopus open text and trust variable for all participants ......... 137

50. Comparison of Tree Octopus open text and trust variable for Group A................... 139

51. Comparison of Tree Octopus open text and trust variable for Group B.................. 140

52. Comparison of Predominant Epistemic Beliefs and trust variable for Tree Octopus 143

53. Comparison of Tree Octopus Feeling and trust variable for Group A ..................... 144

54. Comparison of Tree Octopus feeling and trust variable for Group B ....................... 145

55. Web Evaluation Strategies for the Trusted Hoax Websites Category ...................... 154

56. Epistemic Beliefs for the Trusted Hoax Websites Category ……….......................... 167 
57. Web Evaluation Strategies for the Trusted One but Not the Other Category

58. Epistemic Beliefs for the Trusted One but Not the Other Category 192

59. Web Evaluation Strategies for the Not Trusted Hoax Websites Category 212

60. Epistemic Beliefs for the Not Trusted Hoax Websites Category 226

61. Web Evaluation Strategies for the Neutral Category 236

62. Epistemic Beliefs for the Neutral Category 249

63. Aesthetic appeal for all categories 253

64. Spending Sufficient Time for all categories 254

65. Not Spending Sufficient Time for all categories 254

66. Lateral reading for all categories 255

67. Linear reading for all categories 255

68. Not Knowing Definition of a Hoax Website for all categories 257

69. Knowing the Definition of a Hoax Website for all categories

70. Combination of feeling and evidence for all categories 260

71. Evidence-Based for all categories 261

72. Feeling-Based for all categories 262

73. Political-Based for all categories 263

74. Objective View of Truth for all categories 264

75. Subjective View of Truth for all categories 264 
76. Trusting for all categories

77. Skeptical for all categories. 266

78. Post-Truth Bias for all categories. 267

79. Being Open-minded and Aware of Own Bias for all categories 267

80. Multidimensional View of Knowledge for all categories. 268

81. Empirical View of Knowledge for all categories 269

82. Suggestions for learning web evaluation 281

83. Epistemic Beliefs and Exposure to Web Evaluation Strategies. 300

84. RTD Web Evaluation Model 301 


\section{CHAPTER I: INTRODUCTION}

The Internet contains an overwhelming wealth of information posted by both credible and deceptive sources. It is important for people to navigate the Internet wisely and differentiate between authentic and fake information, especially educators who need to model critical thinking and information literacy for students to learn. According to the National Center for Education Statistics, in 2015, close to $71 \%$ of students ages 3-18 years of age used the Internet (McFarland, Hussar, de Brey, Snyder, Wang, et al., 2017). The results of the National Center for Education Statistics align with research performed by the U.S. Census Bureau on computer and Internet usage. In 2013, 83.8\% owned a computer, $74.4 \%$ of all households in the U.S. had an Internet subscription, and 63.6\% reported a handheld computer, such as a smartphone (File \& Ryan, 2014). Of the household surveyed, $77.7 \%$ were $15-34$ years old, $82.5 \%$ were $35-44$ years old, $78.7 \%$ were 45-64 years old and 58.3\% were 65 years and older (File \& Ryan, 2014). The highest Internet users among Whites, Blacks and Hispanics were Whites (75\%), Blacks (64\%) and Hispanics (61\%) (Snyder, De Brey, \& Dillow, 2016). Since a large percentage of people are using the Internet, it is imperative that they learn to navigate it with a skeptical mind frame using critical thinking skills.

More than twenty years ago, Nigohosian (1996) noticed that the Internet was a powerful tool for research but recognized that it was also full of misleading information, which included self-publications and websites with misinformation, that needed to be properly evaluated and validated. Proper evaluation and validation is even more relevant today with the explosion of online information riddled with several types of hoaxes and related fake sites. Although there is no official count of how many hoax and fake sites 
exist, a poll from the Pew Research Center found that $64 \%$ of U.S. adults believe that fake news is causing confusion about current events (Barthel, Mitchell, \& Holcomb, 2016). Evaluating information in a critical way is important in order for students and teachers to determine if websites are credible, or not. It is alarming that findings from numerous studies (Asher \& Duke, 2011; Brem, Russell, \& Weems, 2001; Clark \& Slotta 2000; Gasser, Cortesi, Malik \& Lee, 2012; Hirsh, 1999; Wineburg \& McGrew, 2017) indicate that students and some teachers show little reflective activity when evaluating the credibility of websites and/or do not distinguish conflicting information sometimes even abandoning searches after not obtaining the desired results. Even undergraduate university students and history teachers with $\mathrm{Ph} . \mathrm{Ds}$. have fallen victim and been easily deceived by websites containing official looking logos and domain names (Wineburg \& McGrew, 2017). Wineburg and McGrew's (2017) study noticed that professionals that evaluated hoax websites for a living practiced lateral reading, which meant that they exited out from the current website and checked other websites and search engines to verify the accuracy of the information. In contrast, undergraduate students and Ph.D. teachers, tended to read vertically (Wineburg \& McGrew, 2017) also called linear reading. Reading vertically, or linearly means that they stayed within the website to evaluate it. Navigating the internet seems to require the necessity of reading information laterally instead of vertically, especially with the amount of information that is both credible and fake.

The Internet provides little to no barriers to entry to upload information and create websites. A recent study has even demonstrated that low-quality information often goes viral and is shared because of the large volume of misinformation observed online which 
limits the individuals' attention span (Qiu, Oliveira, Shirazi, Flammini, Menczer, 2017). Hence, now more than ever, educators and students need to have the right awareness and tools to evaluate websites and determine if they are credible, or a hoax. Speed, no restrictions, easiness of obtaining data are attractive features of the Internet, but they are also the reasons that lead to issues of lack of privacy, fraud, and the propagation of misinformation (Kerka, 1996). Prospective teachers need to be exposed to various types of hoax websites during their undergraduate education program to increase their information literacy and learn how to evaluate effectively websites. Prospective teachers are students that are studying to be teachers, who are in an undergraduate class and in a teacher education program. If teachers model this behavior, then students are more likely to follow (Bandura, 1977). Students and teachers need to know the difference between credible and hoax websites and be aware of the resources available to help them decide.

The present mixed-method study includes a literature review of hoaxes, hoax websites and related fake sites, information literacy, metaliteracy, website and information evaluation models and tools, and epistemic beliefs. The literature review includes popular hoaxes throughout history and the different types of hoax websites that exist. These types of hoax websites include counterfeit, satirical, parody, spoof, questionable, fictitious, malicious, etc. as well as related fake news sites. The literature review also includes a historical overview of information literacy and metaliteracy, models and tools that can be used for evaluating information and websites, and finally epistemic beliefs and their relationship to what information individuals choose to believe, or not. 
Critical thinking skills are crucial in a world that is flooded with a constant barrage of information. The research in the present study, analyzed the website evaluation strategies of prospective teachers in an education major course as they evaluated four websites. There is also an analysis of the prospective teachers' epistemic beliefs concerning the nature of knowledge and the process of knowing. The following sections contains background information on hoaxes, the problem and purpose statements, significance of the study, the research questions, research hypotheses, identification of variables, assumptions, delimitations, a list of definitions and a summary.

\section{Background}

Hoaxes are created for many reasons. These reasons range from benevolent to malicious, but they all aim to trick people into believing that something false is true. There are many different types of hoaxes, hoax websites and related fake sites. The theoretical framework which guided this study included information literacy, metaliteracy and epistemic beliefs. It is important to understand the relationship that exists among these terms.

\section{Hoaxes}

Oxford Dictionaries (2017) defines a hoax as "a humorous or malicious deception." A hoax is "an act intended to trick or dupe" it is also "something accepted or established by fraud or fabrication" (Merriam-Webster, 2017). The origin and etymology of the term hoax is probably a contraction of hocus (Merriam-Webster, 2017), which magicians use when saying "hocus pocus" as they are about to show a magic trick. Merriam-Webster further defined the term hoax for English Language Leaners and for children in more simple terms. In simple terms, the definition of a hoax is "to trick or 
deceive people; an act meant to fool or deceive; and something false passed off as real" (Merriam-Webster, 2017).

In other words, a hoax implies the intention to trick, fool or deceive people into thinking something is true. They are created on purpose to trick people. Kumar (2017) believes that hoaxes are considered to be a part of malicious behavior. Although it is important to note that some hoaxes are created with more benign intentions, such as satire, or humor.

In reviewing the history of hoaxes, Heyd (2012) explains that hoaxing has evolved from the author being known in the $18^{\text {th }}$ century, to anonymous hoaxing in the $20^{\text {th }}$ century and now digital hoaxing. The next section contains literature concerning hoax websites and related fake sites.

\section{Hoax websites and Related Fake Sites}

A website is defined as "a group of World Wide Web pages usually containing hyperlinks to each other and made available online by an individual, company, educational institution, government, or organization” (Merriam Webster, 2017). In simple terms, a hoax website is a deceptive site that contains inaccurate information. General websites that contain false information can range from containing misinformation (intentional or unintentional) to disinformation (intentional) (Hernon, 1995). According to Hernon, misinformation is more benign and can include an "honest mistake" of inaccurate information as opposed to disinformation which might be a "result from a deliberate attempt to deceive or mislead (1995, p. 134).

Hoax websites differ from general websites that contain unintentional false information, or misinformation. In other words, hoax websites contain disinformation, 
which is an intentional way to deceive an audience and provide inaccurate information. According to Heyd, Hoax websites are probably the most 'static form of online hoaxing in terms of their discursive makeup" (2012, p. 139). There are several types of web hoaxes and fake news sites related to hoax websites. These include the following:

1. counterfeit

2. parody or spoof

3. fictitious, questionable and malicious

4. specific discipline-based sites (health, business and science)

5. hacked sites

6. urban legends, folklore, myths, rumors, malware, glurge

7. misleading news, highly partisan news, clickbait and satire

The following section contains the theoretical framework used.

\section{Theoretical Framework}

The theoretical framework used in the present study consists of information literacy, metaliteracy and epistemic beliefs. Information literacy is selected because it is a theoretical base used for evaluating information critically, metaliteracy since it considers multiple literacies and epistemic beliefs because it may influence what people choose to believe, or not.

Information literacy. The definition of information literacy has evolved over the years. Information literacy is a term that stems from the area of library science and has been used and quoted throughout various disciplines for its use in evaluating information.

Traditionally, the information literate student is defined as being able to determine, access, evaluate, incorporate, use and understand information (American 
Library Association, 1989). The latest definition incorporated in 2016 includes the following:

Information literacy is the set of integrated abilities encompassing the reflective discovery of information, the understanding of how information is produced and valued, and the use of information in creating new knowledge and participating ethically in communities of learning (Framework for Information Literacy for Higher Education, 2016, p. 3).

Within these mentioned integrated abilities is the skill to critically evaluate information. Information literacy and critical thinking are sometimes even used interchangeably (Saglam, Çankaya, Üçer, \& Çetin, 2017). According to a few scholars, thinking critically is not possible without information literacy (Saglam, Çankaya, Üçer, \& Çetin, 2017). Critical thinking is defined as "the objective analysis and evaluation of an issue in order to form a judgment" (Oxford Dictionaries, 2017). Critical thinking is a part of information literacy since it deals with the objective analysis of the evaluation of information in order to reach a conclusion. Information literacy is an important aspect of evaluation information on the Internet, especially hoax websites. There are many evaluation models and criteria that stem from the area of information literacy. Today, digital literacy and technological skills are intertwined with the ever-evolving definition of information literacy. Multiple literacies seem to be a part of information literacy, which could possibly be considered an umbrella term. Metaliteracy is related to information literacy.

Metaliteracy. Metaliteracy is related to metacognition, which is where the meta in metaliteracy stems from (Mackey \& Jacobson, 2011). The term metacognition was created by a psychologist named John Flavell in the 1970s. Favell defined the term as “cognition about cognitive phenomena" (Flavell, 1979, p. 906), which also means 
thinking about your own thinking. The prefix meta, means beyond (Metcalfe \& Shimamura,1994), therefore, metaliteracy linguistically means beyond literacy. "Metaliteracy is an overarching and self-referential framework that integrates emerging technologies and unifies multiple literacy types" (Mackey \& Jacobson, 2011, p. 62). These literacies include digital literacy, media literacy, visual literacy, cyberliteracy, critical literacy and information fluency (Mackey \& Jacobson, 2011). Last but not least, epistemic beliefs were also reviewed.

Epistemic beliefs. Epistemic beliefs are beliefs about the nature and source of knowledge, the truth value of knowledge and the justification criteria of assertions, or how one comes to know (Perry, 1970; Hofer, 2001; Mason, Boldrin, \& Ariasi, 2010). Epistemic is defined as "of or relating to knowledge or to the degree of its validation" (Oxford Dictionaries, 2017). In simple terms, epistemic beliefs are beliefs on knowledge and its validation.

\section{Problem Statement}

Numerous studies suggest that there is a deficiency in evaluating the trustworthiness of a website among students (Asher \& Duke, 2011; Brem, Russell, \& Weems, 2001; Clark \& Slotta 2000; Gasser, Cortesi, Malik \& Lee, 2012; Hirsh, 1999; Wineburg \& McGrew, 2017). These studies indicate that students and some teachers show little reflective activity when evaluating the credibility of websites and/or do not distinguish conflicting information sometimes even abandoning searches after not obtaining the results they desired. Another study on reading online and the use of the Internet found that just $4 \%$ of students checked the accuracy of information found on the Internet while in school, and even worse only $2 \%$ of the students in middle school said 
they checked the accuracy of the information outside of school (New Literacies Research Team \& Internet Reading Research Group, 2006). These low percentages signify that most students do not check if the information they find on the Internet is accurate. On the basis of these low percentages, students are at risk to believe information posted on hoax websites and related fake sites. Not checking if information on the Internet is accurate, may create a society of followers who will believe anything that is posted online, unless a major effort is made by teachers and students to learn and teach how to evaluate information critically. Teachers need to model and teach how to evaluate websites using critical thinking in order for students to be able to determine whether information on a website is trustworthy, or a hoax. They also need to realize how their epistemic beliefs influence what they choose to believe, or not.

\section{Purpose Statement}

The purpose of this mixed-method study was to obtain an understanding of the web evaluation strategies of prospective teachers regarding the evaluation of credible and hoax websites and how their epistemic beliefs may influence their web evaluation. Another aspect of the present study is to find out what outcomes result from providing guidance, or not to prospective teachers before reviewing a hoax website. First, the web evaluation strategies of prospective teachers were investigated quantitively and then further insight was obtained qualitatively. In the quantitative section, an online questionnaire (Appendix A) was given to prospective teachers to input their review of the hoax website as well as gather information on their epistemic beliefs. In the qualitative section, interviews were conducted to obtain further insights on their evaluation process and thoughts. 
Mixed method researchers, Creswell and Plano Clark (2010) present two typologies of reasons for mixing methods, which assist in explaining the purpose for using mixing methods in this study. These include Greene, Caracelli and Graham's typology and Bryman's typology. The first typology, Greene, Caracelli and Graham (1989) view the results of both the quantitative method and qualitative method as complementing each other through the "elaboration, enhancement, illustration and clarification" of both results (p. 259). Greene, Caracelli and Graham (1989) refer to this as complementarity. The present study aims to complement findings by first obtaining the quantitative data through the epistemic beliefs questionnaire and then elaborate and clarify the results through the qualitative data of the interviews.

The second typology for mixing methods is based on Bryman (2006). According to Bryman, two reasons that are relevant to mixed method studies are completeness and illustration. Bryman (2006) refers to completeness as the "notion that the researcher can bring together a more comprehensive account of the area of inquiry in which he or she is interested if both quantitative and qualitative research are employed" (Bryman, 2006, p. 106). "Illustration refers to the use of qualitative data to illus trate quantitative findings, often referred to as putting "meat on the bones" of "dry" quantitative find ings" (Bryman, 2006, p. 106).

The interviews in this study provided "completeness" to the quantitative questionnaire analysis by creating a more complete understanding of the web evaluation strategies used by prospective teachers regarding the evaluation of a hoax website and how epistemic beliefs influenced their evaluation. 


\section{Significance of the Study}

Teachers need to be equipped with the tools necessary to evaluate content on the Internet and determine if it is a credible source, or a hoax website in order to instruct and prepare students on this relevant topic. Evaluating content on the Internet is especially critical today where people have a challenging time determining whether content and news articles on the Internet are real, or fake. Prospective teachers need to be specifically taught how to evaluate websites and spot hoaxes and related fake sites. Hoaxes and fake news seems to inundate social media and even reputable news sources. Therefore, teachers and students need to be especially aware of this phenomenon and be equipped with the knowledge and tools to evaluate websites to determine if they are a hoax. Given the studies on the deficiency that exists in evaluating the trustworthiness of a website among students (Asher \& Duke, 2011; Brem, Russell, \& Weems, 2001; Clark \& Slotta 2000; Gasser, Cortesi, Malik \& Lee, 2012; Hirsh, 1999; Wineburg \& McGrew, 2017) teachers need to be prepared to evaluate information on the Web and identify hoax websites in order to make good choices for website resources, not be easily deceived, and assist students.

\section{Research Questions}

This mixed-method study investigated the web evaluation behavior of prospective teachers as they evaluated hoax website and how their epistemic beliefs influenced it. The research questions that were answered include the following:

The research questions include the following:

1. What percentage of prospective teachers trust the content on hoax websites? 
2. What web evaluation strategies do prospective teachers report using regarding hoax websites?

a. What suggestions do prospective teachers have about learning web evaluation strategies?

3. What led prospective teachers to trust, or not trust information posted on hoax websites?

a. How does teaching a specific web evaluation strategy (the WWWDOT Framework) to prospective teachers help them identify credible and hoax websites?

b. How do the epistemic beliefs of prospective teachers correlate to their tendency to trust, or not trust information posted on hoax websites?

c. What web evaluation strategies led prospective teachers to trust, or not information posted on hoax websites?

\section{Research Hypotheses}

The hypotheses for this mixed method study are for research questions one and three since research question two was primarily qualitative. The first one is in response to research question number one and the other ones are related to the sub-questions of research question number three. Below are the hypotheses:

1. The percentage of prospective teachers that trust a hoax website is not less than $33 \%$. This percentage was chosen in order to take into consideration the three trust levels (not trust, neutral and trust). 
2. There is no relationship between teaching the WWWDOT Framework to prospective teachers and their trust level (trust, neutral, not trust) concerning the hoax website.

3. There is no relationship between epistemic beliefs and prospective teachers' trust level (trust, neutral, not trust) concerning the hoax website.

4. There is no relationship between web evaluation strategies and prospective teachers' trust level (trust, neutral, not trust) concerning the hoax website.

\section{Identification of Variables}

The quantitative data included a dependent variable and various independent variables. The dependent variable was whether the participants did not trust, were neutral, or trusted the hoax websites. Since the participants were divided into two groups (control and experimental), the main independent variable was whether they were in Group A, or Group B, which was defined by being given the WWWDOT Framework web evaluation strategy or not. Both variables consisted of categorical, or nominal data using the Likert scale. Other independent variables included the web evaluation strategies (aesthetic appeal, organization, planning to visit the website in the future and usefulness) as well as the epistemic beliefs: feelings, evidence and political.

A questionnaire to measure the web evaluation and epistemic beliefs contained Likert scale questions. The responses on the questionnaire ranged from one to five. Low numbers such as one and two represented strongly disagree and somewhat disagree. High numbers four and five signified somewhat agree and strongly agree answers. The number three signified a neutral answer. Participants were then assigned to the trust level and epistemic belief they predominantly fell into on the basis of their answers. 


\section{Assumptions}

The assumptions of this mixed method study are the following:

1. Prospective teachers have access to a computer with Internet connection to evaluate the hoax website.

2. That prospective teachers have some basic prior knowledge on navigating a website and evaluating information.

3. That the hoax websites selected contain enough clues for prospective teachers to evaluate thoroughly and provide sufficient data. Since they have been used in the past by other researchers, they are assumed to be appropriate hoax websites for evaluating.

4. Another assumption involved the idea that the qualitative data would provide completeness, and illustration for the quantitative data and complementarity would be the results of using both sets of data.

\section{Delimitations}

This study had the following delimitations:

1. The undergraduate education courses where the participants were selected from were chosen since they included students from multiple education undergraduate majors.

2. Even though there are multiple types of hoax websites and related fake sites, the present study was delimited by the evaluation of two hoax and two credible websites. The two hoax websites were the Pacific Northwest Tree Octopus (zapatopi.net/treeoctopus) and the Dihydrogen Monoxide website (DHMO.org). The two credible websites were World Animal Net (worldanimal.net) and 
Imagine H20 (imagineh2o.org). The credible websites were selected based on similar topic to the hoax websites (animals and water) and domain (.net and .org). It was not realistic to request prospective teachers to evaluate more than four websites. Given that the Pacific Northwest Tree Octopus and the Dihydrogen Monoxide websites have been previously used to assess media literacy, they were adequate hoax website choices.

3. The literature reviewed consisted on information literacy and metaliteracy, even though evaluating hoax websites might be related to many other literacies, such as media literacy, digital literacy, visual literacy, etc. Information literacy and metaliteracy were selected since they are both over-arching terms that include multiple literacies.

4. A questionnaire and interviews were the instruments used. A focus group could have been another choice, but it was not done since the researcher did not want the results to be affected by the opinions shared by others.

\section{List of Definitions}

Critical Literacy. "Critical literacy practices encourage students to use language to question the everyday world, to interrogate the relationship between language and power, to analyze popular culture and media, to understand how power relationships are socially constructed, and to consider actions that can be taken to promote social justice" (Lewison, Leland, \& Harste, 2008, p. 3).

Cyberliteracy. "A critical technology literacy, one that includes performance but also relies heavily on people's ability to understand, criticize, and make judgments about a technology's interactions with, and effects on, culture" (Gurak, 2001, p.13). 
Digital Literacy. "Digital Literacy is the ability to assimilate, judge, and communicate information presented in a wide variety of digita/electronic formats" (Hull, Mikulecky, St. Clair, Kerka, 2003, p.11).

Epistemic Beliefs. "Epistemic beliefs are beliefs about the nature and source of knowledge, the truth value of knowledge and the justification criteria of assertions or how one comes to know" (Perry, 1970; Hofer, 2001; Mason, Boldrin, \& Ariasi, 2010).

Epistemology. "The study of the nature, origin, and limits of human knowledge. The term is derived from the Greek epistēmē ("knowledge") and logos ("reason"), and accordingly the field is sometimes referred to as the theory of knowledge" (Martinich, A.P., Stroll, A., 2017, para. 1).

Fake News. "Disinformation and hoaxes published on websites for political purposes or to drive web traffic" and "the incorrect information being passed along by social media" (Macquarie Dictionary, 2017).

Glurge. "Glurge is the body of inspirational tales which conceal much darker meanings than the uplifting moral lessons they purport to offer, and which undermine their messages by fabricating and distorting historical fact in the guise of offering "true stories." Glurge often contains such heart-tugging elements as sad-eyed puppies, sweet-faced children, angels, dying mothers, or miraculous rescues brought about by prayer. These stories are meant to be parables for modern times but fall far short of the mark" (Snopes.com Glossary, 2017).

Hoax. According to Heyd, "Hoaxes are deceptive utterances that occur in one-to-many speech situations" (2012, p. 131). "Relatively large-scale conscious 
creations of falsehood: they aim at deceiving the public and the publishers often accumulate monetary gain or fame" (Vida, 2012, p. 431).

Information Fluency. "A set of intellectual capabilities, conceptual knowledge, and contemporary skills associated with information technology" (Committee on Information Technology Literacy, 1999, p. 49).

Information Literacy. "Information literacy is the set of integrated abilities encompassing the reflective discovery of information, the understanding of how information is produced and valued, and the use of information in creating new knowledge and participating ethically in communities of learning" (Framework for Information Literacy for Higher Education, 2016, p. 3).

Information Literacy 2.0. "Technology changes things and ambient findability and Web 2.0 changes what it means to be an information literate person. Information literate practices are closely entwined with social filtering solutions and services" (Tuominen, 2007, p. 11).

Malware. Malware is a term used to refer to a variety of forms of hostile, or intrusive programs, websites, and online activities, including computer viruses, worms, trojan horses, ransomware, spyware, adware, scareware, and false information deliberately created and spread for financial gain. (Snopes.com Glossary, 2017).

Media Literacy. "The ability to access, understand and create communications in a variety of contexts" (Livingstone, 2004, p. 5).

Metacognition. "Knowledge and cognition about cognitive phenomena" (Flavell, 1979, p. 906). Metacognition is often referred as thinking about one's own thinking. 
Metaliteracy. "A comprehensive model for information literacy to advance critical thinking and reflection in social media, open learning settings, and online communities" (Jacobson \& Mackey, 2013, p. 84).

Mixed-Method Study. "Research in which the investigator collects and analyzes data, integrates the findings, and draws inferences using both qualitative and quantitative approaches or methods in a single study" (Tashakkori \& Creswell, 2007, p. 4).

Multidimensional View of Knowledge. Having a multidimensional view of knowledge is believing that knowledge has various dimensions or aspects and can be true or false.

Personal Epistemology. "An individual's cognitions about the nature of knowledge and the nature of knowing" (Pintrich, 2002, p. 390).

Post-Truth. Post-truth is defined as "relating to or denoting circumstances in which objective facts are less influential in shaping public opinion than appeals to emotion and personal belief' (Oxford Dictionary, 2017).

Post-Truth Bias. For the purpose of this paper, post-truth bias is defined as the acceptance of post-truth by individuals that display a tendency of trusting information that is not true (e.g. hoax websites, fake news, etc.) simply because it aligns with core values, personal beliefs, feelings/emotions, upbringing etc. without any regard to facts and evidence.

Transliteracy. "The ability to read, write and interact across a range of platforms, tools and media from signing and orality through handwriting, print, TV, radio and film, to digital social networks" (Thomas, 2008, p. 101). 
Visual Literacy. "The ability to interpret and evaluate visual messages" (Bristor \& Drake, 1994, p. 74)

Web 2.0. "Web 2.0 refers to a perceived second-generation of web-based services such as social networking sites, wikis, communication tools, and folksonomies that emphasize online collaboration and sharing among users." (Peltier-Davis, 2009, p. 16)

\section{Summary}

Since findings indicate that students show little reflective activity when evaluating the credibility of websites (Asher \& Duke, 2011; Brem, Russell, \& Weems, 2001; Clark \& Slotta 2000; Gasser, Cortesi, Malik \& Lee, 2012; Hirsh, 1999; Wineburg \& McGrew, 2017) indicate that students and some teachers show little reflective activity when evaluating the credibility of websites and/or do not distinguish conflicting information sometimes even abandoning searches after not obtaining the results they desired. it is imperative that prospective teachers are prepared to guide students to not be fooled by hoax websites. The purpose of this mixed-method study was to obtain an understanding of the website evaluation strategies of prospective teachers and how their epistemic beliefs influence their evaluation. Also, the study aimed to find out the outcomes that resulted from providing guidance, or not to prospective teachers before evaluating four websites, two hoaxes and two credible. This mixed-method study includes a literature review of hoaxes, hoax websites and related fake sites, information literacy, metaliteracy, website and information evaluation models and tools, and epistemic beliefs. Research questions, assumptions, delimitations and a list of definitions was also provided. The next chapter provides a review of the literature. 


\section{CHAPTER II: LITERATURE REVIEW}

A literature review relevant to this study was performed, which included the following: hoaxes, hoax websites and related fake sites, information literacy, metaliteracy, website and information evaluation models and tools, and epistemic beliefs.

\section{Hoaxes}

According to Heyd, "Hoaxes are deceptive utterances that occur in one-to-many speech situations" (2012, p. 131). Therefore, in the digital age, hoaxes involve at least a single person or group, who publishes a communication directed to an audience, which contains false information. This false information is published online through a website or a blog. In addition, Heyd explains that the definition of hoaxes contains two features:

1. Every hoax contains, at its core, a false proposition; this deceptive quality may be limited to one central utterance or inform a carefully constructed textual edifice of wrong information.

2. Hoaxes are never purely private statements but are always made toward a multiple audience. While this implies a minimum audience of two, the typical hoax involves a much larger set of communicants; arguably, hoaxes are prototypically performed within a mass media setting.

"Media hoaxes are as old as the earliest forms of mass communication. What they have in common, regardless of whether they appear in the press, on the radio, television, or the Internet, is that they are relatively large-scale conscious creations of falsehood: they aim at deceiving the public and the publishers often accumulate monetary gain or fame" (Vida, 2012, p. 431). This section will review the reasons why hoaxes are created, and a few famous historical hoaxes. 


\section{Why are Hoaxes Created?}

According to Eaton and Hoose (2016), hoaxes serve many purposes or ambitions. The various purposes and ambitions are briefly mentioned in this section, but are further elaborated below: 1) for military advantage (e.g. Trojan Horse hoax); 2) for financial gain (e.g. Hitler Diaries hoax); 3) for fun (e.g. Benjamin Franklin's Witch Trial hoax and War of the Worlds); 4) to reform the world (e.g. DHMO.org hoax and Greenpeace Shell Oil hoax; 5) wanting to fit themselves and their communities more securely into the world (The Piltdown Man and the Patchwork Mouse hoax); and 6) to be artistic and offer an alternative reality (The Loch Ness Monster hoax). Additional reasons individuals create hoaxes was offered by Griffiths (2017), which includes, acts of revenge, boredom, to gain attention, and to demonstrate cleverness. Griffiths (2017) mentions other reasons similar to Easton and Hoose (2016) such as for amusement (fun), to gain fame (wanting to fit themselves and their communities more securely), and to disrupt the status quo and for political cause (to reform the world).

Although some individuals create hoaxes primarily due to a single reason, there may be some who create hoaxes due to a combination of them. Hoaxes have been around for many years and based on the reasons why individuals create hoaxes, it seems like they will continue to exist well into the future. The following subsections includes a list of a few popular hoaxes throughout history organized by their motives, which include, military advantage, financial gain, fun/amusement, reform the world, gain fame and to create an artistic alternative reality.

Military Advantage Hoax: The Trojan Horse. The Trojan Horse hoax is a classic deceptive trick used as a military advantage (Eaton \& Hoose, 2016). In this story, 
three thousand years ago, the Greek soldier Ulysses snuck 30 of his soldiers into a large wooden sculpture of a horse and sneakily gained entrance to the city of Troy by tricking the Trojans. The Greeks got on their ships and acted as if they had left, but before leaving they left behind a liar named Sinon. Sinon told the Trojans that the horse was an offering to the goddess Minerva, which the Greeks had left on purpose due to a prophecy that if the horse would get damaged the Greeks would win the war. The Trojans foolishly believed Sinon and broke the walls of the city to not damage the horse offering. When the Greek soldiers were inside, they attacked and won the Trojan War. Eaton and Hoose (2016) agree that the Trojan Horse hoax has all the details of a classic hoax, which aimed to trick by taking advantage of the desire and beliefs of the Trojans. Sinon's story aligned with the beliefs of that time, that an angry goddess needed to be appeased (Eaton \& Hoose, 2016). Sinon's story also "allowed the Trojans to believe what they truly wanted to believe: the war was over" (Eaton \& Hoose, 2016, p. 4).

Today the term Trojan Horse is used in everyday language as "someone or something intended to defeat or subvert from within, usually by deceptive means" (Merriam-Webster, 2017). The Trojan Horse hoax has also inspired the use of the term in computer science as "a seemingly useful computer program that contains concealed instructions which when activated perform an illicit or malicious action, such as destroying data files" (Merriam-Webster, 2017). The Trojan Horse may be one of the earliest and most popular hoaxes. Some people have created hoaxes not to win wars or for military advantage, but for financial gain. 
Financial Gain Hoax: Hitler Diaries. Some individuals create hoaxes to gain financial benefits. One of these hoaxes includes the Hitler Diaries, which was a collection of diaries that supposedly belonged to Adolf Hitler.

On April 22, 1983, a German publisher named Gerd Heidemann wrote an article in the magazine, Stern, (Hamilton, 1991a) stating that someone had discovered sixty-two volumes of Adolf Hitler's diaries in a wreckage of an airplane that had crashed closed to the city of Dresden in April of 1945 (Winks, 1995). The Hitler Diaries were even backed up by Hugh Trevor-Roper (now Lord Dacre), a British authority on Hitler (Winks, 1995). Lord Dacre might have wanted to believe that it was true just as the Trojans wanted to believe that the war had ended. Heidemann purchased the diaries from Kujau for a total of 9.3 million deutsche marks using Stern's money to acquire the diaries in 1983 (McGrane, 2013) and the magazine Stern sold the rights to various periodicals around the world for a grand total of $\$ 1,975,000$ million dollars in total (Hamilton, 1991c). Kenneth W. Rendell, a well renown handwriting expert, was the one who analyzed the diaries and determined that they were fakes (Hamilton, 1991). The forger of the Hitler Diaries was Konrad Kujau (Hamilton, 1991b). A journalist named Charles Hamilton recognized that it was a hoax from the beginning (Hamilton, 1991a), but most were fooled. Hamilton (1991a) said that he noticed that the handwriting was different and was criticized by making a snap judgment. He responded to critics by stating "You don't have to eat a whole egg to know it's rotten" (Hamilton, 1991a, p. 66). "While the hoax over the Hitler Diaries may tell us a good bit about the gullibility of the public, it tells us even more about how the public media, and the press in particular, induce in the readership a constant need for new sensations, creating a public appetite for such revelations as the 
Hitler Diaries promised to hold" (Winks, 1995, para. 5). Some have created hoaxes not for financial gain, but just for fun or amusement.

\section{Fun/Amusement Hoaxes: Benjamin Franklin's Witch Trial and War of the}

Worlds. Some hoaxes are created for fun, or the sheer pleasure of it. The creator of the hoax might have simply wanted to have some fun, but sometimes these hoaxes are received by the audience with a serious tone. Two hoaxes that were created for fun, or amusement include Benjamin Franklin's Witch Trial and War of the Worlds. Both hoaxes were believed by the masses despite the fun/amusing or entertaining reason for its creation.

Benjamin Franklin's Witch Trial Hoax. Benjamin Franklin, one of the forefathers of the United States, is believed to have published humorous hoaxes and satires (Amacher, 1975). One of his publications titled, "A Witch Trial at Mount Holly" was first published in the Pennsylvania Gazette on October 22, 1731, where "many regarded the hoax as historical and it was reprinted in the British Gentleman's Magazine of 1731" (Robbins, 1959, p. 403). This hoax or satire included experiments performed on a person accused of witchcraft for making a neighbor's sheep dance and causing hogs to speak and sing (Amacher, 1975). According to Amacher (1975), "Franklin gave free play to his humor, spicing his edifying hoaxes and satires with the refreshing power of good old-fashioned American horse" (p. 19). This hoax was believed by the masses who thought that witchcraft existed. Benjamin Franklin probably wrote the article in jest and possibly as a critique to people who rely on beliefs that do not include reason. Another hoax that fooled the masses unintentionally was the radio broadcast War of the Worlds. 
War of the Worlds. H. G. Wells' novel, "War of the Worlds," was adapted for radio by Orson Wells in 1938. This fictional newscast was mistaken by millions for a real newscast, as an apocalyptic belief that there was an invasion of aliens from Mars actually occurring (Morson, 1979). Many have questioned why people believed that it was real (Morson, 1979; Ludlum, 1993). Morson (1979) believes that the narrative's meaning is a matter of context and Ludlum (1993) thinks that it is mostly due to the gullibility of the

public. "Anyone who even vaguely believes our public is not completely gullible to falsehood should read the reports surrounding Orson Well's broadcast. Literally hundreds of panicked citizens called their local police to report actually seeing the aliens nearby." (Ludlum, 1993, p. 16).

The War of the Worlds broadcast is not considered a hoax in the purest form of its definition because it was not intentional. The announcer Orson Wells broadcasted various times that it was not real. However, Orson Wells parodied the novel (Morson,1979). The War of the Worlds broadcast tricked people and it has been included under the hoax or false information umbrella since it can be considered a parody. According to Morson, an 'apocalypse 'defamiliarizes' and 'disautomatizes' our beliefs about the historical process, and so renders them perceptible and the object of attention" (1979, p.10). This demonstrates that when feelings of fear, or sadness take over, people are more inclined to believe things that go against reason or logic. Some hoaxes were created with the hope of reforming the world.

\section{Reform the World Hoaxes: Greenpeace Shell Oil and DHMO.org. Some} hoaxes are created to increase social action, as was the case with the arcticready.com hoax website (no longer online as of 2017). This hoax is also known as the Greenpeace 
Shell Oil Hoax. This website was created to fool people into thinking that Shell was officially announcing to the public their plans to drill in the Arctic. This was done intentionally in order to increase awareness and social action against these plans. The site had official looking logos from shell, kid games and even user generated ads. This website was picked up by reputable media news sources and had 1.8 million-page views in two days (Stenovec, 2012). The elaborate hoax fooled reputable media news sources and people with the sole purpose of promoting social action and awareness of Shell's plans to drill in the Arctic (Stenovec, 2012). In the end, Shell decided not to sue Greenpeace, but the hoax did fool many and people became aware of Shell's plan to possibly drill in the Arctic.

Other hoaxes are purposely created for fun and to promote media literacy, such as the DHMO.org website. DHMO.org is a hoax site about a fake chemical called Dihydrogen Monoxide that is supposed to be colorless and odorless and causes harm to humans. DHMO stands for $\mathrm{H} 2 \mathrm{O}$ (water). If you break apart the word dihydrogen, it means two hydrogens and monoxide means one oxygen. Tom Way, the creator of the hoax site, stated that his "ulterior motives are fairly benevolent" and his goal is mostly to

promote awareness to crosscheck facts and increase information literacy (Watley, 2004). Another reason that people create hoaxes has to do more with vanity and becoming famous.

Gain Fame Hoaxes: The Piltdown Man and Patchwork Mouse. Two famous hoaxes fall under the domain of science. They are the Piltdown Man and the Patchwork Mouse. Both of these hoaxes seem like they were motivated by wanting to gain fame and wanting to fit themselves more securely into their respective fields. 
Piltdown Man Hoax. The Piltdown hoax is one of the best known scientific fraud cases. In 1912, a strange skull and jaw were discovered in southern England by Charles Dawson. (Vandervoort, 1995). Apparently, Dawson combined the mandible of an orangutan and attached it to a human skull and passed it off as a missing link in the evolution of mankind (Weiner, 1955). People believed this hoax for almost forty years until technology in the 1950s allowed researchers to test the bones and figure out that it was a hoax (Weiner, 1955). Even the latest research performed in 2012 on the Piltdown Man fossils has suggested that a single hoaxer created it, who they believe was Charles Dawson (De Groote et al., 2012). The fake fossil was created using a single orangutan and at least two human specimens (De Groote et al., 2012).

The Piltdown Man represents in part an abandonment of the scientific method in the exposure and repudiation of the forgery (Vincent, 1999, p. 1501). There is even a term in science that refers to this type of hoax or misconduct. The term is pathological science and it is a kind of misconduct that the chemist Irving Langmuir (1953) defined as "the science of things that aren't so" (p. 1). Langmuir (1953) says that scientist could come up with false results through wishful thinking. Some have even used the Piltdown Man hoax to teach issues of scientific misconduct. Vincent (1999) used the Piltdown Man hoax to teach freshman chemistry students the importance of the scientific method and the problems of scientific misconduct. Another hoax that could be related to pathological science is the Patchwork Mouse.

Patchwork Mouse Hoax. Dr. William Summerlin, a scientist at the Sloan-Kettering Institute for Cancer Research in New York, claimed that he could transplant patches of skin from a black mouse to a white mouse (Vandervoort, 1995). 
Unfortunately for Dr. Summerlin, one of his assistants noticed that the black skin could be washed off using alcohol (Vandervoort, 1995). After a long investigation, it was determined that Dr. Summerlin had painted the skin of the mouse with a black marker and therefore was forced to resign (Vandervoort, 1995).

\section{Artistic/Alternative Reality: The Great Moon Hoax and Loch Ness Monster.}

Another hoax that fooled the masses was published in "The New York Sun" newspaper in 1835 and included "evidence" that there was life on the moon. This hoax was detailed and artistic and offered the readers an alternative reality that most probably wanted to be true. The Loch Ness Monster is another hoax that provides an imaginative and alternative reality that people believed for almost forty years.

The Great Moon Hoax. The Great Moon Hoax of 1835 can be considered one of the most imaginative newspaper hoax of all time (Vida, 2012). This hoax is "a remarkable blend of early science fiction, and a well-conceived practical joke, tricked hundreds of thousands of readers in and outside of the United States" (Vida, 2012, p. 431) into believing that there was life on the moon. The person responsible for this hoax was Richard Adams Locke, who let his imagination run wild as he reported that the moon had a lunar forest area full of strange looking animals (Vida, 2012). These animals included bison-like creatures with a fleshy appendage over their eyes and a blue goat with a single horn (Vida, 2012) as well as "a strange amphibious creature, of a spherical form, which rolled with a great velocity across the pebbly beach" (Locke, 1975, p. 27).

Various tricks were used to deceive. For example, the article was supposedly written by the renowned astronomer, Sir John Herschel, and the source was the Edinburgh Journal of Science, which had been closed two years earlier (Vida, 2012). This demonstrates that 
hoaxsters will try to deceive people by making the author and the source look credible. The Loch Ness Monster is another hoax that still lives in the imagination of those that grew up with it.

The Loch Ness Monster. "Of all of the 'real' monsters that stir Western imagination, there are few so romantic as the Loch Ness Monster" (Loxton, 2013, p. 118). According to Loxton, the tradition of lake monster and sea serpent hoaxes long predates the modern Nessie legend (2013, p. 125). Many people believed and some even claimed to have seen a plesiosaur living in a Scottish lake, named Loch Ness. The most popular image of the Loch Ness Monster was allegedly taken by a doctor named Robert Kenneth Wilson (Loxton, 2013). This image is known today as the "Surgeon's Photograph" (Loxton, 2013). What reasons might a doctor have to forge a photograph? Since it came from a doctor, it must be true. Unfortunately, the photograph was indeed a hoax. This hoax tricked people into believing in the Loch Ness Monster for more than forty years and some probably still do.

In 1975, the Sunday Telegraph revealed that the photograph was a Wetherell family hoax (Loxton, 2013). Marmaduke Wetherell said they used a small model monster built around a toy submarine, took various pictures, handed the film to Maurice Chambers who passed it to Wilson, who submitted to the newspaper (Loxton, 2013). Winks (1995) maintains that forgeries and other hoaxes will continue to be part of human history. A people who do not interrogate the assumptions of their past are unlikely to interrogate evidence, or even forgeries, they find attractive. Such a people are ripe for the plucking, whether by political extremists, or outright frauds (Winks, 1995, para. 8). However, as Loxton (2013) points out "Nessie swims on, swift and elusive, in the 
imagination of millions" (p. 174). One thing is for sure, hoaxsters will continue to trick people as long as they have the imagination to believe in an alternative reality. These hoaxes will continue to expand in sophistication, especially with the use of modern technologies, such as the Internet, social media and website development. The next section contains a review of the various hoax websites and related fake sites.

\section{Hoax Websites and Related Fake Sites}

For the purposes of this paper, a hoax website is defined as a group of World Wide Web pages usually containing hyperlinks to each other and made available online by an individual, company, educational institution, government, or organization that intentionally placed disinformation (intentional false information) on these pages to deceive people into thinking that it is true. Hoax websites are related to the popular term fake news (Macquarie Dictionary, 2017) and has been organized by Piper (2000) through the following categories: counterfeit, parody or spoof, fictitious, questionable, malicious, specific discipline-based sites (health, business and science), and hacked sites. Other sites related to misinformation are known as urban legends, folklore, myths, rumors, malware, and glurge (Snopes Glossary, 2017), misleading news, highly partisan news, clickbait and satire (Willingham, 2016). Some of the definitions of these types of sites differ in intention and goal, others overlap, but prospective teachers and students need to be aware of them since they all, whether intentional or not, can trick people into believing they are trustworthy. The first hoax website analyzed was the Pacific Northwest Tree Octopus.

This was followed by fake news sites and post-truth bias, and the various categories of hoax websites outlined above, such as counterfeits, parody, fictitious, questionable, malicious, etc. Examples are provided in each section. 


\section{The Pacific Northwest Tree Octopus Website}

One of the hoax websites used for this study, is "The Pacific Northwest Tree Octopus." The Pacific Northwest Tree Octopus website is considered a fictitious website. The site was created in 1998, it seems to be updated every now and then and it is constructed in an appealing fashion. This is a website about a fictitious creature named the Pacific Northwest Tree Octopus. It contains videos and images highlighting the creature as well as "sources" and links to additional information. Some have called it "one of the most famous Internet hoaxes" (Palmer, 2014).

This website has been used by various researchers to evaluate and teach students multiple literacies, including information literacy (Krane, 2006; Baildon \& Baildon, 2012; Heine \& O’Connor, 2014; Palmer, 2014). This hoax website was used in a study performed by researchers from the University of Connecticut's Neag School of Education. According to Krane (2006), these researchers asked 25 seventh grade students to review the website about the fictitious Tree Octopus, all students rated the site as credible except for one. Baildon and Baildon (2012) used this website in an exercise to help students determine the trustworthiness of a source. Rindi Baildon (2012), one of the authors, had the students visit the Pacific Northwest Tree Octopus website and was surprised that most of the students believed the information on the site was trustworthy. Baildon and Baildon point out the need for "a scaffold that can remind students to ask important questions as they work with different sources, as well as the need for ongoing guided practice in thinking about information sources" (2012. p. 13).

Heine and O'Connor (2014) used this website in their book as an example to teach information fluency. Their argument is that teachers and students need to practice 
investigative searching and have students "fall for misinformation," such as the Pacific Northwest Tree Octopus, would be a valuable lesson that "will not cost them too dearly" (Heine \& O'Connor, 2014, p. 84). Interestingly, Heine and Connor point out that "students are believers" and "web hoaxes cannot stop students from believing" (Heine \& O'Connor, 2014, p. 83). It may be that students need to experience firsthand being tricked by web hoaxes in order to hopefully deter them from believing. Heine and Connor conclude that once anyone reaches the point of believing without considering the facts, a foolish choice may be only a click away (Heine \& O'Connor, 2014, p. 83). Heine and Connor (2014) state that the Tree Octopus website helps students learn about authorship and red flags regarding the owner. Investigating the author and owner leads to solving a puzzle that requires going outside of the hoax website into tools available, such as the whois.net website, which gives information on the owner. Heine and Connor (2014) checked the Tree Octopus website on the whois.net site and the author came out as Kevin Fraites.

Palmer's (2014) book on "Teaching the Core Skills of Listening \& Speaking," contains information on the Pacific Northwest Tree Octopus. One of Palmer's exercise for teaching media literacy includes visiting this website. Even though Palmer admits that the website is brilliantly constructed, he mentions that there are clues that demonstrate it is a hoax. At the bottom of the homepage, the author is listed as Lyle Zapato, who declares that he is not affiliated "with any school or educational organization other that the Kelvinic University branch of the Wild Haggis Conservation Society" (Palmer, 2014, p. 76). If indeed Kevin Fraites is the owner, then the made-up "Kelvinic" University 
makes sense! Another type of hoax website that has been popping up everywhere lately are the fake news kind.

\section{Fake News Websites and Post-Truth Bias}

Since the 2016 presidential election, there has been a lot of attention towards the term fake news. An article posted on merriam-webster.com, titled, "The Real Story of Fake News," states that they are "watching" the term fake news, but have not officially added it to their dictionary. They state that fake news is a "self-explanatory compound noun" where "fake news is, quite simply, news ("material reported in a newspaper or news periodical or on a newscast") that is fake ("false, counterfeit")" (Merriam-Webster, 2017). Hoax websites are related to fake news websites since they are both intentional and fake, but they differ since hoax websites are not always presented in a news-style format and it does not always contain material reported in a newspaper, news periodical, or on a newscast. The difference between them is that fake news contains misinformation (intentional and unintentional) and disinformation (intentional) as opposed to hoax websites that contain only disinformation. Fake news websites aim to look like a reputable news website and hoax websites often contain many formats and diverse types of fake information that is not necessarily termed "news."

At times, it seems like the term fake news is being used as a catch all phrase for fake information on the Internet, but there are many distinct types of disinformation and misinformation. David Mikkelson (2016) from snopes.com, a popular fact checking website, prefers the term bad news. Mikkelson warns to not organize everything under the fake news category since this is a subset of the more general "bad news phenomenon" (2016). The bad news phenomenon includes fake news, but it also contains repackaged 
old news, a combination of true and false, inaccurately gathering information and reporting it, etc. (Mikkelson, 2016).

It may be wise to formally define the term fake news. Defining the term may increase awareness of this phenomenon and allow people to use it properly. Apparently, some are using the term fake news too broadly to include news outlets that display a political stance regarding those who seemingly "helped Donald Trump get elected" (Mikkelson, 2016). President Donald Trump, has used the term fake news multiple times since his election. He may be attributed to the increasing popularity of this term. On February 17, 2017, President Donald J. Trump tweeted that the New York Times, NBC News, ABC, CBS and CNN were the Fake News media, which were not his enemy, but the enemy of the American People:

Donald J. Trump \&

@realDonald Trump

\section{Follow}

The FAKE NEWS media (failing @nytimes, @NBCNews, @ABC, @CBS, @CNN) is not my enemy, it is the enemy of the American People!

5:48 PM - Feb 17, 2017

$\oslash 77,016$ † 52,496 $\bigcirc 160,814$

Figure 1. Tweet on fake news by President Donald J. Trump.

The lack of a formal definition towards the fake news term is not allowing people to use the term correctly. Even worse, some people are letting their opinions be shaped by emotion and personal beliefs to the point of even rejecting objective and fact-based information. This has led to the new term post-truth, which was Oxford Dictionary's 2016 word of the year (Oxford Dictionary, 2017). Post-truth is defined as "relating to or denoting circumstances in which objective facts are less influential in shaping public 
opinion than appeals to emotion and personal belief' (Oxford Dictionary, 2017). For the purpose of this paper, post-truth bias is defined as the acceptance of post-truth by individuals that display a tendency of trusting information that is not true (e.g. hoax websites, fake news, etc.) simply because it aligns with core values, personal beliefs, feelings/emotions, upbringing etc. without any regard to facts and evidence. Post-truth bias is related to confirmation bias. Confirmation bias is "the tendency for people to favor information that confirms their preconceptions or hypotheses regardless of whether the information is true (Plous, 1993, p. 233)." Post-truth bias is a combination of confirmation bias in the context of the post-truth phenomenon.

The closest thing to a formal definition of fake news was provided by the Macquarie Dictionary, a subscription-based Australian English dictionary, which selected the term fake news as the 2016 word of the year (Macquarie, 2017). It defines fake news as "disinformation and hoaxes published on websites for political purposes or to drive web traffic" and "the incorrect information being passed along by social media" (Macquarie Dictionary, 2017). This definition is closer to a hoax website since it opens the term to general disinformation, hoaxes and misinformation. Below are a few examples of twenty of the most popular fake news websites according to LaCapria (2017) from snopes.com. Since there are new ones popping up every day, it is important to know how to evaluate websites and information.

1. National Report

2. World News Daily Report

3. Huzlers

4. Empire News

5. Stuppid

6. News Examiner

7. Newswatch28 (now Newswatch33) 
8. Naha Daily

9. The Stately Harold

10. NewsBuzzDaily

11. Now8News

12. The Reporterz

13. Empire Herald

14. Satira Tribune

15. NC Scooper (Nevada County Scooper)

16. Associated Media Coverage

17. React 365

18. The Burrard Street Journal

19. The Last Line of Defense (The Resistance)

20. BreakingNews365.net and Breadkingnews247.net

Although these websites are housed under the fake news category, some of these websites can also fall under the category of counterfeit and others try their best to contain a mix of satire, fake and truthful information to make it even more complicated and confusing for people to evaluate its trustworthiness. Fake news is a problem with real world consequences. People are believing the information and reacting to it sometimes in aggressive ways. For example, Kang and Goldman's (2016) news article in the New York Times highlighted how fake news resulted in someone using a gun. In December of 2016, a 28-year-old man and father of two, had read a fake news article online stating that a pizza restaurant called Comet Ping Pong, was abusing children by treating them as sex slaves in a child-abuse ring supposedly led by Hilary Clinton (Kang \& Goldman, 2016). He believed the news article was credible and decided to take matters into his own hands. He drove for six hours to the pizza restaurant and fired an assault-like AR-15 rifle (Kang \& Goldman, 2016). Thankfully, he was arrested, and no one was hurt, but it does demonstrate how potentially dangerous fake news can be. 
Fiegerman (2017) from CNN, interviewed Mikkleson where he stated that "fake news is not a disease itself, it's a symptom of a disease. The much larger issue goes by many names, including the "filter bubble" (Fiegerman, 2017). This shows that fake news is but one aspect of the many untrustworthy information available online. Facebook begun an effort to fact-check fake news through a "disputed" tag in March of 2017 (Christian, 2017). A study performed by Yale researchers, Pennycook and Rand (2017), state that flagging a post on Facebook as "disputed" makes individuals just $3.7 \%$ less likely to believe it. Counterfeit websites are considered even worse than fake news sites.

\section{Counterfeit Websites}

Counterfeit sites attempt to pass themselves as authentic and are "the most troublesome of hoax Internet sites" (Piper, 2000, p.41). The website martinlutherking.org is an example of a counterfeit site. It has been described by Piper as "one of the most odious sites on the Web" (2000, p. 42). This site contains misinformation that aims to deceive students into believing that Martin Luther King should not have a holiday named after him. The martinlutherking.org site was created by a White nationalist group called Stormfront. Counterfeit websites are not the only ones that are hoaxes since there are also parody or spoof websites.

\section{Parody or Spoof Websites}

Satirical, parody or spoof sites aim mostly to entertain, and the fake information is usually obvious (Piper, 2000). Parody sites imitate real sites, but in an exaggerated and humorous manner. People usually know that the site is not real. Satire is related to parody, but they are different in the sense that satire does not imitate, it just simply makes fun of things or people using exaggerated humor. Piper (2000) groups spoof sites with 
parody since they are a lesser version of a parody, but they are related through humor. An example of a parody or spoof site is whitehouse.org. This website contains exaggerated and "humorous" but unflattering stories of president Trump. This website uses a URL that looks reputable just as the martinlutherking.org site. This trick demonstrates that teachers need to be prepared to evaluate the credibility of a website and go beyond just looking at a URL that looks trustworthy. This is especially true in politics as seen in the parody whitehouse.org website domain. As Ludlum (1993) points out, even though parody is a large and historically significant part of our political culture, they do not expand ideas and even worse promote the propagation of misinformation, which is not understood as false by people.

Ludlum explains that parodies are protected and "ordained as sacred by our Supreme Court" (1993, p. 20). Ludlum (1993) argues that as technology advances and becomes more sophisticated, parodies will become more realistic and therefore more deceptive. There is a greater need to inform the reader that the parody story is fiction through a written warning or notice since people might not be familiar with this genre, or the details of the story (Ludlum, 1993). Aside from parody or spoof websites there are also fictitious, questionable and malicious websites.

\section{Fictitious, Questionable, and Malicious Websites}

The website ruritania.net is about the country of Ruritania. This site is a fictitious site since the country does not exist (Piper, 2000). The website contains information about its government, foreign ministry, history, royal family, and emblem. A site presented by Piper (2000) as a questionable site would be lipbalmanonymous.com, a site with a 12-step program for lip balm addicts. This is probably because it is questionable 
that applying lip balm would be considered an addiction. This was similar to the business rumor that Carmex lip contained ground glass (or other irritants), which would allegedly make people use it continuously, and possibly become addicted (Mikkelson, 2011). This claim was rated false by Barbara Mikkelson from snopes.com back in 2011. An example of a malicious site is the Institute for Historical Review, ihr.org, which claims that the holocaust did not occur. Another malicious site would be the martinlutherking.org site previously mentioned. Malicious sites are hate sites. It is also important to note that there are a few disciplines were hoax websites are prevalent.

\section{Specific Discipline-Based Websites (Health, Business and Science).}

The three discipline-based areas where misinformation is published is health, business and science. According to Piper, health information is "the most troublesome of all information on the web" $(2000$, p. 46). This is probably because people are constantly searching information based on their symptoms. Health misinformation that has been

published includes "antiperspirants cause breast cancer, cooking in aluminum pans cause Alzheimer's, and Costa Rican bananas carry flesh eating bacteria" (Piper, 2000, p. 48). An example provided by Piper (2000) of a health site that contains misinformation is virusmyth.com. This health site contains controversial information regarding HIV. According to the creators of the site, HIV does not cause AIDS. In addition, they state that AIDS is not sexually transmitted, and people are not dying from AIDS, but instead they are being poisoned to death by the antiviral drug given to them. Creators of fake news and hoax sites take advantage of the complexity of subjects such as health and science to trick people. 
Business is another area that misinformation reigns and can have a direct effect on stocks and prices. For example, Green Oasis Environmental at greenoasis.com (no longer active as of 2017) claimed that they had perfected the technology to convert waste motor oil into diesel fuel, which made stock prices go from $\$ 1$ to $\$ 10$ in February 1997 (Piper, 2000). This is similar to something that occurred in 2013, when AP's twitter account was hacked, and someone posted about an explosion that injured Barack Obama and \$130 billion in stock value was wiped out in a matter of minutes (Rapoza, 2013). In science, the DHMO.org site serves as a perfect example. DHMO.org as mentioned earlier, is a hoax site about a fake chemical called Dihydrogen Monoxide that is supposed to be colorless and odorless and causes harm to humans. Another type of hoax website includes those that are hacked.

\section{Hacked Websites}

Hacked sites are sites that have been hacked and altered. An example of a site that was hacked and fake news was posted is the Qatar News Agency website. This site was hacked on May 23, 2017 (Browning, 2017). Qatar's state news agency was hacked, and false statements credited to the country's ruler were posted. As a result of these statements, Saudi Arabia, Egypt, and the United Arab Emirates as well as other countries severed their ties with Qatar. This situation demonstrates the dramatic results that a hacked site can have in politics and relations between countries.

Within this category are URL hijacks. URL hijacks are redirects to other sites. An example of this occurred during the 2016 U.S. presidential election when someone purchased the domain jebbush.com and redirected the site to Donald Trump's official site (Wang, 2016). Domain appropriation and cybersquatting sends a message that domain 
names are easy to obtain and can be inappropriately used for various purposes that go against the expected domain owners. Domain appropriation and cybersquatting also deceive people into believing that the website is trustworthy since the URL is usually one of the first things that people notice. This demonstrates that the criteria used to evaluate websites need to go beyond a seemingly reputable URL. Urban legends, malware and glurge are also a type of hoax website.

\section{Urban Legends, Malware and Glurge Websites}

The Snopes glossary (2017) includes other terms related to misinformation. These terms are urban legends, malware, and glurge.

- Urban legends are tales told as true, local, and recent occurrences, and often contain names of places or entities located within the teller's neighborhood or surrounding region. Folks commonly equate 'urban legend' with 'false' Though most are pure invention, a handful turn out to be based on real incidents.

- Malware is a term used to refer to a variety of forms of hostile or intrusive programs, websites, and online activities, including computer viruses, worms, trojan horses, ransomware, spyware, adware, scareware, and false information deliberately created and spread for financial gain.

- Glurge is the body of inspirational tales which conceal much darker meanings than the uplifting moral lessons they purport to offer, and which undermine their messages by fabricating and distorting historical fact in the guise of offering "true stories." Glurge often contains such hearttugging elements as sad-eyed puppies, sweet-faced children, angels, dying mothers, or miraculous rescues brought about by prayer. These stories are meant to be parables for modern times but fall far short of the mark.

Urban legends are interesting since it has the appeal of familiarity. Since urban legends supposedly occur in local neighborhoods and are told by people "who knows someone... who knows someone," these types of websites and stories tend to be shared often. According to Heyd (2012), one of the traits of a hoax includes a sender and a 
creator. The sender is usually identified, and the creator is anonymous, which is associated with rumors, or urban legends (Heyd, 2012).

Malware websites are created for financial gain and can completely infect computers and mobile technology. Some malware websites provide free things to lure people to click on their links and download viruses and other intrusive programs. Finally, websites containing "glurge" content should be a red flag when believing the information posted on a website, especially since this strategy used by hoax creators is disguised as inspirational, sad or emotionally charged to appeal to people who follow their intuition or feelings when believing information. There are also other misleading and false news websites.

\section{Other Misleading and False News Websites}

Below are other types of misleading and false news that Willingham (2016) came up with the assistance Dr. Melissa Zimdars, an associate professor at Merrimack College in Massachusetts and Alexios Mantzarlis, the head of the International Fact-Checking Network at the Poynter Institute.

1. Misleading news: These are the hardest to debunk, because they often contain a kernel of truth: A fact, event or quote that has been taken out of context. Look for sensational headlines that aren't supported by the information in the article.

2. Highly partisan news: A type of misleading news, this may be an interpretation of a real news event where the facts are manipulated to fit an agenda.

3. Clickbait: The shocking or teasing headlines of these stories trick you into clicking for more information -- which may or may not live up to what was promised.

4. Satire: This one is tough, because satire doesn't pretend to be real and serves a purpose as commentary or entertainment. But if people are not familiar with a satire site, they can share the news as if it is legitimate. 
Misleading news, highly partisan news, clickbait and satire websites all pose a risk for people believing in the content produced by these websites and news sources. An example of a hoax website that is satirical is theonion.com. Created in 1988, The Onion is considered the best satirical news source in the U.S (Emery, 2017). The goal of the satire site is to be humorous, but even satire sites can trick people. Heyd (2012) believes that the goal of the hoax is purely textual, and it is meant to be humorous instead of fraudulent such as with scams and plagiarism. Heyd's definition of a hoax aligns more with the satire type of website. This aligns with Tom Way's motive on creating the hoax, or science satire website DHMO.org. One of the theoretical frameworks that people can use to evaluate hoax websites is information literacy.

\section{Information Literacy}

The term information literacy was first used in 1974 by Paul G. Zurkowski (1974) in a paper titled "The Information Service Environment Relationships and Priorities. Related Paper No. 5." Zurkowski (1974) was affiliated with the National Commission on Libraries and Information Science, Washington D.C. and the National Program for Library and Information Services, which had at its goal to achieve universal information literacy by 1984. Back then, Zurkowski stated that only people who "trained in the application of information resources to their work can be called information literates" (1974, p.6). Zurkowski's (1974) version of information literacy was related to the "techniques and skills" for using a large selection of information tools and primary sources to apply information solutions to problems. Zurkowski (1974) argued that even though almost $100 \%$ of the people in the U.S. were literate since they could read and write, only a small number (about one-sixth) were information literates. These 
percentages were before the digital age and might greatly differ today, but it still points out that information literacy requires much more than being able to read and write information.

Interestingly, Heyd (2012) points out that the audience which receives the information is usually split with some people realizing that it is a hoax and others accepting the information as true. This split in the audience in whether accepting the hoax or not can serve as a good indicator of a receiver's information literacy. This is where the information literacy of the receiver comes into play since it can be argued that the more information literate, the less they are misled by hoax websites. The next few subsections includes the Information Literacy Competency Standards for Higher Education, information literacy and technology, Framework for Information Literacy for Higher Education, National Information Literacy Awareness Month, Information literacy and gender and future of information literacy.

\section{Information Literacy Competency Standards for Higher Education}

Another definition on information literacy was published in 1989 by the American Library Association, where the individual had to display skills to "recognize when information is needed and have the ability to locate, evaluate, and use effectively the needed information." Both definitions focus on a set of skills or abilities and the use of information. In 2000, the Association of College and Research Libraries' (ACRL) expanded on this definition and added standards. This resulted in the ACRL's "Information Literacy Competency Standards for Higher Education." ACRL organized information literacy into the six standards below, where the information literate student can determine, access, evaluate, incorporate, use and understand the following: 
1. determine the nature and extent of information needed

2. access needed information effectively and efficiently

3. evaluate information and its sources critically

4. incorporate selected information into his or her knowledge base

5. use information effectively to accomplish a specific purpose

6. understand the economic, legal, and social issues surrounding the use of information and access and uses information ethically and legally

The Information Literacy Competency Standards for Higher Education mentions the importance to evaluate information and its sources critically, which serves as a starting point for educators to bring awareness to false information on the Internet promoted by hoax websites. Although these standards and definition do seem somewhat outdated, especially since there is no mention of different types of literacies and the use, creation and sharing of information in the digital era. Some scholars have expressed the need to expand or reframe information literacy to include technology as computer and media literacy (McClure, 1994). This combination or emergence of Information literacy and technology led to the creation of Information and Communication Technology (ICT) literacy.

\section{Information Literacy and Technology}

Information and Communication Technology (ICT) has also added to the definition of information literacy by incorporating technology and communication into it. ICT literacy is defined as "using digital technology, communications tools, and/or networks to access, manage, integrate, evaluate, and create information in order to function in a knowledge society" (International ICT Literacy Panel, 2002, p. 2). A definition that has combined the traditional definition of information literacy with technology was presented by McClure (1994) by incorporating the ability to solve information problems with the four dimensions of information literacy: traditional 
literacy, computer literacy, media literacy and network literacy. Others also added the use of technological tools by defining information literacy as the capability to locate, evaluate, use, produce and share information using technological tools (Wen \& Shih, 2008). This definition is similar to the one created by the ACRL in 2000, but it adds the component of technological tools. This trend of mentioning technology and the changes of how information is created and shared through digital mediums highlighted the need to update the definition and standards provided by the ACRL back in the year 2000. The ACRL standards were replaced by the Framework for Information Literacy for Higher Education in 2016.

\section{Framework for Information Literacy for Higher Education}

The ACRL's Information Literacy Competency Standards for Higher Education previously mentioned, were publicly rescinded by the ACRL on June 25, 2016 during the ALA Annual Conference. After almost sixteen years, these standards were replaced with the "Framework for Information Literacy for Higher Education." This update was the result of the standards being outdated and not addressing more relevant emerging literacies that included the use of technology and digital media. The ACRL stated that their reason for updating the standards was to consider information fluency and the "expanding definition of information literacy to include multiple literacies, for example, transliteracy, media literacy, digital literacy, etc." (Framework for Information Literacy for Higher Education, 2016, p. 15).

The revised publication produced by the ACRL contained an updated and more integrated definition of information literacy. This definition included terms such as reflective discovery, ethical participation and the understanding of how information is 
produced, valued and used for creating new information. Below is the definition of information literacy provided in the Framework for Information Literacy for Higher Education:

Information literacy is the set of integrated abilities encompassing the reflective discovery of information, the understanding of how information is produced and valued, and the use of information in creating new knowledge and participating ethically in communities of learning (Framework for Information Literacy for Higher Education, 2016, p. 3).

The revised six concepts of the framework include the following: Authority is Constructed and Contextual; Information Creation is a Process; Information Has Value; Research as Inquiry; Scholar as Conversation; and Searching as Strategic Exploration (Framework for Information Literacy for Higher Education, 2016, p. 3). These six concepts mention throughout the importance of critically evaluating information. For example, the Authority is Constructed and Contextual frame mentions that "learners need to critically examine all evidence" (Framework for Information Literacy for Higher Education, 2016, p.4). The Information Creation as a Process concept mentions to "critically evaluate the usefulness of the information" (Framework for Information Literacy for Higher Education, 2016, p.5). Lastly, the Scholarship as Conversation concept mentions that learners need to "critically evaluate contributions made by others in participatory information environments" (Framework for Information Literacy for Higher Education, 2016, p.8).

This framework has received mixed reviews with some scholars preferring the previous publication (Jackman \& Weiner, 2016), but it does consider a more inclusive stance regarding the unity of multiple literacies. In reviewing these concepts, there is no 
mention of the Internet, digital media or technology per se, but it does consider

metaliteracy. The creators of the framework openly state that "the Framework draws significantly upon the concept of metaliteracy" (Framework for Information Literacy for Higher Education, 2016, p. 3). During close inspection, one of the members of the Task Force selected to create the framework stands out. This Task Force member is Trudi E. Jacobson, who is also one of the creators of the term metaliteracy. Metaliteracy offers a revised vision of information literacy and is now accepted as a leading concept in the critical review of false information on the Internet, including hoax websites and fake news. Information literacy has also been recognized by previous presidents and has even led to the creation of a national information literacy awareness month.

\section{National Information Literacy Awareness Month}

It is evident that the definition of information literacy has evolved since 1974.

Nowadays many have adopted the term and recognized its importance. In 2009, president Barack Obama declared October "National Information Literacy Awareness Month." In Proclamation 8429 of October 1, 2009, president Obama stated the following:

Though we may know how to find the information we need, we must also know how to evaluate it. Over the past decade, we have seen a crisis of authenticity emerge. We now live in a world where anyone can publish an opinion or perspective, whether true or not, and have that opinion amplified within the information marketplace. At the same time, Americans have unprecedented access to the diverse and independent sources of information, as well as institutions such as libraries and universities, that can help separate truth from fiction and signal from noise.

Unfortunately, this initiative has slowly been taking off with only a few universities and colleges still celebrating it in 2017. Now more than ever, information literacy needs to be taught to teachers and students to critically analyze information and not fall for fake news 
and hoax websites. A study on information literacy and gender had interesting results, which can assist teachers learn about gender differences.

\section{Information Literacy and Gender}

A recent study on information literacy and gender revealed that female respondents attending college were more discerning than males in evaluating Internet sources; furthermore, male respondents trusted the accuracy and credibility of the results returned by search engines more than females (Taylor \& Dala, 2017). This information could aid educators in targeting students and providing the necessary tools based on gender differences. The future of information literacy will most likely include various technological advances in information and communication.

\section{Future of Information Literacy}

In ten or twenty years as communication mediums evolve, we might be re-defining it to include emerging technologies such as wearable technology, implanted micro-chips and touch sensitive surfaces, holograms and virtual realities. Hoaxes transmitted through these mediums would attempt to deceive users. Critical thinking and information literacy will hopefully be used to diminish the number of people falling for misinformation and disinformation. Metaliteracy is considered a part of information literacy, which is discussed in the next section.

\section{Metaliteracy}

At the core of metaliteracy is the concept that the user is not only a consumer of information, but also a creator of information. This is evident in social media where people can provide feedback and comment on information as it is being shared. In other words, people are now empowered to add to the dialogue of information and this has 
resulted in the need of a revised definition of information literacy through the metaliteracy framework. The authors of metaliteracy envision it as a "comprehensive model for information literacy to advance critical thinking and reflection in social media, open learning settings, and online communities" (Jacobson \& Mackey, 2013, p. 84). The metaliterate individual is described by Mackey and Jacobson (2014) in their book titled Metaliteracy: Reinventing Information:

The metaliterate individual has the capability to adapt to changing technologies and learning environments, while combining and understanding relationships among related literacies. This requires a high level of critical thinking and analysis about how we develop our self-conception of information literacy as metacognitive learners in open and social media environments (p. 2).

As far as literacies go, information literacy can be considered the grandparent of metaliteracy. Whether metaliteracy ends up replacing information literacy is hard to say since the term information literacy is popular and has been around for more than forty years. Although metaliteracy is now six years old, it has been rapidly growing in popularity, but it would not have existed given information literacy. This ensures that information literacy at least from a historical point of view will continue to thrive and be used. Information literacy could end up as an all-encompassing literacy term that is redefined and adapted to innovative technologies. According to Mackey and Jacobson, "metaliteracy promotes critical thinking and collaboration in a digital age, providing a comprehensive framework to effectively participate in social media and online communities" (Mackey \& Jacobson, 2011, p. 62). Metaliteracy is organized by elements, goals and domains. 


\section{Elements, Goals and Domains of Metaliteracy}

In 2011, metaliteracy had seven elements. Below are the seven elements of metaliteracy:

1. Understand Format Type and Delivery Mode.

2. Evaluate User Feedback as Active Researcher.

3. Create a Context for User-generated Information.

4. Evaluate Dynamic Content Critically.

5. Produce Original Content in Multiple Media Formats.

6. Understand Personal Privacy, Information Ethics and Intellectual Property Issues.

7. Share Information in Participatory Environments. (Mackey \& Jacobson, 2011, pp.70-76)

In 2014 , the seven elements of metaliteracy were revised into the following four goals:

1. Evaluate content critically, including dynamic, online content that changes and evolves, such as article preprints, blogs, and wikis;

2. Understand personal privacy, information ethics, and intellectual property issues in changing technology environments;

3. Share information and collaborate in a variety of participatory environments;

4. Demonstrate ability to connect learning and research strategies with lifelong learning processes and personal, academic, and professional goals. (Jacobson \& O'Keeffe, 2014, p. 28).

In comparing these goals to the initial seven elements, it is evident that some of the elements were removed. The first three goals were adapted from the initial elements, but the fourth goal was added. This demonstrates that the authors recognize the value of connecting learning to lifelong processes and goals. Another aspect of metaliteracy is that it has four domains: behavioral, cognitive, affective and metacognitive (Jacobson \& O'Keeffe, 2014). Adding these domains ensures that metaliteracy considers skills, competencies, comprehension, critical thinking, feelings, beliefs, and thinking about their own thinking. One of the main goals of metaliteracy is to evaluate content critically. Metaliteracy unites all literacies and adds to the information literacy theoretical 
framework, which can assist people when evaluating hoax websites and other related fake sites. Metaliteracy is considered an overarching term, which includes multiple literacies.

\section{Metaliteracy: An Overarching Term}

"Metaliteracy reinforces stronger connections between information literacy and other literacy frameworks" (Mackey \& Jacobson, 2011, p. 70). There are many literacies that are related to information literacy and metaliteracy. Some may even be considered subsets of information literacy. The skills and abilities associated with information literacy have been variously referred to as critical literacy, media literacy, or digital literacy (Kerka, 1999). Mackey and Jacobson also mention that information literacy is a metaliteracy since it recognizes the relationships between "core information literacy competences and emergent literacy frameworks" (Mackey \& Jacobson, 2011, p. 68).

Metaliteracy serves as an integrated and collaborative approach that infuses technology to information literacy and considers to be overarching and related to many literacy frameworks including information fluency, technology literacy, computer literacy, digital literacy, media literacy, information fluency, information literacy 2.0 (which includes web 2.0 technologies), critical literacy, transliteracy, among others (Mackey \& Jacobson, 2011). "As each new form of literacy is introduced, the shared literacy goals related to critical thinking and information skills are often overlooked, creating an unnecessary divide between information literacy and other literacy types" (Mackey \& Jacobson, 2011, p. 70). It is evident that metaliteracy is an all-encompassing literacy that aims to address how information is produced and shared in the $21^{\text {st }}$ century through the Internet and social media using critical thinking and combining multiple 
literacies. The next section of this literature review contains website/information evaluation criteria and tools.

\section{Website/Information Evaluation Criteria and Tools}

It is imperative for teachers and students to learn how to evaluate websites and information as well as being aware of the tools that exist. According to Fidel et al. (1999), prior knowledge on a topic is helpful in evaluating the credibility of information accessed on the Web since it can assist in recognizing inaccurate information more easily. Some researchers have found that the most frequently cited criteria related to shaping people's views on whether a website is credible or not is the content, design and aesthetics of a website (Deering \& Eng, 1999). Although prior knowledge on a topic can certainly help, the evaluation of websites needs to go beyond design and aesthetics and into evaluation criteria that uses critical thinking skills.

Winks (1995) explains that journalism (or in today's case things posted on the web) is instant history, and this is a contradiction since an individual is not able to instantly analyze a body of arguments, set of facts, or any collection of documents. Winks (1995, para. 4) states that "there is an old rule of evidence, taught to every first-year graduate student in history or law: No "fact" may be presumed to be "true" until it is verified by a second source and is not contradicted by a third." This demonstrates that figuring out whether a website is trustworthy or not requires time and effort and it not an instant or automatic phenomenon.

There are various evaluation models and tools that teachers and students can use to evaluate information in general and on the web. The models and tools used in this paper include the following: 
1. The Big6

2. WWWDOT Framework

3. A.A.O.C.C.

4. A.S.A.P., A.S.P.E.C.T. and W5 for W3

5. Health websites and Reliability Components

6. Fact Checking Websites

7. Evaluating Information from a Historian's Perspective

8. Ten Guidelines for Spotting Untrustworthy Websites

\section{The Big6}

The Big6 is an information problem solving process created by Mike Eisenberg and Bob Berkowitz that contains six $21^{\text {st }}$ century skills that can be used to learn and teach information and skills related to technology (Eisenberg, 2003). The six stages include: 1) define the task, 2) select, 3) locate, and 4) use appropriate information sources, and 5) pull the information together; and, 6) decide that the task is in fact, complete, (Eisenberg, 2003, p. 14). Below is the Big6 model in detail:

1. Task Definition

1.1 Define the information problem 1.2 Identify information needed

2. Information Seeking Strategies

2.1 Determine all possible sources

2.2 Select the best sources

3. Location and Access

3.1 Locate sources (intellectually and physically)

3.2 Find information within sources

4. Use of Information

4.1 Engage (e.g., read, hear, view, touch)

4.2 Extract relevant information

5. Synthesis

5.1 Organize from multiple sources

5.2 Present the information

6. Evaluation

6.1 Judge the product (effectiveness)

6.2 Judge the process (efficiency) 
Step three and step four of the Big6 model is relevant to evaluating websites. Spitzer (2000), wrote that it is important to use "discretion when "buying into" information. Teaching using a Big6 approach "means that students develop critical thinking through various settings and situations for them to continuously question the reliability and accuracy of information sources within multiple sources" (Spitzer, 2000). Considering step four of the Big6, Spitzer provided the following criteria for evaluating websites:

1. Who is the author or sponsor of the website?

2. What authority does the author or sponsor have to write this type of material?

3. Does this information tell about the author's background, education, or credentials?

4. Does the author or sponsor provide a source for the material that was included in the website? Is that source reputable?

5. Is there any bias evident in the information? Is the information onesided?

6. Is the information fact or opinion?

7. When was the site last updated?

8. Is the material relevant to your need?

Aside from the Big6, another way to evaluate website is by using the WWWDOT

Framework. This is the framework used by this study.

\section{WWWDOT Framework}

The WWWDOT is a framework created by Zhang and Duke for improving the awareness of the need and ability to evaluate websites as sources of information for elementary school students (Zhang \& Duke, 2011, p. 136). Table 1 contains the WWWDOT Framework: 
Table 1

The WWWDOT Framework

\begin{tabular}{|c|c|}
\hline WWWDOT & Some Key Teaching Points \\
\hline $\begin{array}{l}\text { Who wrote this and what credentials do } \\
\text { they have? }\end{array}$ & $\begin{array}{l}\text { Check author's name, credentials, } \\
\text { contact information. } \\
\text { - If no author is identified, check who } \\
\text { sponsors the Web site. } \\
\text { - If no sponsor is identified, check signs } \\
\text { of qualification of author such as } \\
\text { self-contradictions or } \\
\text { spelling/grammatical mistakes. }\end{array}$ \\
\hline Why did they write it? & $\begin{array}{l}\text { Be aware of possible purposes of } \\
\text { writing: to entertain, to share, to } \\
\text { support, to inform, to educate, to sell, } \\
\text { and to persuade. } \\
\text { Be aware that one topic can be } \\
\text { approached differently with different } \\
\text { purposes. }\end{array}$ \\
\hline When was it written and updated? & $\begin{array}{l}\text { - Understand there are three categories } \\
\text { of works: timeless, limited life, time } \\
\text { sensitive. } \\
\text { - Understand that timeliness may also } \\
\text { reflect whether the author is still } \\
\text { maintaining the site. }\end{array}$ \\
\hline Does this help meet my needs (and how)? & $\begin{array}{l}\text { - Ask questions, including: Does the site } \\
\text { give the type of information that I } \\
\text { need? Is it too difficult for me? }\end{array}$ \\
\hline Organization of Web site & $\begin{array}{l}\text { - Be aware that knowing how a Web } \\
\text { site is organized helps readers to } \\
\text { navigate and find information. } \\
\text { - Be aware that knowing how a Web } \\
\text { site is organized can help readers } \\
\text { understand the content. }\end{array}$ \\
\hline To-do list for the future & $\begin{array}{l}\text { - Have a plan, which may help diminish } \\
\text { distraction. } \\
\text { - Use a to-do list to keep track of } \\
\text { additional Web sites and other sources } \\
\text { to achieve a better understanding of } \\
\text { the topic. }\end{array}$ \\
\hline
\end{tabular}

Note. From Zhang \& Duke, 2011, p.136. 
The term WWWDOT is an acronym, which stands for the first letter of each of the questions or sections in Table 1. The three WWWs stand for Who, Why and When and the DOT stands for Does this help meet my needs, Organization and To-do list. A few of the questions provided in the WWWDOT framework are similar to the ones provided by Spitzer (2000) in the previous section. For example, they both mention authorship, authority, whether the site was updated and if it meets the person's need.

New features include the reason why the author wrote it, organization of the website and the to-do list for the future.

\section{AAOCC}

Tate and Alexander (1996) as well as Gardner (1999) argue that evaluating information on the web is the same as print. They offer five criteria that can be used to evaluate a website. These elements are the following:

1) Authority: Is the author mentioned on the website and what are the author's qualifications? Is there an institutional affiliation listed?

2) Accuracy: Is the information reliable and free of errors? Does the site include a bibliography? Is it clear who is responsible for the accuracy of the material? Are there links to other reliable sources?

3) Objectivity: Is the information presented with the least possible bias? Is the site factual, or does the author try to change the user's mind? Are graphics or imagery used to sway the opinion of the user?

4) Currency: Is the date of the latest revision of the site clearly stated? Is the date given for when the information was gathered? Is the page kept current? Are the links current and do they work? Is this truly the latest information on the topic?

5) Coverage: Is the scope of the topic clearly stated? Are supporting materials (bibliography, charts, statistics, etc.) given? Are there links to other resources on the topic? Is the site still under construction? (Tate \& Alexander, 1996; Gardner, 1999).

Similar web evaluation frameworks to the AAOCC were developed by the librarians from the Clark College Libraries. 


\section{A.S.A.P., A.S.P.E.C.T. and W5 for W3}

Other adaptations of the A.A.O.C.C. that use catchy acronyms include the A.S.A.P. and the A.S.P.E.C.T., both evaluation tools were created by Clark Librarians from the Clark College Libraries (2017). The librarians called this section of their webpage "Evaluate Information A.S.A.P." (Clark College Libraries, 2017). Below is a quick way to evaluate content on a website using the A.S.A.P. tool.

1) Author: Look for the author's name(s), credentials, expertise, other work, reputation, recommendations

2) Sources: Look for a bibliography, works cited, or other list of sources the author used

3) Age: Look for the publication or copyright date. Is it current enough for your topic?

4) Publisher: Look for the name of the publisher (or parent website). What other kinds of sources does this publisher provide? (Clark College Libraries, 2017)

The A.S.P.E.C.T. section of the Clark College Libraries is titled "Evaluate Every

A.S.P.E.C.T.” (Clark College Libraries, 2017). The acronym stands for the following:

\section{A: Authority}

- Is there an author's name?

- Can you locate the author's credentials?

- Can you find evidence of author expertise in the subject?

- Have you located similar works by this author?

- Do you have personal recommendations for this author?

- Do you know the publisher's credentials and reputation?

- Are there similar works from this publisher?

\section{S: Sources}

- Is information presented as fact? If yes...

- Does the author provide documentation? (Bibliography, footnotes, links, etc.)

- If documentation/sources are included, are they from credible sources?

\section{P: Purpose}

- Was this source written to inform and educate?

- Does the source argue a perspective or specific opinion?

- Is the source intended to entertain or sell?

- Is the content aimed at a general audience, or is it written for readers with expertise in the subject?

- Is the source too basic, too technical, too advanced? 
- Is the source just right for your research needs?

E: Evenness

- Does the author recognize other points of view?

- Is the information presented objective?

- If the source is biased, does the author acknowledge the bias?

C: Coverage

- Is the information new? Does it support what you have found in other sources?

- Is the source comprehensive or inclusive enough for your needs?

- Does this source provide information that is relevant to your needs?

T: Timeliness

- When was the source published?

- Is the date appropriate for your topic? (Clark College Libraries, 2017).

There is definitively a pattern emerging among these website/information evaluation models. The pattern is that most of them are adaptations of traditional information evaluation criteria used for print. The acronyms created by the Clark Librarians do add a touch of creativity and can assist students and teachers to remember these evaluation tools. Finally, the W5 for W3 is presented as a tool that can assist in evaluating websites. There are five W's for evaluating the WWW (World Wide Web), hence the W3. The W5 for W3 include the following:

1. Who is responsible for the site?

2. What kind of site is it?

3. When was the site created?

4. Where can you find more information?

5. Why is this site here?

This is a simplified version of previous evaluation tools, but nevertheless a starting point for students to begin evaluating websites. Websites can also be evaluated using reliability components which were used to evaluate health websites.

\section{Health Websites and Reliability Components}

Although this evaluation tool was specifically created for health websites, it can also be used for other types of sites. Usher and Skinner (2008), two doctors from Griffith 
University, selected the eight most common criteria for evaluating the reliability of health websites. They selected this criteria by reviewing 29 published rating tools and 100 journal articles that contained explicit criteria for evaluating health websites (Usher \& Skinner, 2008). Usher and Skinner define reliability as "the quality and level of trustworthiness of information/material found on the website" (2008, p. 32). Below are the eight reliability criteria:

1. Authority: The extent to which material is the creation of a person or organization that is recognized as having definitive knowledge of a given subject area.

2. Accuracy: The extent to which information is reliable and free from errors.

3. Objectivity: The extent to which material expresses facts or information without distortion by personal feelings or other biases (sponsorship).

4. Currency: The extent to which material can be identified as up to date.

5. Coverage: The range of topics included in a work and the depth to which those topics are addressed.

6. Intended Audience: The group of people for whom material was created.

7. Confidentiality: Confidentiality of data relating to individual patients and visitors to a health website, including their identity, is respected by this website.

8. Justifiability: Any claims relating to the benefits/performance of a specific treatment, commercial product or service will be supported by appropriate, balanced evidence.

This evaluation tool does not contain a creative acronym like the ones created by the Clark Librarians, but in honor of their cleverness and considering it is for evaluating health websites, it can be remembered by saying: when you are searching the web, take your A2, C3 vitamins and do not forget your OJ (Orange Juice). A2 stands for authority and accuracy, C3 is currency, coverage and confidentiality and $\mathrm{OJ}$ is objectivity and justifiability. Again, this also borrows from the traditional print information evaluation model. Another tool that can be used are fact checking websites. 


\section{Fact Checking Websites}

Fact checking websites provide a resource for teachers and students to use. They evaluate the trustworthiness of a website or other online information and usually rate them by stating if they are true, false, mostly true, or mostly false. Below are the most popular and reliable fact checking websites:

1. Snopes.com

2. Factcheck.org

3. Buzzfeed

4. Hoaxy

5. Media Bias

These websites can be used to cross-reference facts. They are usually made of a team that takes the time to evaluate content on the web and provide detailed information with cited sources on rate the information. They have also posted articles to assist people in navigating the web using a critical stance and advice based on their experience. LaCapria (2016) from snopes.com posted an article on "6 Quick Ways to Spot Fake News." They include:

1) Date (It) Yourself: Some stories are old and are recycled, check the publication date.

2) The Echo Chamber: If a story that simultaneously appears on many different popular news sites sounds too good to be true, check to see if all of those sites are referencing the same source.

3) The History of Lie-O-Lence: Check to see if the source is a site that was created purely for spreading fake news, such as the National Report. There are lists out there with known fake news websites.

4) The Deception is in the Details: Pay attention to the details such as the URL. If it has an extra .co or .info for example, wahingtonpost.com.co, it is most likely a fake news site.

5) Picture Diss: Use reverse image searching through Google Image Search or TinEye to check for recycled photographs. This section is also related to the fauxtography term mentioned earlier.

6) Where In the World? ... Fake news about things that occur in Russia or China are often fabricated due to language barriers and perceived cultural differences. 
An example of number four's example of paying attention to the URL, can be seen in the case of the martinlutherking.org website, where "the deception is achieved first and foremost through the use of the seemingly trustworthy domain name - a form of "cyberquatting" that exploits the iconic power that URLs hold." (Heyd, 2012, p. 140). This is also called "domain name appropriation" (Piper, 2000 p. 43). Obtaining domain names that look reputable is a common strategy by people who create hoax websites. This is especially true in politics as seen in the parody whitehouse.org website domain. The main thing from this article is that it is important to follow a critical thinking strategy. This cheat sheet is presented with created titles and useful information based on their experience evaluating fake news. Another fact check website that posted information on evaluating fake news is factcheck.org.

Kiely and Robertson (2016) from factcheck.org published a guide on, "how to spot fake news." This guide was used by the IFLA (International Federation of Library Associations and Institutions) (2017) and they created the following infographic containing eight steps: 


\section{HOW 10 SP T FAKE NEWS}

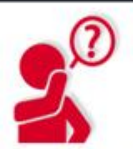

CONSIDER THE SOURCE

Click away from the story to investigate the site, its mission and its contact info.

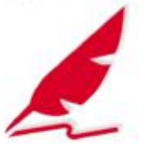

CHECK THE AUTHOR

Do a quick search on the author. Are they credible? Are they real?

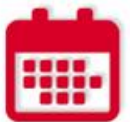

CHECK THE DATE

Reposting old news stories doesn't mean they're relevant to current events.

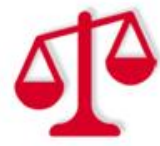

CHECK YOUR BIASES

Consider if your own beliefs could affect your judgement.

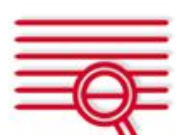

READ BEYOND

Headlines can be outrageous in an effort to get clicks. What's the whole story?

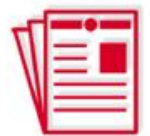

SUPPORTING SOURCES?

Click on those links. Determine if the

info given actually supports the story.

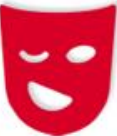

IS IT A JOKE?

If it is too outlandish, it might be satire. Research the site and author to be sure.

\section{ASK THE EXPERTS}

Ask a librarian, or consult a fact-checking site.

Figure 2. IFLA infographic on how to spot fake news.

This infographic has been translated into 37 languages. Its graphical presentation and simplicity has the possibility of making it appealing for students to follow. Fact checking websites are tools that can be used when evaluating suspicious content on the web. A word of caution is presented by Uscinski and Butler (2013) regarding fact checkers and their sometimes "naïve" methods of selection criteria where their own biases can sometimes have an effect on their ratings (true, false, somewhat true, somewhat false, etc.) Although Uscinski and Butler (2013) were referring mostly to fact checkers in political discourse, it is a good reminder that fact checking websites are a good start when evaluating the trustworthiness of a site or story, but it should not be the 
only tool used. The best practice would be to use a combination of tools and methods outlined in this section. A good word of advice comes from Ebbinghouse: "Think before you forward. Investigate before you believe. If it sounds too good or too bad/sad to be true, it probably isn't' (1998, p. 55). Web evaluation strategies have also been provided by historians.

\section{Evaluating Information from a Historian's Perspective}

From the perspective of the historian Winks, information needs to be evaluated by interrogating primary sources "as one would question a hostile witness, for it is prudent to assume that participants in an event were, at the least, partial to one view (their own) and, equally likely, have consciously shaped any written statement to reinforce that view" (1995, para. 7). Wink (1995) warns that the "forger will always be with us, and for precisely this reason one must maintain constant vigilance against being deceived" (para. 7). The steps originally outlined by Winks (1995) when evaluating historical texts considering the Hitler Diaries hoax and adapted for website evaluation for this paper includes the following:

1) Ask the right question(s): a question that can be answered, that is significant, that is interesting and true (being able to defend its premises).

2) Seek out the data: things about the participants or author that can be examined about the events to be reconstructed, e.g.: photographs, videos, publication date, references provided, etc. In other words, the evidence, which needs to be significant and not based on just one source.

3) Sources and data must be tested for authenticity: Who created it? When was it published? Why was it created? Is the creator an expert?

This evaluation also serves as another way to reinforce the use of multiple sources and ask questions about authorship, publication date, purpose, evidence collection and asking 
the "right" questions. Another web evaluation framework included ten guidelines

provided by Fogg's (2002) research.

\section{Ten Guidelines for Spotting Untrustworthy Websites}

The following ten items were adapted from Fogg's (2002) guidelines for boosting a website's credibility. The ten guidelines have been restructured in reverse as red flags for figuring out untrustworthy websites:

1. It is difficult to verify the accuracy of the information on the site. (It does not include third party support, such as references and citations.)

2. There is no real organization behind the site. (It is not a member of the chamber of commerce and there is no physical address or a photo of where it is located.)

3. The expertise of the organization and the content and services provided are not highlighted. (There are no experts mentioned on the website, credentials are not listed or there is no affiliation to a credible association.)

4. There are no honest and trustworthy people who stand behind the site. (The site contains no bios.)

5. It is not easy to contact the people who created the site or who the site represents. (There is no clear phone number, address or email.)

6. The design does not look professional. (The layout, typography, images and videos look unprofessional. For example, the images look photoshopped or videos that look blurry and edited unprofessionally.)

7. The site is not easy to use or useful. (Websites that are too complicated to use or cater too much to their own company's ego or try to dazzle with web technology are not good.)

8. The site is not updated often or reviewed recently. (It is a red flag if the website has not been updated or reviewed in a long time.)

9. There are too many promotional items such as ads and offers.

(Websites that try to sell you something should always be reviewed with a skeptical and critical mind frame.)

10. There are errors. (There are many grammatical mistakes or broken links and the site goes down often.)

Fogg's et al. (2002) study found that Web users perceive websites as credible

when the content is attributed to specific sources, author credentials, and references. In addition, ads and advertising damaged the credibility even more so when there was no 
clear distinction between the ad and the content (Fogg et al., 2002). On the other hand, Fogg et al. (2002) found that an "earned credibility" can be obtained by the user previously having a positive experience with a website. Aside from web evaluation strategies and frameworks, this literature review also included epistemic beliefs.

\section{Epistemic Beliefs}

Epistemic beliefs are beliefs about the nature and source of knowledge, the truth value of knowledge and the justification criteria of assertions or how one comes to know (Perry, 1970; Hofer, 2001; Mason, Boldrin, \& Ariasi, 2010). Epistemic beliefs are also referred as an individual's personal epistemology. Epistemology is "the theory of knowledge, especially with regards to its methods, validity, and scope; the investigation of what distinguishes justified belief from opinion" (Oxford Dictionaries, 2017). Hoaxes take advantage of beliefs. "Hoaxsters know that we act according to our beliefs, and by manipulating our beliefs they try to get us to act in certain ways" (Eaton \& Hoose, 2016, p. 204). Francis Bacon's quote below could shed some light on why beliefs can influence what people choose to believe:

For man always believes more readily that which he prefers. He, therefore, rejects difficulties for want of patience in investigation; sobriety, because it limits his hope; the depths of nature, from superstition; the light of experiment, from arrogance and pride, lest his mind should appear to be occupied with common and varying objects; paradoxes, from a fear of the opinion of the vulgar; in short, his feelings imbue and corrupt his understanding in innumerable and sometimes imperceptible ways. (Francis Bacon, 1620, p. 26)

\section{Dimensions of Epistemic Beliefs}

Hofer and Pintrich (1997) state that there are two areas of personal epistemology (epistemic beliefs), which have multiple dimensions: the nature of knowledge and the nature or process of knowing. In "Nature of Knowledge" (what one believes knowledge 
is, e.g. relativistic, contextual, constructivist, etc.), there are the following two dimensions: 1) Certainty of knowledge: ranges in degree from low-level view consisting of a belief in absolute truth and high-level view consisting of knowledge as tentative and evolving; and 2) Simplicity of knowledge: ranges from low-level view of knowledge as discrete, concrete, knowable facts and high-level view as knowledge as relative, contingent and contextual (Hofer \& Pintrich, 1997).

There are also two dimensions within the "Nature of Knowing" (beliefs about how one comes to know, e.g. source of knowledge, justification, evaluation of evidence, and role of authority): 1) Source of knowledge: ranges from low-level view consisting of knowledge originating outside the self and transmitted through an external authority and high-level view of knowledge constructed by the self; 2) Justification of knowing: how people evaluate knowledge ranges from acceptance of opinions to reasoned justification for beliefs (Hofer \& Pintrich, 1997). This framework allows researchers to organize epistemic beliefs in a way that results in "personal theories" on knowledge and knowing (Hofer \& Pintrich, 1997).

\section{Epistemic Beliefs and Evaluation of Trustworthiness}

A study performed by Strøms $\varnothing$, Bråten and Britt (2011) used the dimensions provided by Hofer \& Pintrich (1997) to examine epistemic beliefs in predicting students' evaluation of the trustworthiness of two science documents related to climate change. The researchers found that individuals whose epistemic beliefs consisted on relying on personal interpretation rather than on authorities, trusted both documents less and used the content of the document or their opinion as criteria for judging its trustworthiness (Strøms $\varnothing$ et al., 2011). On the other hand, individuals whose epistemic beliefs consisted 
on knowledge claims being critically evaluated through logic and rules evaluated the documents as more trustworthy and used the criteria of their opinion, author and content more than those who relied on their own experience (Strøms $\varnothing$ et al., 2011). The effects mentioned held true even after the authors controlled for the individual's prior knowledge and text comprehension (Strømsø et al., 2011). Another study found that individuals with low knowledge on a topic were more inclined to trust less trustworthy sources and put more importance on criteria of little significance when evaluating knowledge (Rouet, Favart, Britt, Perfetti, 1997). The same may occur if individuals with low topic knowledge evaluate websites, since they may end up trusting hoax websites and related fake sites by using criteria that is no relevant when evaluating the content.

Some studies have shown that epistemic beliefs can affect comprehension and influence judgement and reasoning (Schommer, 1990; Hofer, 2001), which can in turn affect whether someone believes a hoax or fake news site or not. It may be that a person's epistemic beliefs have an influence in assessing knowledge provided through hoax websites or related fake sites. Evaluating the credibility of Web resources is not an automatic process (Mason, Boldrin, \& Ariasi, 2010), it requires students to activate their epistemic beliefs when reflecting on the source of knowledge and its justification (Hofer and Pintrich, 2002).

\section{Epistemic Beliefs of Intuition, Evidence and Truth is Political}

A study performed by Garrett and Weeks (2017) confirms that epistemic beliefs have important implications for what is perceived as true. The study conducted by Garrett and Weeks measured three areas of epistemic beliefs: "reliance on intuition for factual beliefs (Faith in Intuition for Facts), importance of consistency between empirical 
evidence and beliefs (Need for Evidence), and conviction that "facts" are politically constructed (Truth is political)" (2017, p. 1). The "truth is political" epistemic belief refers to a social constructivist approach to truth where multiple "truths," exists and in turn facilitates a post-modern paradigm (Kata, 2012), where there are no objective facts and science it just one of many valid ways of understanding the world (Boghossian, 2006). Epistemic beliefs, that consist of the existence of various truths and no objective facts or the belief that intuition could be factual, may possibly lead to individuals believing more often in misinformation and disinformation posted on hoax websites and fake news.

Individuals tend to maintain beliefs that are aligned with their political ideology, financial view of the world, and ethical standards, which can influence their inclination to accept claims with little or no empirical evidence (Garrett \& Weeks, 2017). This phenomenon is related to the term post-truth mentioned earlier, which is defined as circumstances in which objective facts are less influential in shaping public opinion than appeals to emotion and personal belief. The satirist, comedian and actor Stephen Colbert also captured this notion when he used the term "truthiness," which is the subjective feeling that something is true, regardless of the evidence (Starnes, 2006). Garret and Weeks's (2017) study found that individuals who base themselves on intuition are likely to exhibit conspiracist ideation (belief of conspiracy theories) and those who maintained that beliefs should be based on evidence, where less likely to accept conspiracy theories and other falsehoods. These falsehoods could include hoax websites and other related fake sites. According to Garrett and Weeks (2017) individuals who believed that facts 
were shaped by politics and power were more susceptible to misperception than those who believed that truth transcended social context.

Garrett and Weeks (2017) suggest that epistemic beliefs that emphasize the importance of evidence and the careful use of feelings should be promoted. This advice can come in handy when evaluating the trustworthiness of a website, since it is best to rely on evidence and be conscious of how feelings or emotions can play a role when accepting the information provided by questionable sites. There is likely a relationship between epistemic beliefs and whether a hoax or fake website is believed as trustworthy or not. For example, it is possible that if a person does feel or agree politically or socially with climate change that they would call a site containing this type of information a hoax or fake news, regardless of the evidence provided.

\section{Epistemic Beliefs and Website Evaluation}

Brem, Russell, and Weems's (2001) study found an interaction between epistemic beliefs and the evaluation of websites. In their study, students in grades 9-12 were instructed to use certain criteria to evaluate scientific arguments. Their results demonstrated a tendency of students looking for true arguments indicating an epistemic belief of certain or absolute knowledge, and "real scientist" (external authority) through various sources (Brem, Russell, \& Weems, 2001). Students had the epistemic belief that knowledge had to be certain or right as a criterion for evaluating websites. They determined if the information was right or wrong by checking the author, credentials, whether it contained detailed information such as quotes and statistics. In short, the results demonstrated that epistemic beliefs can affect the way students' criteria selection when evaluating websites. 
Other studies in information science have also looked into credibility and authority as it pertains to evaluating websites (e.g. Fogg et al. 2002; Wathen \& Burkell 2002). These studies point out how adults view diverse types of websites. Essentially, trustworthiness and expertise contribute to the credibility of a webpage (Fogg et al., 2002). Trustworthiness refers to the "well-intentioned, truthful and unbiased nature of information," while credibility "captures the knowledge and skills (competence) of a source" (Mason, Boldrin \& Ariasi, 2010, p. 68). Wathen and Burkell's (2002) study mentioned various factors related to three areas that contribute to an individual's judgement in deciding whether to believe something or not.

1. source: expertise

2. message: plausibility

3. receiver: prior beliefs about a topic

The third area above, which includes the receiver and prior beliefs about a topic, may also include epistemic beliefs.

\section{Criterialist and Relativist Epistemic Beliefs}

A study by VanSledright, Alexander, Maggioni, Kelly, and Meuwissen (2004) related Elementary school teachers' epistemological stances (beliefs) to the criteria used to judge and evaluate sources in history and how the criteria was used. The two stances or beliefs analyzed in their study were "criterialist" and "relativist." The criterialist stance referred to those individuals who believed that criteria accepted in the history domain were more reliable than perspectives found within the content (VanSledright et al., 2004). The naïve relativist stance referred to individuals who judged conflicting sources to be of the same value and relied more on opinion (VanSledright et al., 2004). The pattern that is emerging from these studies is that epistemic beliefs are associated to using a criterion 
based on either justified evidence/facts or opinion/intuition/feelings. This can also be associated with objectivity vs. subjectivity. These studies suggest that individuals' epistemic beliefs can influence what types of information they trust and what type of criteria they use when evaluating knowledge.

\section{Summary}

The literature review contained information pertinent to the study, which included the following:

1. popular hoaxes in history

2. types of hoax websites and related fake sites

3. information literacy and metaliteracy

4. website and information evaluation criteria and tools

5. epistemic beliefs.

The literature review assisted in the creation of the questions in chapter one. Based on the review of the literature, there is a need for studies that analyze the evaluation of information on the Internet since numerous studies demonstrated that students and people in general are easily deceived by hoaxes. Information literacy and metaliteracy provide a framework for critically evaluating information and online hoaxes. Also, it appears that there is an urgent need for studies that provide a more empirical understanding of the evaluation of hoax websites that go beyond quantitative methods. This mixed-method study will add to the body of literature since the qualitative phase provides a more in-depth analysis. Lastly, studies show that the epistemic beliefs of people are related to what they choose to believe or not. Chapter three contains the methods used in this study. 


\section{CHAPTER III: METHODS}

\section{Participants}

The present mixed method study included post-secondary prospective teachers enrolled in an undergraduate education course, at a South Florida University. Education students enrolled at this South Florida University are usually made up of $85-90 \%$ females and $10-15 \%$ males. Undergraduate applicants are also predominantly females with 13,163 applications made by females in Fall 2016 compared to 8,646 applications made by males (National Center for Education Statistics, 2017).

The age range of the students at this South Florida University is between 18-25 years of age. The undergraduate student age is $72 \% 24$ and under, and $28 \% 25$ and over (National Center for Education Statistics, 2017). About 80\% of the students are majoring in early childhood education or elementary education. The remaining $20 \%$ of the students are majoring in art, physical education, or special education. The grand total of bachelor's degrees awarded for the 2015-2016 year in the education program included 377. Of these 377,148 degrees were in early childhood education and 103 in elementary education (The National Center for Education Statistics, 2017).

Most of the participants are Hispanic at this South Florida University. According to the National Center for Education Statistics (2017), 67\% of the University's undergraduate population is Hispanic/Latino, 12\% Black or African American, 9\% White, and 2\% Asian. The participants are all enrolled in a Bachelor of Science degree and most are planning on teaching once they graduate. Below is Table 2 with the above-mentioned statistics based on the National Center for Education Statistics (2017): 
Table 2

Information on University's Undergraduate Population

\begin{tabular}{lll}
\hline Enrollment & Student Age & Race/Ethnicity \\
\hline Females: 13,163 & 24 and under: 72\% & Hispanic/Latino: 67\% \\
Males: 8,646 & 25 and over: 28\% & Black or African American: 12\% \\
& & White: 9\% \\
& Asian: 2\% \\
\hline
\end{tabular}

\section{Research Questions}

This mixed-method study investigated the web evaluation behavior of prospective teachers as they evaluated hoax website and how their epistemic beliefs influenced it. The research questions that were answered include the following:

1. What percentage of prospective teachers trust the content on hoax websites?

2. What web evaluation strategies do prospective teachers report using regarding hoax websites?

a. What suggestions do prospective teachers have about learning web evaluation strategies?

3. What led prospective teachers to trust or not trust information posted on hoax websites?

a. How does teaching a specific web evaluation strategy (the WWWDOT Framework) to prospective teachers help them identify credible and hoax website?

b. How do the epistemic beliefs of prospective teachers correlate to their tendency to trust or not trust information posted on hoax website?

c. What web evaluation strategies led prospective teachers to trust or not information posted on hoax website? 


\section{Setting}

Participants from six undergraduate education courses were used. Each course contained between 10-30 undergraduate students. A total of 72 undergraduate education prospective teachers volunteered for the study. Undergraduate education courses were selected since the participants are prospective teachers. These courses are designed to teach prospective teachers various education related subjects in multiple type settings. Most students were taken to a computer lab setting, where each student had access to their own computer. On the rare occasion that this was not possible, they used their own laptops or smartphones.

\section{Instrumentation}

Several instruments were used in this study. These instruments included an online epistemic belief questionnaire (Appendix A) on evaluating websites using the survey software Qualtrics and interviewing after the websites were evaluated. Four websites were used, which included two credible and two hoax websites.

\section{Epistemic Belief Questionnaire}

The epistemic belief questionnaire was adapted from the questionnaire created by Garrett and Weeks (2017) regarding Faith in Intuition for Facts, Need for Evidence and Truth as Political. Table 3 contains the questionnaire where prospective teachers selected from a range between strongly disagree to strongly agree, with neither agree nor disagree in the middle: 
Table 3

Epistemic Beliefs Questionnaire

\begin{tabular}{|c|c|c|c|c|c|}
\hline \multicolumn{2}{|c|}{ Faith in Intuition for Facts } & \multicolumn{2}{|c|}{ Need for Evidence } & \multicolumn{2}{|c|}{ Truth is Political } \\
\hline Feell & $\begin{array}{l}\text { I trust my gut to tell me } \\
\text { what's true and what's } \\
\text { not }\end{array}$ & Evidl & $\begin{array}{l}\text { Evidence is more } \\
\text { important than } \\
\text { whether something } \\
\text { feels true }\end{array}$ & Polil & $\begin{array}{l}\text { Facts are } \\
\text { dictated by } \\
\text { those in } \\
\text { power }\end{array}$ \\
\hline Feel2 & $\begin{array}{l}\text { I trust my initial } \\
\text { feelings about the facts }\end{array}$ & Evid2 & $\begin{array}{l}\text { A hunch needs to be } \\
\text { confirmed with data }\end{array}$ & Poli2 & $\begin{array}{l}\text { What counts } \\
\text { as truth is } \\
\text { defined by } \\
\text { power }\end{array}$ \\
\hline Feel3 & $\begin{array}{l}\text { My initial impressions } \\
\text { are almost always right }\end{array}$ & Evid3 & $\begin{array}{l}\text { I trust the facts, not } \\
\text { my instincts, to tell } \\
\text { me what is true }\end{array}$ & Poli3 & $\begin{array}{l}\text { Scientific } \\
\text { conclusions } \\
\text { are shaped } \\
\text { by politics }\end{array}$ \\
\hline Feel4 & $\begin{array}{l}\text { I can usually feel when } \\
\text { a claim is true or false } \\
\text { even if I can't explain } \\
\text { how I know }\end{array}$ & Evid4 & $\begin{array}{l}\text { I need to be able to } \\
\text { justify my beliefs with } \\
\text { evidence }\end{array}$ & Poli4 & $\begin{array}{l}\text { "Facts" } \\
\text { depend on } \\
\text { their } \\
\text { political } \\
\text { context }\end{array}$ \\
\hline
\end{tabular}

Note. From Garrett \& Weeks, 2017 p. 5

This first part of the questionnaire contained questions regarding the aesthetic appeal, organization, planning to visit the website in the future, usefulness and trusting the content on the websites (trust level). An open-ended box was included in the questionnaire after each website in order for the participants to include any additional thoughts on their review of the website. The last part of the questionnaire contained a total of twenty-one items containing epistemic belief statements, which assisted in seeing which epistemic beliefs participants predominately agreed with.

\section{Interview}

Interviews were performed after the participants reviewed the website and filled out the epistemic beliefs questionnaire. The interview was primarily structured although it could be considered a hybrid between structured and unstructured in the sense that the 
same questions were asked, but they also led to additional questions depending on the answers of the participants. The interview questions were guided by the research questions (Appendix B). The following is a list of the questions asked during the interviews.

The interviews served as a suitable way to expand upon the epistemic beliefs questionnaire and obtain in-depth knowledge on the website evaluation strategies and epistemic beliefs of the prospective teachers concerning the evaluation of the hoax website.

\section{Procedure}

The study included the participation of human subjects, therefore certification from the Collaborative Institutional Training Initiative (CITI) was obtained as well as an Exempt approval from the University's Institutional Review Board (IRB). CITI certification and IRB Exempt approval was obtained to ensure the ethical handling of the participants. After the CITI certification and IRB approval, six education undergraduate courses were visited, and 72 participants volunteered for the research study.

Two groups were created, Group A and Group B. Neither of the groups were told that they were evaluating hoax websites. They were simply told that they were going to evaluate four websites. Group A was instructed to visit a link which took them to a Qualtrics online questionnaire. The first screen of the questionnaire contained a link and a section on demographic information. This was followed by links to the four websites (two hoaxes and two credible). Prospective teachers visited the websites, rated them on aesthetic appeal, organization, trust level, visit in the future and usefulness and were also able to input brief sentences in an open text box. A second screen contained questions 
regarding epistemic beliefs. The questionnaire contained questions on epistemic beliefs to check if there was a statistically significance between the epistemic beliefs of the participants and whether they trusted the website, remained neutral or did not trust it. Group B followed the same procedure as Group A, except they were provided with an overview of the WWWDOT Framework in order to teach them how to evaluate websites using a critical stance. The WWWDOT Framework was taught to Group B in a classroom computer lab setting for about 15 minutes before completing the online questionnaire. The WWWDOT Framework was displayed on an interactive whiteboard. From the 72 participants that completed the online questionnaire, 16 prospective teachers were purposefully selected based on their trust level (not trust, trust, remain neutral or trust one hoax but not the other). One of the goals of the interview was to obtain an understanding of why the prospective teachers fell into a specific trust level. Another goal of the interview was to obtain additional information on the website evaluation strategies used and their epistemic beliefs.

\section{Design}

The present mixed method study included quantitative and qualitative methods. A mixed-method study is defined as "research in which the investigator collects and analyzes data, integrates the findings, and draws inferences using both qualitative and quantitative approaches or methods in a single study" (Tashakkori \& Creswell, 2007, p. 4). The mixed method design used was sequential explanatory, which contains two phases.

The first phase was quantitative, and the second phase was qualitative. The second phase followed up on specific results from the quantitative phase (Creswell \& 
Plano Clark, 2010). The quantitative phase included the epistemic beliefs questionnaire and the qualitative phase included interviews. The qualitative phase helped to provide more in-depth and rich information about the quantitative results. By using a mixedmethod sequential explanatory design, the study was able to obtain statistical significance through the epistemic beliefs questionnaire and interpretive meaning through the interviews. The present study sought to identify an ontological view of prospective teachers' website evaluation strategies and epistemic beliefs. An ontological view is an examination into the feelings and perceptions usually not visible on the surface, but which requires personal experience (Azzouni, 2010). Figure 3 below contains a diagram of the process of the sequential explanatory design that this study used:

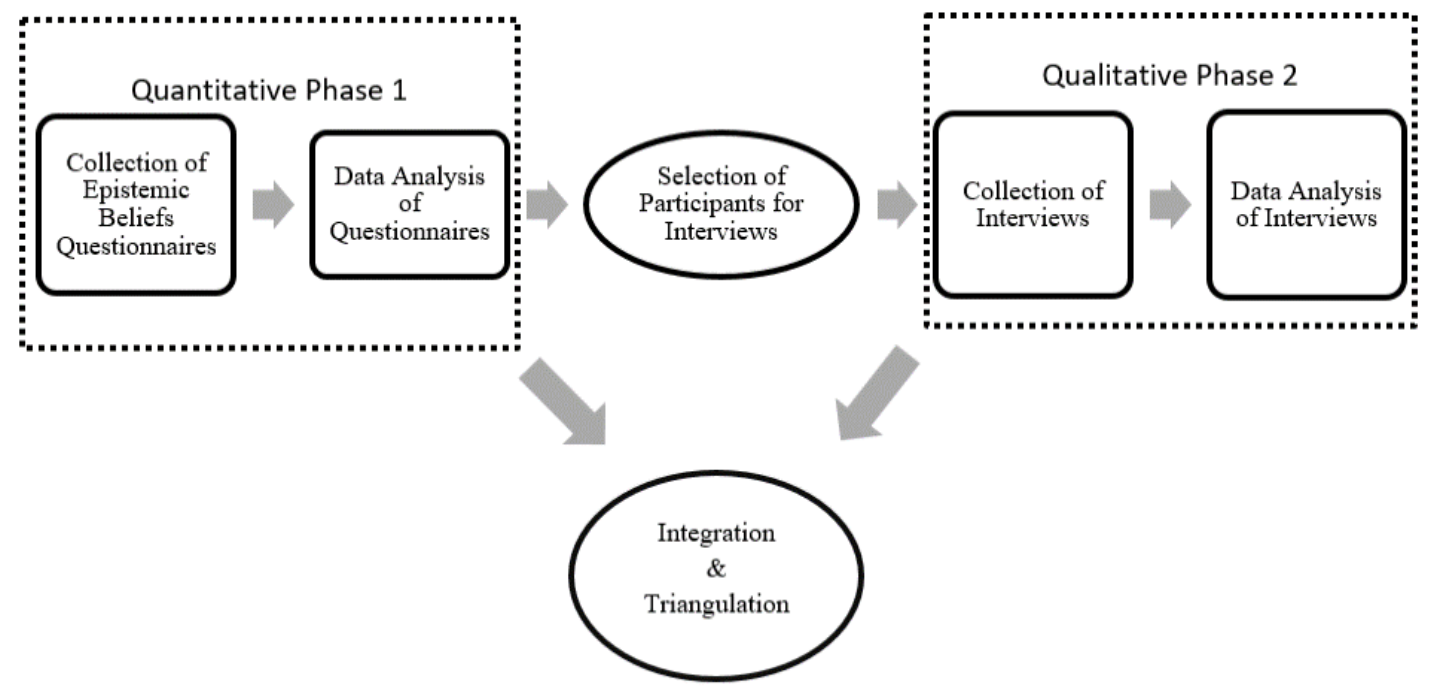

Figure 3. Sequential explanatory design.

Both Group A and Group B followed the process above. The only difference was that Group B was provided with an overview of the WWWDOT Framework to teach them how to evaluate websites using a critical stance before completing the questionnaire and interview. The information was delivered through a ten-minute presentation on the 
WWWDOT Framework. Group A was provided with no guidance. They simply evaluated the website using their own merit and prior knowledge on evaluating information. Figures 4, 5 and 6 below illustrate the difference:

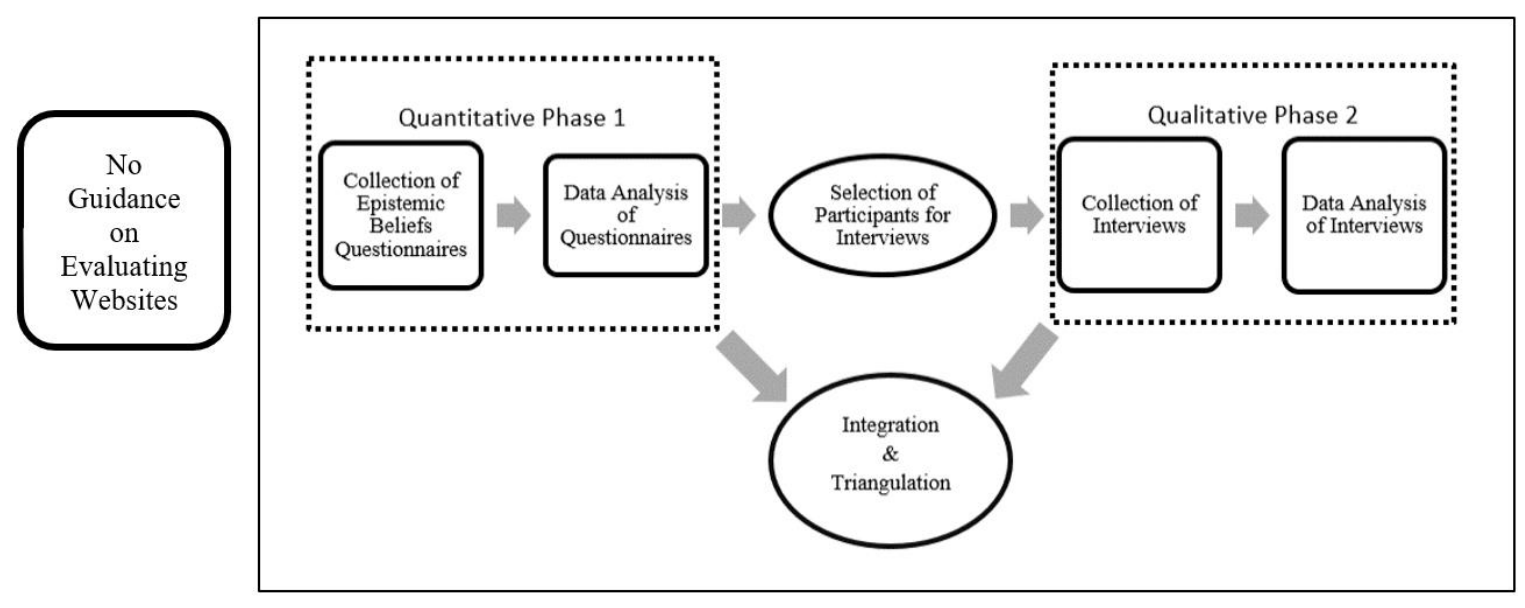

Figure 4. Sequential explanatory design for Group A.

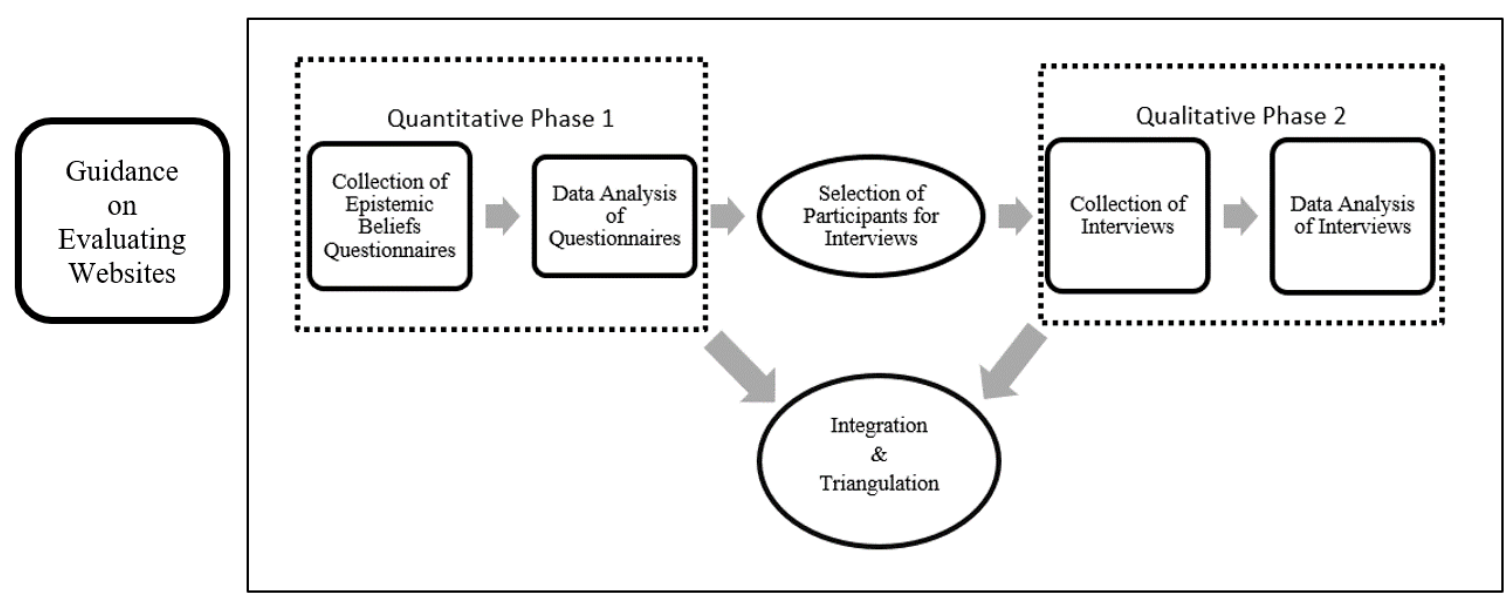

Figure 5. Sequential explanatory design for Group B. 


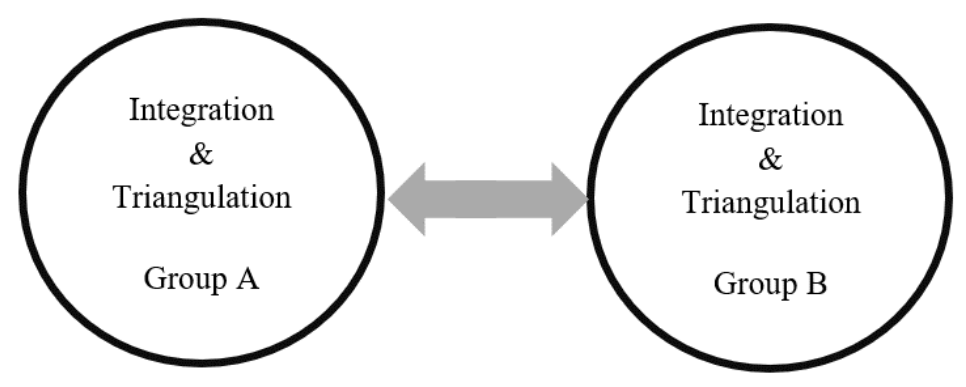

Figure 6. Comparison of results between Group A and Group B.

\section{Data Analysis}

The quantitative data analysis used inferential statistics obtained from the quantitative phase, which led to inferences about the association between variables (Morgan, Leech, Gloeckner, Barrett, 2007). The variables in the present study are epistemic beliefs, and the trust level (not trust, neutral and trust) of the prospective teachers regarding the hoax websites, coding the levels of each variable using the original Likert scale.

The online questionnaire's Likert scale was designed to measure results concerning the prospective teachers' evaluation of the websites and the epistemic beliefs of the individuals in association with their level of trust. The responses on the questionnaire ranged from one to five. Low numbers such as one and two signified disagreement and high numbers four and five signified agreement. The number three signified a neutral answer. The three epistemic beliefs categories where the participants fell into were: Faith in Intuition for Fact (reliance on intuition for factual beliefs), Need for Evidence (importance of consistency between empirical evidence and beliefs), and Truth is Politics (conviction that "facts" are politically constructed Garrett \& Weeks, 2017, p. 1). Participants were then assigned to the trust level and epistemic belief they fell 
into on the basis of the answers. The open-ended box included in the questionnaire after each website was analyzed by coding the topic of the text based on themes and frequency counts.

The validity and reliability of the questionnaire is addressed by calculating coefficient of correlations between questions and outcome variables. The independent variable was the type of epistemic belief and the dependent variable was the level of trust (not trust, neutral and trust) displayed by the prospective teachers regarding the hoax websites. The level of trust was measured by the Likert scale with not trusting, remaining neutral and trusting.

Subsequently, statistical tests were run to see if any of the epistemic belief categories were associated with whether the participant identified a hoax website. The quantitative data were entered into SPSS and analyzed for findings (Morgan, Leech, Gloeckner, Barrett, 2007). In addition, the reporting section of the Qualtrics software was also utilized. Statistics were used to test the hypotheses. Frequencies and crosstabulations were used for comparing counts and percentages between groups and answer hypothesis number one. Pearson's chi-square tests were used for testing hypotheses two and four. Fisher's test was used when there was an expected count of less than five in the cells. Zero order correlations (Bivariate Pearson Correlation) were run to test hypothesis number three regarding the three epistemic beliefs (Feeling, Evidence and Political) and trusting the respective hoax website. The $\mathrm{p}$ level for significance was set at the standard .05 based on Fisher (2006).

The qualitative data were analyzed by checking for patterns or common themes (Creswell, 2008) in the interview transcriptions and comparing the responses from the 
epistemic beliefs questionnaire. Various methods were implemented to ensure validity, reliability and trustworthiness of the qualitative data. A second person was used to code to control for bias, which is known as triangulation (Creswell, 2008). In order to account for personal biases, memos were written down to assist in the credibility and conceptualization of the codes and themes. Records were meticulously kept and organized. Also, rich and thick verbatim of participants' accounts were included. The data collected in the qualitative phase were subjective values determined by participants' explanation on whether they trusted the hoax websites, trusted one hoax but not the other, remained neutral or did not trust the hoax websites. The epistemic beliefs displayed were also analyzed during the interview in relation to the participants' trust level regarding the hoax websites.

\section{Summary}

The participants are undergraduate prospective teachers enrolled in an undergraduate education courses. The courses are taught mostly in a computer lab-type setting at a South Florida University that is predominately Hispanic. The instrumentation includes an epistemic belief questionnaire and interviews. The design is a mixed-method study utilizing both quantitative and qualitative data. The mixed-method design type is sequential explanatory. Two groups were analyzed. Group A had no guidance before the questionnaire and Group B had guidance on evaluating websites beforehand by teaching them the WWWDOT Framework. There were two phases. The quantitative phase was first and included the questionnaire, followed by the qualitative phase which included interviews. The data was analyzed using statistical tests in SPSS for the questionnaire and theme or patterns that emerged from the interviews. 


\section{CHAPTER IV: RESULTS}

Chapter four includes the results of the present mixed method study. The purpose of the study was to answer the three research questions. Primary data were collected through an online questionnaire and structured interviews conducted with prospective teachers. Seventy-two prospective teachers completed the online questionnaire. Of the 72 prospective teachers that completed the questionnaire, 16 were interviewed. These 16 interviewees were purposefully selected on the basis of the responses from the questionnaire and group they belonged, Group A (Control) or Group B (Experiment). From each group, two were selected that trusted the hoax websites, two that did not trust the hoax websites, two that trusted one hoax, but not the other and two that were neutral for a total of eight participants in each group. Thematic analysis was used to organize the results following the research questions.

The 16 prospective teachers were interviewed. The interviews were transcribed and then they were coded, and recoded various times as consistent patterns emerged. The codes went from specific to more general. A table was created in Excel (Appendix C) to organize the themes and sub-themes that emerged from the data collected using the research questions as the guide and the transcriptions. The excel spreadsheet, had nine columns and 640 rows of quotes, which were sorted to view the clusters of codes that belonged together and count the frequency. The nine columns included the interview number, page number, line number, group, trust level (trust, not trust, neutral and trust one but not the other), quote, sub-theme, theme and memo. The themes that emerged were organized by trust level and included web evaluation strategies, epistemic beliefs, and suggestions for learning web evaluation strategies. Quantitative statistical analysis 
was used to test the four hypotheses. Frequencies and crosstabulations were used for comparing counts and percentages between groups and answer hypotheses number one. Pearson's chi-square tests were used for testing hypotheses two and four. Fisher's test was used when there was an expected count of less than five in the cells. Zero order correlations (Bivariate Pearson Correlation) were run to test hypotheses number three regarding the three epistemic beliefs (Feeling, Evidence and Political) and trusting the respective hoax website. The demographics for Group A and Group B are presented in this chapter, as well as the quantitative analysis of the online questionnaire data, qualitative analysis of the interview data, results of the three research questions and corresponding hypotheses, and a summary.

\section{Demographics}

Of the 72 participants, $8.3 \%$ were male and $91.7 \%$ were female. The low number of males may be a delimitation of the study since most of the participants were females. Please see Figure 7 below to view these percentages:

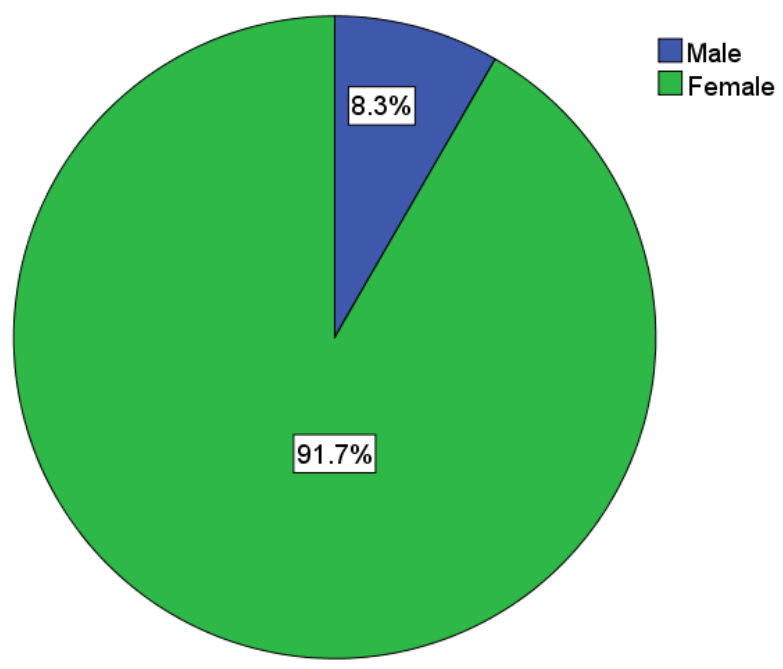

Figure 7. Percentages of females and males. 
These percentages were the same for both Group A and Group B. Please see table below containing gender information:

Table 4

Gender

\begin{tabular}{lcc}
\hline & Frequency & Percent \\
\hline Group A & & \\
Male & 3 & 8.3 \\
Female & 33 & 91.7 \\
Total & 36 & 100 \\
Group B & & \\
Male & 3 & 8.3 \\
Female & 33 & 91.7 \\
Total & 36 & 100 \\
Total & & \\
Male & 6 & 8.3 \\
Female & 66 & 91.7 \\
Total & 72 & 100 \\
\hline
\end{tabular}

Aside from gender, another question from the questionnaire dealt with race and ethnicity. From the 72 participants, a person from Group A did not provide a response. The demographics consisted of 39 (54.9\%) White, 11 (15.5\%) Black or African American, three (4.2\%) Asian and 18 (25.4\%) other. From the other category, $12(16.7 \%)$ were Hispanic, one (1.4\%) Haitian, and one (1.4\%) "Citizen of the World." Below are two tables with the responses: 
Table 5

Ethnicity

\begin{tabular}{lccc}
\hline & Frequency & Percent & Valid Percent \\
\hline Group A & & & \\
White & 19 & 52.8 & 54.3 \\
Black or African American & 6 & 16.7 & 17.1 \\
Asian & 0 & 0 & 0 \\
Other & 10 & 27.8 & 28.6 \\
Total & 35 & 97.2 & 100 \\
Missing & 1 & 2.8 & \\
Group B & & & \\
White & 20 & 55.6 & 55.6 \\
Black or African American & 5 & 13.9 & 13.9 \\
Asian & 3 & 8.3 & 8.3 \\
Other & 8 & 22.2 & 22.2 \\
Total & 36 & 100 & 100 \\
Total & & & \\
White & 39 & 54.2 & 54.9 \\
Black or African American & 11 & 15.3 & 15.5 \\
Asian & 3 & 4.2 & 4.2 \\
Other & 18 & 25 & 25.4 \\
Total & 71 & 98.6 & 100 \\
\hline
\end{tabular}

Table 6

Ethnicity-Other

\begin{tabular}{lcc}
\hline & Frequency & Percent \\
\hline Group A & & \\
Cuban (white/brown) & 1 & 2.8 \\
Haitian & 1 & 2.8 \\
Hispanic & 6 & 16.7 \\
Total & 36 & 100 \\
Group B & 1 & \\
Citizen of the world & 4 & 2.8 \\
Hispanic & 1 & 11.1 \\
White/Hispanic & 36 & 2.8 \\
Total & 1 & 100 \\
Total & 1 & 1.4 \\
Citizen of the world & 1 & 1.4 \\
Cuban (white/brown) & 10 & 1.4 \\
Haitian & 1 & 13.9 \\
Hispanic & 72 & 1.4 \\
White/Hispanic & & 100 \\
Total & &
\end{tabular}


In addition to gender and ethnicity, the participants' age range was also provided. The 72 participants varied in age from 18-35 years of age. Most them were less than 24 years of age, with $83.3 \%$ within $18-24$ years and $16.7 \%$ between $25-35$ years old. Below is Table 7 with the age group results:

Table 7

\begin{tabular}{lcc} 
Age & & \\
\hline Group & Frequency & Percent \\
\hline Group A & 29 & 80.6 \\
$18-24$ & 7 & 19.4 \\
$25-35$ & 36 & 100 \\
Total & & \\
Group B & 31 & 86.1 \\
$18-24$ & 5 & 13.9 \\
$25-35$ & 36 & 100 \\
Total & & \\
Total & 60 & 83.3 \\
$18-24$ & 12 & 16.7 \\
$25-35$ & 72 & 100 \\
Total & & \\
\hline
\end{tabular}

Most of the participants were elementary education majors. This was followed by early childhood education, special education and art education as seen on Table 8. 
Table 8

Education Major

\begin{tabular}{lcc}
\hline & Frequency & Percent \\
\hline Group A & 4 & \\
Early Childhood Education & 23 & 11.4 \\
Elementary Education & 5 & 63.9 \\
Art Education & 3 & 13.9 \\
Special Education & 35 & 8.3 \\
Total & 1 & 97.2 \\
Missing & 36 & 2.8 \\
Total & & 100 \\
Group B & 10 & \\
Early Childhood Education & 21 & 27.8 \\
Elementary Education & 5 & 58.3 \\
Special Education & 36 & 13.9 \\
Total & & 100 \\
Total & 14 & \\
Early Childhood Education & 44 & 19.4 \\
Elementary Education & 5 & 61.1 \\
Art Education & 8 & 6.9 \\
Special Education & 71 & 11.1 \\
Total & 1 & 98.6 \\
Missing & 72 & 1.4 \\
Total & & 100 \\
\hline
\end{tabular}

More than half of the prospective teachers were elementary education majors, specifically $61.1 \%$, this was followed by early childhood education with $19.4 \%$, special education with $11.1 \%$ and art education with $6.9 \%$. The next section contains the quantitative analysis results of the questionnaire data.

\section{Quantitative Analysis of Questionnaire Data}

The dependent variable was whether the participants did not trust, were neutral or trusted the hoax website. Both variables consisted of categorical or nominal data using the Likert scale and group also the dependent variable was not normally distributed, therefore the main statistical analysis used were frequency, Pearson Chi-Square or Fisher's Exact Tests, if there was an expected count less than five in the cells. Other 
independent variables included aesthetic appeal, organization, usefulness, visit in the future and the epistemic beliefs feelings, evidence and political.

Of the 72 participants, 35 of them trusted a hoax website, regardless of whether they were in Group A or Group B. That means that almost half of the participants (48.6\%) trusted at least one of the hoax websites, which is visible in Figure 8 below:

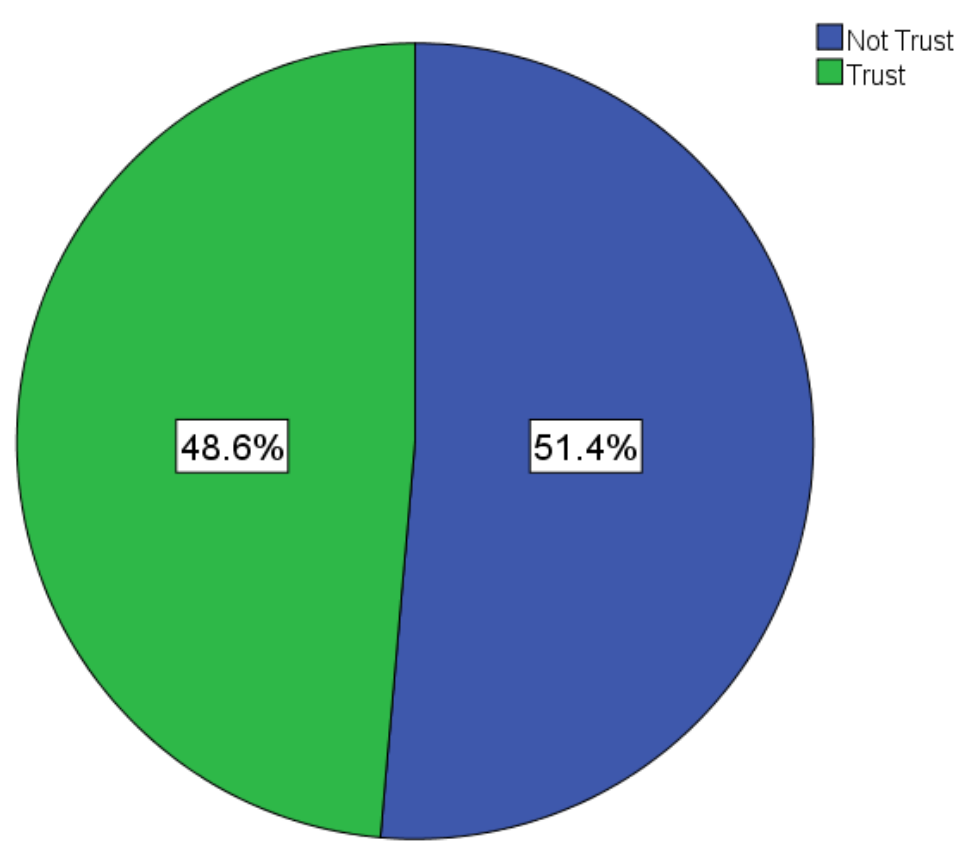

Figure 8. Percentages of Trust and Not Trust.

The results were even more clear when analyzed by group. In Group A, 21 of the 36 participants trusted a hoax website. That means that $58.3 \%$ of the participants from Group A, trusted at least one hoax website. In contrast, $38.9 \%$ or 14 out of 36 participants in Group B trusted a hoax website. Most of the participants in Group A trusted a hoax website and most from Group B did not. In Group B, 22 of the 36 or $61.1 \%$, did not trust a hoax website. This suggests that in general the WWWDOT Framework helped prospective teachers to not trust a hoax website. Below is Table 9 and Figure 9, which show these numbers and percentages: 
Table 9

Trusted At Least One Hoax Website

\begin{tabular}{lccc}
\hline Group & $\begin{array}{c}\text { Not Trust } \\
\mathrm{n}(\%)\end{array}$ & $\begin{array}{c}\text { Trust } \\
\mathrm{n}(\%)\end{array}$ & $\begin{array}{c}\text { Total } \\
\mathrm{n}(\%)\end{array}$ \\
\hline Group A & $15(41.7)$ & $21(58.3)$ & $36(100)$ \\
Group B & $22(61.1)$ & $14(38.9)$ & $36(100)$ \\
Total & $37(51.4)$ & $35(48.6)$ & $72(100)$ \\
\hline
\end{tabular}

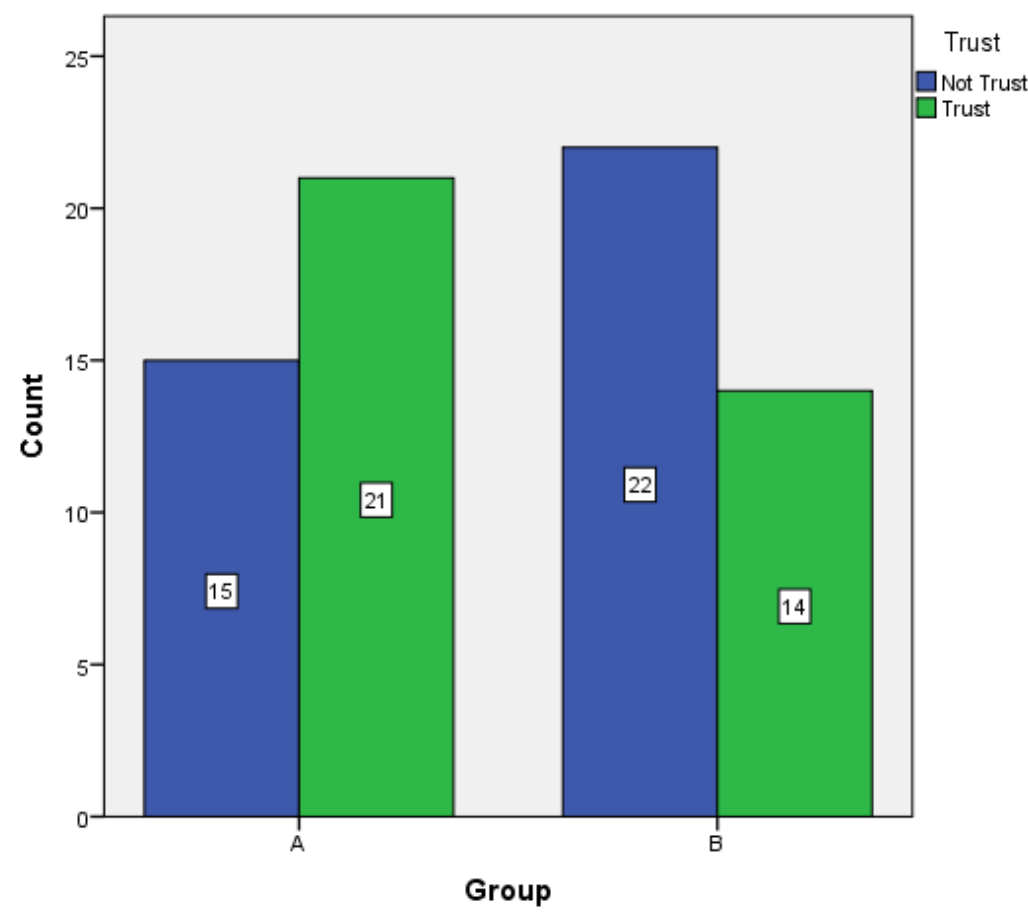

Figure 9. Comparison of Group A and Group B with trust variable.

Gender, age and ethnicity did not have enough participants and showed no statistical significance. Interestingly, the results varied between the DHMO.org and the Tree Octopus hoax websites. The next section contains quantitative analysis of these two hoax websites. 


\section{DHMO.org Hoax Website}

Of the 72 participants, $43.1 \%$ did not trust the content on the DHMO.org website, $26.4 \%$ trusted the content and $30.6 \%$ neither agreed or disagreed with trusting the content. The majority did not trust the content. Below is Figure 10 with these results:

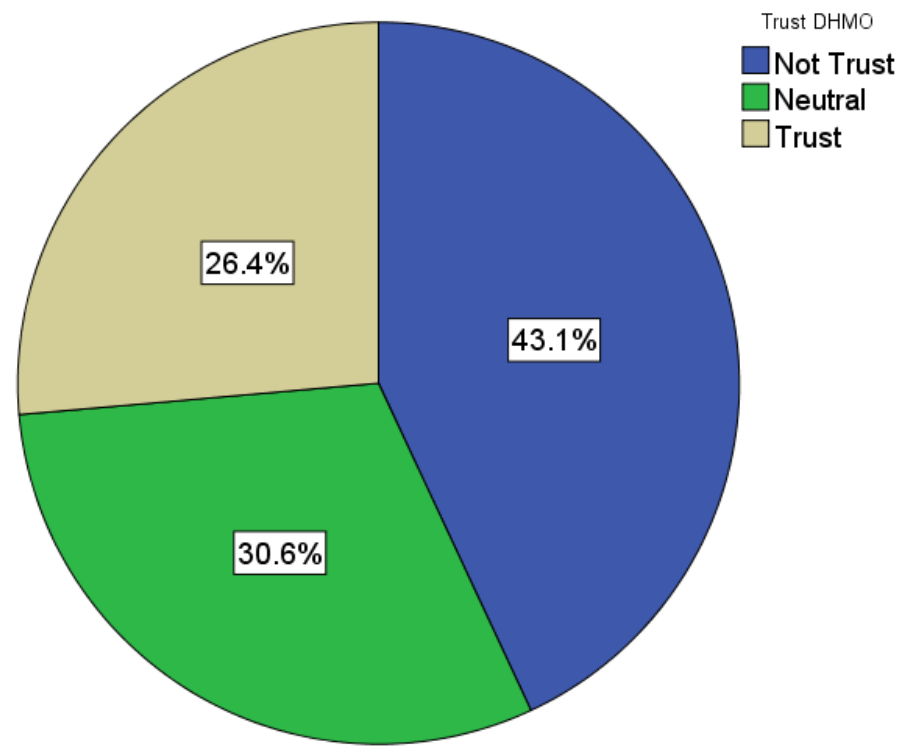

Figure 10. Percentages of DHMO.org trust variable.

From Group A, $36.1 \%$ did not trust the DHMO.org website compared to 50\%

from Group B. This suggests that the WWWDOT Framework may have helped to slightly increase the number of participants that did not trust the DHMO.org hoax website since Group B was exposed to the WWWDOT Framework and Group A was not. In Group A, 27.8\% trusted the DHMO.org website compared to 25\% in Group B. The WWWDOT framework may have helped lower the number of participants that trusted the hoax website by a bit. Please see Table 10 and Figure 11 below. 
Table 10

DHMO.org Group and Trust Variables

\begin{tabular}{lllll}
\hline & \multicolumn{1}{c}{$\begin{array}{c}\text { Not Trust } \\
\mathrm{n}(\%)\end{array}$} & \multicolumn{1}{c}{$\begin{array}{c}\text { Neutral } \\
\mathrm{n}(\%)\end{array}$} & $\begin{array}{r}\text { Trust } \\
\mathrm{n}(\%)\end{array}$ & $\begin{array}{r}\text { Total } \\
\mathrm{n}(\%)\end{array}$ \\
\hline Group A & $13(36.1)$ & $13(36.1)$ & $10(27.8)$ & $36(100)$ \\
Group B & $18(50)$ & $9(25)$ & $9(25)$ & $36(100)$ \\
Total & $31(43.1)$ & $22(30.6$ & $19(26.4)$ & $72(100)$ \\
\hline
\end{tabular}

Pearson Chi-Square $=1.586$

$\mathrm{p}=.452$ (not statistically significant)

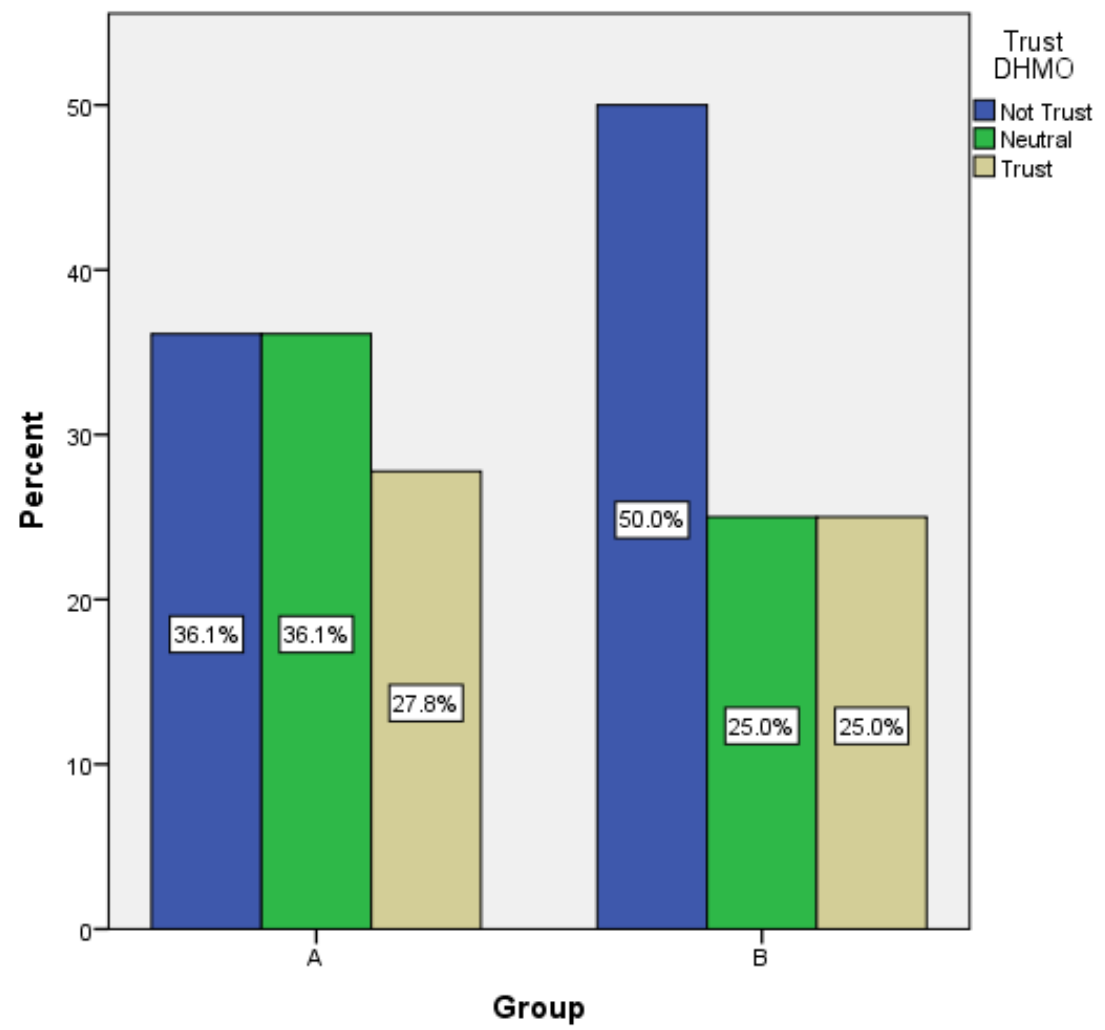

Figure 11. Comparison of Group A and Group B with DHMO.org trust variable.

However, there was no statistical significance between the group variable and trusting the content on the DHMO.org website since the Pearson Chi-Square Test was 1.586 , which resulted in a $\mathrm{p}$ value of .452 , which is above .05 . This means that the WWWDOT Framework did not result in a significant change in trusting, remaining neutral or not trusting the DHMO.org website. However, it is important to note that the 
DHMO.org website was rated low regarding aesthetic appeal and organization, which may explain the small number of participants that trusted this website compared to the Tree Octopus website, which was rated as visually appealing. This is confirmed by the following quantitative analysis of the aesthetic appeal and trust variables for the DHMO.org website.

DHMO.org Aesthetic Appeal and Trust. A total of 55 participants or 76.4\% rated the aesthetic appeal of the DHMO.org website as not aesthetically appealing, which means that most of the participants thought it was poorly designed. These results are supported by the information obtained from the interviews, where most people did not trust the dhmo.org website because of its poor design, structure, organization, as opposed to the Tree Octopus hoax website, which was trusted more due to its aesthetically pleasing design (refer to qualitative section for more information on these results.) As seen in Figure 12 below, $76.4 \%$ of the participants thought the DHMO.org website was not aesthetically appealing, $11.1 \%$ was neutral and $12.5 \%$ thought it was aesthetically appealing: 


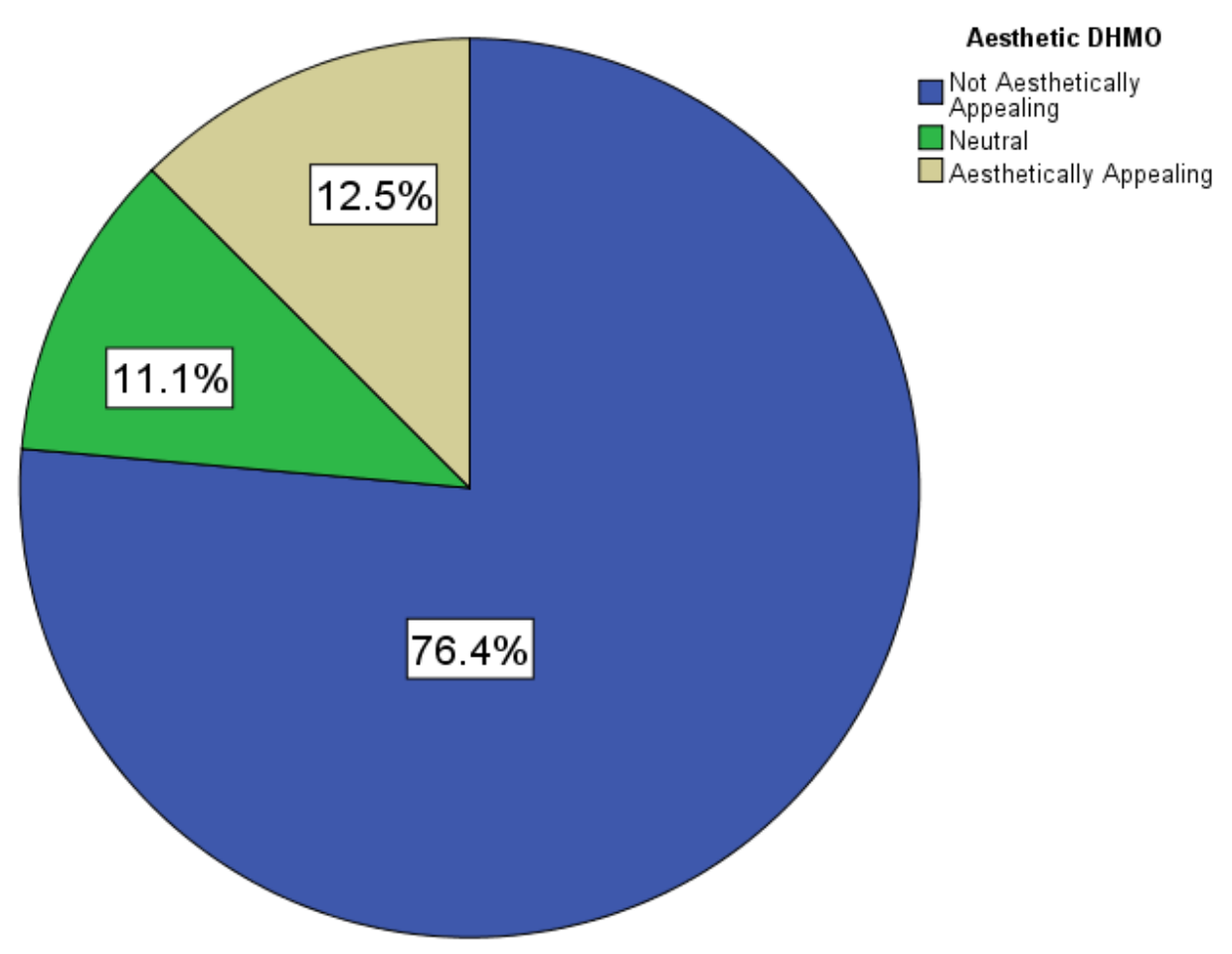

Figure 12. Percentages of DHMO.org aesthetic appeal.

A crosstabulation analysis of the Aesthetic Appeal of the DHMO.org website with the trust dependent variable, was conducted. As seen in Table 11, 29 out of the 55 participants $(52.7 \%)$ thought the website was not aesthetically appealing, did not trust it either. In addition, most of the participants that thought it was aesthetically appealing six out of nine $(66.7 \%)$ did trust the DHMO.org website. Individual Chi-Square Tests for Group A and B between the variables trusting the DHMO.org website and the level of aesthetic appeal, resulted in no statistical significance. Group A had a Fisher's Exact Test value of 7.345 with a p value of .058, and Group B had a Fisher's Exact Test value of 7.389 with a $\mathrm{p}$ value of .051 . Since these two $\mathrm{p}$ values were above .05 , they are not statistically significant. However, when the total number of participants was analyzed, there was a statistical significance since the Fisher's Exact Test was 13.399 with a $p$ value of .004 , which is less than .05 . Below is Table 11 and Figure 15 with these results: 
Table 11

DHMO.org Aesthetic Appeal and Trust Variables for Total

\begin{tabular}{lcccc}
\hline & Not Trust & Neutral & Trust & Total \\
& $\mathrm{n}(\%)$ & $\mathrm{n}(\%)$ & $\mathrm{n}(\%)$ & $\mathrm{n}(\%)$ \\
\hline Not Appealing & $29(52.7)$ & $16(29.1)$ & $10(18.2)$ & $55(100)$ \\
Neutral & $2(25)$ & $3(37.5)$ & $3(37.5)$ & $8(100)$ \\
Appealing & $0(0)$ & $3(33.3)$ & $6(66.7)$ & $9(100)$ \\
Total & $31(43.1)$ & $22(30.6)$ & $19(26.4)$ & $72(100)$ \\
\hline
\end{tabular}

Fisher's Exact Test $=13.399 \mathrm{p}=.004$ (statistically significant)

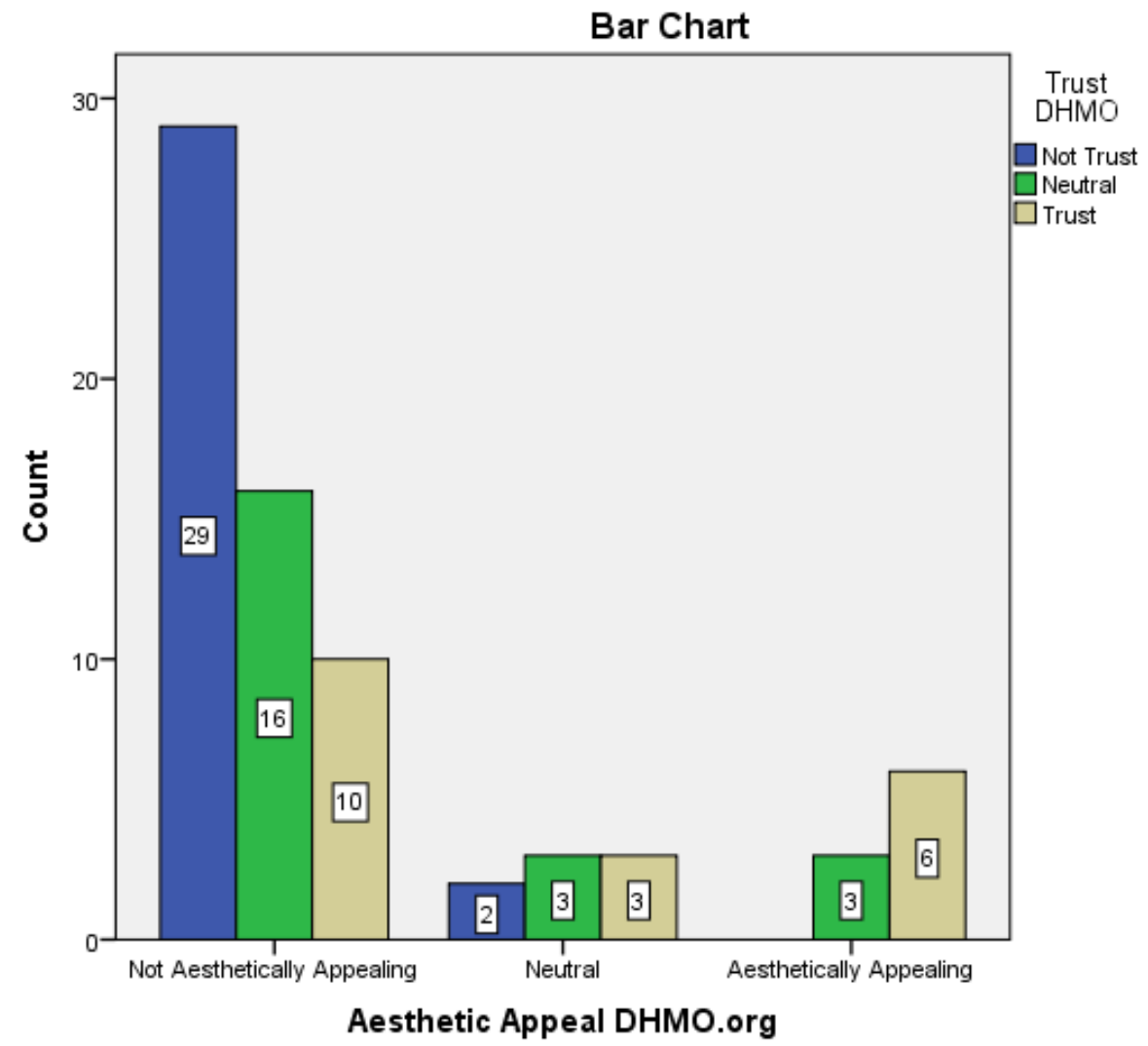

Figure 13. Comparison of DHMO.org aesthetic appeal and trust variable for all participants.

In general, most of the participants that thought the DHMO.org website was not aesthetically appealing did not trust it. In addition, most of the participants that thought the DHMO.org website was aesthetically appealing did trust it. Below is Figure 14 that 
illustrates the relationship between aesthetic appeal and trust for the DHMO.org website in Group A:

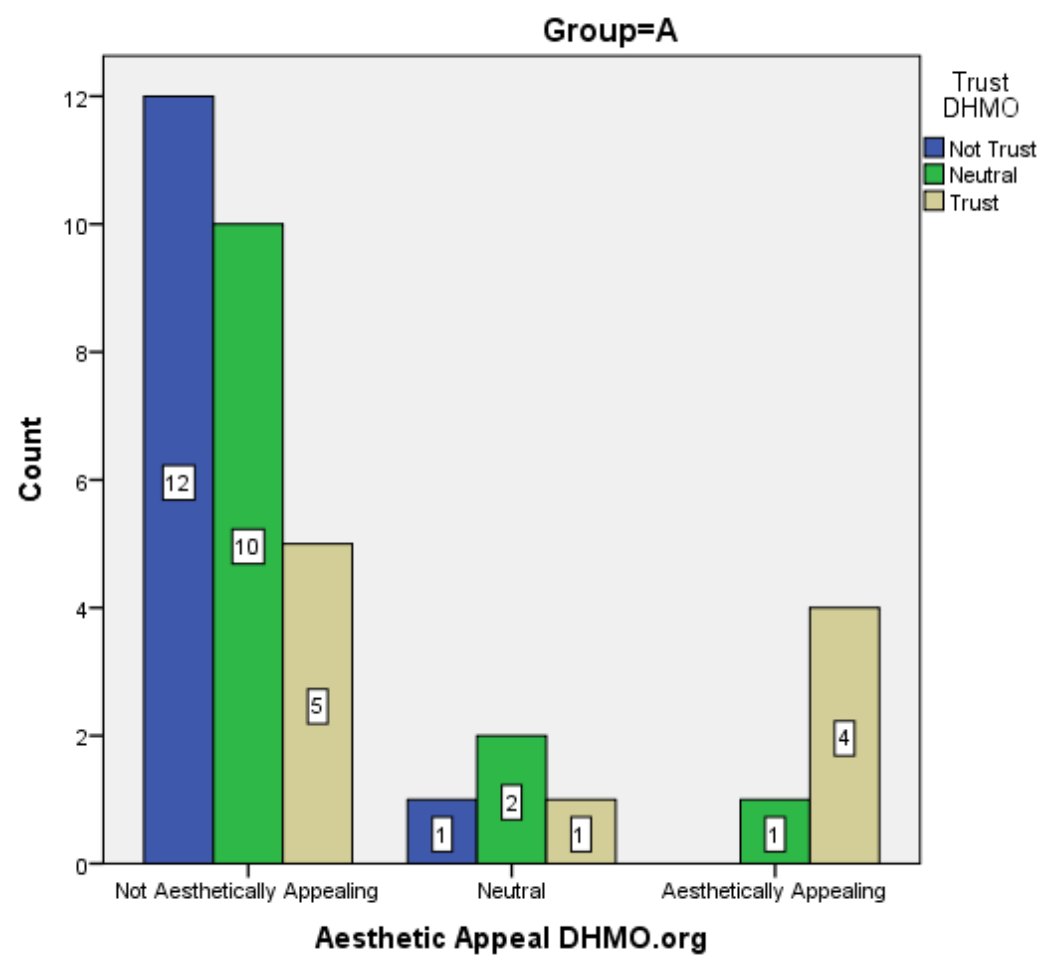

Figure 14. Comparison of DHMO.org aesthetic appeal and trust variable for Group A.

Most of the participants who said that the DHMO.org website was not aesthetically appealing, did not trust it either. However, as mentioned earlier this number was not statistically significant. Group B was close to being statistically significant at .051 , but it was not statistically significant either. Figure 15 below shows how most of the participants who thought it was not aesthetically appealing did not trust it either: 


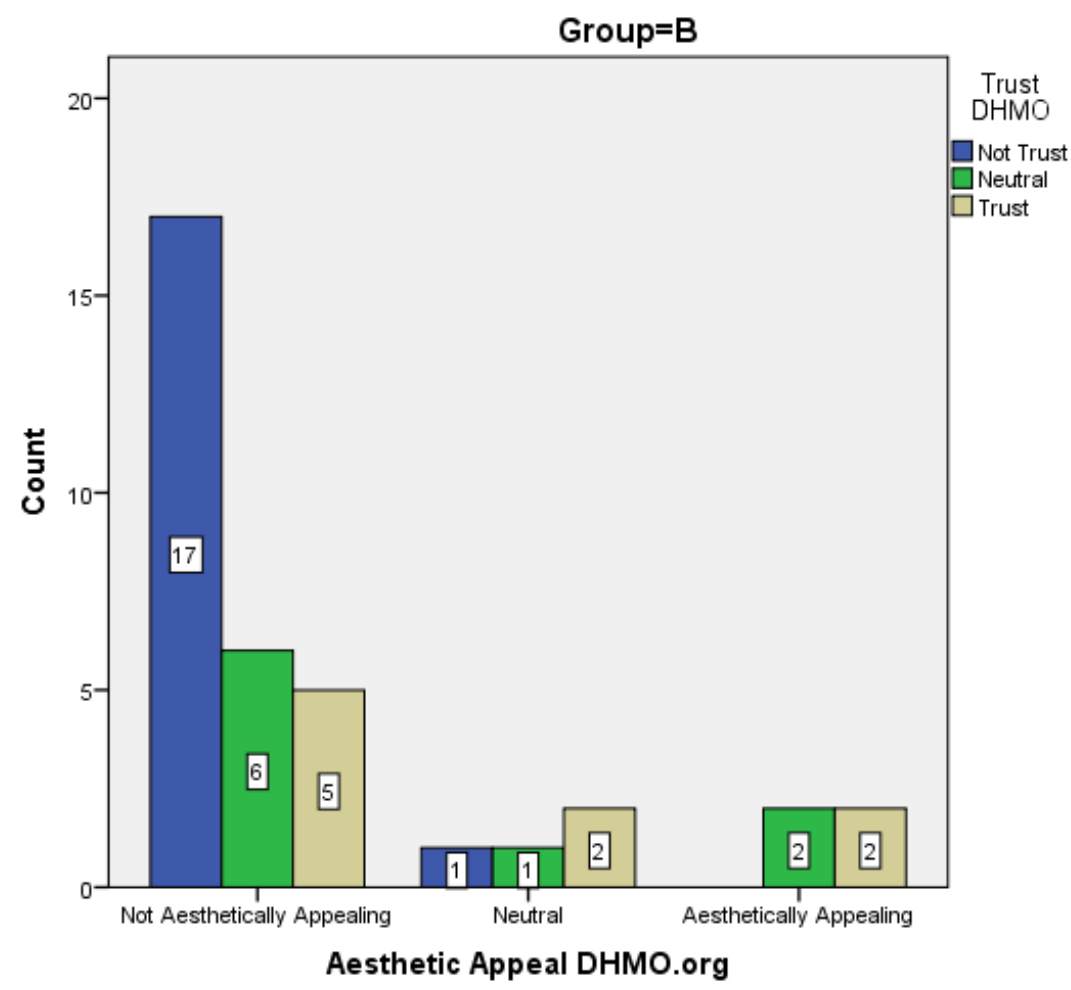

Figure 15. Comparison of DHMO.org aesthetic appeal and trust variable for Group B. Seventeen of the twenty-eight or $47.2 \%$ that said it was not aesthetically appealing, did not trust it either. Again, this was not statistically significant, however it was close with a $\mathrm{p}$ value of .051 . The following variables analyzed were organization and trust.

DHMO.org Organization and Trust. Organization was also another variable that resulted in a statistical significant number. More than half of the total number of participants, $38(52.8 \%)$, thought that the DHMO.org website was not organized. Below is Figure 16 with these results: 


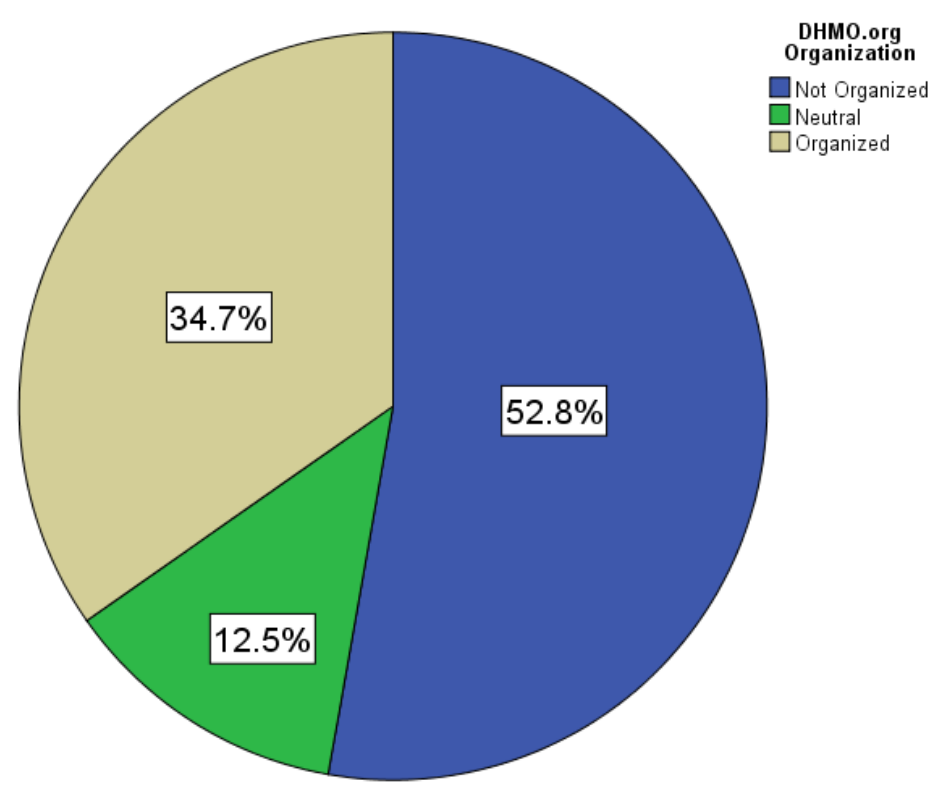

Figure 16. Percentages of DHMO.org organization.

Of the 38 participants who thought it was not organized, $63.2 \%$ did not trust the website, and 12 or $48 \%$ of those that thought it was organized, trusted the DHMO.org website. The same was statistically significant for the total number of participants and for Group A, but it was not statistically significant for Group B. Table 12 and Figure 17 below contain the results for the organization and trust variable for the total number of participants:

Table 12

DHMO.org Organization and Trust Variables for Total

\begin{tabular}{lllll}
\hline & \multicolumn{1}{c}{ Not Trust } & \multicolumn{1}{c}{ Neutral } & \multicolumn{1}{c}{ Trust } & \multicolumn{1}{c}{ Total } \\
\hline Not Organized & $24(63.2)$ & $9(23.7)$ & $5(13.2)$ & $38(100)$ \\
Neutral & $3(33.3)$ & $4(44.4)$ & $2(22.2)$ & $9(100)$ \\
Organized & $4(16)$ & $9(36)$ & $12(48.0)$ & $25(100)$ \\
Total & $31(43.1)$ & $22(30.6)$ & $19(26.4)$ & $72(100)$ \\
\hline
\end{tabular}

Fisher's Exact Test $=16.427$

$\mathrm{p}=.001$ (statistically significant) 


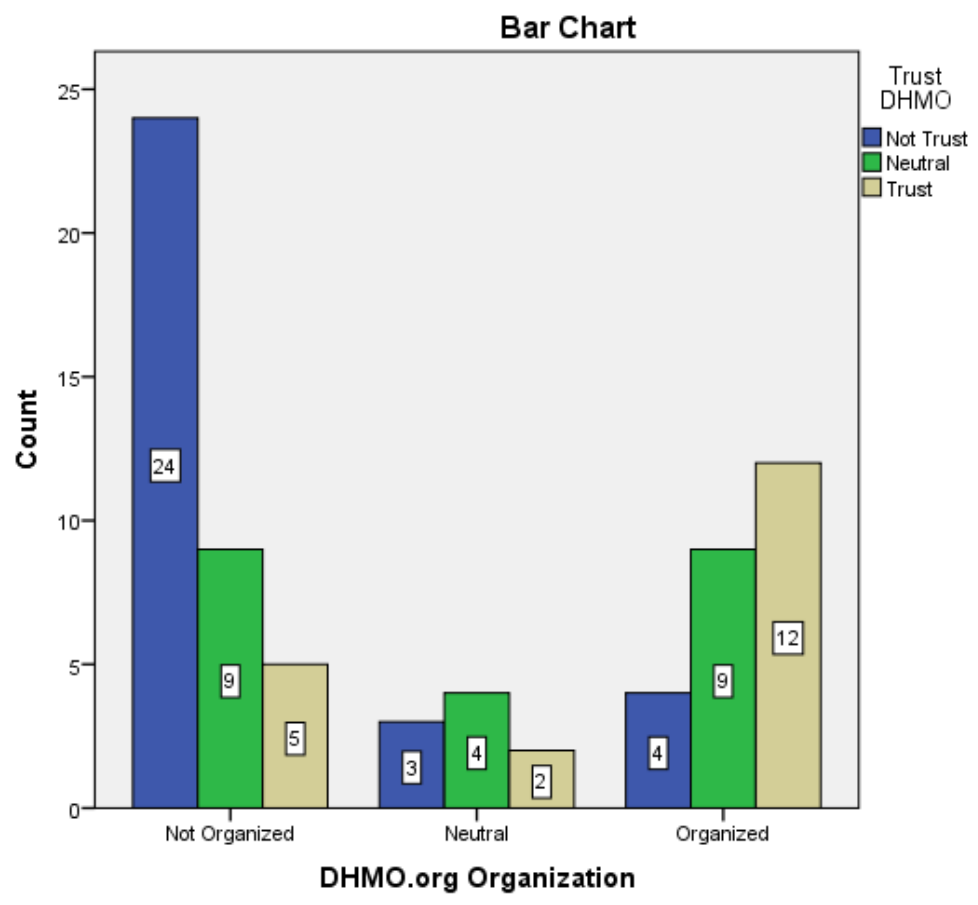

Figure 17. Comparison of DHMO.org organization and trust variable for all participants.

Table 12 and Figure 19, show that those who thought it was organized, also trusted it, which was precisely, 24 of 38 or $63.2 \%$. In addition, those who said it was not organized, did not trust it, which was 12 of 25 or $48 \%$. Fisher's Exact Test for the total number of participants was 16.427 with a $\mathrm{p}$ value of .001 (<.05 sig.). Group A was 13.442 with a $\mathrm{p}$ value of $.006(<.05$ sig.) and Group B was 6.905 with a p value of .088 (>.05 not sig.). The percentages within the "not organized" category that did not trust the DHMO.org website was also high for Group A (68.8\%) and Group B (59.1\%). This shows that the majority did not trust the DHMO.org website since they thought it was not organized. Below is a Table 13 and Figure 18 with information on these two variables for Group A: 
Table 13

DHMO.org Organization and Trust Variables for Group A

\begin{tabular}{lllll}
\hline & \multicolumn{1}{c}{ Not Trust } & \multicolumn{1}{c}{ Neutral } & \multicolumn{1}{c}{ Trust } & \multicolumn{1}{c}{ Total } \\
\hline Not Organized & $11(68.8)$ & $3(18.8)$ & $2(12.5)$ & $16(100)$ \\
Neutral & $1(14.3)$ & $4(57.1)$ & $2(28.6)$ & $7(100)$ \\
Organized & $1(7.7)$ & $6(46.2)$ & $6(46.2)$ & $13(100)$ \\
Total & $13(36.1)$ & $13(36.1)$ & $10(27.8)$ & $36(100)$ \\
\hline
\end{tabular}

Fisher's Exact Test $=13.442$

$\mathrm{p}=.006$ (statistically significant)

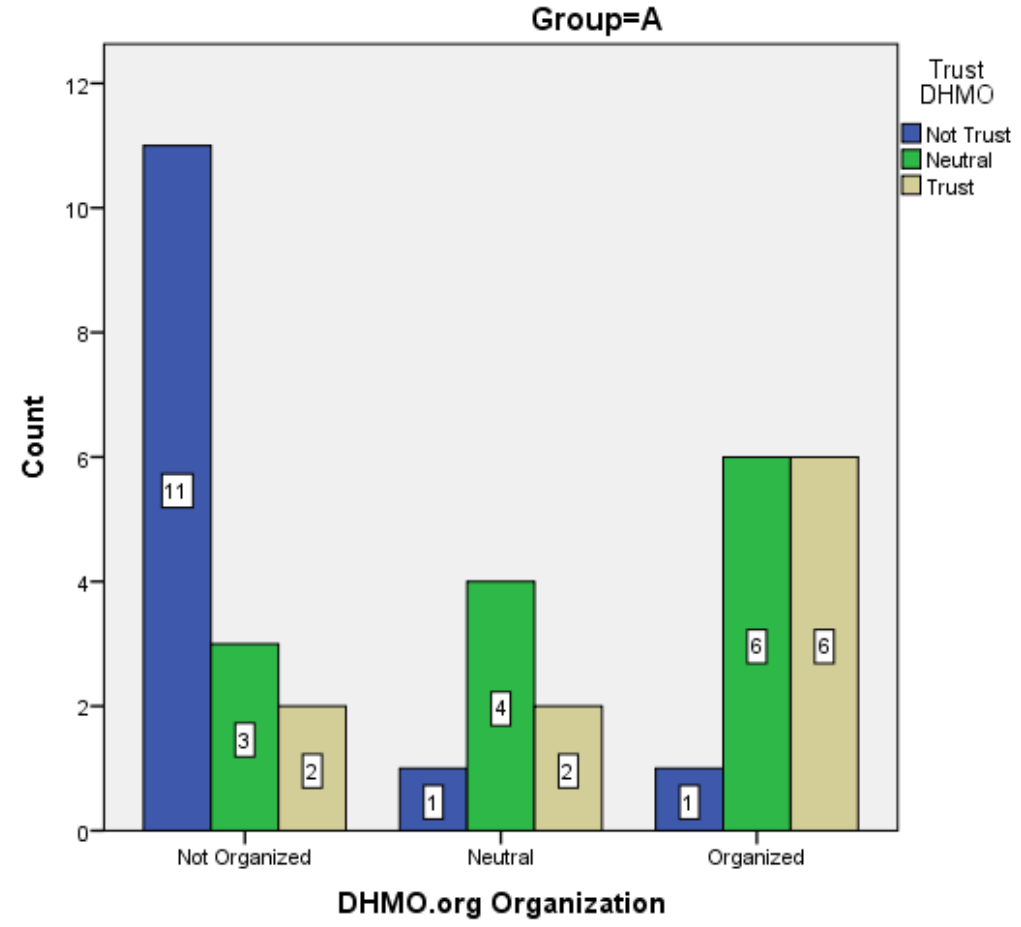

Figure 18. Comparison of DHMO.org organization and trust variable for Group A.

The percentages within the "not organized" category that did not trust the

DHMO.org website was also high for Group A, 11 or $68.8 \%$ and Group B, 13 or $59.1 \%$.

This shows that the majority did not trust the DHMO.org website since they thought it was not organized. It was statistically significant for the total number of participants and for Group A, but it was not statistically significant for Group B. This suggests that for Group A and the total number of participants, if a website is not organized, then people will tend to not trust it. Also, if it is organized then it would most likely be trusted. Since 
the $\mathrm{p}$ value for Group A was significant, it is clear that most of the participants that thought it was not organized, did not trust it either. Exactly, 11 of the 16 or $68.8 \%$ said they thought the DHMO.org website was not organized did not trust it either. The results were similar for Group B however it was not statistically significant. Below is Figure 19 with these results.

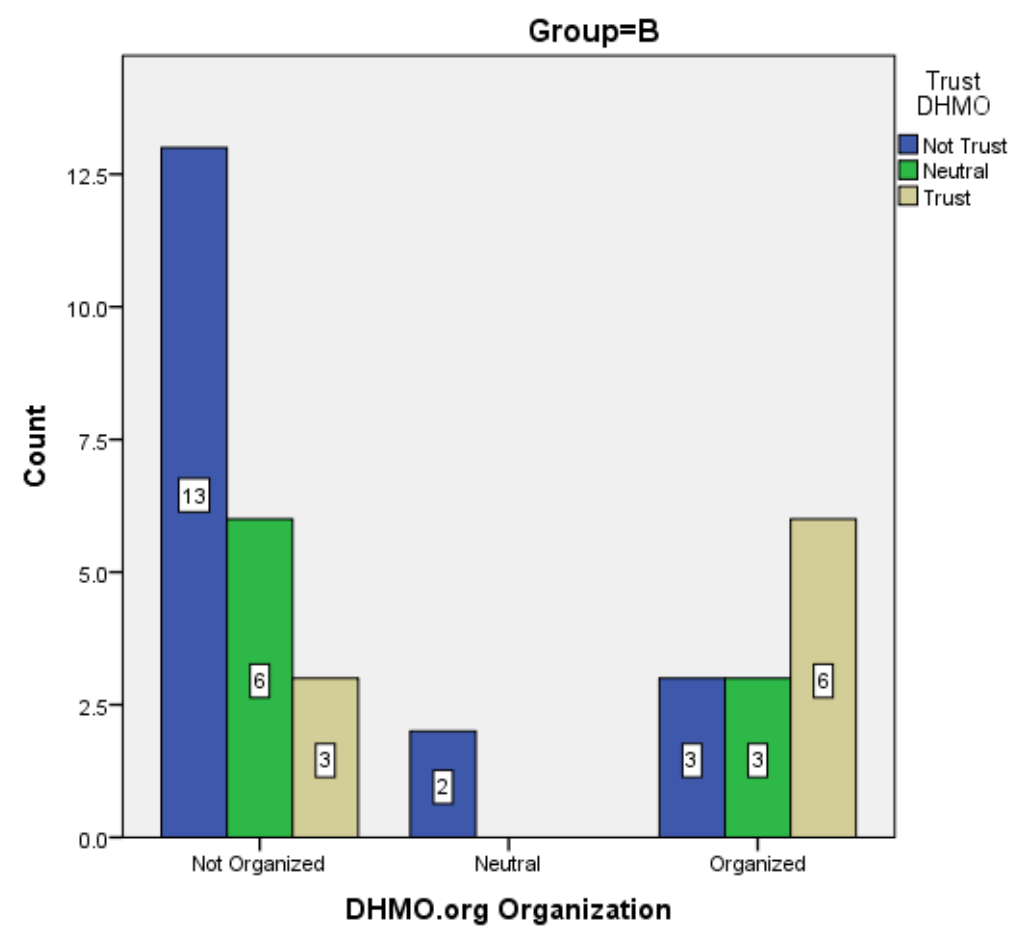

Figure 19. Comparison of DHMO.org organization and trust variable for Group B.

Thirteen of the twenty-two or 59.1\% who said the DHMO.org website was not organized, did not trust it either. The results for all the participants in general show how organization influenced the trust level. The next variables analyzed were trust and whether participants would visit the DHMO.org website in the future.

DHMO.org Visit in the Future and Trust. Most of the individuals in the study said that they would not visit the DHMO.org website again in the future. A total of $80.6 \%$ 
said that they would not visit it, $9.7 \%$ remained neutral and $9.7 \%$ said that they would visit it again in the future. Below is Figure 20 with these results:

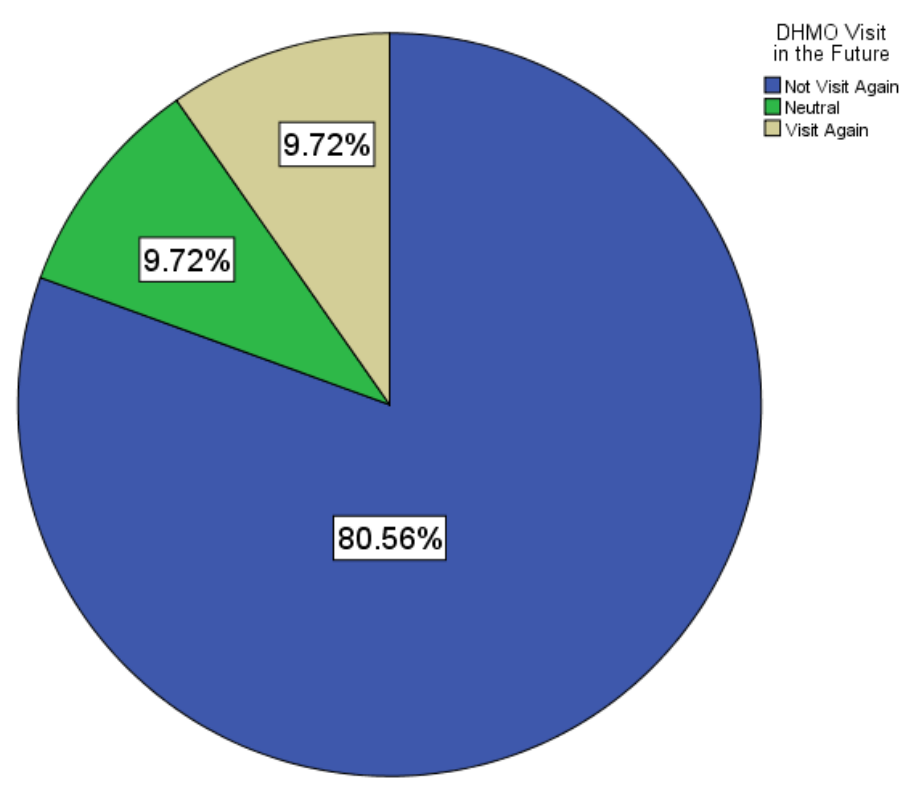

Figure 20. Percentages of DHMO.org visit in the future.

In contrast, a total of seven $(9.7 \%)$ said that they would visit the DHMO.org website in the future and five of the seven or $71.4 \%$ also trusted the DHMO.org website. The Fisher's Exact test was used since the Pearson Chi-Square had an expected count less than five in a few cells. The Fisher's Exact Test for the total number of participants was 14.326 with a $\mathrm{p}$ value of .001 , which was statistically significant. Table 14 and Figure 21 below contain these results: 
Table 14

DHMO.org Visit in the Future and Trust Variables for Total

\begin{tabular}{|c|c|c|c|c|}
\hline & $\begin{array}{l}\text { Not Trust } \\
\mathrm{n}(\%)\end{array}$ & $\begin{array}{l}\text { Neutral } \\
\mathrm{n}(\%)\end{array}$ & $\begin{array}{l}\text { Trust } \\
\mathrm{n}(\%)\end{array}$ & $\begin{array}{l}\text { Total } \\
\mathrm{n}(\%)\end{array}$ \\
\hline Not Visit & $30(51.7)$ & $16(27.6)$ & $12(20.7)$ & $58(100)$ \\
\hline Neutral & $0(0)$ & $5(71.4)$ & $2(28.6)$ & 7 (100) \\
\hline Visit & $1(14.3)$ & $1(14.3)$ & $5(71.4)$ & 7 (100) \\
\hline Total & $31(43.1)$ & $22(30.6)$ & $19(26.4)$ & $72(100)$ \\
\hline
\end{tabular}

Fisher's Exact Test $=14.326$

$\mathrm{p}=.001$ (statistically significant)

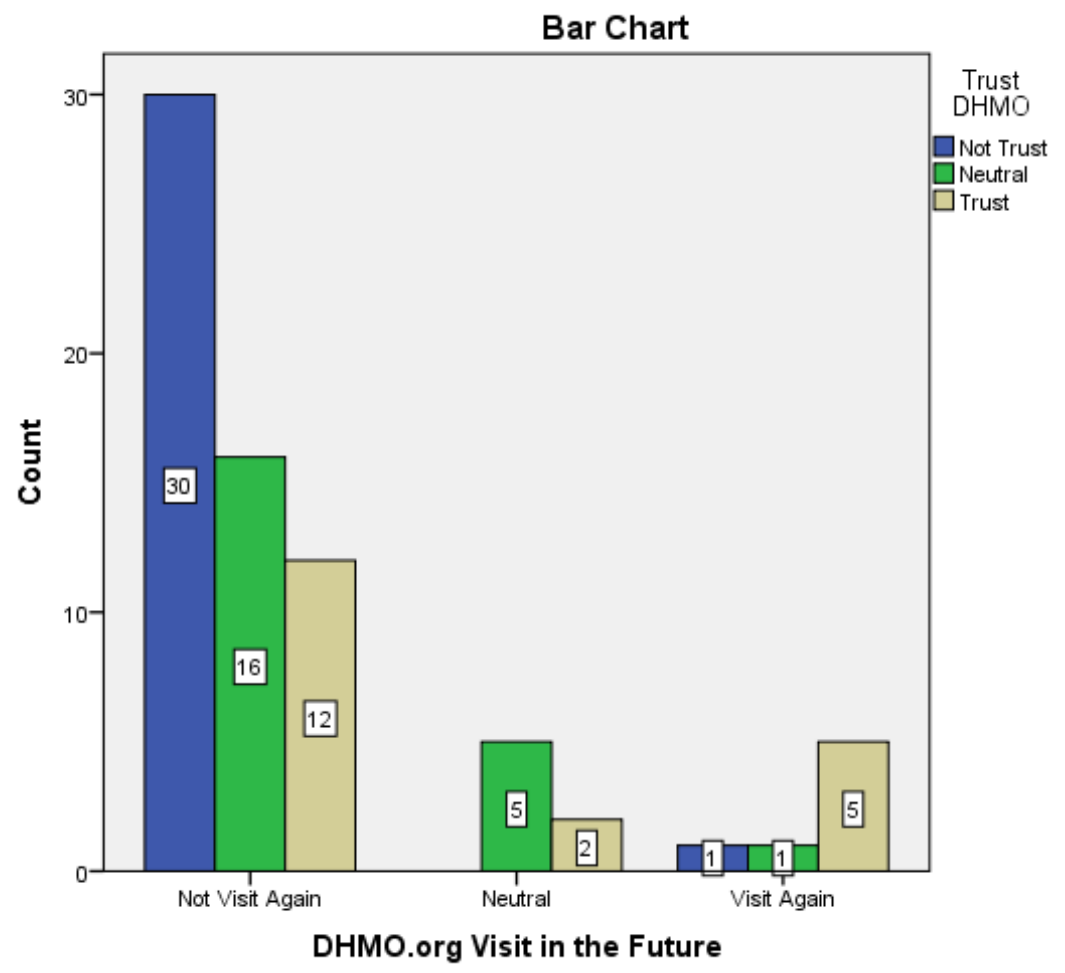

Figure 21. Comparison of DHMO.org visit in the future and trust variable for all participants.

Thirty of the 58 or $51.7 \%$, who said they would not visit the website again, did not trust it either. Also, five of the seven or $71.4 \%$ who stated they would visit it again, did trust it. These numbers suggest that if participants said they would not visit the DHMO.org website in the future, then it would most likely result with not trusting the 
DHMO.org website. Also, if the participants stated that they would visit the DHMO.org website in the future, then they would most likely tend to trust the DHMO.org website. This was true for Group B and for the total number of participants, but not for Group A, since the $\mathrm{p}$ value for Group A was not significant. The Fisher's Exact test was used since the Pearson Chi-Square had an expected count less than five in a few cells. The Fisher's Exact Test for Group A was .199, which was not statistically significant. Below is Figure 22 that provides a visual representation of these two variables for Group A.

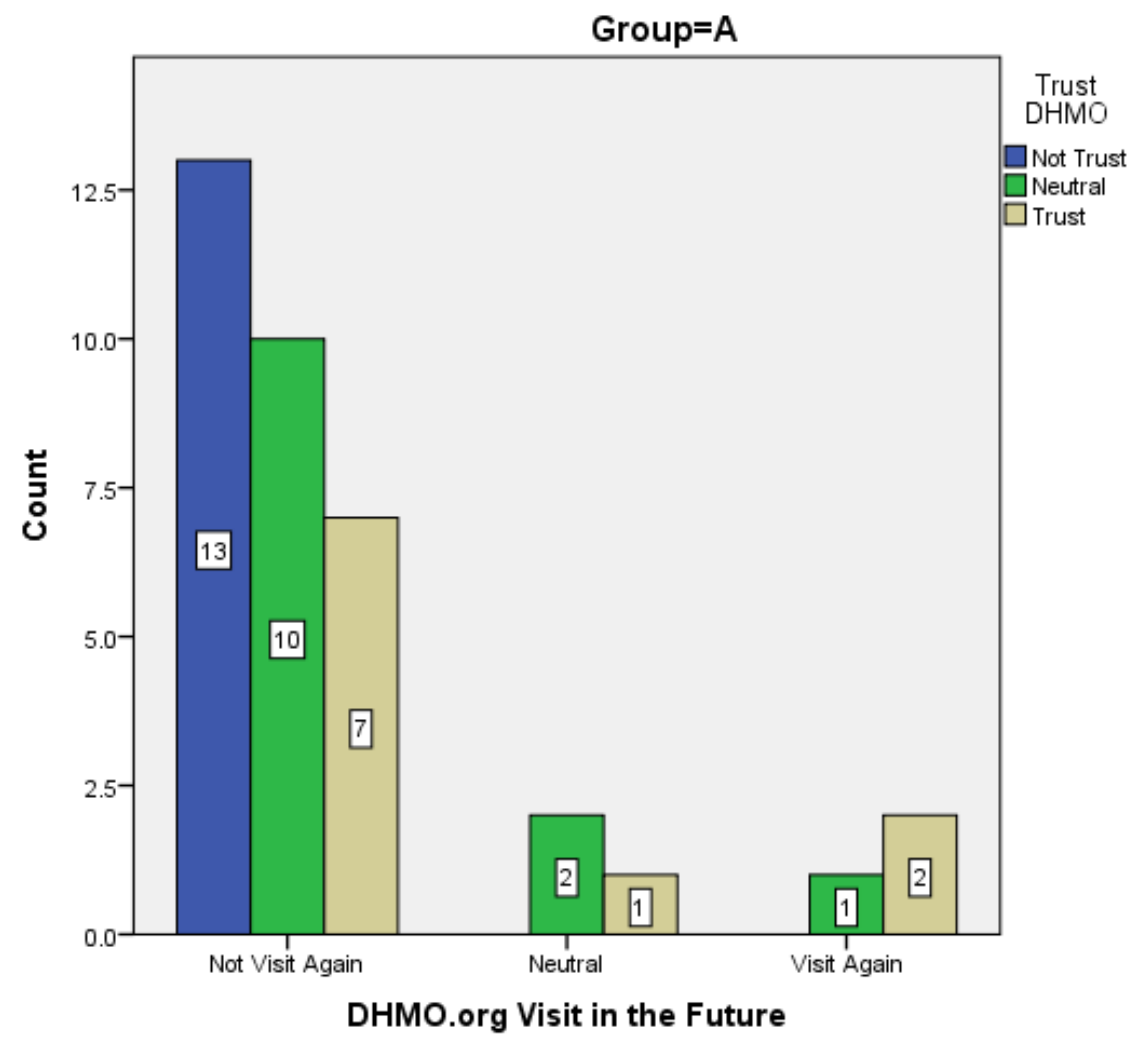

Figure 22. Comparison of DHMO.org visit in the future and trust variable for Group A. Even though the results for Group A were not statistically significant, the bar chart above shows that most of the participants that said they would not visit it again did not trust the DHMO.org website either. However, the Fisher's Exact Test for Group B 
was 10.398 with a $p$ value of .009 , which was statistically significant. Please see Table 15 and Figure 23 below for a visual representation of the crosstabulation between visiting the website in the future and the trust variable for Group B:

Table 15

DHMO.org Visit in the Future and Trust Variables for Group B

\begin{tabular}{lllll}
\hline & \multicolumn{1}{c}{$\begin{array}{c}\text { Not Trust } \\
\mathrm{n}(\%)\end{array}$} & \multicolumn{1}{c}{$\begin{array}{c}\text { Neutral } \\
\mathrm{n}(\%)\end{array}$} & $\begin{array}{r}\text { Trust } \\
\mathrm{n}(\%)\end{array}$ & $\begin{array}{r}\text { Total } \\
\mathrm{n}(\%)\end{array}$ \\
\hline Not Visit & $17(60.7)$ & $6(21.4)$ & $5(17.9)$ & $28(100)$ \\
Neutral & $0(0)$ & $3(75)$ & $1(25)$ & $4(100)$ \\
Visit & $1(25)$ & $0(0)$ & $3(75)$ & $4(100)$ \\
Total & $18(50)$ & $9(25)$ & $9(25)$ & $36(100)$ \\
\hline
\end{tabular}

Fisher's Exact Test $=10.398$

$\mathrm{p}=.009$ (statistically significant)

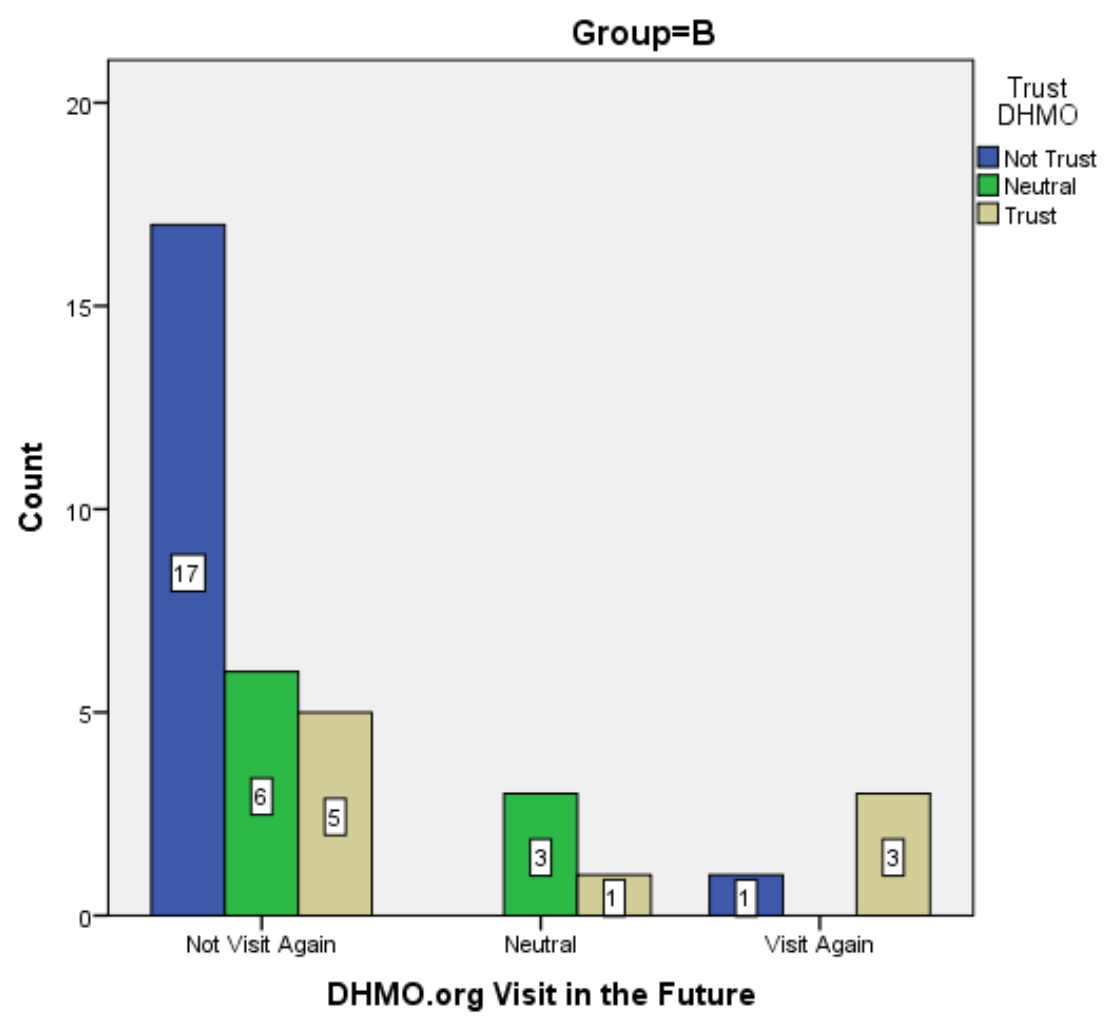

Figure 23. Comparison of DHMO.org visit in the future and trust variable for Group B.

Most of the participants from Group B, 17 of the 28 or $60.7 \%$, who said they would not visit the DHMO.org website again in the future did not trust it either. Three of 
the four or $75 \%$ who said they would visit it again also said they trusted it. These results were consistent for both groups combined. The next variable analyzed was whether the DHMO.org website was deemed useful and trusted.

DHMO.org Useful and Trust. A total of $34.7 \%$ participants said that they found the content on the DHMO.org website as useful, $31.94 \%$ remained neutral and $33.3 \%$ did not find it useful. Below is Figure 24 with these results:

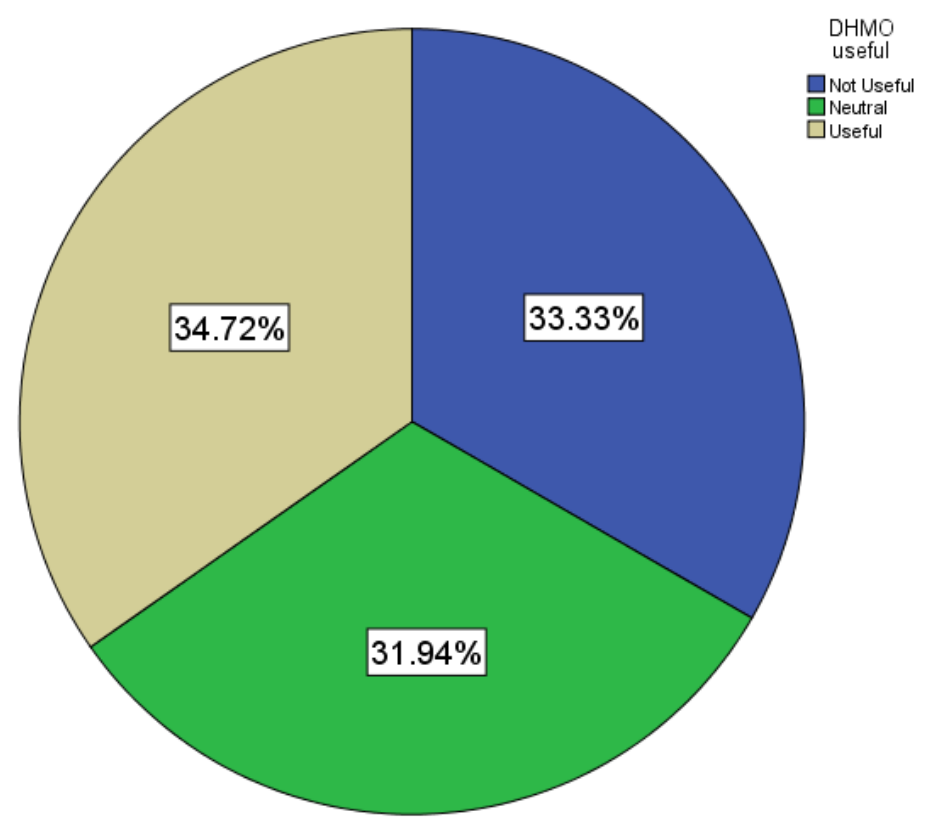

Figure 24. Percentages of DHMO.org useful.

In other words, 25 of the 72 participants (34.7\%) agreed that the DHMO.org website was useful, and 15 of the $25(60 \%)$ also trusted the DHMO.org website. The majority who thought that it was useful also trusted the website. Conversely, 24 of the 72 participants (33.3\%) agreed that the DHMO.org website was not useful, 18 of the 24 (75\%) did not trust the DHMO.org website either. Most of the participants that thought it was not useful, did not trust the website either. The Fisher's Exact Test was 29.686 with a 
$\mathrm{p}$ value of .000 , which is statistically significant. Table 16 and Figure 25 below illustrate these results:

Table 16

DHMO.org Useful and Trust Variables for Total

\begin{tabular}{lllll}
\hline & \multicolumn{1}{c}{$\begin{array}{c}\text { Not Trust } \\
\mathrm{n}(\%)\end{array}$} & \multicolumn{1}{c}{$\begin{array}{c}\text { Neutral } \\
\mathrm{n}(\%)\end{array}$} & $\begin{array}{r}\text { Trust } \\
\mathrm{n}(\%)\end{array}$ & $\begin{array}{r}\text { Total } \\
\mathrm{n}(\%)\end{array}$ \\
\hline Not Useful & $18(75)$ & $6(25)$ & $0(0)$ & $24(100)$ \\
Neutral & $8(34.8)$ & $11(47.8)$ & $4(17.4)$ & $23(100)$ \\
Useful & $5(20)$ & $5(20)$ & $15(60)$ & $25(100)$ \\
Total & $31(43.1)$ & $22(30.6)$ & $19(26.4)$ & $72(100)$ \\
\hline
\end{tabular}

Fisher's Exact Test $=29.686$

$\mathrm{p}=.000$ (statistically significant)

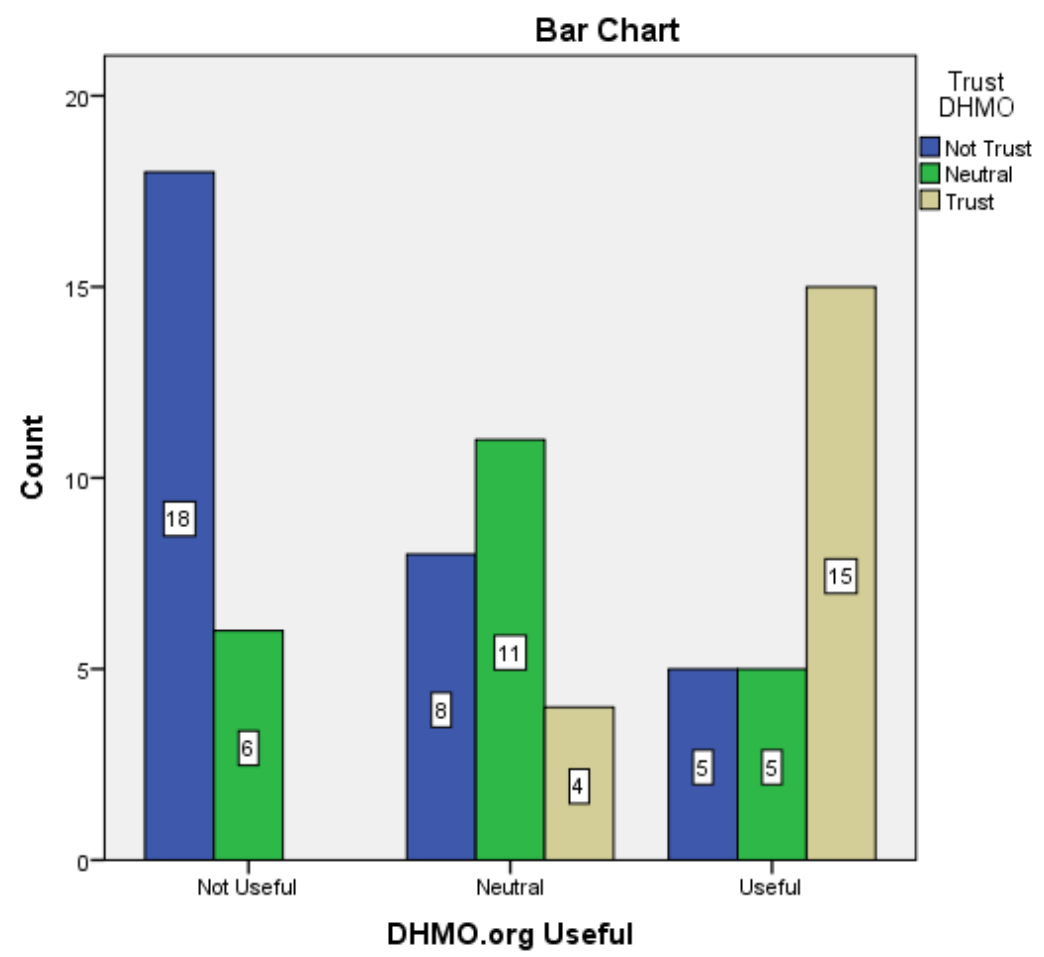

Figure 25. Comparison of DHMO.org useful and trust variable for all participants.

As seen in the bar chart above, again most of the participants that said the DHMO.org website was useful also trusted it and most that said it was not useful did not trust it either. This was the case for Group A and Group B as well. The Fisher's Exact Test for Group A was 10.008 with a p value of .036 and 19.217 with a p value of .000 for 
Group B, which are both statistically significant This suggests that if participants agreed that the DHMO.org website was useful then they would most likely trust it. Table 17 and

Figure 26 below illustrates these results for Group A:

Table 17

DHMO.org Useful and Trust Variables for Group A

\begin{tabular}{lllll}
\hline & $\begin{array}{c}\text { Not Trust } \\
\mathrm{n}(\%)\end{array}$ & $\begin{array}{c}\text { Neutral } \\
\mathrm{n}(\%)\end{array}$ & $\begin{array}{r}\text { Trust } \\
\mathrm{n}(\%)\end{array}$ & $\begin{array}{r}\text { Total } \\
\mathrm{n}(\%)\end{array}$ \\
\hline Not Useful & $5(55.6)$ & $4(44.4)$ & $0(0)$ & $9(100)$ \\
Neutral & $5(38.5)$ & $6(46.2)$ & $2(15.4)$ & $13(100)$ \\
Useful & $3(21.4)$ & $3(21.4)$ & $8(57.1)$ & $14(100)$ \\
Total & $13(36.1)$ & $13(36.1)$ & $10(27.8)$ & $36(100)$ \\
\hline
\end{tabular}

Fisher's Exact Test $=10.008$

$\mathrm{p}=.036$ (statistically significant)

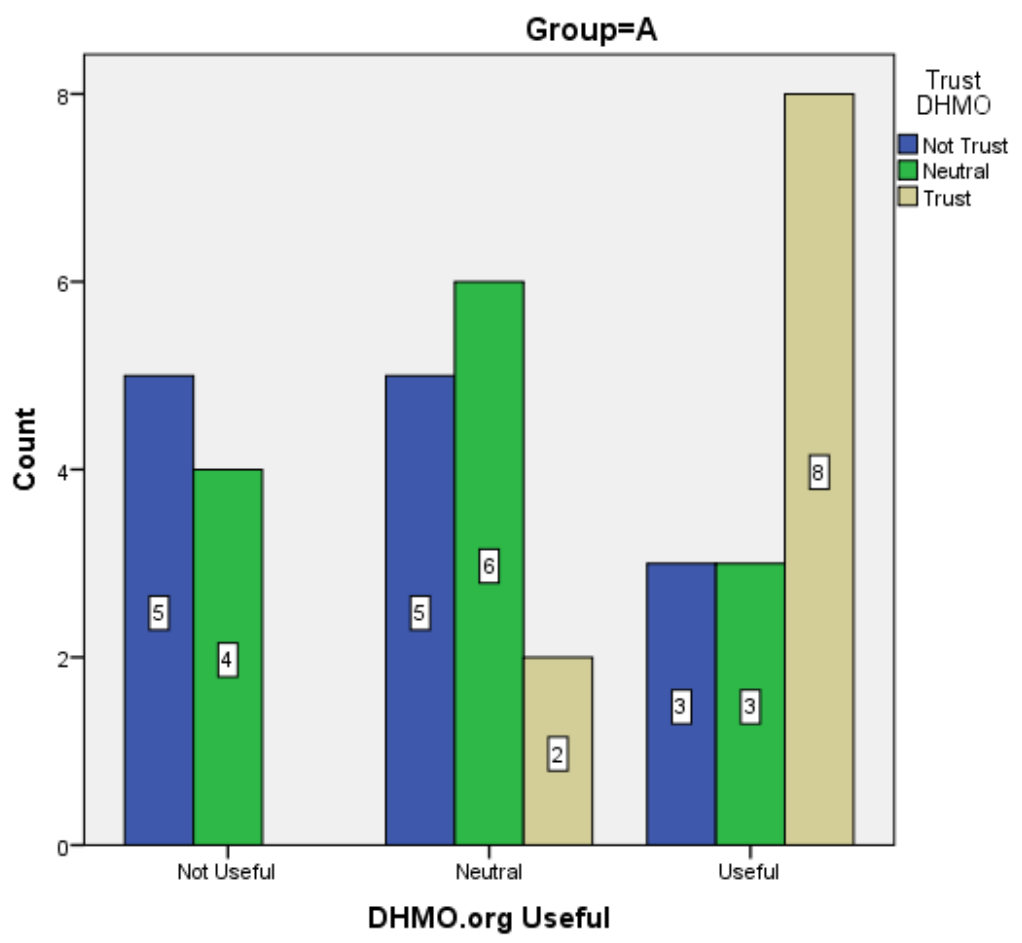

Figure 26. Comparison of DHMO.org useful and trust variable for Group A.

Most of the participants in Group A that said the DHMO.org website was useful, specifically eight of 14 or $57.1 \%$ also trusted it and most of the ones that said it was not useful, five of nine or $55.6 \%$ did not trust it either. This is even more prevalent in Group 
$\mathrm{B}$, since 13 of the 15 or $86.7 \%$ that thought the DHMO.org website was not useful did not trust it either. In addition, seven of the 11 or $63.7 \%$ who said it was useful, did trust it.

This data is illustrated in Table 18 and Figure 27 below:

Table 18

DHMO.org Useful and Trust Variables for Group B

\begin{tabular}{lllll}
\hline & $\begin{array}{l}\text { Not Trust } \\
\mathrm{n}(\%)\end{array}$ & $\begin{array}{l}\text { Neutral } \\
\mathrm{n}(\%)\end{array}$ & $\begin{array}{l}\text { Trust } \\
\mathrm{n}(\%)\end{array}$ & $\begin{array}{l}\text { Total } \\
\mathrm{n}(\%)\end{array}$ \\
\hline Not Useful & $13(86.7)$ & $2(13.3)$ & $0(0)$ & $15(100)$ \\
Neutral & $3(30)$ & $5(50)$ & $2(20)$ & $10(100)$ \\
Useful & $2(18.2)$ & $2(18.2)$ & $7(63.6)$ & $11(100)$ \\
Total & $18(50)$ & $9(25)$ & $9(25)$ & $36(100)$ \\
\hline
\end{tabular}

Fisher's Exact Test $=19.217$

$\mathrm{p}=.000$ (statistically significant)

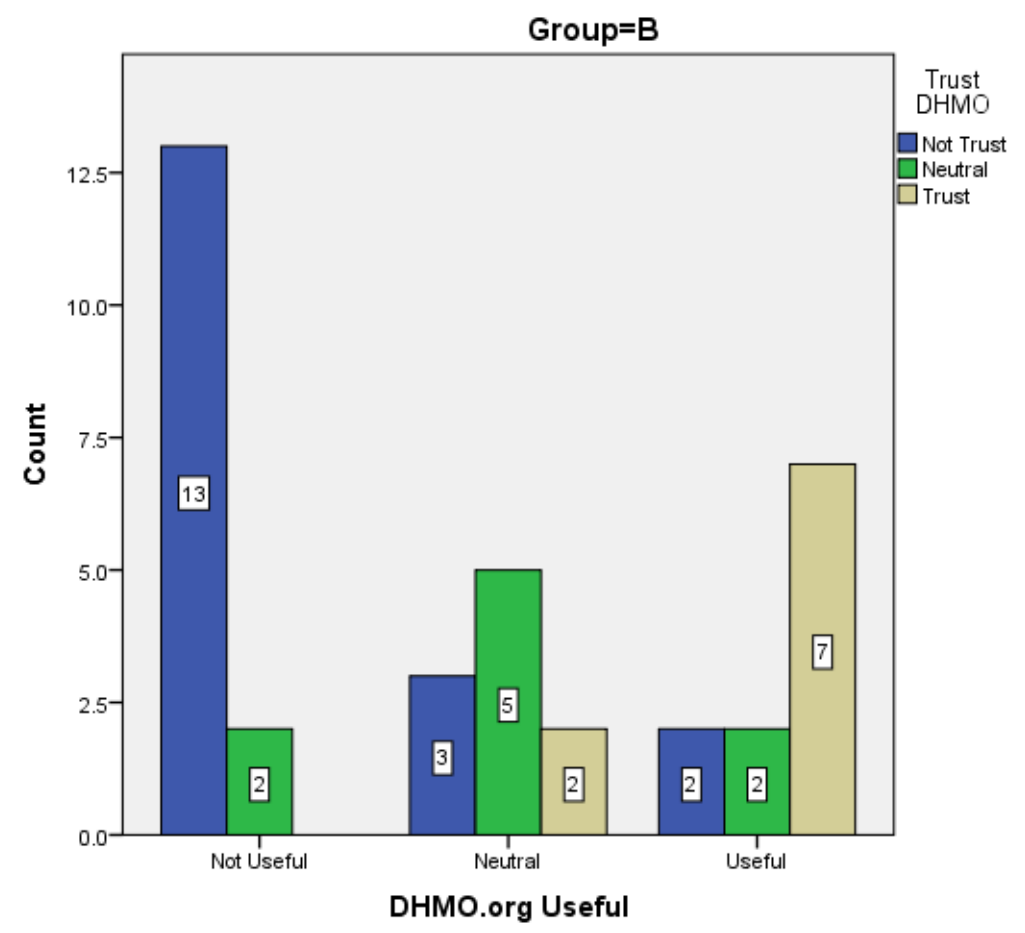

Figure 27. Comparison of DHMO.org useful and trust variable for Group B.

Since the percentage or counts of Group B are much higher than Group A that is why the p value of Group B (.000) is even lower than Group A's (.036). The variables useful and trust were statistically significant with both groups separately and combined. 
Interestingly the term useful was inputted a few times in the open text box question of the questionnaire. The following section contains the quantitative analysis of the open text box for the DHMO.org website.

DHMO.org Open Text. The open text box was placed into the questionnaire to obtain participant's thoughts concerning their evaluation of the DHMO.org website. These short sentences were coded based on their topic. Frequency counts were run to see which codes were mentioned the most. The following codes emerged from the data:

1. I don't know

2. Not organized

3. Organized

4. Not aesthetically appealing

5. Lengthy

6. Short simple

7. Ads/asking for money

8. Fake

9. Factual

10. Useful

11. Bad

12. Good

In general, $34.7 \%$ said it was fake, $22.2 \%$ thought it was not organized and $11.1 \%$ said it was fake. When a crosstabulation was run between these open text codes and whether the participant trusted the DHMO.org website produced the following results. In general, most of the participants who said in the open text box that the DHMO.org website was not aesthetically appealing, contained ads/asked for money, and was fake did not trust it either. Below is Table 19 with a frequency count for the Tree Octopus open text field codes and Figure 28 with a comparison of the open text and the trust variable for all participants: 
Table 19

Frequencies DHMO.org-Open Text for Total

\begin{tabular}{lll}
\hline & Frequency & Percent \\
\hline Total & & \\
I don't know & 2 & 2.8 \\
Not Organized & 16 & 22.2 \\
Organized & 2 & 2.8 \\
Not Appealing & 25 & 34.7 \\
Lengthy & 3 & 4.2 \\
Short Simple & 1 & 1.4 \\
Ads Asking Money & 7 & 9.7 \\
Fake & 8 & 11.1 \\
Factual & 2 & 2.8 \\
Useful & 3 & 4.2 \\
Bad & 1 & 1.4 \\
Good & 2 & 2.8 \\
Total & 72 & 100.0 \\
\hline
\end{tabular}

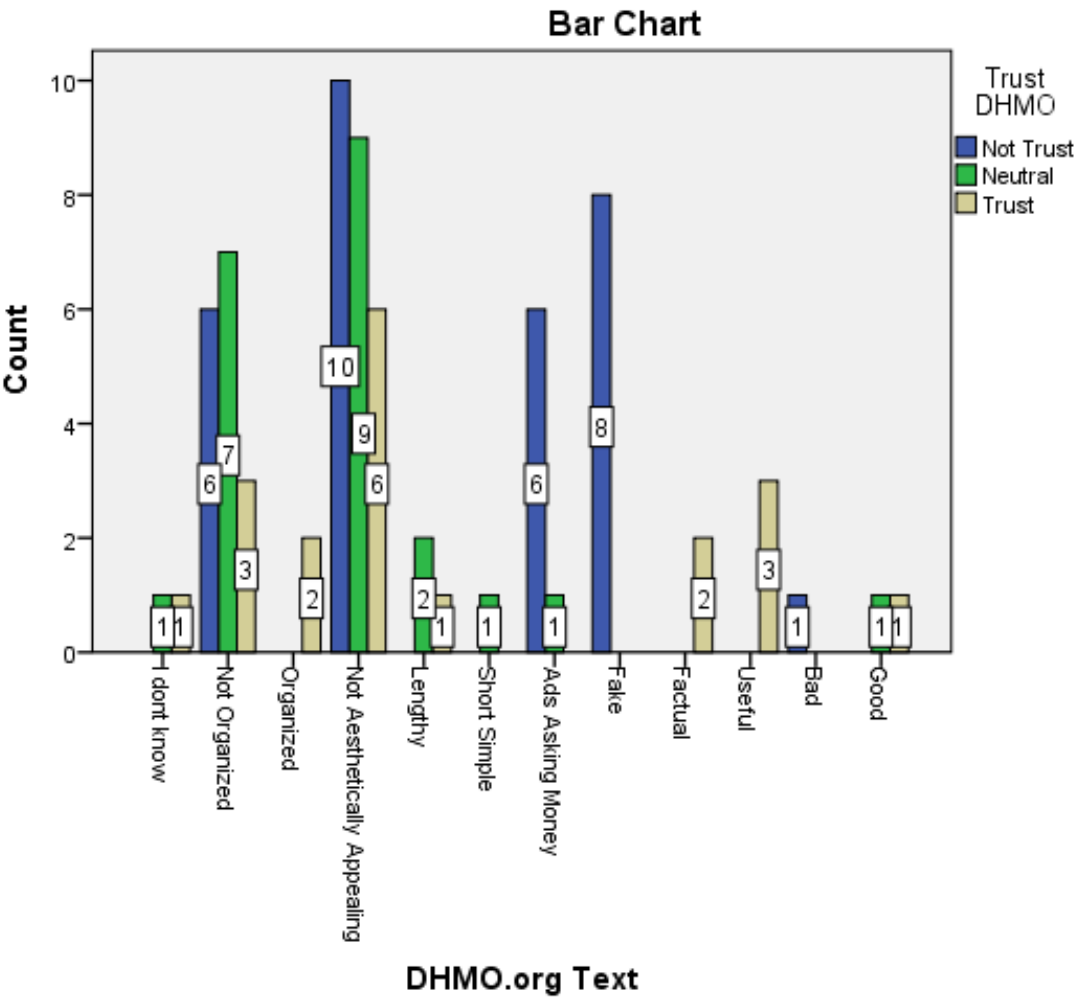

Figure 28. Comparison of DHMO.org open text and trust variable for all participants. 
Based on the table and figure above, most of the participants, regardless of the group they were in, thought that the DHMO.org website was not aesthetically appealing and not organized. For Group A, 33.3\% described the DHMO.org website as not aesthetically appealing, $27.8 \%$ as not organized, and $8.3 \%$ as fake. In Group A, most of the participants that said it was not organized and fake, did not trust the website either. This is illustrated by Table 20 and Figure 29 below:

Table 20

Frequencies DHMO.org-Open Text for Group A

\begin{tabular}{lll}
\hline & Frequency & Percent \\
\hline I don't know & 1 & 2.8 \\
Not Organized & 10 & 27.8 \\
Organized & 2 & 5.6 \\
Not Appealing & 12 & 33.3 \\
Lengthy & 2 & 5.6 \\
Short Simple & 1 & 2.8 \\
Ads/asking Money & 2 & 5.6 \\
Fake & 3 & 8.3 \\
Factual & 1 & 2.8 \\
Useful & 1 & 2.8 \\
Good & 1 & 2.8 \\
Total & 36 & 100.0 \\
\hline
\end{tabular}




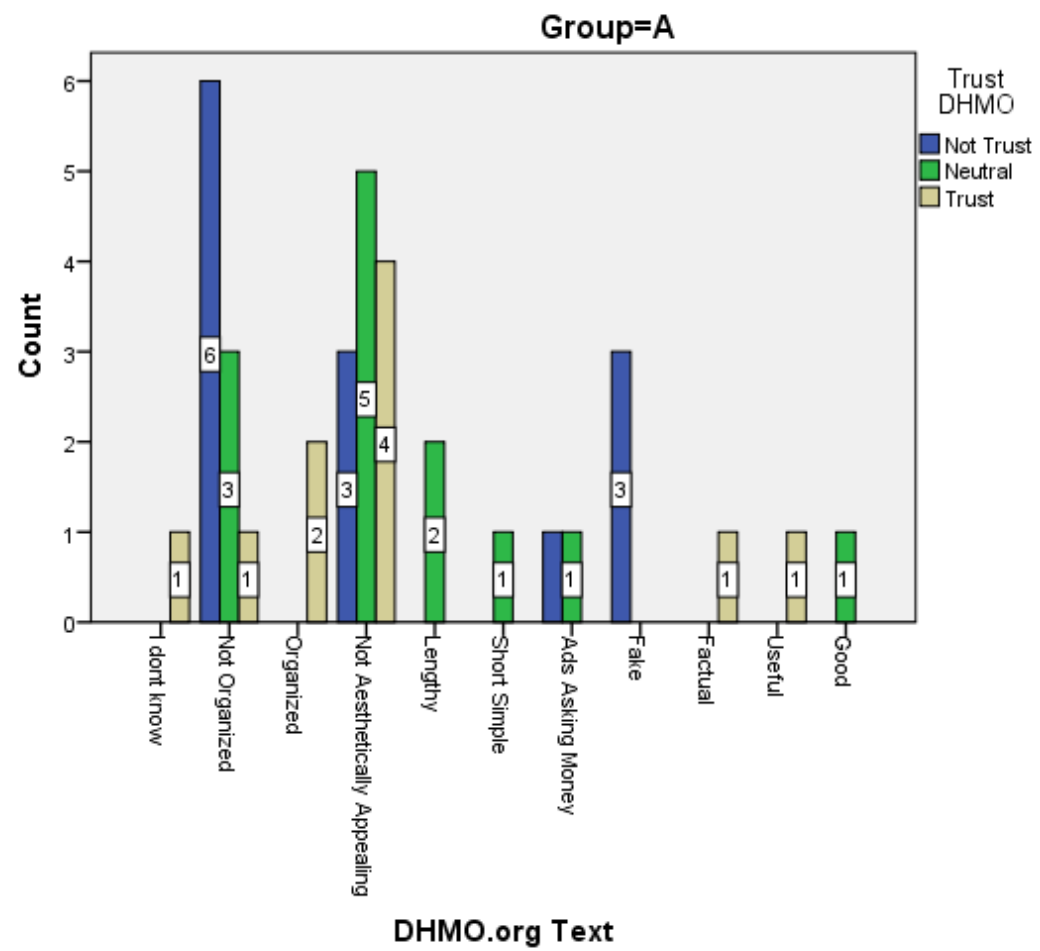

Figure 29. Comparison of DHMO.org open text and trust variable for Group A.

In Group B, 36.1\% made statements that the DHMO.org website was not aesthetically appealing, $16.7 \%$ said it was not organized and $13.9 \%$ said it contained ads/asked for money and that it was fake. The majority that said it was not aesthetically appealing, contained ads/asked for money and stated it was fake, did not trust it either. Below is Table 21 and Figure 30 with this information: 
Table 21

Frequencies DHMO.org-Open Text for Group B

\begin{tabular}{lll}
\hline & Frequency & Percent \\
\hline I don't know & 1 & 2.8 \\
Not Organized & 6 & 16.7 \\
Not Appealing & 13 & 36.1 \\
Lengthy & 1 & 2.8 \\
Ads Asking Money & 5 & 13.9 \\
Fake & 5 & 13.9 \\
Factual & 1 & 2.8 \\
Useful & 2 & 5.6 \\
Bad & 1 & 2.8 \\
Good & 1 & 2.8 \\
Total & 36 & 100.0 \\
\hline
\end{tabular}

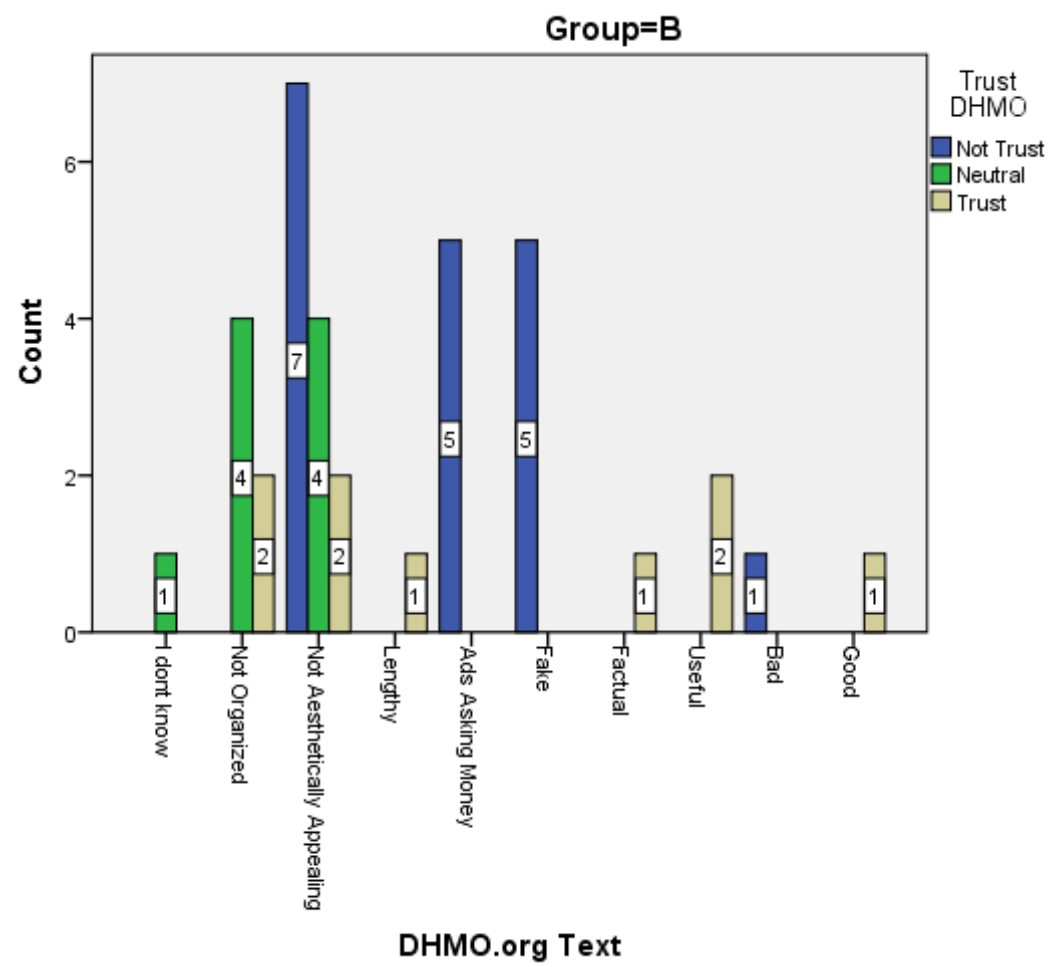

Figure 30. Comparison of DHMO.org open text and trust variable for Group B.

Aside from DHMO.org website, the other hoax website that the participants reviewed was the Tree Octopus website. The next section contains quantitative analys is of this website. 


\section{Tree Octopus Hoax Website}

Of the 72 participants, $45.8 \%$ did not trust the content on the Tree Octopus website, $37.5 \%$ trusted the content and $16.7 \%$ neither agreed or disagreed with trusting the content. The majority did not trust the Tree Octopus hoax website. Below Figure 31 with these percentages:

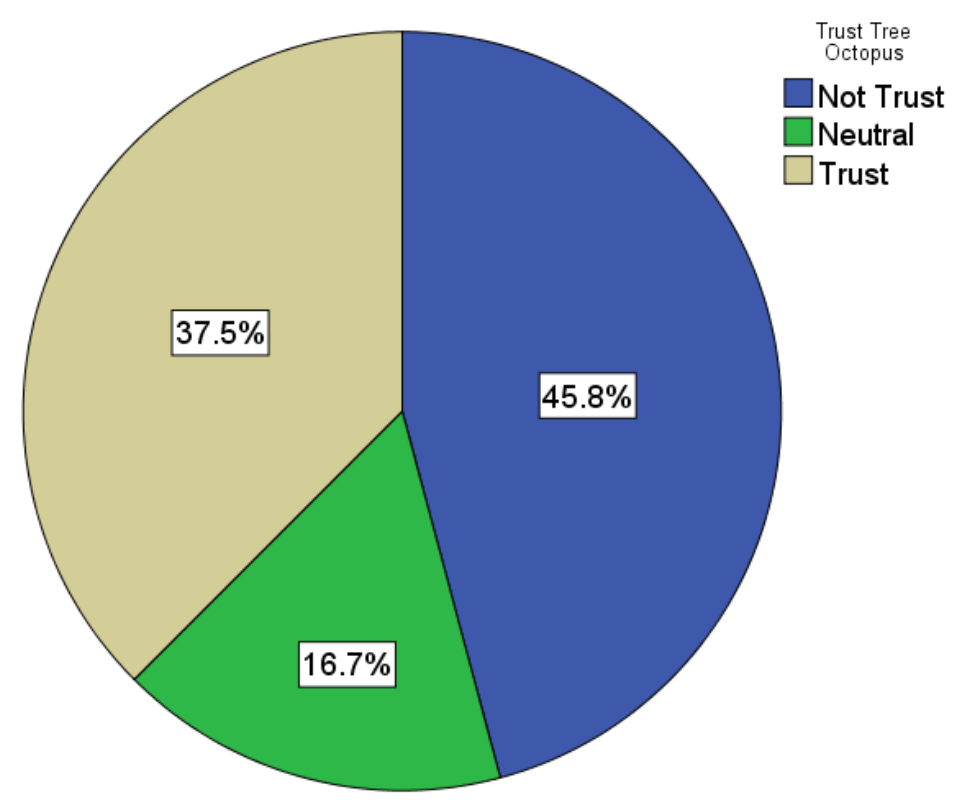

Figure 31. Percentages of Tree Octopus trust variable.

There were significant differences between Group A and Group B regarding the level of trust. In Group A, 30.6\% did not trust the Tree Octopus website compared to $61.1 \%$ from Group B. It may be that the web evaluation strategy (WWWDOT Framework) given to Group B significantly increased the percentage of participants that did not trust the Tree Octopus Hoax website. It is important to note that $50 \%$ of the participants in Group A, trusted the Tree Octopus hoax website compared to $25 \%$ from Group B. Please see Table 22 below: 
Table 22

Tree Octopus Group and Trust Variables

\begin{tabular}{lcccc}
\hline & $\begin{array}{c}\text { Not Trust } \\
\mathrm{n}(\%)\end{array}$ & $\begin{array}{c}\text { Neutral } \\
\mathrm{n}(\%)\end{array}$ & $\begin{array}{c}\text { Trust } \\
\mathrm{n}(\%)\end{array}$ & $\begin{array}{c}\text { Total } \\
\mathrm{n}(\%)\end{array}$ \\
\hline Group A & $11(30.6)$ & $7(19.4)$ & $18(50)$ & $36(100)$ \\
Group B & $22(61.1)$ & $5(13.9)$ & $9(25)$ & $36(100)$ \\
Total & $33(45.8)$ & $12(16.7)$ & $27(37.5)$ & $72(100)$ \\
\hline
\end{tabular}

Pearson Chi-Square $=7.000$

$\mathrm{p}=.030^{*}$ (statistically significant)

In other words, most of the participants from Group A trusted the Tree Octopus hoax website. The opposite is true for Group B since most of the participants, $61.1 \%$ of them, did not trust it. Below is Figure 32, which illustrates these differences in percentage:

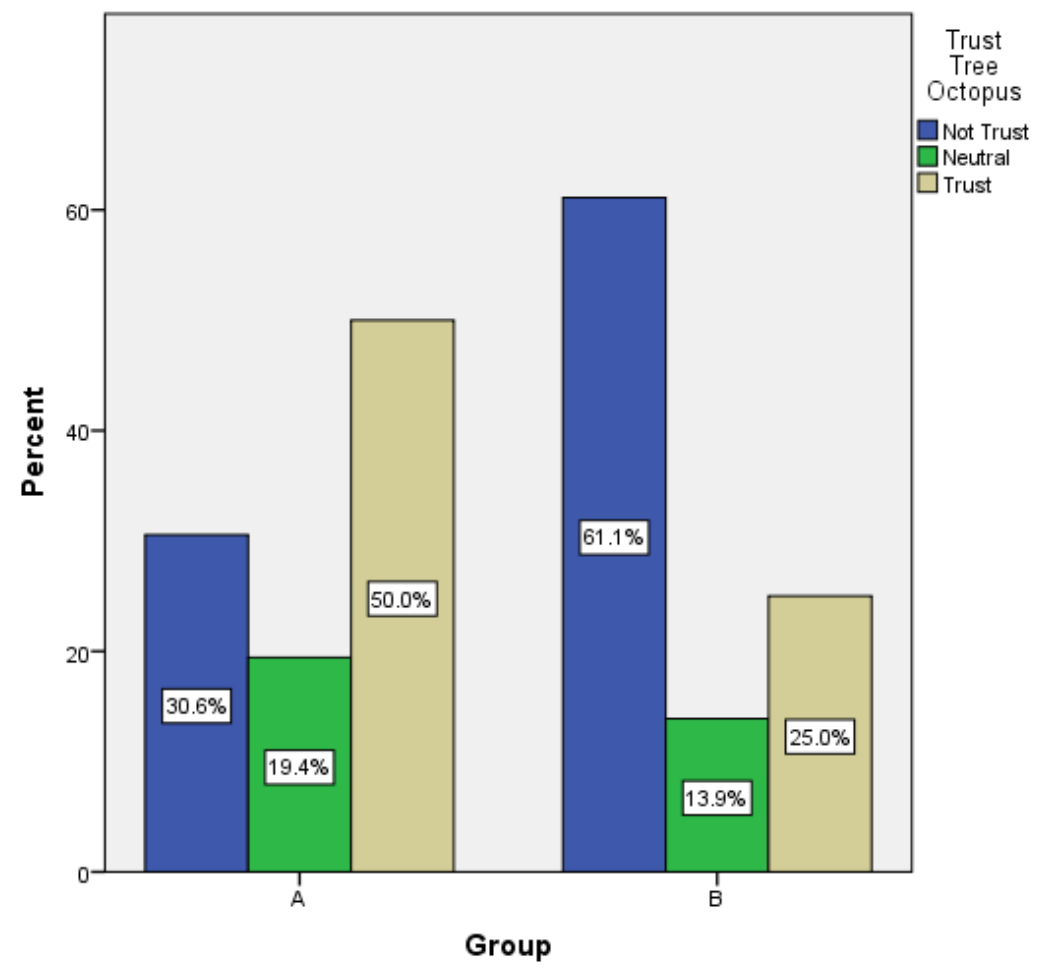

Figure 32. Comparison of Tree Octopus trust variables for Group A and Group B.

This suggests that the WWWDOT Framework was effective in reducing the percentage of participants that trusted the hoax website and ultimately increasing the 
percentage that did not trust it. This was confirmed by the Pearson Chi-Square Test, which resulted in a statistical significance between the Groups (A and B) and the trust dependent variable (whether they trusted, were neutral or not trusted the website). The Pearson Chi-Square test was .030, which was less than .05.

Tree Octopus Aesthetic Appeal and Trust. A total of 57 (79.2\%) of the participants rated the Tree Octopus website as aesthetically appealing. In Group A, of the 30 who thought it was aesthetically appealing, $17(56.7 \%)$ trusted the website. In contrast, of the 27 in Group B who thought it was aesthetically appealing, 15 (55.6\%) did not trust the website. Figure 33 below shows a pie chart representation of these percentages. This may suggest that giving the WWWDOT Framework to Group B allowed participants to not let aesthetic appeal influence their decision to trust the content on the website. The Fisher's Exact Test confirms this as well.

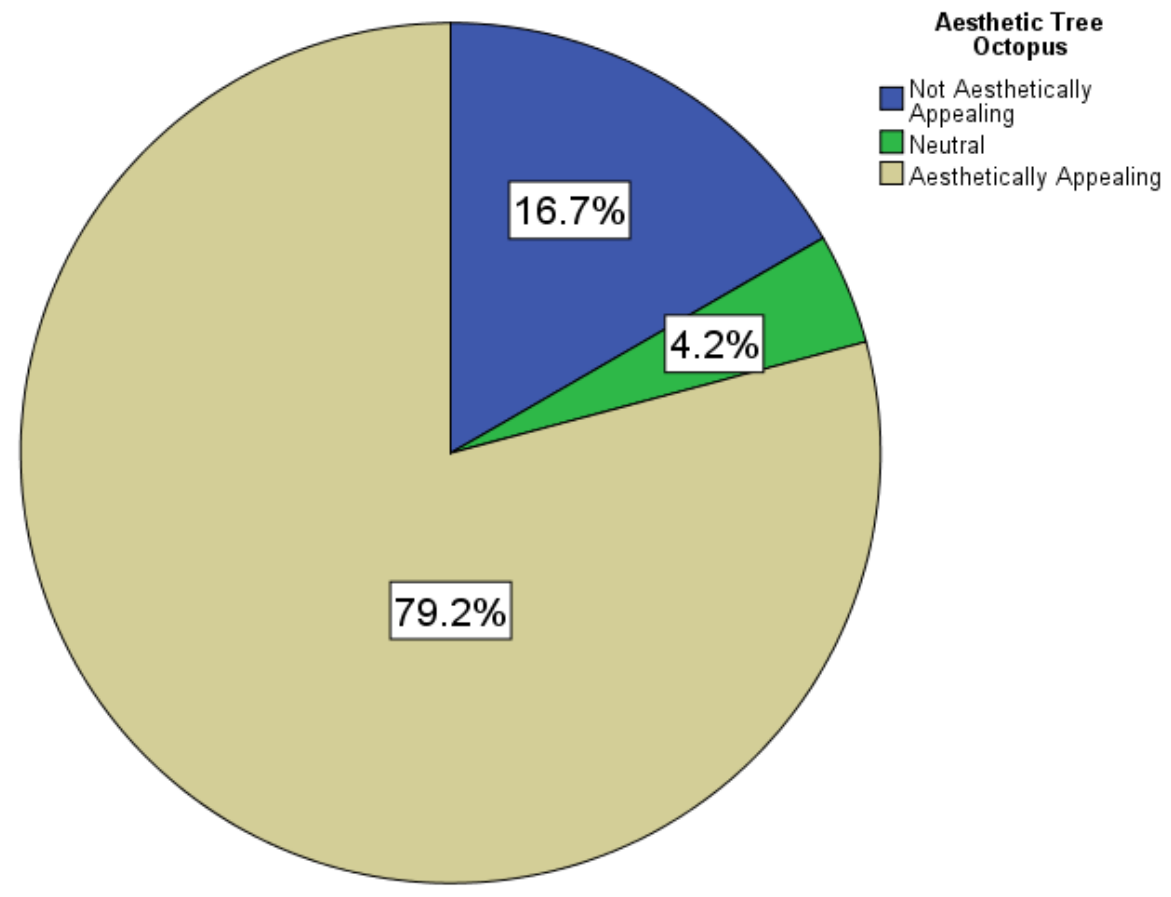

Figure 33. Percentages of Tree Octopus for aesthetic appeal. 
The total Fisher's Exact Test between the Aesthetic Appeal of the Tree Octopus and the dependent variable Trust Tree Octopus was 8.830 , which was statistically significant at .031, which is less than .05 . In other words, the aesthetic appeal in general does seem to influence whether prospective teachers trust the website or not. Below is a Table 23 with the count, percentage and $p$ value of these two variables:

Table 23

Tree Octopus Aesthetic Appeal and Trust Variables for Total

\begin{tabular}{lllll}
\hline & \multicolumn{1}{c}{$\begin{array}{c}\text { Not Trust } \\
\mathrm{n}(\%)\end{array}$} & \multicolumn{1}{c}{$\begin{array}{c}\text { Neutral } \\
\mathrm{n}(\%)\end{array}$} & $\begin{array}{c}\text { Trust } \\
\mathrm{n}(\%)\end{array}$ & \multicolumn{1}{c}{$\begin{array}{c}\text { Total } \\
\mathrm{n}(\%)\end{array}$} \\
\hline Not Appealing & $10(83.3)$ & $1(8.3)$ & $1(8.3)$ & $12(100)$ \\
Neutral & $2(66.7)$ & $0(0)$ & $1(33.3)$ & $3(100)$ \\
Appealing & $21(36.8)$ & $11(19.3)$ & $25(43.9)$ & $57(100)$ \\
Total & $33(45.8)$ & $12(16.7)$ & $27(37.5)$ & $72(100)$ \\
\hline
\end{tabular}

Fisher's Exact Test $=8.830$

$\mathrm{p}=.031^{*}$ (statistically significant)

In general, the majority of the participants that rated the Tree Octopus website as aesthetically appealing also trusted the website. Conversely, most of the participants that rated it was not aesthetically appealing, did not trust it either. Figure 34 illustrates the crosstabulation between these two variables: 


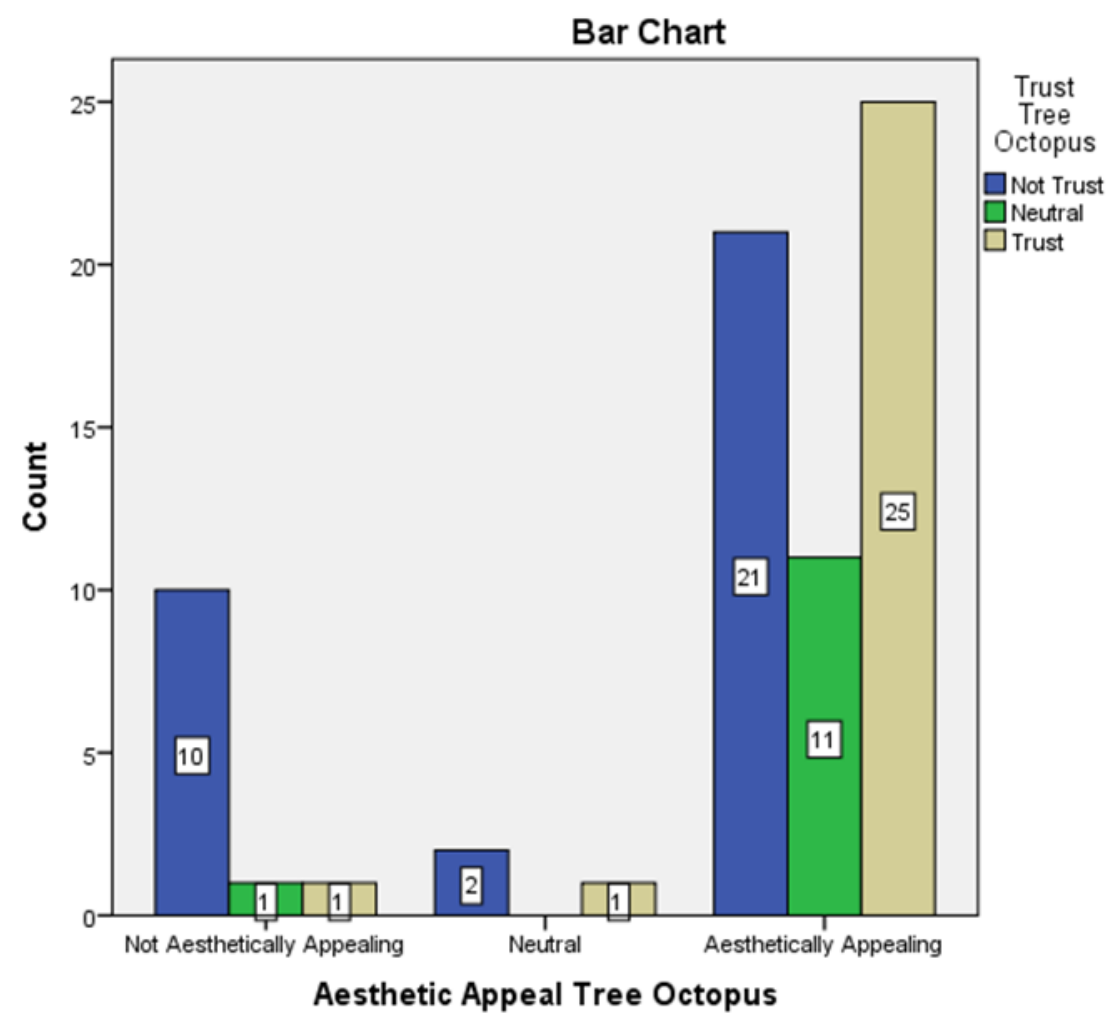

Figure 34. Comparison of Tree Octopus aesthetic appeal and trust variable for all participants.

Analyzing the results by group demonstrates how in one group it is statistically significant and in the other it is not. Interestingly, when the results are divided by group, the Fisher's Exact Test of Group A was 8.997, which is statistically significant at .015 (<.05). However, the Fisher's Exact Test was 2.287 for Group B, which was not statistically significant at $.840(>.05)$. The Fisher's Exact test was used since there were cells that had less than 5, which is a requirement for the Chi-Square Test. Therefore, aesthetic appeal had an effect in Group A, but not in Group B. Below is Table 24 which shows the results for Group A: 
Table 24

Tree Octopus Aesthetic Appeal and Trust Variables for Group A

\begin{tabular}{lllll}
\hline & \multicolumn{1}{c}{$\begin{array}{c}\text { Not Trust } \\
\mathrm{n}(\%)\end{array}$} & \multicolumn{1}{c}{$\begin{array}{c}\text { Neutral } \\
\mathrm{n}(\%)\end{array}$} & $\begin{array}{c}\text { Trust } \\
\mathrm{n}(\%)\end{array}$ & $\begin{array}{r}\text { Total } \\
\mathrm{n}(\%)\end{array}$ \\
\hline Not Appealing & $4(100)$ & $0(0)$ & $0(0)$ & $4(100)$ \\
Neutral & $1(50)$ & $0(0)$ & $1(50)$ & $2(100)$ \\
Appealing & $6(20)$ & $7(23.3)$ & $17(56.7)$ & $30(100)$ \\
Total & $11(30.6)$ & $7(19.4)$ & $18(50)$ & $36(100)$ \\
\hline
\end{tabular}

Fisher's Exact Test $=8.997$

$\mathrm{p}=.015$ (statistically significant)

This may suggest that giving the WWWDOT Framework to Group B allowed participants to not let aesthetic appeal influence their decision to trust the content on the website. For Group A, aesthetic appeal was indeed statistically significant. Below Figure 35, illustrates the relationship between aesthetic appeal and trust for the Tree Octopus website in Group A:

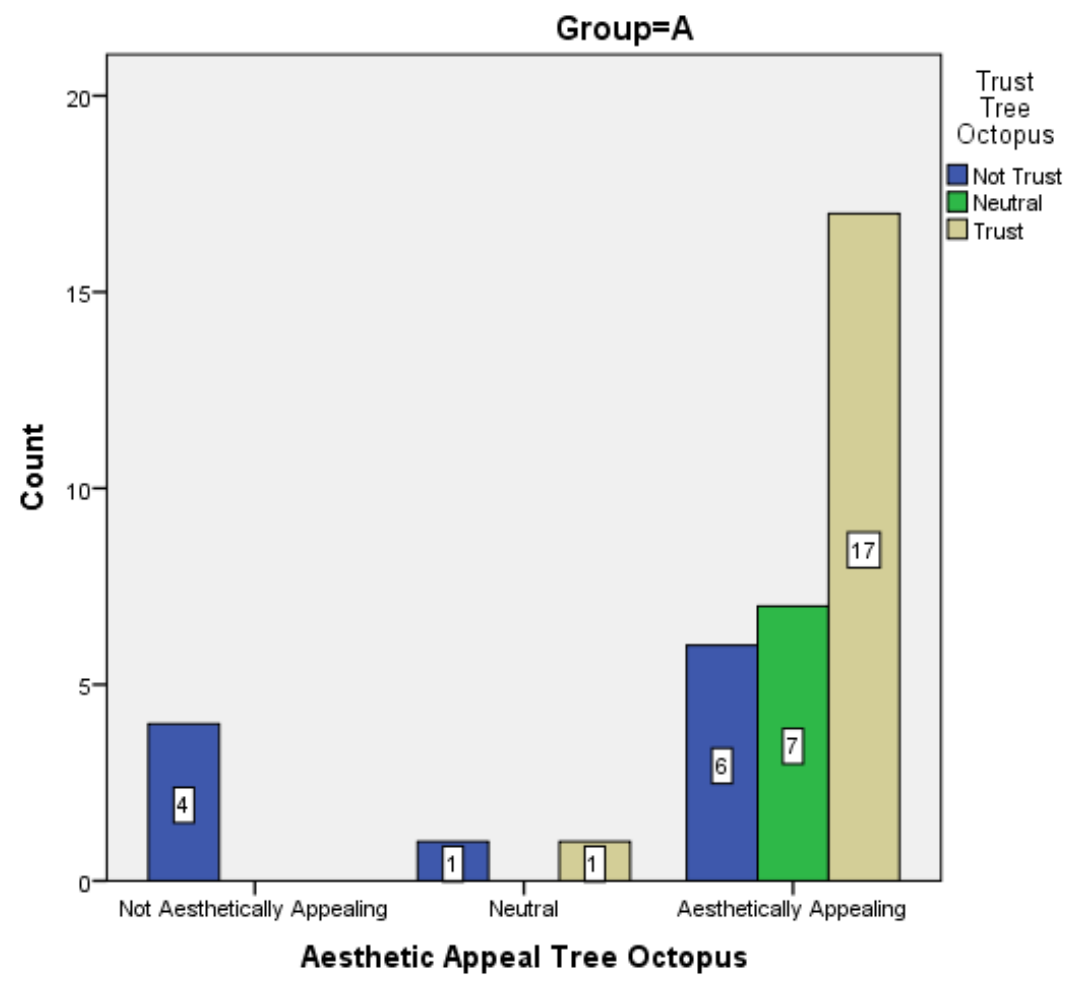

Figure 35. Comparison of Tree Octopus aesthetic appeal and trust variable for Group A. 
As seen in the bar graph above, most of the participants that thought it was aesthetically appealing, a total of 17 of the 30 or $56.7 \%$, also trusted the Tree Octopus website. Conversely, all the participants who said it was not aesthetically appealing did not trust it. In Group B, most participants did not trust the Tree Octopus website regardless of whether they said it was aesthetically appealing or not. Figure 36 illustrates that the aesthetic appeal and trust variables for Group B is not statistically significant:

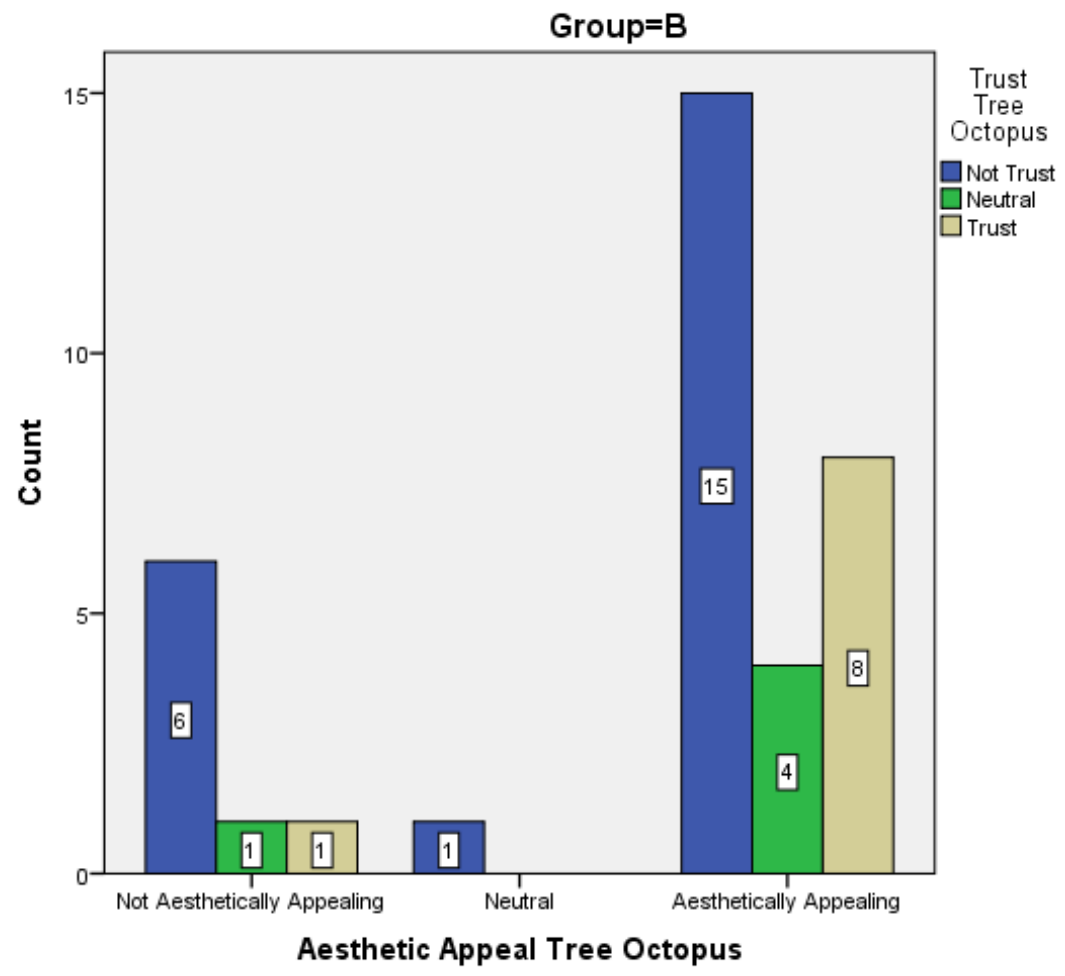

Figure 36. Comparison of Tree Octopus aesthetic appeal and trust variable for Group B.

The results illustrated in Figure 33, suggests that the WWWDOT Framework might have helped in not letting the aesthetic appeal of the Tree octopus website influence the participants decision to trust the website since most of the participants in Group B did not trust the website regardless of its aesthetic appeal. Aside from aesthetic appeal, organization was another variable that was analyzed. 
Tree Octopus Organization and Trust. Most of the participants, 53 (73.6\%)

thought that the Tree Octopus website was organized. In Group A, of the 30 participants that rated the website as organized, $16(53.3 \%)$ trusted the website. However, in Group B, of the 23 who thought it was organized, $11(47.8 \%)$ did not trust the Tree Octopus Website. Figure 37 below illustrates these percentages. This suggests that the WWWDOT Framework might have allowed participants to not let organization influence their decision on trusting or not the website. Statistical analysis confirms this notion.

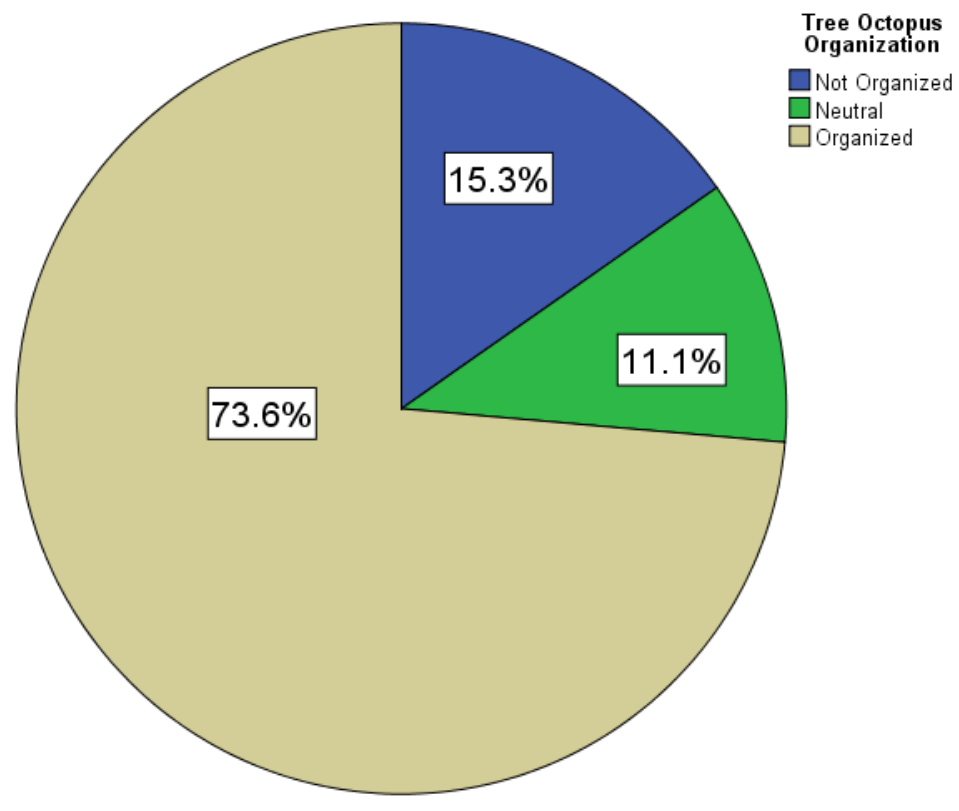

Figure 37. Percentages of Tree Octopus organization.

The Fisher's Exact Test was used since some cells were less than 5. It was statistically significant for the total number of participants, but not individually by Group. Group A, which resulted in .190 (> .05 not sig.) and Group B was .342 (> .05 not sig.). However, the Fisher's Exact Test for the total was 10.808, which was significant at .018 (<.05), which makes it statistically significant. The comparison between the Tree Octopus organization and trust variables with the corresponding $\mathrm{p}$ values are in Table 25 below: 
Table 25

Tree Octopus Organization and Trust Variables for Total

\begin{tabular}{|c|c|c|c|c|}
\hline & $\begin{array}{c}\text { Not Trust } \\
\mathrm{n}(\%)\end{array}$ & $\begin{array}{c}\text { Neutral } \\
\mathrm{n}(\%)\end{array}$ & $\begin{array}{l}\text { Trust } \\
\mathrm{n}(\%)\end{array}$ & $\begin{array}{l}\text { Total } \\
\mathrm{n}(\%)\end{array}$ \\
\hline Not Organized & $9(81.8)$ & $1(9.1)$ & $1(9.1)$ & $11(100)$ \\
\hline Neutral & $6(75)$ & $0(0)$ & $2(25)$ & $8(100)$ \\
\hline Organized & $18(34)$ & $11(20.8)$ & $24(45.3)$ & $53(100)$ \\
\hline Total & $33(45.8)$ & $12(16.7)$ & $27(37.5)$ & $72(100)$ \\
\hline
\end{tabular}

Fisher's Exact Test $=10.808$

$\mathrm{p}=.018$ (statistically significant)

This means that in general if the Tree Octopus was considered organized, more

than likely it would be trusted. The data also suggests that if participants said that the Tree Octopus was not organized then they would most likely not trust it. Below is Figure 38, which illustrates this:

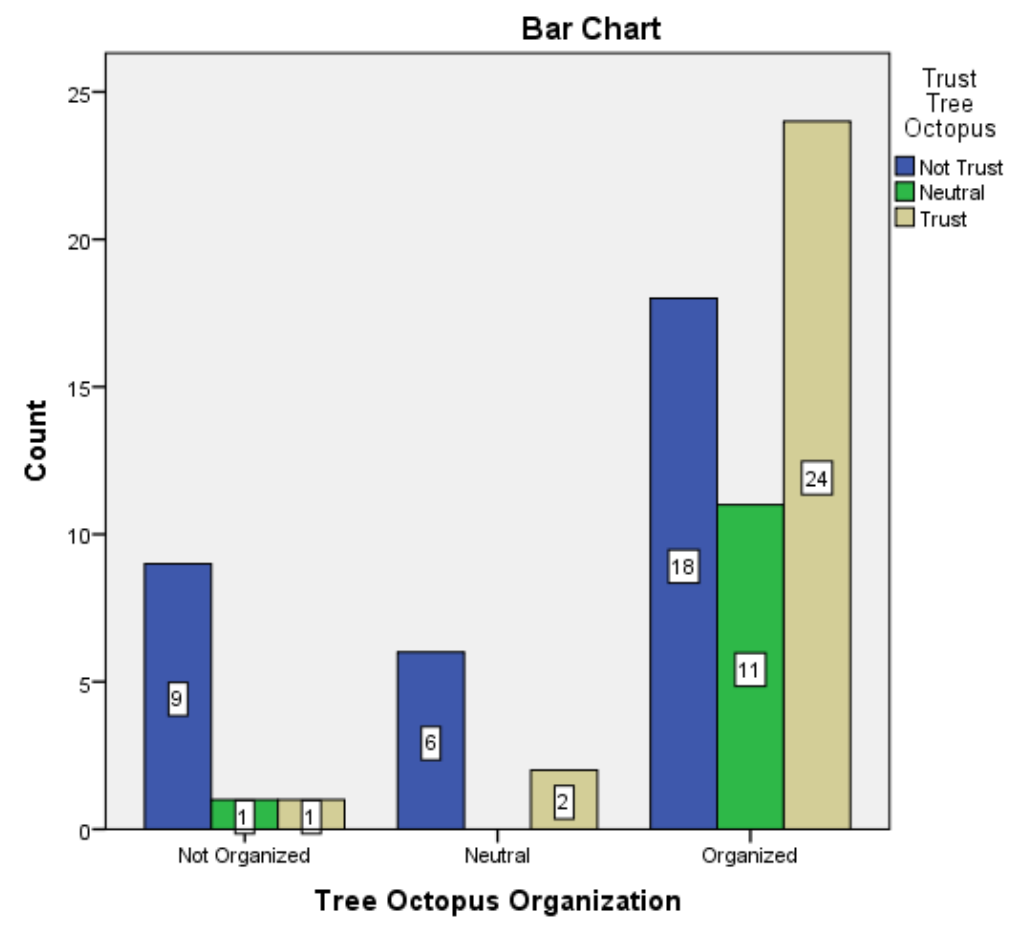

Figure 38. Comparison of Tree Octopus organization and trust variable for all participants. 
As illustrated in Figure 38, regardless of the group, most of the participants who said it was organized also trusted the website and most who said it was not organized did not trust it. The results varied by group since most in Group A who thought it was organized trusted it and most in Group B that thought it was organized did not trust it.

In Group A, the majority that thought the website was organized also trusted the website. However as mentioned before, organization and trust were not statistically significant for Group A. Figure 39 below shows how most of the participants in Group A said it was organized also trusted it:

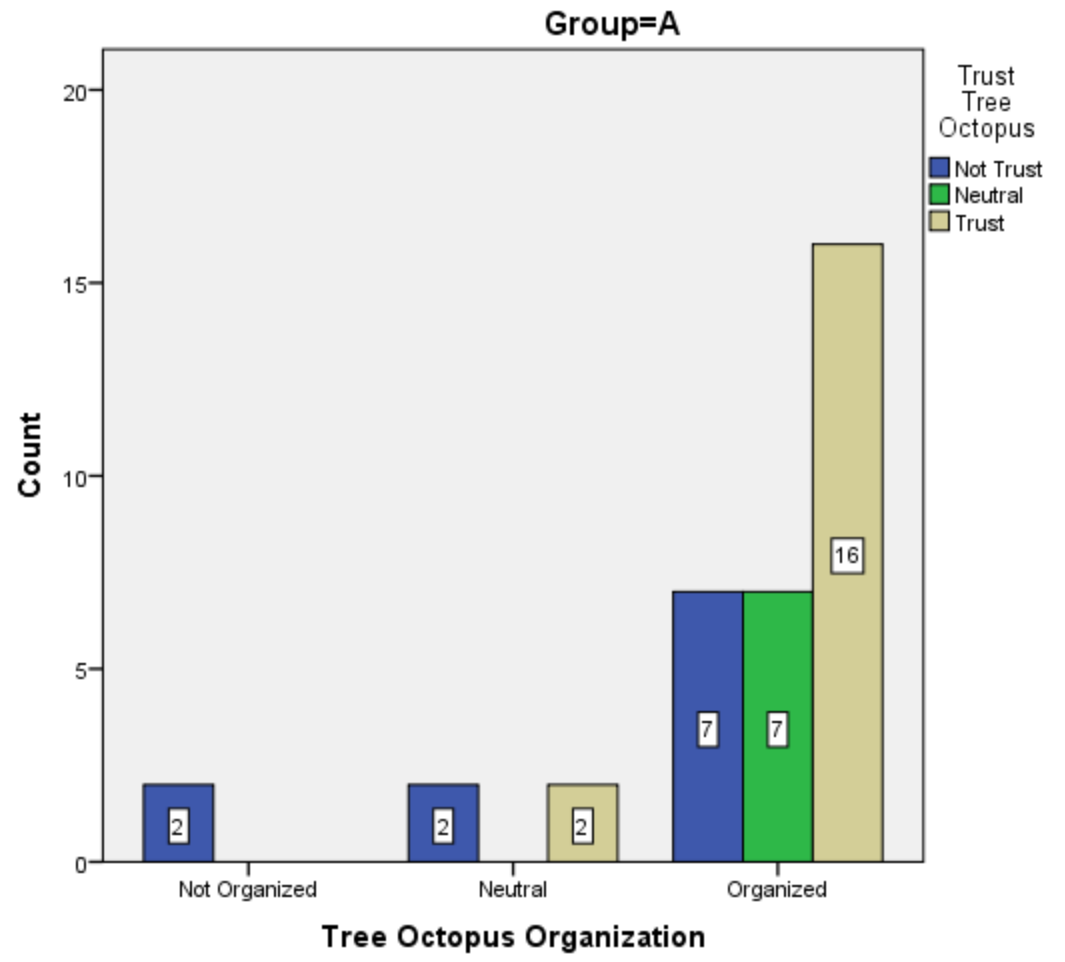

Figure 39. Comparison of Tree Octopus organization and trust variable for Group A.

A total of 16 of the 30 or $53.3 \%$ of the participants that said the Tree Octopus website was organized also trusted the website. This was not the case for Group B, where most of the participants that thought it was organized did not trust the website. This 
suggest that the WWWDOT framework might have helped in not letting an organized website convince the participant to trust it. Again, organization and trust were not statistically significant for Group A or B. Below is Figure 40, which graphically illustrates this:

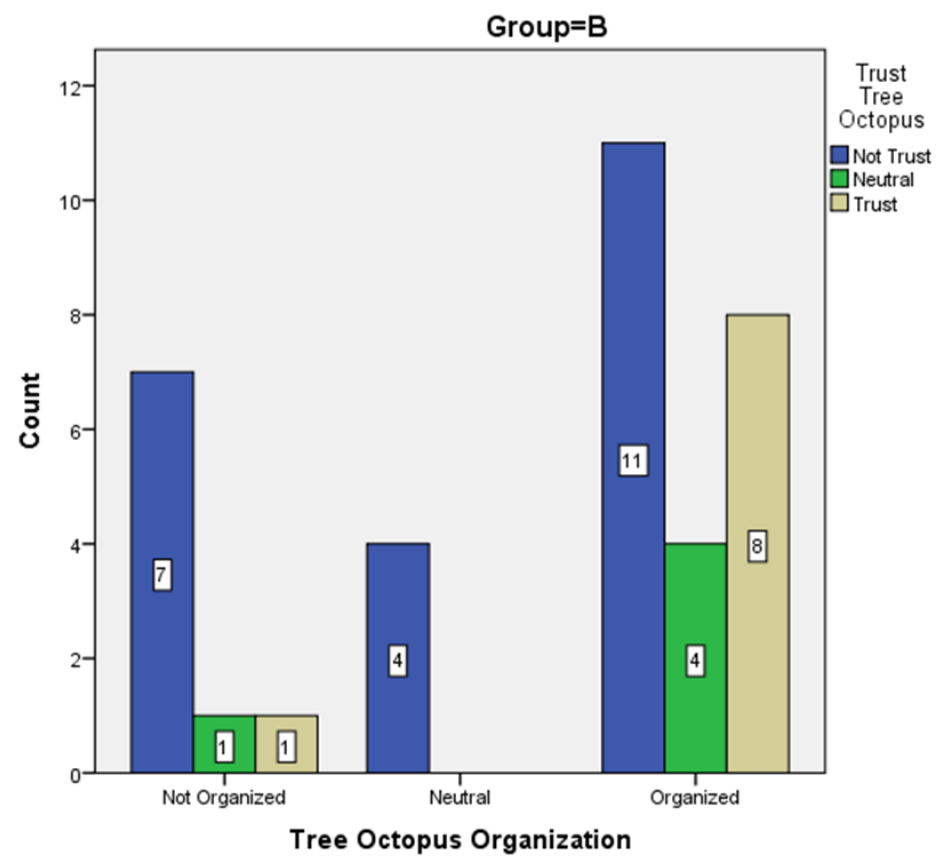

Figure 40. Comparison of Tree Octopus organization and trust variable for Group B.

As is evident from the bar chart above, participants from both the organized and not organized categories did not trust the Tree Octopus website, which may the reason it was not statistically significant. Aside from organization, the other independent variable was whether the participants would visit the website in the future. The next section contains quantitative results on the two variables visit in the future and trust.

Tree Octopus Visit in the Future and Trust. In general, $55.6 \%$ of the participants said that they would not visit the Tree Octopus website again in the future and $19.4 \%$ said that they would. Below is Figure 41 with these results: 


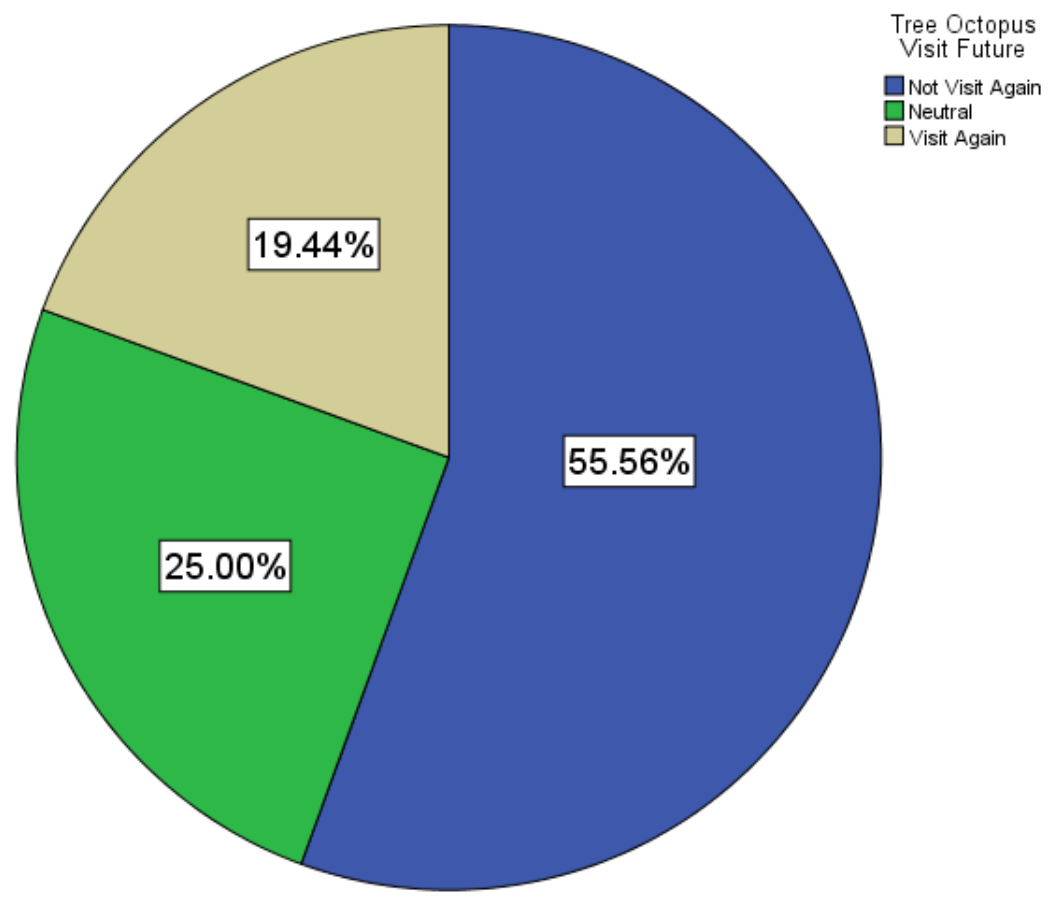

Figure 41. Percentages of Tree Octopus visit in the future variable.

A total of 40 of the 72 participants $(55.6 \%)$ stated that they would not visit the Tree Octopus website again, 30 of the $40(75 \%)$ did not trust the Tree Octopus website either. Conversely, a total of 14 of the 72 participants $(19.4 \%)$ said that they would visit the Tree Octopus website again and 13 of the $14(92.9 \%)$ also trusted the Tree Octopus website. The Pearson Chi-Square and Fisher's Exact Test was .000 for the total number of participants, which is statistically significant. Below is Table 26 and Figure 42 with these results:

Table 26

Tree Octopus Visit in the Future and Trust Variables for Total

\begin{tabular}{lllll}
\hline & \multicolumn{1}{c}{$\begin{array}{c}\text { Not Trust } \\
\mathrm{n}(\%)\end{array}$} & \multicolumn{1}{c}{$\begin{array}{c}\text { Neutral } \\
\mathrm{n}(\%)\end{array}$} & $\begin{array}{c}\text { Trust } \\
\mathrm{n}(\%)\end{array}$ & $\begin{array}{r}\text { Total } \\
\mathrm{n}(\%)\end{array}$ \\
\hline Not Visit & $30(75)$ & $5(12.5)$ & $5(12.5)$ & $40(100)$ \\
Neutral & $3(16.7)$ & $6(33.3)$ & $9(50)$ & $18(100)$ \\
Visit & $0(0)$ & $1(7.1)$ & $13(92.9)$ & $14(100)$ \\
Total & $33(45.8)$ & $12(16.7)$ & $27(37.5)$ & $72(100)$ \\
\hline
\end{tabular}

Fisher's Exact Test $=40.731 \mathrm{p}=.000$ (statistically significant) 


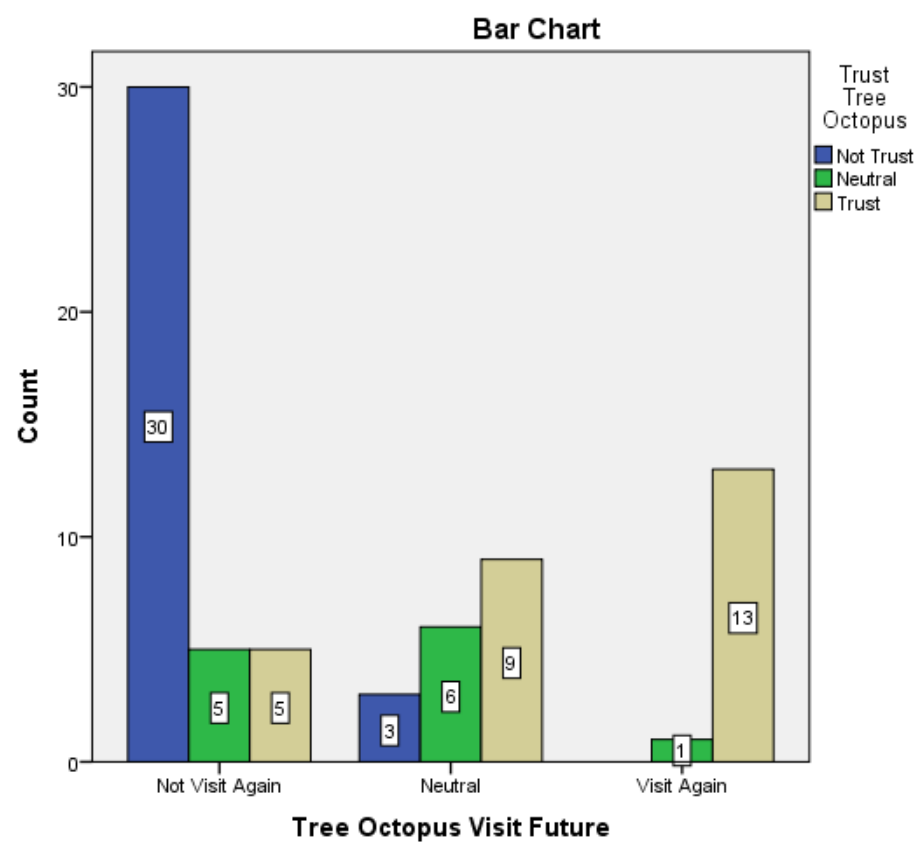

Figure 42. Comparison of Tree Octopus visit in the future and trust variable for all participants.

Figure 42 above, clearly shows that 30 of the 40 or $75 \%$ that said they would not visit the website again did not trust it either. In addition, 13 of the 14 or $92.9 \%$ that stated they would visit again, did trust the Tree Octopus website.

The Fisher's Exact Test for Group A was .018, which is statistically significant. Table 27 and Figure 43 below contains the comparison between the visit in the future and trust variables for the Tree Octopus website and the corresponding $\mathrm{p}$ value for Group A: 
Table 27

Tree Octopus Visit in the Future and Trust Variables for Group A

\begin{tabular}{lllll}
\hline & \multicolumn{1}{c}{$\begin{array}{c}\text { Not Trust } \\
\mathrm{n}(\%)\end{array}$} & \multicolumn{1}{c}{$\begin{array}{c}\text { Neutral } \\
\mathrm{n}(\%)\end{array}$} & $\begin{array}{c}\text { Trust } \\
\mathrm{n}(\%)\end{array}$ & $\begin{array}{r}\text { Total } \\
\mathrm{n}(\%)\end{array}$ \\
\hline Not Visit & $9(56.3)$ & $3(18.8)$ & $4(25)$ & $16(100)$ \\
Neutral & $2(16.7)$ & $3(25)$ & $7(58.3)$ & $12(100)$ \\
Visit & $0(0)$ & $1(12.5)$ & $7(87.5)$ & $8(100)$ \\
Total & $11(30.6)$ & $7(19.4)$ & $18(50)$ & $36(100)$ \\
\hline
\end{tabular}

Fisher's Exact Test $=10.854$

$\mathrm{p}=.018$ (statistically significant)

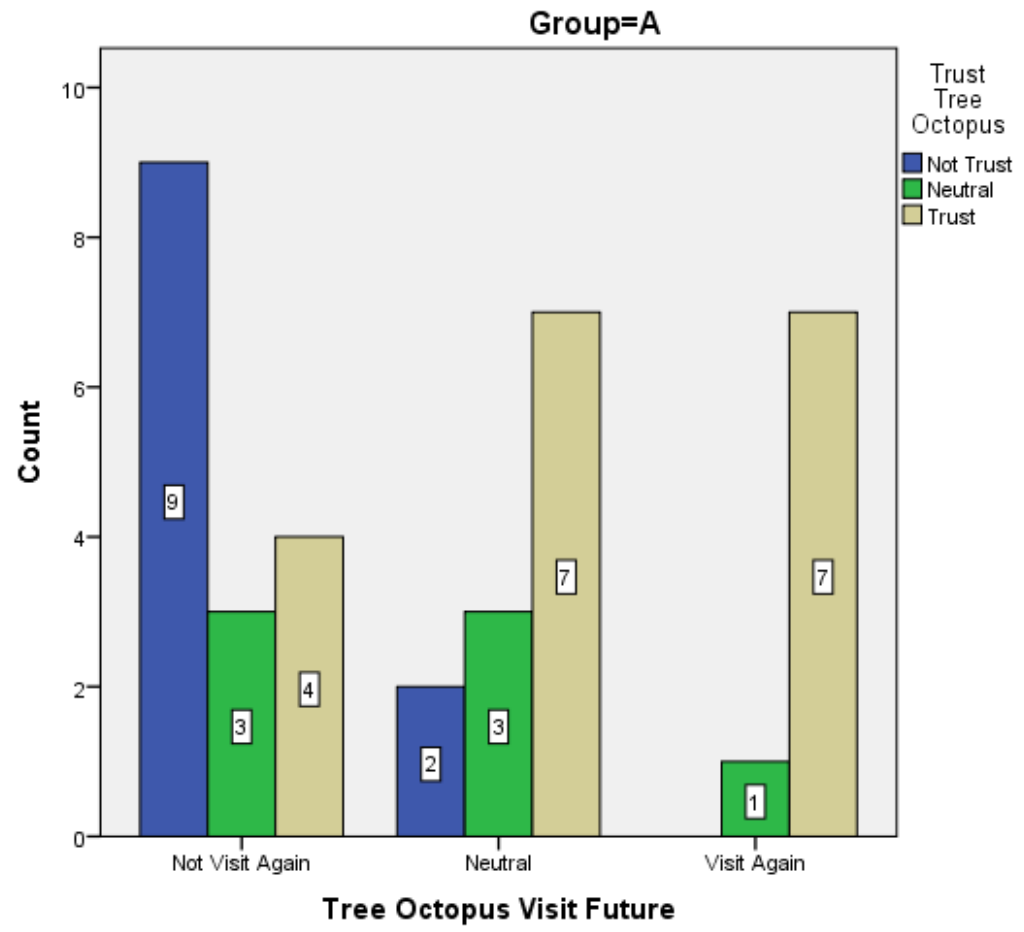

Figure 43. Comparison of Tree Octopus visit in the future and trust variable for Group A.

Based on the results on Table 19 and Figure 43 above, the majority that said they would visit the Tree Octopus in the future also trusted the website. A total of seven of the eight or $87.5 \%$ would visit it again and trusted it. The majority that said they would not visit the website, did not trust it. Precisely, nine of the 16 or $56.3 \%$ who said they would not visit the Tree Octopus website in the future, did not trust it either. This was also the case for Group B. 
The Fisher's Exact Test for Group B was 27.705, which was statistically significant since the $\mathrm{p}$ value was .000 . Table 28 and Figure 44 below contains the comparison between the visit in the future and trust variables for the Tree Octopus website and the corresponding $\mathrm{p}$ value for Group B:

Table 28

Tree Octopus Visit in the Future and Trust Variables for Group B

\begin{tabular}{lcccc}
\hline Group & Not Trust & Neutral & Trust & Total \\
\hline Not Visit & $21(87.5)$ & $2(8.3)$ & $1(4.2)$ & $24(100)$ \\
Neutral & $1(16.7)$ & $3(50)$ & $2(33.3)$ & $6(100)$ \\
Visit & $0(0)$ & $0(0)$ & $6(100)$ & $6(100)$ \\
Total & $22(61.1)$ & $5(13.9)$ & $9(25)$ & $36(100)$ \\
\hline
\end{tabular}

Fisher's Exact Test $=27.705 \mathrm{p}=.000$ (statistically significant)

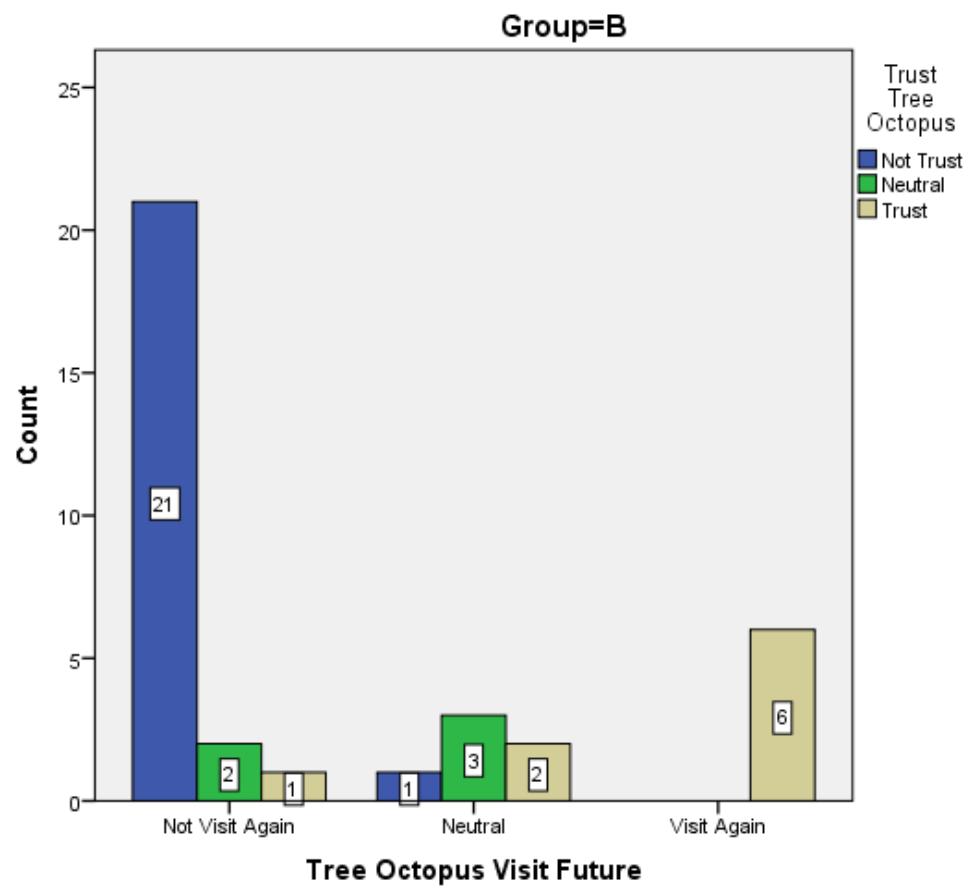

Figure 44. Comparison of Tree Octopus visit in the future and trust variable for Group B.

A total of 21 of the 24 participants or $87.5 \%$ who said they would not visit the Tree Octopus website again, said they do not trust it either; furthermore, all the participants who said they would visit the Tree Octopus website again, also trusted it. This suggests that if participants said that they would not visit the Tree Octopus website 
again in the future, then it would most likely result with not trusting the Tree Octopus website either. Finally, if the participants said that they would visit the Tree Octopus website in the future, then they would most likely trust it as well. Aside from stating whether they would visit the website in the future, participants were also asked if they thought the Tree Octopus website was useful. The next section contains the results for the useful and trust variables.

Tree Octopus Useful and Trust. Most of the participants said that they found the content on the Tree Octopus website useful. A total of $47.2 \%$ said it was useful, $15.3 \%$ remained neutral and $37.5 \%$ said it was not useful. Below is Figure 45 with these results:

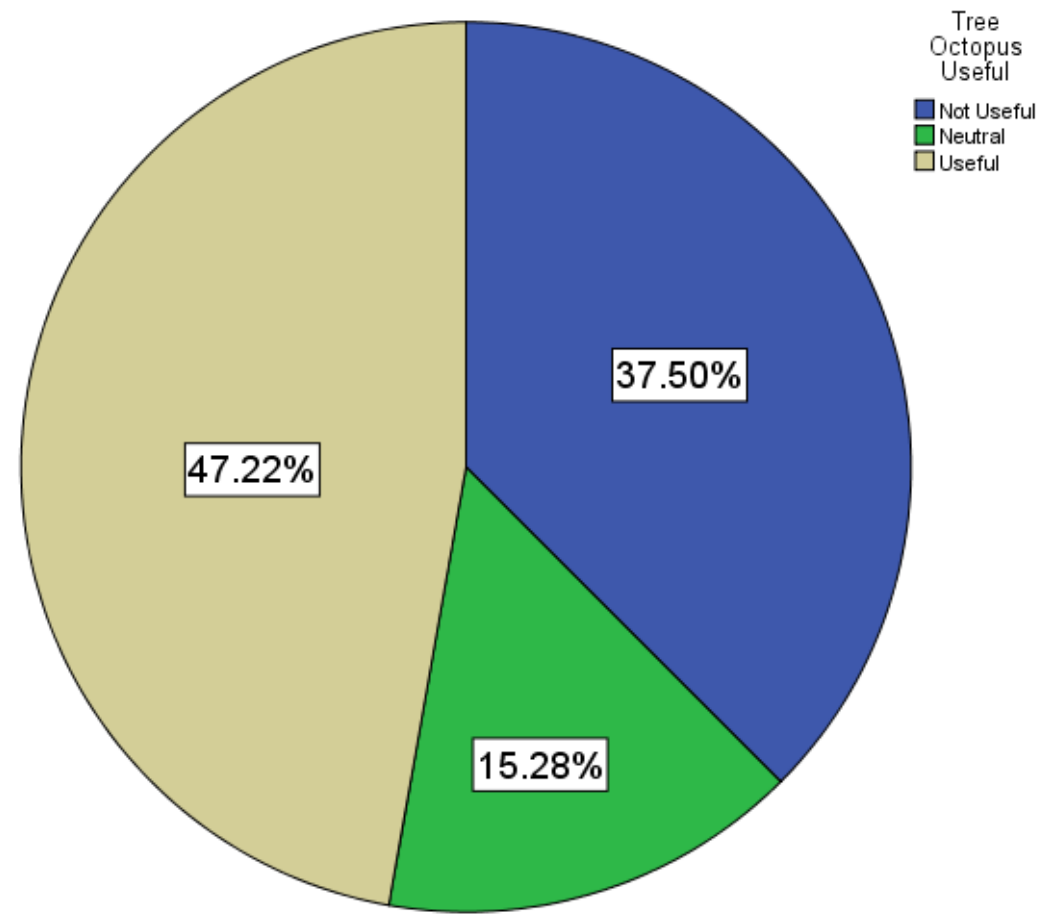

Figure 45. Percentages for Tree Octopus useful variable.

A total of 27 of the 72 participants (37.5\%) agreed that the Tree Octopus website was not useful, 25 of the $27(92.6 \%)$ did not trust the Tree Octopus website either. 
Conversely, a total of 34 of the 72 participants (47.2\%) agreed that the Tree Octopus website was useful and 22 of the $34(64.7 \%)$ trusted the Tree Octopus website. The Fisher's Exact Test for the total participants was 51.403, which was statistically significant since the $\mathrm{p}$ value was .000 . Table 29 and Figure 46 below contain these results:

Table 29

Tree Octopus Useful and Trust Variables for Total

\begin{tabular}{lcccc}
\hline & Not Trust & Neutral & Trust & Total \\
\hline Not Useful & $25(92.6)$ & $1(3.7)$ & $1(3.7)$ & $27(100)$ \\
Neutral & $6(54.5)$ & $1(9.1)$ & $4(36.4)$ & $11(100)$ \\
Useful & $2(5.9)$ & $10(29.4)$ & $22(64.7)$ & $34(100)$ \\
Total & $33(45.8)$ & $12(16.7)$ & $27(37.5)$ & $72(100)$ \\
\hline
\end{tabular}

Fisher's Exact Test $=51.403 \mathrm{p}=.000$ (statistically significant)

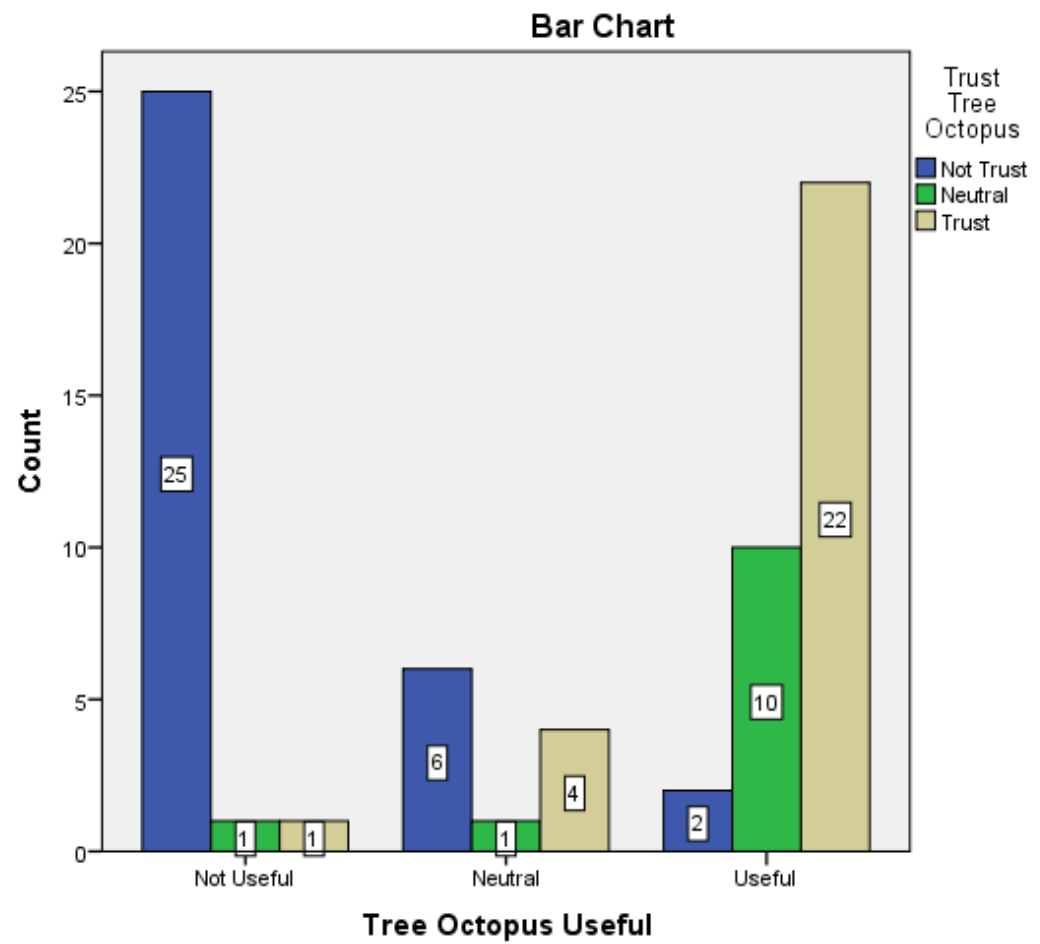

Figure 46. Comparison of Tree Octopus useful and trust variable for all participants.

Table 20 and Figure 46 above clearly shows how most of the participants 25 of the 27 or 92.6\% that thought it was not useful, did not trust the website either. In addition, most of 
the participants, 22 of the 34 or $64.7 \%$, who rated the Tree Octopus website as useful also trusted it. This suggests that if participants stated that the Tree Octopus website was not useful, then it most likely resulted with not trusting it. Finally, if the participants said that they thought the Tree Octopus website was useful then they most likely trusted it. The Fisher's Exact Test for Group A was 20.253, which was statistically significant with a p value of .000 . Below is Table 30 and Figure 47 with the results of the crosstabulation between the variable useful and trust for the Tree Octopus website for Group A.:

Table 30

Tree Octopus Useful and Trust Variables for Group A

\begin{tabular}{llllr}
\hline & \multicolumn{1}{c}{ Not Trust } & Neutral & \multicolumn{1}{c}{ Trust } & Total \\
\hline Not Useful & $6(85.7)$ & $1(14.3)$ & $0(0)$ & $7(100)$ \\
Neutral & $4(57.1)$ & $1(14.3)$ & $2(28.6)$ & $7(100)$ \\
Useful & $1(4.5)$ & $5(22.7)$ & $16(72.7)$ & $22(100)$ \\
Total & $11(30.6)$ & $7(19.4)$ & $18(50)$ & $36(100)$ \\
\hline
\end{tabular}

Fisher's Exact Test $=20.253 \mathrm{p}=.000$ (statistically significant)

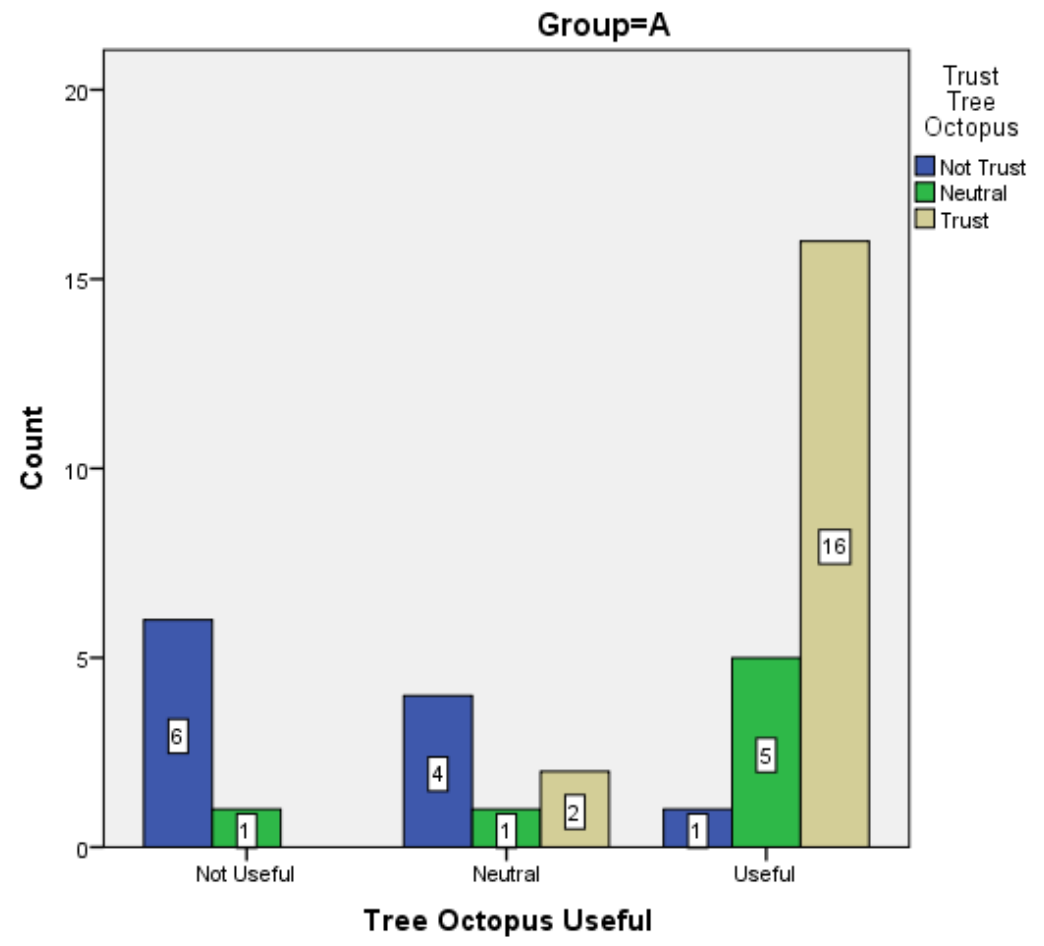

Figure 47. Comparison of Tree Octopus useful and trust variable for Group A. 
As it is illustrated in the Figure 47 above, the majority that thought the Tree Octopus website was useful also trusted it. Precisely, 16 of the 22 or $72.7 \%$ who thought it was useful trusted it. The Fisher's Exact Test for Group A was 26.290, which was statistically significant at .000 . The results for Group B show how the majority fell in the not useful and not trust categories. Below is Table 31 and Figure 48, which graphically illustrates this:

Table 31

Tree Octopus Useful and Trust Variables for Group B

\begin{tabular}{lllll}
\hline & \multicolumn{1}{c}{ Not Trust } & \multicolumn{1}{c}{ Neutral } & \multicolumn{1}{c}{ Trust } & \multicolumn{1}{c}{ Total } \\
\hline Not Useful & $19(95)$ & $0(0)$ & $1(5)$ & $20(100)$ \\
Neutral & $2(50)$ & $0(0)$ & $2(50)$ & $4(100)$ \\
Useful & $1(8.3)$ & $5(41.7)$ & $6(50)$ & $12(100)$ \\
Total & $22(61.1)$ & $5(13.9)$ & $9(25)$ & $36(100)$ \\
\hline
\end{tabular}

Fisher's Exact Test $=26.290 \mathrm{p}=.000$ (statistically significant)

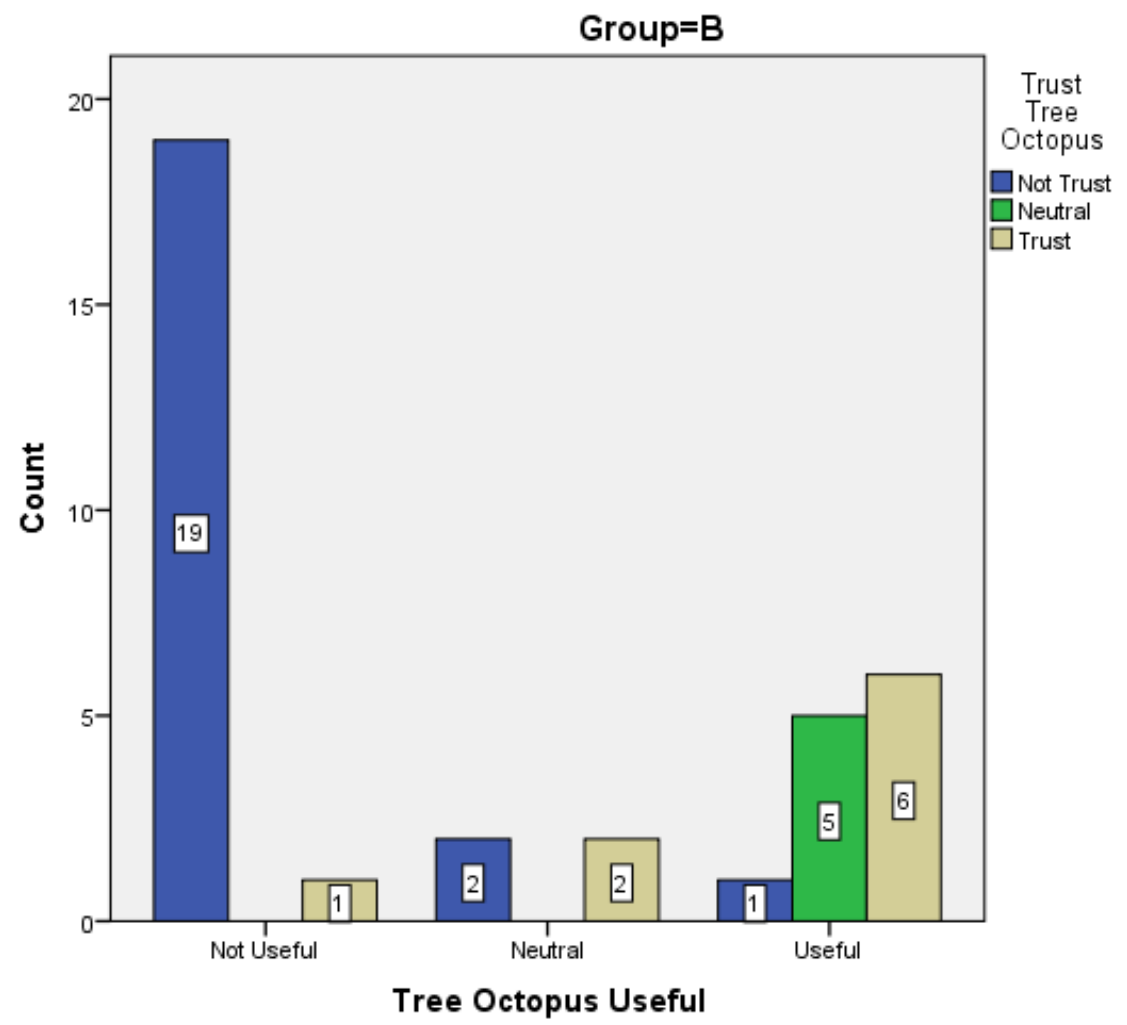

Figure 48. Comparison of Tree Octopus useful and trust variable for Group B. 
Of the 20 who thought the Tree Octopus website was not useful, 19 or $95 \%$ did not trust it either. A few participants even used the open text box to describe the website as useful. The next section contains the results for the open text question from the questionnaire.

Tree Octopus Open Text. This open text box was placed into the questionnaire to obtain participants' thoughts concerning the evaluation of the Tree Octopus website. These short sentences were coded based on their topic. Frequency counts were run to see which codes were mentioned the most. The following codes emerged from the data:
13. I don't know
14. Not organized
15. Organized
16. Not aesthetically appealing
17. Aesthetically appealing
18. Lengthy
19. Short simple
20. Ads/asking for money
21. Fake
22. Factual
23. Not useful
24. Useful
25. Bad
26. Good

Most of the participants wrote that the Tree Octopus website was fake, aesthetically appealing and organized. Specifically, 38.9\% said the Tree Octopus website was fake, $16.7 \%$ thought it was aesthetically appealing and $12.5 \%$ made a statement of it being organized. Below is Table 32 with the frequency count for the Tree Octopus open text field codes: 
Table 32

Frequencies Tree Octopus-Open Text for Total

\begin{tabular}{lcc}
\hline & Frequency & Percent \\
\hline I don't know & 4 & 5.6 \\
Not Organized & 1 & 1.4 \\
Organized & 9 & 12.5 \\
Not Appealing & 6 & 8.3 \\
Appealing & 12 & 16.7 \\
Lengthy & 1 & 1.4 \\
Ads Asking Money & 1 & 1.4 \\
Fake & 28 & 38.9 \\
Factual & 2 & 2.8 \\
Useful & 4 & 5.6 \\
Good & 3 & 4.2 \\
Total & 71 & 98.6 \\
Missing & 1 & 1.4 \\
Total & 72 & 100.0 \\
\hline
\end{tabular}

In general, of the 28 people who said it was fake, 27 did not trust the Tree

Octopus website. Eight of the nine that said it was organized trusted the website and eight of the 12 that said it was aesthetically appealing also trusted the website. The four that said it was useful also trusted the website. In other words, participants that described the Tree Octopus website as organized, aesthetically appealing or useful tended to trust it. Below is Figure 49 with these results: 


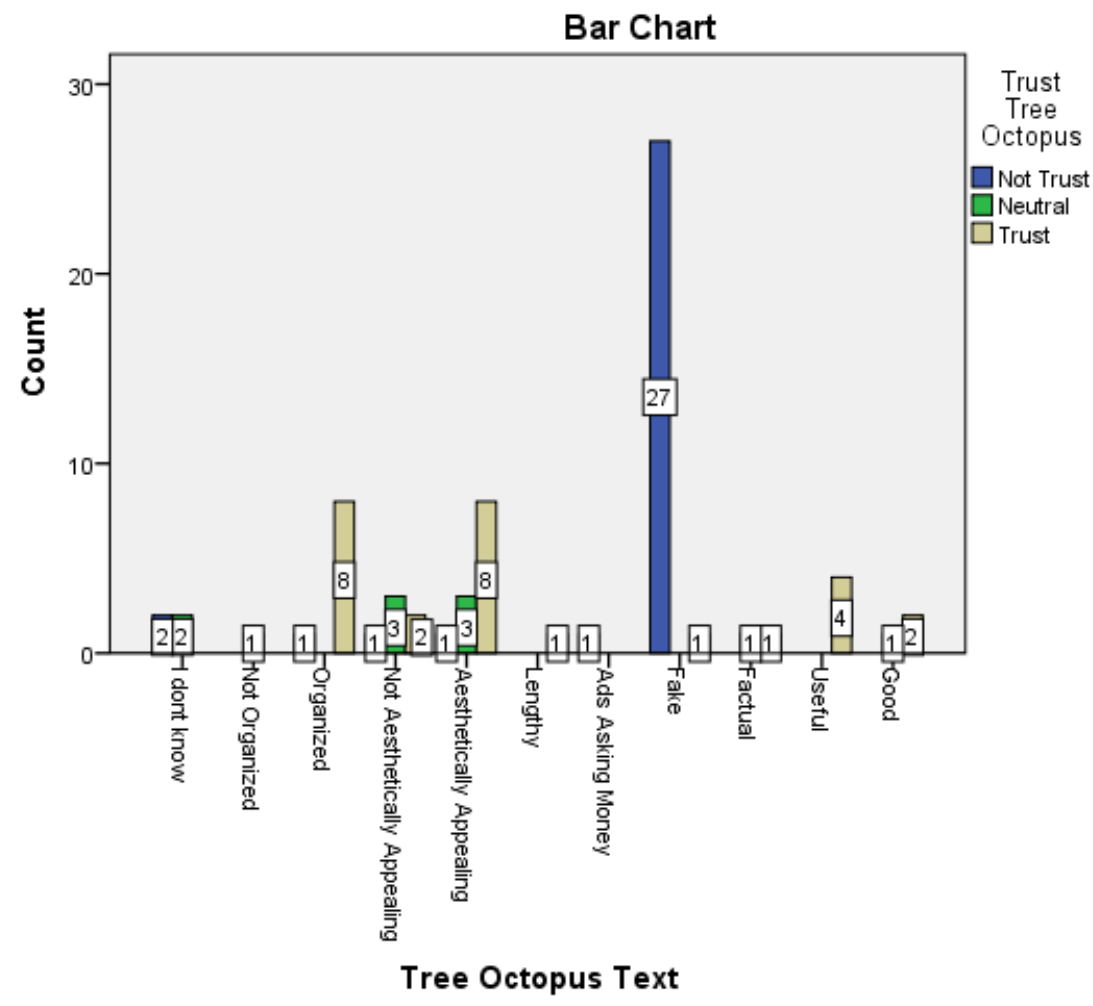

Figure 49. Comparison of Tree Octopus open text and trust variable for all participants.

Most of the participants from Group A wrote about how the Tree Octopus website was aesthetically appealing. These results align with the data obtained from the interviews. This was followed by fake and then by organized. For Group A, 25\% described the Tree Octopus as aesthetically appealing, $22.2 \%$ as fake, and $16.7 \%$ as organized. Table 33 below contains the frequencies for the open text for Group A regarding the Tree Octopus: 
Table 33

Frequencies Tree Octopus-Open Text for Group A

\begin{tabular}{lcc}
\hline & Frequency & Percent \\
\hline I don't know & 2 & 5.6 \\
Organized & 6 & 16.7 \\
Not Appealing & 5 & 13.9 \\
Appealing & 9 & 25.0 \\
Fake & 8 & 22.2 \\
Useful & 4 & 11.1 \\
Good & 1 & 2.8 \\
Total & 35 & 97.2 \\
Missing & 1 & 2.8 \\
Total & 36 & 100 \\
\hline
\end{tabular}

When a crosstabulation was run between these open text codes and whether the participants trusted the Tree Octopus website produced the following results. In Group A, most of the participants that said it was aesthetically appealing, organized and useful also trusted the Tree Octopus website. The ones that said it was fake, did not trust it. This is illustrated by Figure 50: 


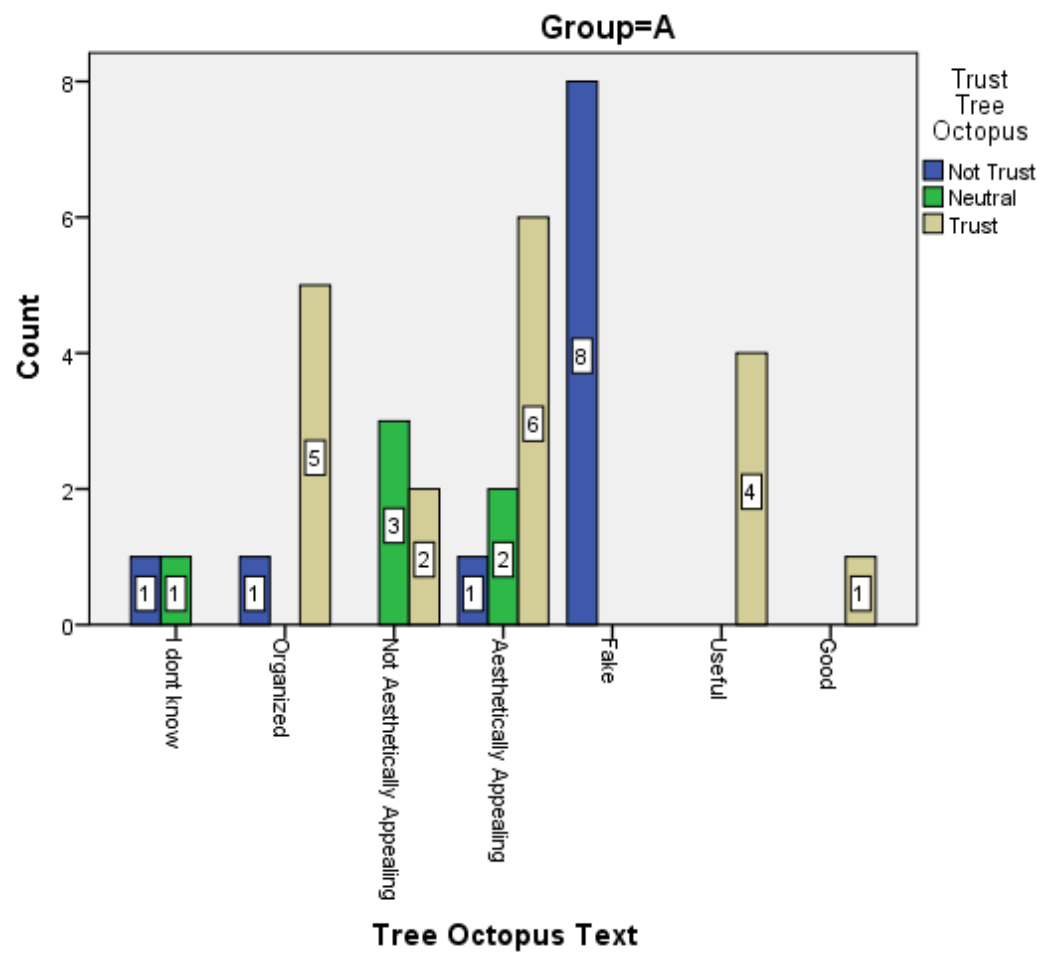

Figure 50. Comparison of Tree Octopus open text and trust variable for Group A.

In contrast, more than half of the text field open codes in Group B contained statements of the Tree octopus website being fake. In Group B, 55.6\% described it as fake, and $8.3 \%$ said it was organized and aesthetically appealing. Below in Table 34 are these results for Group B: 
Table 34

Frequencies Tree Octopus-Open Text for Group B

\begin{tabular}{lcc}
\hline & Frequency & Percent \\
\hline I don't know & 2 & 5.6 \\
Not Organized & 1 & 2.8 \\
Organized & 3 & 8.3 \\
Not Appealing & 1 & 2.8 \\
Appealing & 3 & 8.3 \\
Lengthy & 1 & 2.8 \\
Fake & 20 & 55.6 \\
Factual & 2 & 5.6 \\
Good & 2 & 5.6 \\
Total & 36 & 100.0 \\
\hline
\end{tabular}

As for Group B, the majority that said that the Tree Octopus website was fake did not trust it. As is evident in Figure 51 below, more than half (19 of the 36) of the participants in Group B described the Tree Octopus website as fake.

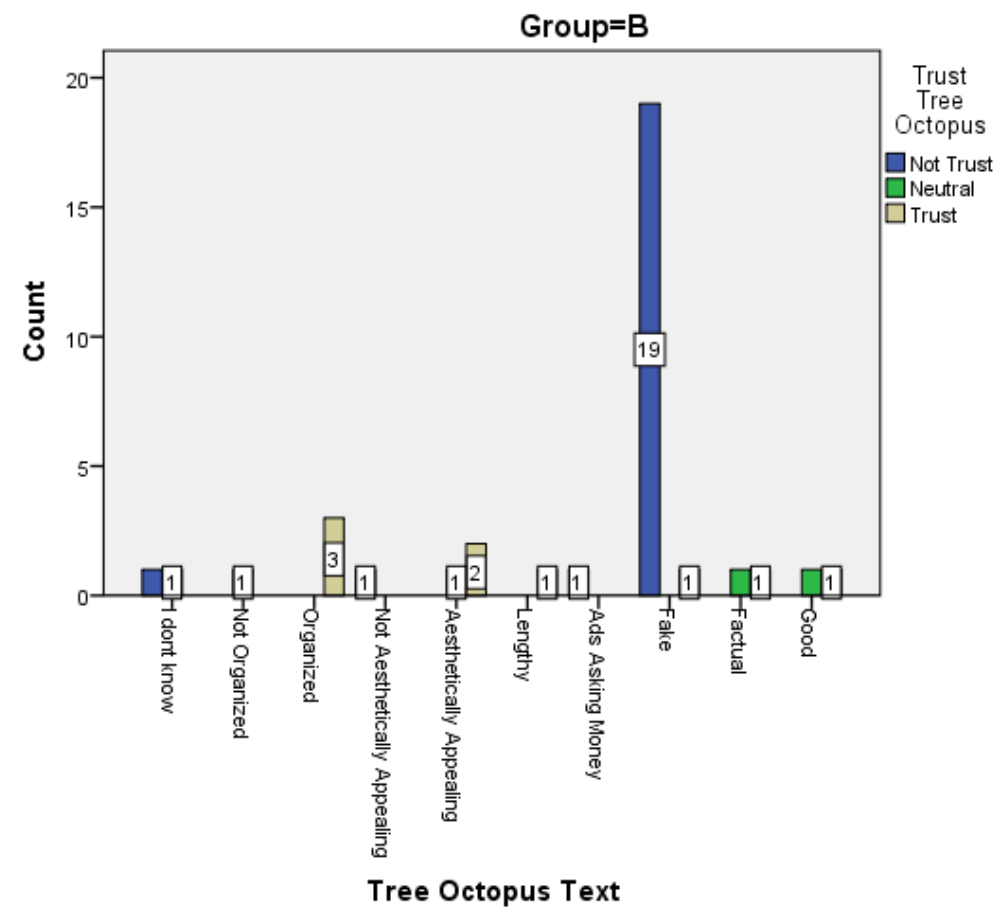

Figure 51. Comparison of Tree Octopus open text and trust variable for Group B. 
Aside from the hoax websites, another independent variable that was analyzed were the epistemic beliefs. The next section contains quantitative analysis on the epistemic beliefs.

\section{Epistemic Beliefs}

Frequency counts were run for the three epistemic beliefs, feeling, evidence and political. Fifty displayed evidence-based epistemic beliefs, 39 had feeling-based and nine had political. A few participants displayed a combination of epistemic beliefs that were of equal weight and that is why there are more than 72 in the count. Below is a table 35 with the frequency count:

Table 35

Epistemic Beliefs Frequencies

\begin{tabular}{lcc}
\hline & Frequency & Percent \\
\hline Group A & 19 & \\
Feeling & 24 & 52.8 \\
Evidence & 1 & 66.7 \\
Political & & 2.8 \\
Group B & 20 & \\
Feeling & 26 & 55.6 \\
Evidence & 8 & 72.2 \\
Political & & 22.2 \\
Total & 39 & \\
Feeling & 50 & 54.2 \\
Evidence & 9 & 69.4 \\
Political & & 12.5 \\
\hline
\end{tabular}

Since some displayed an equal combination of epistemic beliefs, these combinations were analyzed. Group B displayed more combinations of epistemic beliefs compared to Group A. Group B had evidence and political, feeling and political and political, which Group A did not. The majority in both groups fell into the 
evidence-based category followed closely by the feeling category and then by the equal combination of feeling and evidence. Below is a table 36 with these combinations:

Table 36

Epistemic Beliefs Combinations

\begin{tabular}{lcc}
\hline & Frequency & Percent \\
\hline Group A & & \\
E & 17 & 47.2 \\
F & 12 & 33.3 \\
FE & 6 & 16.7 \\
FEP & 1 & 2.8 \\
Total & 36 & 100.0 \\
Group B & & \\
E & 12 & 33.3 \\
EP & 3 & 8.3 \\
F & 8 & 22.2 \\
FE & 7 & 19.4 \\
FEP & 4 & 11.1 \\
FP & 1 & 2.8 \\
P & 1 & 2.8 \\
Total & 36 & 100.0 \\
Total & & \\
E & 29 & 40.3 \\
EP & 3 & 4.2 \\
F & 20 & 27.8 \\
FE & 13 & 18.1 \\
FEP & 5 & 6.9 \\
FP & 1 & 1.4 \\
P & 1 & 1.4 \\
Total & 72 & 100.0 \\
\hline
\end{tabular}

E=Evidence, $\mathrm{F}=$ Feeling, $\mathrm{P}=$ Political

Based on the bar chart below, the majority that displayed evidence-based epistemic beliefs did not trust the Tree Octopus website and the majority that had feeling-based epistemic beliefs did trust it. However, based on the statistical analysis, they were not in general significant enough. The only statistically significant result was in Group A regarding feeling-based epistemic beliefs. Below is Figure 52, which 
graphically illustrates the predominant epistemic beliefs displayed and the trust level for the Tree Octopus website:

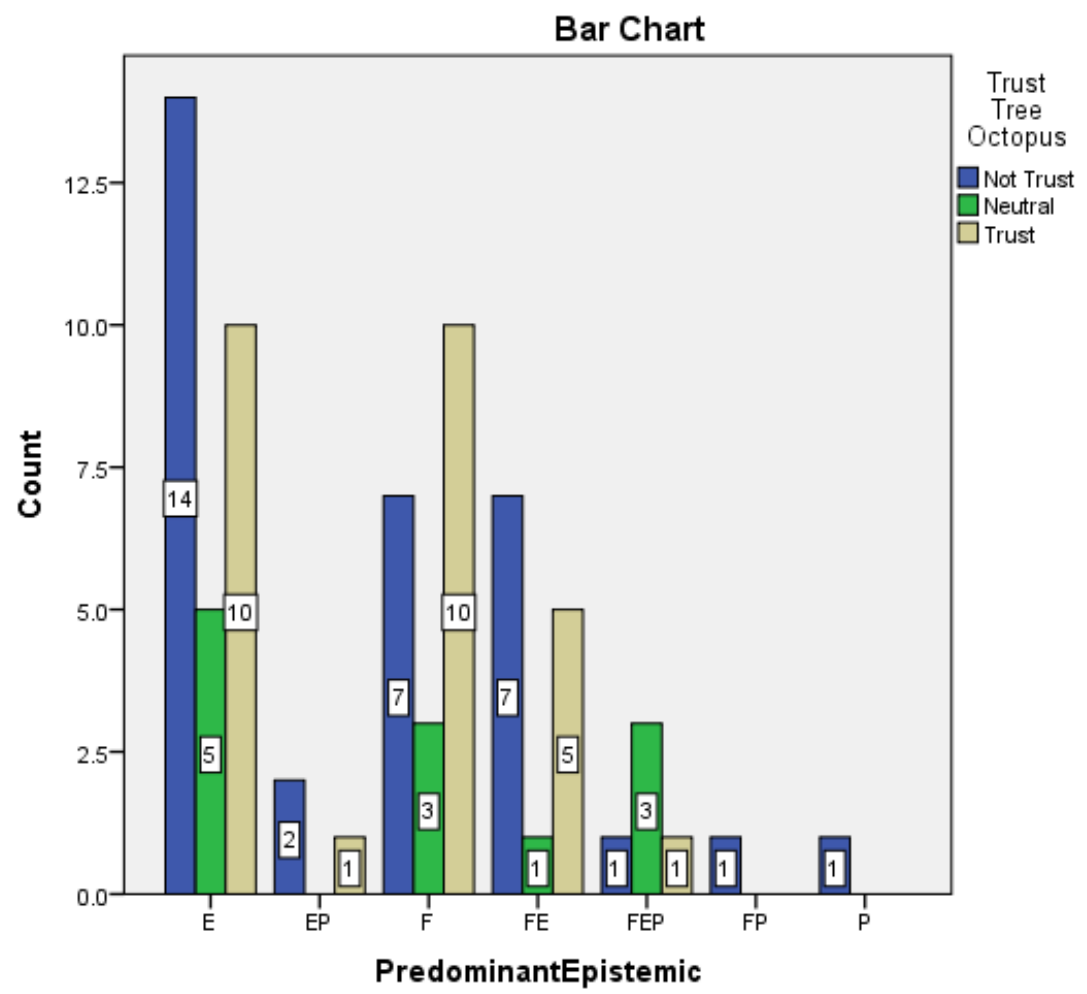

Figure 52. Comparison of Predominant Epistemic Beliefs and trust variable for Tree Octopus.

Zero order correlations (Bivariate Pearson Correlation) were run to see if there were any significant results between the three epistemic beliefs (Feeling, Evidence and Political) and trusting the respective hoax website. None of the epistemic beliefs had a statistically significant outcome in regard to the DHMO.org website. It may be that the low rating in aesthetic appeal and organization of this website surpassed the possible effects of epistemic beliefs. The epistemic belief "feeling" had a statistical significant number of $.023(<.05)$ when it came to the dependent variable of trusting the Tree Octopus hoax website in Group A since the Pearson Correlation was .377. Below is table 
37 with the results comparing Group A and Group B regarding the Feeling Epistemic

Belief:

Table 37

Feeling Epistemic Beliefs

\begin{tabular}{|c|c|}
\hline & $\begin{array}{c}\text { Tree Octopus } \\
\text { Pearson Correlation }(\mathrm{p})\end{array}$ \\
\hline \multicolumn{2}{|l|}{ Group A } \\
\hline Feeling & $.377\left(.023^{*}\right)$ \\
\hline \multicolumn{2}{|l|}{ Group B } \\
\hline Feeling & $-.045(.796)$ \\
\hline
\end{tabular}

This suggests that prospective teachers that had feeling-based epistemic beliefs tended to trust the Tree Octopus, unless a web evaluation strategy such as the WWWDOT framework was taught to them since the number was not significant in Group B (.796>.05). Below is Figure 53, which illustrates the epistemic beliefs and the trust variable for Group A:

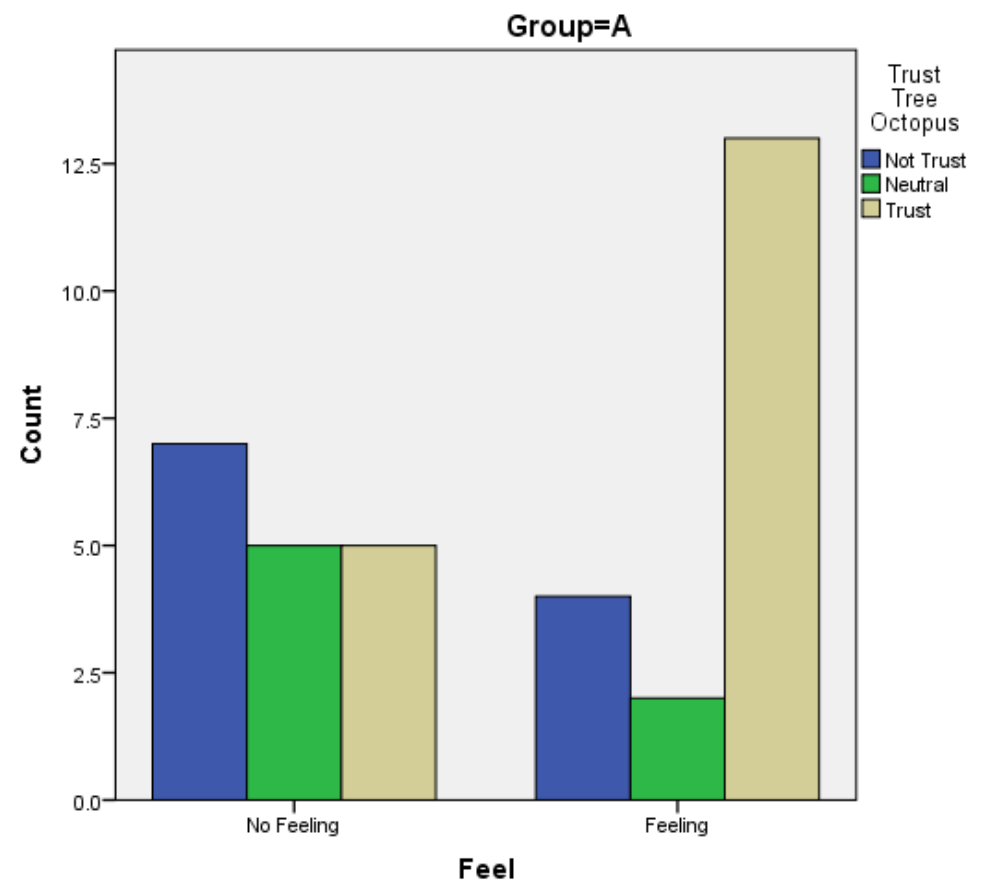

Figure 53. Comparison of Tree Octopus Feeling and trust variable for Group A. 
It is evident from Figure 53, that in Group A the majority that displayed feeling-based epistemic beliefs also trusted the Tree Octopus website. However, in Group B feeling-based epistemic beliefs were not associated with trusting the Tree Octopus Website, since the majority did not trust it regardless of having feeling-based epistemic beliefs or not, which can be seen in Figure 54 below:

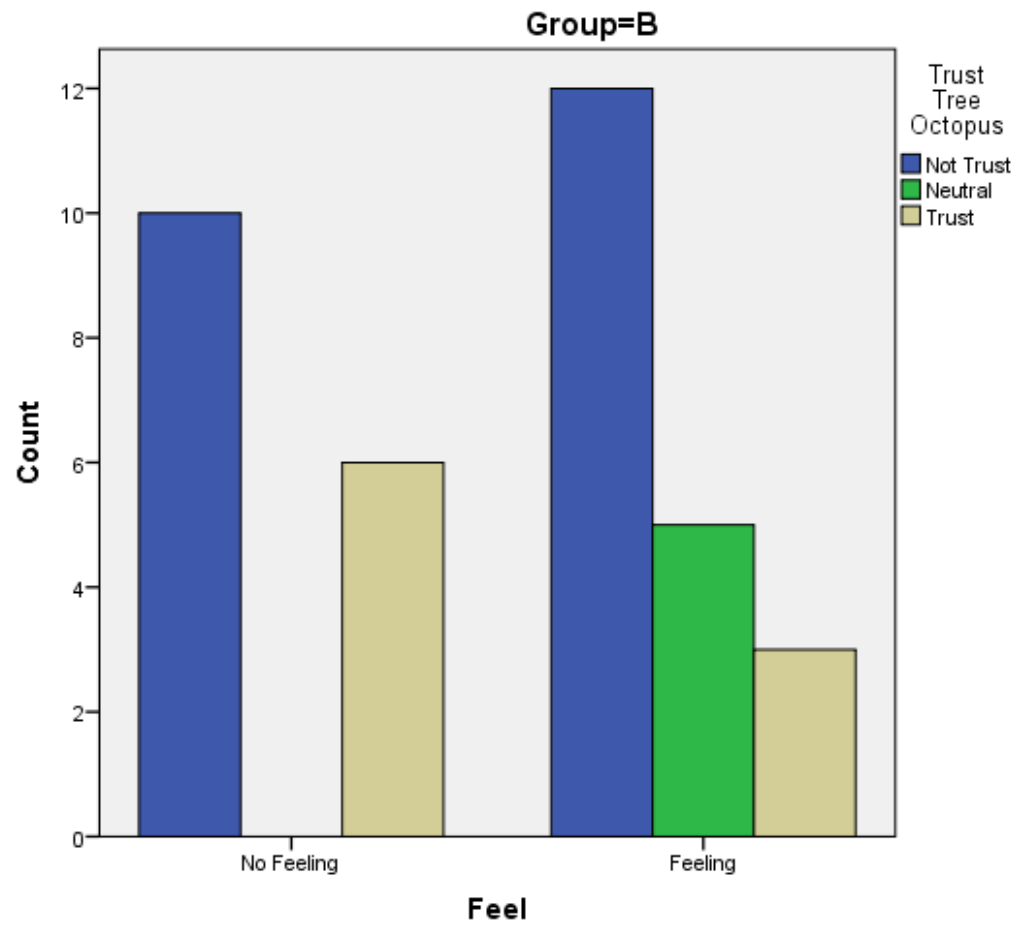

Figure 54. Comparison of Tree Octopus feeling and trust variable for Group B.

The following section contains an overview of the quantitative results.

\section{Overview of Quantitative Results of Questionnaire}

Below is table 38 with the Pearson Chi-Square, Fisher's Exact Test and Pearson Correlation with their respective $\mathrm{p}$ values for the various variables from the questionnaire and the independent variable trust. It clearly shows the ones that were statistically 
significant and the ones that were not for the DHMO.org and Tree Octopus websites divided by Group A, Group B and all participants:

Table 38

Probability Values for Independent Variables and Dependent Variable Trust

\begin{tabular}{|c|c|c|c|}
\hline & $\begin{array}{c}\text { Group A } \\
\text { Pearson } \\
\text { Chi-Square/ } \\
\text { Fisher's Exact } \\
\text { Test/Pearson } \\
\text { Correlation (p) }\end{array}$ & $\begin{array}{c}\text { Group B } \\
\text { Pearson } \\
\text { Chi-Square/ } \\
\text { Fisher's Exact } \\
\text { Test/Pearson } \\
\text { Correlation (p) }\end{array}$ & $\begin{array}{c}\text { Total } \\
\text { Pearson } \\
\text { Chi-Square/ } \\
\text { Fisher's Exact } \\
\text { Test/Pearson } \\
\text { Correlation (p) }\end{array}$ \\
\hline \multicolumn{4}{|l|}{ DHMO.org } \\
\hline WWWDOT & N/A & $1.586(.452)$ & N/A \\
\hline Aesthetic Appeal & $7.345(.058)$ & $7.389(.051)$ & $13.399(.004 * *)$ \\
\hline Organization & $13.442(.006 * *)$ & $6.905(.088)$ & $16.427(.001 * *)$ \\
\hline Visit in the Future & $4.929(.199)$ & $10.398(.009 * *)$ & $14.326(.001 * *)$ \\
\hline Useful & $10.008\left(.036^{*}\right)$ & $19.217(.000 * *)$ & $30.281(.000 * *)$ \\
\hline \multicolumn{4}{|l|}{ Tree Octopus } \\
\hline WWWDOT & N/A & $7.000(.030 *)$ & N/A \\
\hline Aesthetic Appeal & $8.997\left(.015^{*}\right)$ & $2.287(.840)$ & $8.830(.031 *)$ \\
\hline Organization & $5.025(.190)$ & $4.205(.342)$ & $10.808\left(.018^{*}\right)$ \\
\hline Visit in the Future & $10.854\left(.018^{*}\right)$ & $27.705(.000 * *)$ & $40.731(.000 * *)$ \\
\hline Useful & $20.253(.000 * *)$ & $26.290(.000 * *)$ & $51.403(.000 * *)$ \\
\hline Feeling & $.377\left(.023^{*}\right)$ & $-.045(.796)$ & $.163(.172)$ \\
\hline
\end{tabular}

Based on Table 38 above, the participants from Group A, who evaluated the DHMO.org website were influenced by its organization and usefulness. In other words, the participants in Group A that thought the DHMO.org website was not organized and not useful, did not trust it and those that thought it was organized and useful did trust it. None of the epistemic beliefs had any influence concerning the DHMO.org website. As for the Tree Octopus website, the participants from Group A were influenced by its aesthetic appeal, whether it was visited in the future, its usefulness, and by having feeling-based epistemic beliefs. 
If the Tree Octopus website was deemed aesthetically appealing, would be visited in the future and it was considered useful, then it was most likely trusted. The opposite was also true. If the Tree Octopus website was considered not aesthetically appealing, would not be visited in the future, and was not useful, then it was not trusted. The feeling-based epistemic beliefs had an influence in Group A for the Tree Octopus websites. Those that had predominant feeling-based epistemic beliefs were more likely to trust the Tree Octopus website. Group A had more variables that were statistically significant compared to Group B. Group A had six variables and Group B had four variables that were statistically significant. The following is an analysis of the results for Group B.

Regarding the DHMO.org website, Group B was influenced by whether the participants would visit the website in the future and its usefulness. In other words, if participants said they would visit it in the future and that it was useful then they tended to trust it. If they said they would not visit it in the future and it was not useful, then they tended to not trust the DHMO.org website. The results were the same for Group B regarding the Tree Octopus website since the two variables that were statistically significant were also visiting the website in the future and its usefulness. In general, aesthetic appeal, organization, visiting the website in the future and usefulness were statistically significant for both the DHMO.org website and the Tree Octopus regardless of the group. This means that these variables influenced the participants in general regarding whether they trusted the hoax websites. If the participants thought the website was aesthetically appealing, organized, would visit it in the future and was useful, then they tended to trust it. In contrast, if the website was considered as not aesthetically 
appealing, not organized, would not visit it in the future and was not useful, then they tended to not trust it. The main variable analyzed was whether the WWWDOT Framework had any influence on the trust level.

The WWWDOT Framework was not statistically significant regarding the DHMO.org website, but it was for the Tree Octopus website. It is important to note that most participants rated the DHMO.org website as not being aesthetically appealing, not organized, and would not visit it in the future, which influenced the trust level of participants in general since these variables were statistically significant. In other words, participants tended to not trust the DHMO.org website based on these variables. As for the Tree Octopus website, most participants rated it as aesthetically appealing, organized, and useful, however, the WWWDOT Framework did influence the decision between Group A and Group B since most from Group A trusted the Tree Octopus website and most from Group B did not trust it. This suggests that the WWWDOT Framework can help increase the number of people that do not trust a hoax website that is considered aesthetically appealing, organized and useful. However, people in general will tend to not trust websites that are not aesthetically appealing and not organized whether they are exposed to the WWWDOT Framework or not. This is especially true when websites are evaluated simply by the look and feel or aesthetic appeal. The qualitative analysis of the interview data provides insights on how websites were evaluated.

\section{Qualitative Analysis of Interview Data}

A total of 16 participants were purposely selected to be interviewed. This means that $22 \%$ of the 72 prospective teachers were interviewed. Sixteen were selected since the data reached data saturation. Eight of them were from Group A and the other eight were 
from Group B. Four participants from each category below were interviewed. There were four categories based on the level of trust:

1. Trusted Hoax Websites (4)

2. Trusted One Hoax Website but Not the Other (4)

3. Not Trusted Hoax Websites (4)

4. Neutral (Neither Trusted or Not Trusted the Hoax Websites) (4)

The following section contains results organized by the four levels of trust categories mentioned above.

\section{Trusted Hoax Websites Category}

The major themes found within the Trusted Hoaxes website category were Web Evaluation Strategies and Epistemic Beliefs. There was a total of four interviewees in this category, two from Group A and two from Group B. Various sub-themes arose from each theme. The sections below contain information on these sub-themes.

Web Evaluation Strategies. The following is a list of the five major sub-themes under Web Evaluation Strategies mentioned by the interviewees that trusted the hoax websites from both Group A and Group B:

1. Aesthetic Appeal (4/4)

2. Not Spending Sufficient Time to Read and Evaluate (4/4)

3. Linear Reading (4/4)

4. Not Knowing the Definition of a Hoax Website (3/4)

5. Ease of Use (2/4)

All the individuals in this category (Interviewees $3,4,7 \& 12$ ) said that the aesthetic appeal was important. In addition, Interviewees $3,4,7 \& 12$ expressed that they did not 
spend sufficient time reading and evaluating the websites. In addition, they read linearly, which means that they stayed within the website and did not visit any outside sources or google to research the credibility of the websites. Below is Table 39 with a few quotes from various interviewees that illustrate the first three main sub-themes of Aesthetic Appeal, Not Spending Sufficient Time to Read and Evaluate and Linear Reading:

Table 39

Trusted-Aesthetic Appeal, Not Spending Sufficient Time to Read and Evaluate and Linear Reading

Interviewee Group

Aesthetic Appeal

"I think what really led me to accept everything has to do 3

A

with the layout for me."

"Whichever ones I was only aesthetically pleased to."

"OK I think what made me trust the hoax websites were like for that one (tree octopus) it was the way the information was presented the appealing look." "I evaluated based on display and looks."

"I basically just went with what the website looks like. If it would look nice or if it was you know, if they grab your attention or not."

How did you evaluate the websites? "Pictures or the visuals."

Not Spending Sufficient Time to Read and Evaluate "When I looked at each website, I was just kind of going through them quickly, so I wasn't like reading every single word or anything." "Whether the information was credible, I didn't really have time to research further on it."

"It didn't even get my attention to read it." "I didn't look like into it that deep. I know I am supposed to..." "I would say people don't do that because they don't think it's needed they don't think as deep down as it should be."

"I think most of the time and students like myself, if I just don't know something, I just look it up on the Internet and whatever information it gives me I usually just trust it right away." 
"When I read the first paragraph, I thought it was true, so I

figured the rest was fine. I didn't read through them that well."

\section{Linear Reading}

'I didn't get a chance to use resources because I was crunch

for time, so I wasn't able to like go to a different site to look up the information."

"No, I did not compare the information, or like make sure that it was credible."

$4 \quad \mathrm{~A}$

'I didn't leave the website. I just kind of read about information on the website. That's it."

$7 \quad \mathrm{~B}$

"I probably just read like the first paragraph and then went

Based on the quotes above, it seems that if the website was aesthetically appealing, it was trusted. In addition, all the interviewees that trusted both hoax websites did not spend sufficient time reading and evaluating the websites since they trusted the information right away (Interviewee \# 7), did not read enough (Interviewee \# 4 and 12), and reviewed them quickly (Interviewee \# 3). Basically, not enough time was spent doing deep research. Linear reading is another factor that seems to have led these participants into trusting the hoax websites. None of them went outside of the website to verify the information. Interviewees 3, 4, 7, and 12 stayed within the specific websites and read linearly, as opposed to laterally.

The fourth subtheme that was present in both groups was not knowing the definition of a hoax website. Three of the four interviewees that trusted the two hoax websites had no clue of what it meant or had an incorrect definition. These quotes can be seen in Table 40 below: 
Table 40

Trusted-Not Knowing the Definition of a Hoax Website

\begin{tabular}{lcc}
\hline "A hoax website will have to mean nothing to me because I & Interviewee & Group \\
have no clue what that means." & 4 & A \\
"A hoax website would be something just completely out of & 7 & B \\
the ordinary, doesn't make any sense you know. It's just like & \\
putting in fact, without any evidence." & 12 & B \\
"Something that everybody can write their own opinions on." &
\end{tabular}

Interviewee \# 4 had no clue of what a hoax website meant. The other two, who did not know the definition of a hoax website, were not as clueless as Interviewee \# 4, however their definition was not correct. Not knowing the definition of a hoax website might have also led them to trust the hoax websites. The fifth sub-theme was ease of use. An interviewee from each group stated the importance of ease of use as a web evaluation strategy. Please see Table 41 below with the corresponding quotes:

Table 41

Trusted-Ease of Use

"How easily accessible it was to get to the different Interviewee Group information and the clarification on everything. So, one thing 3 A that I was really drawn to was like if you had like different tabs the intro and this is how this works, and this is how it's important to whatever. So, stuff like that. I am like the tabs are really important to me because it's easier for me to like focus my thoughts on everything."

"I look at what the website looks like and then I look to see 
As mentioned earlier, these five sub-themes were shared among both Group A and Group B. However, there were a few sub-themes that were only present in Group A, or Group B. The following are the sub-themes mentioned by only one of the groups:

\section{Group A:}

1. Complex Terminology $(2 / 2)$

2. Knowing the Definition of a Hoax Website (1/1)

Group B:

1. Authorship $(2 / 2)$

2. Not using WWWDOT Framework (2/2)

3. No Experience Evaluating Websites (1/2)

Interviewees from Group A that trusted the hoax websites mentioned that the presence of complex terminology, or the way it was said made them trust the hoax websites. Only one member from Group A knew the definition of a hoax website. Interviewees from Group B said that they trusted the website based on the authorship and admitted to not using the WWWDOT Framework. Also, a member from Group B explained that evaluating websites was a completely new experience. Figure 55 below summarizes the information presented in this section: 

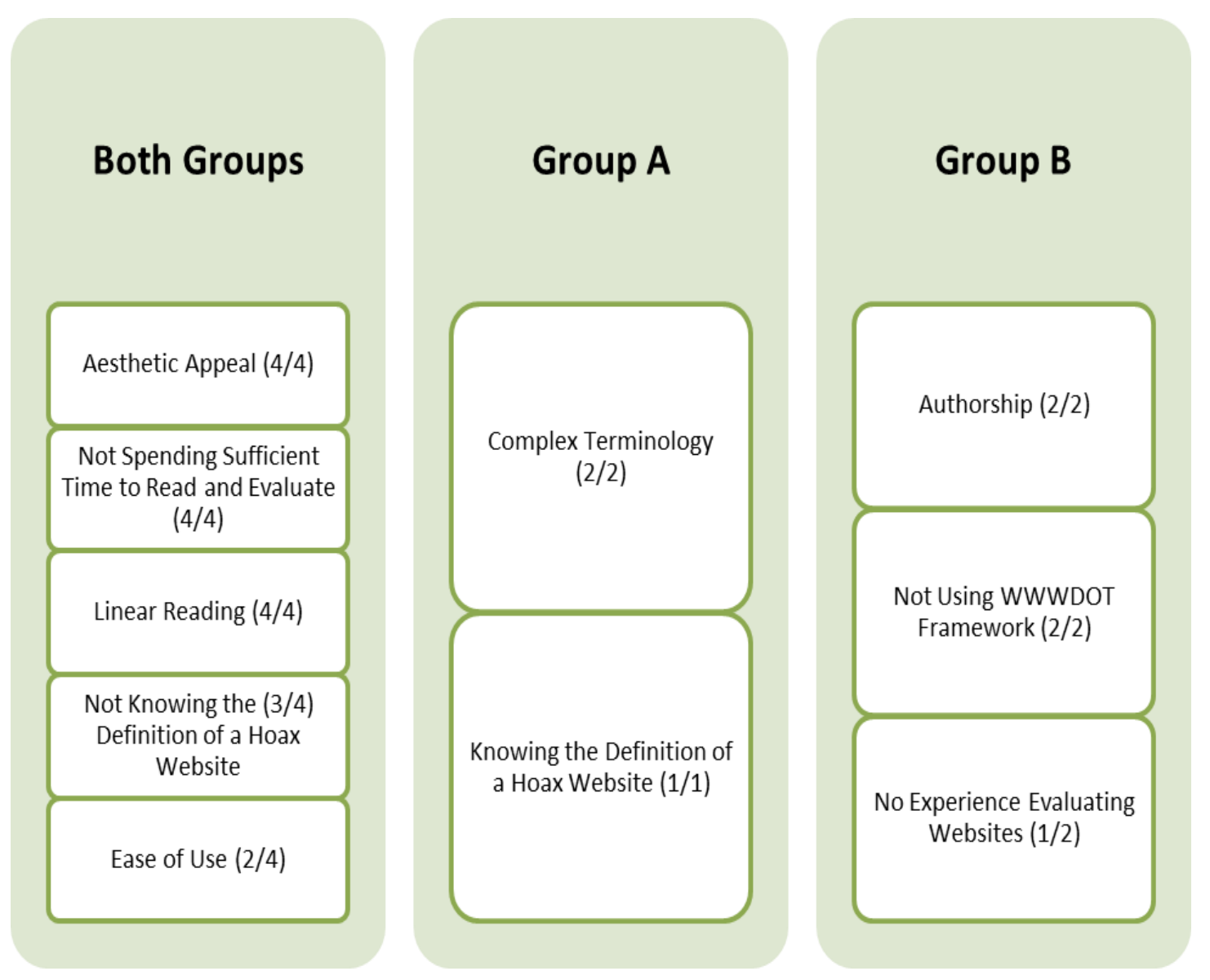

Figure 55. Web Evaluation Strategies for the Trusted Hoax Websites Category.

The Interviewees from Group A that trusted the hoax websites stated that the complex terminology, or the way things were said made them think that the websites were trustworthy. Interviewee \# 3 and Interviewee \# 4 explained this below in Table 42: 
Table 42

Trusted-Complex Terminology

\begin{tabular}{lcc}
\hline & Interviewee & Group \\
\hline "Just more the way that the information was presented kind & 3 & A \\
of either put me on one side of the spectrum, like believing it & \\
or not. So, there is some stuff like super sciencey and I like & \\
had no idea if it was credible or not." & \\
"The ones that I said that I did think were credible, just the & \\
way they had their information, how they said it was really, it & A \\
seemed like convincing, like scholarly." & \\
"OK, what made me trust it was like I would say like the & \\
word content, like the way it was expressed in, like the & \\
certain words and how much words were there. It seemed & \\
like the person knew what they were talking about." &
\end{tabular}

Both interviewees were convinced the hoax websites were true, due to the presence of complex words that sounded scholarly. Aside from complex terminology, it is also important to note that only one individual from Group A knew the definition of a hoax website. Interviewee \#3 had a better understanding of the definition compared to the other three individuals mentioned earlier that trusted the hoax websites. This quote can be seen in Table 43 below:

Table 43

Trusted-Knowing the Definition of a Hoax Website

\begin{tabular}{lcc}
\hline & Interviewee & Group \\
\hline "Basically, a hoax website is a website that has false & 3 & $\mathrm{~A}$ \\
information but also a website that has bias information." & & \\
\hline
\end{tabular}

The definition of a hoax website provided by Interviewee \# 3 is acceptable since it mentions false and bias information. Interviewees from Group B did not mention complex terminology but did make statements related to authorship. Interviewee \# 7 (Group B) stated that information about the creator was important regarding the 
credibility of the website and Interviewee \# 12 (Group B) also mentioned authorship.

Please see quotes below in Table 44:

Table 44

Trusted-Authorship

"I think the credibility of the website or enough information Interviewee Group about who created the website is a big deal for me when it comes to credibility of the website. So, if you didn't have any information about the creator, I am more likely would think it's a fake website."

"I think that when it comes to websites they are from people that have read and understood, sometimes have gone to the places or the things that they're talking about, so they will have knowledge on the topic or the subject."

Since both hoax websites mentioned the creator, they were trusted. The DHMO.org website had Tom Way next to the copyright information and the Tree Octopus website had Lyle Zapato as the author. Authorship is mentioned in the WWWDOT Framework strategy under the Who category, which was taught to Group B. Unfortunately, both individuals admitted to not using the WWWDOT Framework. Below are the statements made in reference to this in Table 45: 
Table 45

Trusted-Not Using WWWDOT Framework

\begin{tabular}{lcc}
\hline & Interviewee & Group \\
\hline What about the WWWDOT Framework that we went over & 7 & B \\
at the beginning of the class? 'It was very quick, and I & \\
really didn't have time to process it. So, like a rubric, like a & \\
checklist, just so that people can have something to look & \\
back on. Like you can actually look on the checklist. It & \\
would say, does the website have credible authors and then \\
you would look for that or is it accessible, easily accessible \\
and then you would look for that. Kind of like what the \\
survey was asking, but something to look back on." \\
Did you use the WWWDOT Framework that we talked \\
about at the beginning of the class? Like the who, why, \\
when, etc.? \\
'No, I didn't use the WWW Framework." \\
Why didn't you use it? \\
"Honesty, I am kind of lazy and I don't like to read that's \\
why." \\
OK so you think it should be more than just teaching the \\
WWWDOT Framework? 'Yes, definitely, I think it should \\
be like a class or a workshop."
\end{tabular}

Interviewee \# 7 expected to have a hardcopy checklist of the WWWDOT

Framework and felt that the explanation was too quick to be processed. Interviewee \# 12

did not use the WWWDOT Framework because of being lazy and not being fond of

reading. Interviewee \# 12 also suggested that a class, or a workshop be taught instead of

just a strategy. This suggests that some prospective teachers could benefit from a

workshop, or a class solely dedicated to teaching web evaluation. The last factor

mentioned by a member from Group B was related to not having any experience

evaluating websites. Table 46 below contains this quote: 
Table 46

Trusted-No Experience Evaluating Websites

\begin{tabular}{lcc}
\hline & Interviewee & Group \\
\hline "It was actually interesting to do that because I don't really & 7 & B \\
go to the computer to evaluate websites and was able to find & \\
information. So, to understand that some of the information & \\
could be untrue or just made up information, it's interesting. & \\
I was also a little bit overwhelmed because I didn't really & \\
have any background information or strategies or methods & \\
of how to evaluate a website." & & \\
\hline
\end{tabular}

Based on the quote above, it seems that not having prior experience/knowledge may lead some people to trust hoax websites. Interviewee \# 7 found the process of evaluating websites as interesting since there was no experience/knowledge on it. Aside from web evaluation strategies mentioned, the other major theme within this category were the epistemic beliefs.

Epistemic Beliefs. As for the epistemic beliefs theme, interviewees from both groups that trusted both hoax websites possessed the following sub-themes:

1. Post-Truth Bias (4/4)

2. Subjective View of Truth (4/4)

3. Feeling-Based (3/4)

4. Empirical View of Knowledge (3/4)

5. Trusting (3/4)

6. Being Open-Minded and Aware of Own Bias (2/4)

7. Political-Based (2/4)

All Interviewees from both groups mentioned statements related to post-truth bias and possessed a subjective view of truth. For the purpose of this paper, post-truth bias is defined as the tendency of trusting information that is not true (e.g. hoax websites, fake 
news, etc.) simply because it aligns with core values, beliefs, feelings, upbringing etc.

without any regard to facts and evidence that may be against it. This term was created for this paper given the tendency of some prospective teachers to trust websites simply because they believed in the content due to it aligning with their core values, beliefs, feelings, upbringing, etc.

Three out of four relied heavily on their feelings and intuition, had an empirical view of knowledge (based on experiences) and considered themselves trusting individuals. One from each group mentioned the importance of being open-minded and aware of their own bias as well as their political-based epistemic beliefs. Table 47 contains quotes for the first sub-theme of post-truth bias:

Table 47

Trusted-Post-Truth Bias

\begin{tabular}{l}
\hline \\
"Since I was so adamant about environmental issues and \\
things like that, then the ones about the octopus and things, I \\
definitely felt it was more true to me, necessarily maybe not \\
to other people, but to me it felt like it was the right thing." \\
"If I knew like background information from things in the \\
past, like I would agree with it more. I would be more prone \\
to disregard the information that I didn't already know." \\
'I think, the things that I previously have believed, \\
especially concerning like my political stance or intuition, \\
those things I automatically think they're more credible, but \\
which is not always necessary true. But I feel like that's just \\
the way a lot of people are these days, like they don't \\
necessarily take the time to go research things out because if \\
it's against their views and then a lot of people don't want to \\
believe that it's true." \\
"If you have a certain affinity for certain situations, it \\
doesn't matter how much information or facts that that \\
person puts on that site to back up what they are saying. If \\
you personally do not believe it, seeing that information is \\
not going to make you change your mind."
\end{tabular}


"What makes it true for me, however, is honestly, is about how I feel. It's not about what I see, what I know or what can back it up."

"If you feel like something is true already. Like for example,

if you are you know made a bet with a friend about a question and then you look it up on the Internet and then what you're saying is what the Internet is saying, you can automatically say, you see.. I was right, the content is true." "If you already know something for so long and then it contradicts of what is posted on the website, you're more than likely you're going to be like, no this is not credible and then try to find other sources that might be similar to what you were already thinking."

"I think my feelings do affect it (trusting content on a website) because how do I say it? For example, if I feel that Halloween is bad and I was taught that it was bad if I visit a website that says good things about it, then I would not believe in it just because it's on a website."

The quotes above show that there seems to be a tendency among some individuals to trust content, if the websites do not contradict with their preconceived beliefs. In other words, if the information on the websites aligned with prior beliefs, upbringing, or core values, then people tended to trust it. Being passionate about environmental issues (Interviewee \# 3), or having certain affinities (Interviewee \# 4), finding other sources that match your thinking (Interviewee \# 7), and even upbringing (Interviewee \# 12) influenced these interviewees' decision to trust the content on the hoax websites. Post-truth bias should definitively be researched further since all the interviewees in this group expressed statements related to it.

The second sub-theme was about having a subjective view of truth. All the interviewees that trusted both hoax websites had some sort of subjective view of truth 
based on the idea that multiple truths may exists, or that truth could be based on opinions.

These subjective view of truth quotes can be seen in Table 48 below:

Table 48

Trusted-Subjective View of Truth

"I guess truth is really what is credible to me."

Interviewee

Group

"What makes it true for me, however, is honestly, is about
how I feel. It's not about what I see, what I know or what

3

A

4

A

can back it up. It's about how I feel like deep down inside, like myself, my nature of knowledge."

"Like something could be true to you and not to the other person, like religion for example. Not sure if that has to do with websites."

"If it's like a study about humanity or race, I feel like opinions can make something true."

What makes something true for you? "Reading it or seeing it or experiencing it or being told sometimes."

Based on the quotes above there is a clear message that all of them had this idea that multiple truths may exists. Truth was described, as what is personally credible (Interviewee \# 3), as being deep down inside and not based on any evidence, but personal feelings (Interviewee \# 4), as being true to one person and not to another (Interviewee \# 7), and even if someone simply tells you (Interviewee \# 12). All of these express an idea of thinking of truth as subjective. Having a subjective view of truth might explain why these individuals trusted the hoax websites.

The third sub-theme was based on the epistemic beliefs of feelings and intuition. Three of the four individuals expressed statements related to feelings. Table 49 below contains quotes on this topic: 
Table 49

Trusted-Feeling-Based

\begin{tabular}{lcc}
\hline & Interviewee & Group \\
\hline "I tended to trust it because I didn't necessarily have anything & 3 & A \\
to back up why it would not be credible. It just really depended & \\
on how the information made me feel." & \\
What made you trust the Tree Octopus website? & \\
"I guess how I was looking at it and how I felt about the & A \\
subject because in high school, I was really like into & \\
environmental things. So, like things like that really got to me. \\
So, my feelings started really high and so I was more into the \\
content, I guess." \\
"What makes it true for me, however, is honestly, is about how \\
I feel. It's not about what I see, what I know or what can back it \\
up. It's about how I feel like deep down inside, like myself, my \\
nature of knowledge." \\
'I think my feelings do affect it because how do I say it? For \\
example, if I feel that Halloween is bad, and I was taught that it \\
was bad, if I visit a website that says good things about it then I \\
would not believe in it just because it's on a website." \\
\hline
\end{tabular}

It is evident that for the three individuals above, feelings played a key role in their decision to trust the website. These individuals felt that the content was true solely based on whether their feelings ran high regarding the topic (Interviewee \# 3), or how the information made them feel deep inside (Interviewee \# 4). In addition, some let their feelings determine whether something was bad (not trusted), or conversely trusted (Interviewee \# 12). The fourth sub-theme was the empirical view of knowledge. Three of the four individuals shared this view, which was based on the idea that experiences are what make up knowledge. Please see Table 50 below, which contains empirical view of knowledge quotes: 
Table 50

Trusted-Empirical View of Knowledge

\begin{tabular}{lcc}
\hline & Interviewee & Group \\
\hline "The nature of our knowledge really comes from our & 3 & A \\
experiences and teachers experiences and it's just like a & \\
domino effect. So, our teachers learn from their teachers, who & \\
learn from their teachers. So, it really depends on our & \\
experience, I guess." & B \\
I think experiences is a big nature of knowledge. I think & 7 \\
depending on where you've been and what you know and who & \\
you hang out with, really determines how much knowledge you \\
have and of course also other sources like books and you know \\
getting an education and reading information you may not \\
know. But, I think the biggest part of the nature of knowledge \\
is experience." \\
"Something is true to me, if I've experienced it, if I've seen it \\
happen." \\
"I think knowledge comes from studying and reading. \\
Knowledge can also come from others and experiences."
\end{tabular}

The three individuals above expressed their view of knowledge being based on experiences. The first one explains that it is about experiences being passed down (Interviewee \# 3), the second one states that if something has been experienced, it is true (Interviewee \# 7), and finally that knowledge can comes from experiences (Interviewee \# 12). Since basing knowledge mostly on experiences can lead a person to believe things that are not true, it is possible that this empirical view of knowledge led a few of them to trust hoax websites. The fifth sub-theme was having a trusting trait. Three of the four individuals expressed this trusting trait in Table 51: 
Table 51

Trusted-Trusting

\begin{tabular}{lcc}
\hline "I didn't think I would get played I just trusted what I was & Interviewee & Group \\
seeing I guess" & A \\
"I think most of the time and students like myself, if I just & 7 & B \\
don't know something, I just look it up on the Internet and & \\
whatever information it gives me I usually just trust it right & \\
away." & B \\
"It seemed as though it was correct when I read through some & \\
of them. I don't know I have this thing of websites being & \\
honest, too." & \\
So, you're a trusting person? "Yes, so for like people tell me \\
about wiki that it's not good because people could actually \\
write in it, but like I feel like with those types of websites \\
people... everybody just can't put in their opinions."
\end{tabular}

The quotes above state the opposite of being skeptical. The first quote explains that the website was trusted because there was no thought of the possibility of being played (Interviewee \# 4). The second quote expresses a complete trust to whatever information is found on the internet especially if they don't know something (Interviewee \# 7) and the last individual simply admits to being trusting and the belief that websites are honest in general (Interviewee \# 12). Sub-themes six and seven were composed of a single interviewee from each group. These sub-themes were being open minded and aware of their own bias and having a political-based epistemic belief. Being open-minded was stated by two of the four individuals from the trusted hoaxes category, which can be seen in Table 52: 
Table 52

Trusted-Being Open-Minded and Aware of Own Bias

\begin{tabular}{|c|c|c|}
\hline & Interviewee & Group \\
\hline $\begin{array}{l}\text { 'If it's (website) against my prior knowledge or my views on it } \\
\text { then it kind of shows me that the world isn't all like a tunnel } \\
\text { vision like path. It allows me to be more open minded about } \\
\text { different topics especially whichever I was researching it } \\
\text { allows me to be accepting of not just my own beliefs, but it } \\
\text { helps me to be more accepting of other people and their } \\
\text { beliefs." }\end{array}$ & 3 & $\mathrm{~A}$ \\
\hline $\begin{array}{l}\text { OK so what about when the evidence or facts do not align with } \\
\text { your beliefs? 'I think then I would probably have to do further } \\
\text { research on the information because I'm a pretty open-minded } \\
\text { person. So, I feel like if more than three, four research give me } \\
\text { the same answer, I probably would then you know would } \\
\text { switch my opinion. I'm not one to really just stay on what I } \\
\text { believe in if there's proven facts that other things have been } \\
\text { correct." }\end{array}$ & 7 & B \\
\hline
\end{tabular}

Both individuals above stressed the importance of being open-minded.

Interviewee \# 3 expressed that if a website goes against a view, it demonstrates that the world is not a tunnel vision path and facilitates the acceptance of other people's beliefs. Interviewee \# 7 admitted to being open-minded and to the possibility of changing his/her mind based on consistent research. Since all four individuals in this category made statements concerning post-truth bias, it is important to note that at least two of the individuals mentioned the idea of being aware of your own bias and trying to be open-minded. New models of web evaluation strategies should contain information on post-truth bias and being aware of your own bias. The seventh sub-theme was having a political-based epistemic belief. Table 53 contains quotes related to this sub-theme: 
Table 53

Trusted-Political-Based

\begin{tabular}{lcc}
\hline & Interviewee & Group \\
\hline "I feel like we live based off how politics are formed. So, with & 4 & A \\
that being said like for instance let's use Obamacare, for & \\
example, like most people I feel like Obamacare made more & \\
people want to actually get insurance, but even if they did not & \\
use Obamacare, but it pushed the urge for that. So, basically & B \\
things dealing with politics move other things." & 7 \\
"I think that scientific conclusions are shaped by politics & \\
because at the end of the day, whatever you put has to have like & \\
some type of background and I think that's politics. It's mostly \\
opinions of other people, but it's also based on some type of \\
study, which would make it scientific. If you have years and \\
years of study and then you make a conclusion of it, I feel like \\
the politics of it, which would be more beneficial, what people \\
would want in the end, would be what would be concluded. \\
Even if it may not have been the conclusion of the study." \\
"I think the same reason why I believe scientific conclusions \\
are shaped by politics. I mean if you say something is true most \\
of the time it's backed up to something that is beneficial for it \\
to be true like uh which would make it political."
\end{tabular}

The two individuals above mentioned the importance of politics and truth. Interviewees 4 and 7 both agreed with statements such as, truth being political, or scientific conclusions shaped by politics. Interviewee \# 4 expressed that political things can move other things and that life is based on how politics are formed. Interviewee \# 7 explained that politics are related to beneficial outcomes that people want. It is interesting that political-based epistemic beliefs are not just in this category but are also present in other levels of trust categories. Figure 56 below summarizes the seven sub-themes mentioned that both groups displayed and shows a few sub-themes that were indicative of Group A, or Group B. 

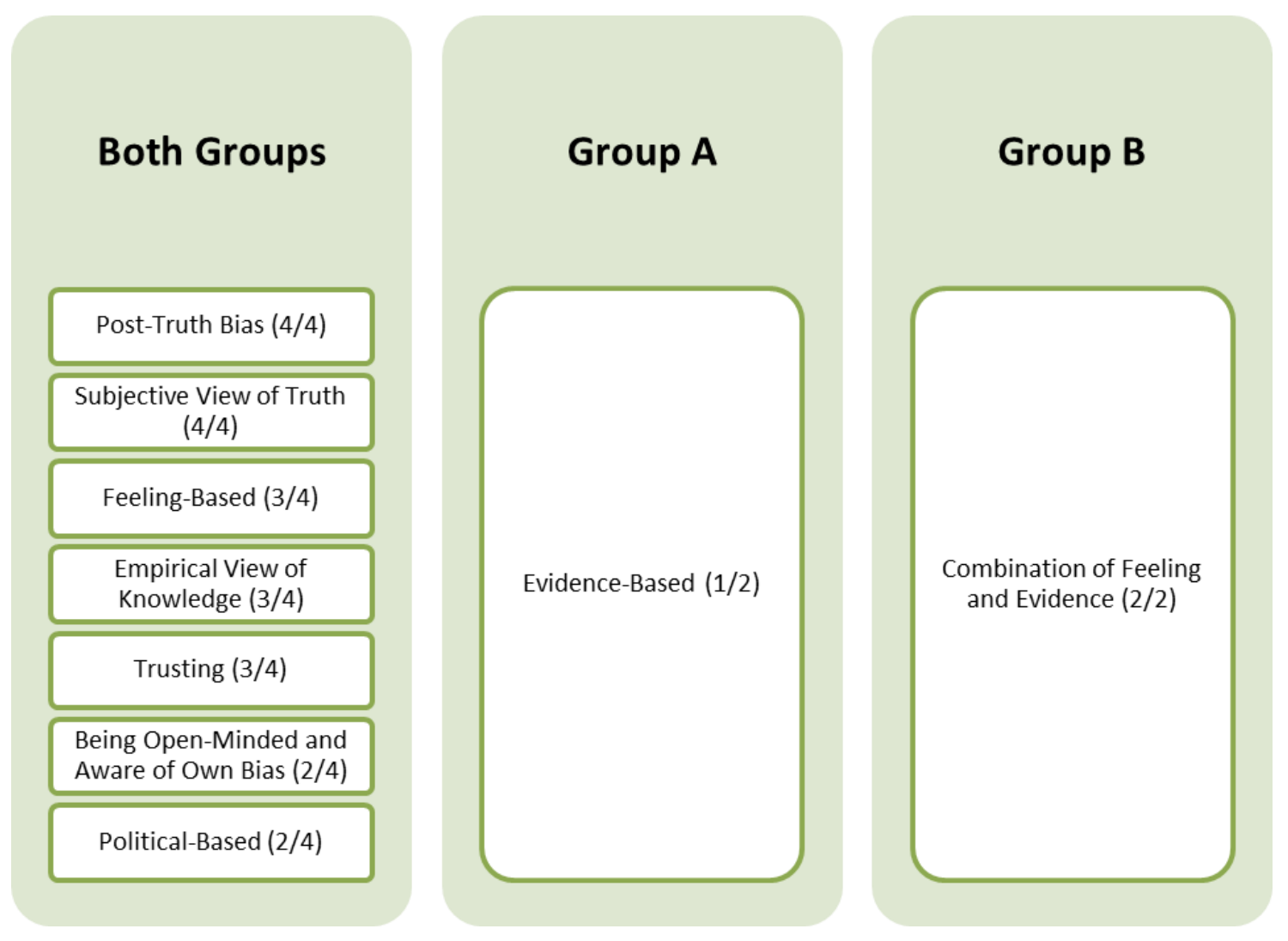

Figure 56. Epistemic Beliefs for the Trusted Hoax Websites Category.

The following are the sub-themes mentioned by only one of the groups:

1. Group A: Evidence-Based (1/2)

2. Group B: Combination of Feeling and Evidence (2/2)

One of the interviewees from Group A stated to have evidence-based epistemic beliefs.

Please see Interviewee \# 4's statements regarding evidence in Table 54: 
Table 54

Trusted-Evidence-Based

\begin{tabular}{|c|c|c|}
\hline & Interviewee & Group \\
\hline $\begin{array}{l}\text { "I believe that if you cannot find anything to back up what } \\
\text { you're saying, then it may not have too much validity to it. } \\
\text { Reason being like for instance let's say technology enhances } \\
\text { learning that's just like a thought, but if you can't find anything } \\
\text { that backs it up unless I mean if you are doing a research, how } \\
\text { true can it be?" }\end{array}$ & 4 & $\mathrm{~A}$ \\
\hline $\begin{array}{l}\text { "Truth means to me basically, I feel like if you cannot prove it, } \\
\text { back it up or have some evidence, that proves your statement, } \\
\text { then it's not true. It means nothing. It's basically your word } \\
\text { against the next person's word." }\end{array}$ & & \\
\hline
\end{tabular}

Interviewee \# 4 was the only individual from the trusted hoaxes category that expressed an evidence-based epistemic belief statement. Although as noted earlier in the third sub-theme (feeling-based epistemic belief), this statement was contradicted when the following confession was made later in the interview:

What makes it true for me, however, is honestly, is about how I feel. It's not about what I see, what I know or what can back it up. It's about how I feel like deep down inside, like myself, my nature of knowledge. (Interviewee \# 4, Group A)

It may be that the first evidence-based statement was made based on what is considered "correct" but once rapport was established, there was an honest explanation of how this individual truly thought about what makes something true, which is based on feelings. Both interviewees from Group B stated that they use a combination of feeling and evidence depending on the situation. Table 55 below contains quotes on this sub-theme: 
Table 55

Trusted-Combination of Feeling and Evidence

\begin{tabular}{lcc}
\hline & Interviewee & Group \\
\hline "Like something could be true to you and not to the other & B \\
person, like religion for example. Not sure if that has to do with & \\
websites." & \\
"I think I evaluate things using both a little bit of feelings and \\
intuition and obviously facts and evidence have to be there, \\
too. But it depends on the content, depends on the subject. So, \\
if it's like a scientific study you are going to go with facts, \\
evidence, but if it's like a study about humanity or race, I feel \\
like opinions can make something true." \\
Do you evaluate things using feelings, intuition or do you base \\
your evaluations on fact and evidence? \\
"I think it depends on what it is that I am evaluating."
\end{tabular}

Interviewee \# 7 specifically mentioned that feelings were used for humanities/religious topics and evidence for scientific, or academic purposes. Interviewee \# 12 simply stated that both evidence and feelings were used depending on what was being evaluated. The next trust level category constitutes the individuals that trusted one hoax website, but not the other.

\section{Trusted One Hoax Website but Not the Other Category}

Four interviewees $(2,6,9, \& 13)$ trusted one hoax website, but not the other. Compared to the trusted hoax websites category, which only had five sub-themes, this category contains twelve. This demonstrates that this category of interviewees had a bit more experience compared to the trusted hoax websites category. Again, the main themes were Web Evaluation Strategies and Epistemic Beliefs. Each of these themes had a variety of sub-themes. 
Web Evaluation Strategies. The following is a list of the thirteen sub-themes within the web evaluation strategies theme mentioned in this category by individuals from both Group A and Group B:

1. Aesthetic Appeal (4/4)

2. Not Spending Sufficient Time to Read and Evaluate (3/4)

3. Complex Terminology (3/4)

4. Knowing the Definition of a Hoax Website (3/4)

5. Poor Design/Layout (3/4)

6. Citations (3/4)

7. Prior Knowledge (3/4)

8. Authorship (2/4)

9. Lateral Reading (2/4)

10. Linear Reading $(2 / 4)$

11. Ease of Use (2/4)

12. Not letting Design Affect Decision to Trust Content (2/4)

13. Making Sense (2/4)

All four interviewees stated that the aesthetic appeal was a key factor in evaluating the websites. Below are a few quotes in Table 56 that illustrate this: 
Table 56

Trusted One-Aesthetic Appeal

Interviewee Group

"The features that I evaluated were the images, content, the wording, the way that the word structures are and the colors."

"I mostly evaluated the design of the website."

9

A

"I think what led me to accept or disregard the information posted on the website was the design."

"I was just focused on the design, so I didn't really read the information."

"So, I would trust it by the way it looks. I don't know anything about it, I would think that's trustable."

How did you evaluate the websites?

"The look and if it's like clear and to the point. So, then first is the look and second if it's clear. And lastly... oh and pictures, too. I guess it's visual, too. So, the pictures, I guess."

"Honestly, I would say it was whatever it's appealing."

Interviewees mentioned images, colors (Interviewee \# 2), evaluating based solely on design (Interviewee \# 9), trusting based on looks (Interviewee \# $6 \& 13$ ), pictures and whatever is appealing (Interviewee \# 13). Based on the previous category (trusted hoax websites) and this one, aesthetic appeal is the number one feature that most people base their evaluations on. The second sub-theme which was also present in the trusted hoax websites category, was not spending sufficient time to read and evaluate. Three of the four interviewees mentioned a statement related to this, as is evident from the quotes in Table 57: 
Table 57

Trusted One-Not Spending Sufficient Time to Read and Evaluate

\begin{tabular}{|c|c|c|}
\hline & Interviewee & Group \\
\hline $\begin{array}{l}\text { "I just didn't have enough time to research deeply into all of } \\
\text { the websites." }\end{array}$ & 2 & $\bar{A}$ \\
\hline \multicolumn{3}{|l|}{$\begin{array}{l}\text { "What made me accept was that I did not have enough time to } \\
\text { actually go in depth and research and for the sake of time I just } \\
\text { pressed accept." }\end{array}$} \\
\hline "Honestly, I didn't really read the information." & 9 & A \\
\hline \multicolumn{3}{|l|}{$\begin{array}{l}\text { "No, I did not notice it (if any website was a hoax). I was just } \\
\text { focused on the design, so I didn't really read the information." }\end{array}$} \\
\hline $\begin{array}{l}\text { "I feel like I needed more time to read what it said and not base } \\
\text { it on the length, subheading it had or pictures." }\end{array}$ & 6 & $\mathrm{~B}$ \\
\hline
\end{tabular}

Interviewee \# 2 expressed not having enough time to do deep research.

Interviewee \# 9 admitted to not reading the information and being focused more on the design and finally Interviewee \# 6 stated the need for more time to read. All three stated that they did not spend sufficient time to read and evaluate the websites. Reading and spending sufficient time to evaluate websites seems like a principal factor in determining whether a website is a hoax, or not since most interviewees in the trusted hoax websites category and in this one did not spend sufficient time to read and evaluate. It seems like in these cases the less time spent to read and evaluate, the more the website is trusted. More research should be done in this area. The third sub-theme was complex terminology.

Three out of four interviewees in this category stated that complex terminology made them trust the hoax websites. Below is Table 58 with quotes that mention how complex words, or how things are said influenced their decision: 
Table 58

Trusted One-Complex Terminology

\begin{tabular}{l}
\hline \\
"I felt like they used too big words to just look like they were \\
smarter and they were able to explain it. But they might've \\
been false and people just go through it because they don't \\
want to do the research. They are just lazy and they find it \\
true." \\
"Sometimes people just use big words to just make you think it \\
is true rather than sometimes just the simplest words will be the \\
truth." \\
What made you believe that the content on the dhmo.org was \\
true? \\
"The vocabulary. If I don't know a word and it looks fancy I'll \\
believe it." \\
"Mostly vocabulary words like big words that would describe \\
something." \\
What about the tree octopus one? 'The octopus one I did not \\
think it was a hoax. You know telling me now I look back on it \\
and you're like oh I could see why, but for a moment the things \\
they were saying about it, to me it sounded believable. I don't \\
know. I just, I actually did believe it. I would actually talk \\
about that to someone else."
\end{tabular}

"Big words" made Interviewee \# 2 trust the DHMO.org hoax website.

Interviewee \# 6 also trusted the DHMO.org website due to the "vocabulary words," which were described as "fancy." Interviewee \# 13 did not trust the DHMO.org website however the Tree Octopus hoax website was trusted due to the way things were said, which made it sound believable. The use of complex words made a few of the individuals trust hoax websites. The fourth and fifth sub-theme were knowing the definition of a hoax website and poor design. Three of the four individuals in this category knew the 
definition of a hoax website and stated that the poor design made them not trust the hoax

websites. Below are quotes in Table 59 on these two sub-themes:

Table 59

Trusted One-Knowing the Definition of a Hoax Website and Poor Design/Layout

\section{Knowing the Definition of a Hoax Website}

"A hoax website is a false website or a website that somebody just puts out there and then gain whatever they're trying to gain through it and making people fall for whatever they believe because they know the people are vulnerable and they would believe anything that's on the internet."

"A hoax website is a website with fake information."

"A hoax website for me is definitely something that doesn't look trustworthy, but they are also websites that look credible. So, I think it depends for me because I can't tell which is which sometimes you just have to know not to believe everything you read on the Internet. Like the website on the tree octopus I would have totally talked about it during a dinner conversation thinking that it was true."

\section{Poor Design/Layout}

"I would then look at the content and how it was displayed and if it made my eyes kind of everywhere, I wouldn't give it a high rating."

What red flags did you noticed? "Low-quality (images). If it was a professional who was trying to make a purpose point, they will find the best images that they could have to have high definition and prove their point."

"I didn't trust the information on the DHMO one because I think I have seen that website before, or maybe the information also I didn't like the design."

"The DHMO.org as soon as I saw it, I knew it was fake because I have seen others that are fake, and they look the same way and you just know that, just by the way, just by looking at it. The second you see it, looks fuzzy and it doesn't look trustworthy."
Interviewee

2

Group

A

9

A

13

B

2

A

9

A

13

B 
Interviewees \# 2, 9 and 13 knew the definition of a hoax website. A hoax website was described as false, fake and not trustworthy. Poor Design was also mentioned by the same interviewees. Interviewee \# 2 explained that if a website had low quality images, then it would not be trusted and that a low rating was given to websites that were poorly displayed. Interviewees \# 9 and 13 expressed that they did not trust the DHMO.org hoax website due to the poor design, which was not liked and was "fuzzy" looking. The presence of citations was sub-theme six. This sub-theme was also mentioned by three out of the four interviewees. Please see Table 60 below:

Table 60

Trusted One-Citations

\begin{tabular}{|c|c|c|}
\hline & Interviewee & Group \\
\hline $\begin{array}{l}\text { "What makes information credible for me is like if the } \\
\text { information is cited." }\end{array}$ & 9 & A \\
\hline $\begin{array}{l}\text { "Also looking for like citations at the bottom that they got it } \\
\text { from a book, or someone like a doctor, or whatever the topic is } \\
\text { about." }\end{array}$ & 6 & B \\
\hline $\begin{array}{l}\text { "Making sure that the website is backed up by the resources, or } \\
\text { the bibliography and it shows the sources where they got their } \\
\text { information because you just don't come up with everything. } \\
\text { You have to have sources for that stuff.. for what you say." }\end{array}$ & 13 & B \\
\hline
\end{tabular}

Interviewees \# 9, 6 and 13 explained that for a website to be trusted, it needed to have citations. Interviewee \# 9 stated that information needed to be cited and looking for citations at the bottom of the website was mentioned by Interview \# 6. Interviewee \# 13 stated that the website needed to be backed up by a bibliography. It is interesting to note that there are hoax websites that contain bogus citations. For example, the Tree Octopus hoax website has citations on their media webpage. In addition, the DHMO.org website contains a webpage on research reports that highlight fake studies. Sub-theme seven was 
prior knowledge. The quotes in Table 61 below demonstrate how prior knowledge

influenced the decision of three out of four interviewees to trust, or not the content on a

website:

Table 61

Trusted One-Prior Knowledge

'I think the more you don't know about a subject, the more you believe that information is true and the more you know the Interviewee Group less likely you will be convinced that it's true. The more you know the less likely you will be convinced that it's true."

What made you trust one website compared to the other? You

6 B did not trust the tree octopus website, but you did trust the dhmo.org website Why?

"Prior knowledge"

Why prior knowledge?

"Because I know those (tree octopus) do not exist, but at the same time I don't know about the other website. So, since I don't know about the topic, I would read it and think oh OK that's what it means without knowing if it's right or wrong. So, I would trust it by the way it looks. I don't know anything about it, I would think that's trustable, but the octopus one I know they are in the water only, so I know that's not true." (Laughs)

Did you notice if any websites were a hoax?

"Yes, the octopus one because of prior knowledge of it."

"Mostly prior knowledge and common sense affects what I think and what I see on a website."

What led you to accept or disregard the information posted on the websites?

"I guess whenever I read something there's some things I already knew so when I read something I was like oh yeah that sounds about right kind of thing."

Interviewee \# 9 and 6 explained that having no prior knowledge made them trust one of the hoax websites. The idea mentioned is that the less a person knows about a 
subject the more they will trust and the more they know the less they will trust. This concept is also explained by Interviewee \# 6, who trusted the DHMO.org website because there was no prior knowledge on it but did not trust the Tree Octopus website because of having prior knowledge. Interviewee \# 13 said that the content on the websites was accepted or disregarded depending on whether there was some knowledge on the information. If things sounded right based on prior knowledge, then it would be accepted. Sub-themes eight through eleven involve, an interviewee from each group, for a total of two out of four. These sub-themes include authorship, lateral reading, linear reading and ease of use, which can be seen in Table 62: 
Table 62

Trusted One-Authorship, Lateral Reading, Linear Reading and Ease of Use

\begin{tabular}{|c|c|c|}
\hline & Interviewee & Group \\
\hline $\begin{array}{l}\text { Authorship } \\
\text { "What made me believe it was true was sometimes the } \\
\text { expertise that were inside of the website." }\end{array}$ & 2 & $\mathrm{~A}$ \\
\hline $\begin{array}{l}\text { "Looking for the authors and the people that wrote the website } \\
\text { or edited the website." }\end{array}$ & 6 & B \\
\hline Lateral Reading & & \\
\hline $\begin{array}{l}\text { "I just researched. Like vocabulary words in Google and try to } \\
\text { click on a different website to compare to that one." }\end{array}$ & 2 & A \\
\hline $\begin{array}{l}\text { "Some sources I used was another website. The other tab, the } \\
\text { Internet itself to find other professionals." }\end{array}$ & & \\
\hline $\begin{array}{l}\text { "I make sure I don't just look at one website and go to different } \\
\text { ones." }\end{array}$ & 13 & B \\
\hline Linear Reading & & \\
\hline $\begin{array}{l}\text { "First I don't remember maybe I looked at the title and then } \\
\text { second I looked at the design and third I scanned the } \\
\text { information." What strategies did you use? "I just used like } \\
\text { maybe the overall feel of the website." What tools did you use? } \\
\text { "No, I didn't use anything." }\end{array}$ & 9 & $\mathrm{~A}$ \\
\hline $\begin{array}{l}\text { "First, I saw the whole image on the website, the illustrations } \\
\text { and then the links that it had I just went through it to see how it } \\
\text { was organized." Did you use any strategies? "I don't know of } \\
\text { any strategies." }\end{array}$ & 6 & B \\
\hline $\begin{array}{l}\text { Ease of Use } \\
\text { "I liked how it was structured like it gave me the option that if I } \\
\text { clicked on something I could return back to the homepage not } \\
\text { clicking back, back, back or retracing everything that I went } \\
\text { through I could go through it and navigate it." }\end{array}$ & 2 & A \\
\hline $\begin{array}{l}\text { "Well I look for that the website is definitely not } \\
\text { overwhelming. I look for if that it doesn't go on too much of } \\
\text { clicking on just so many different things." }\end{array}$ & 13 & B \\
\hline
\end{tabular}

As seen from the table above, authorship was important for two out of the four interviewees in this category. Interviewee \# 2 and 6 stated that they looked for the 
expertise inside the website and the author(s) who wrote the website. Interviewees \# 2

and 13 made statements about searching words in Google and visiting other websites, which is lateral reading. Interviewees \# 9 and 6 displayed linear reading since they stayed within the websites. Interviewees \# 2 and 13 also mentioned that for them it was important to not feel overwhelmed and that the websites were easy to navigate. It seems that if the website was easy to navigate then it would be trusted. Sub-theme twelve also included an interviewee from each group, for a total of two out of four. This sub-theme was not letting design affect decision to trust content which can be seen in Table 63:

Table 63

Trusted One-Not Letting Design Affect Decision to Trust Content

\begin{tabular}{lcc}
\hline "My favorite website was actually the octopus one because of & Interviewee & Group \\
the colors and how it had a lot of facts and it tried to confuse & A \\
you with the facts, but I liked how it was lengthy and you & \\
didn't have to go through many websites to find all of the & \\
information that you needed for the project let's say if you & \\
needed to do it on the octopus. I just wish it were true." & B \\
"A hoax website for me is definitely something that doesn't & \\
look trustworthy, but they are also websites that look credible, & \\
so I think it depends for me because I can't tell which is which & \\
sometimes you just have to know not to believe everything you & \\
read on the Internet. Like the website on the tree octopus I & \\
would have totally talked about it during a dinner conversation & \\
thinking that it was true." & \\
\hline
\end{tabular}

Not letting an aesthetically appealing design influence decision to trust, or not trust was the other concept mentioned by Interviewees \# 2 and 13. Interviewee \# 2 referred to enjoying the Tree Octopus website due to its colors but that did not influence the decision to trust it since ultimately Interviewee \# 2 did not trust it. Interviewee \# 13 said that in general a hoax website may not look trustworthy, but it can also look credible 
and that people should just not believe everything that is on the internet. Finally, Subtheme thirteen include statements related to the website content making sense. Please see Table 64 below:

Table 64

Trusted One-Making Sense

What makes something true for you? "If it makes sense." Interviewee Group

"Why would you accept something is true? Just believing... 6 A just if it makes sense in my mind, I'll believe it."

Interviewees \# 9 and 6 explained through their statements that they would trust a website if the content made sense. Interviewee \# 9 trusted the Tree Octopus Website and Interviewee \# 6 trusted the DHMO.org website. One of the reasons given by these interviewees is that they trusted these websites because the content made sense. There were a few sub-themes that were only present in Group A, or Group B. These were the following:

Group A:

1. Experience Evaluating Websites (1/2)

Group B:

1. Useful $(2 / 2)$

2. WWWDOT Framework (2/2)

3. Not Knowing the Definition of a Hoax Websites (1/2)

4. Ads/Asking for Money (1/2)

These themes can be seen in Figure 57 below: 

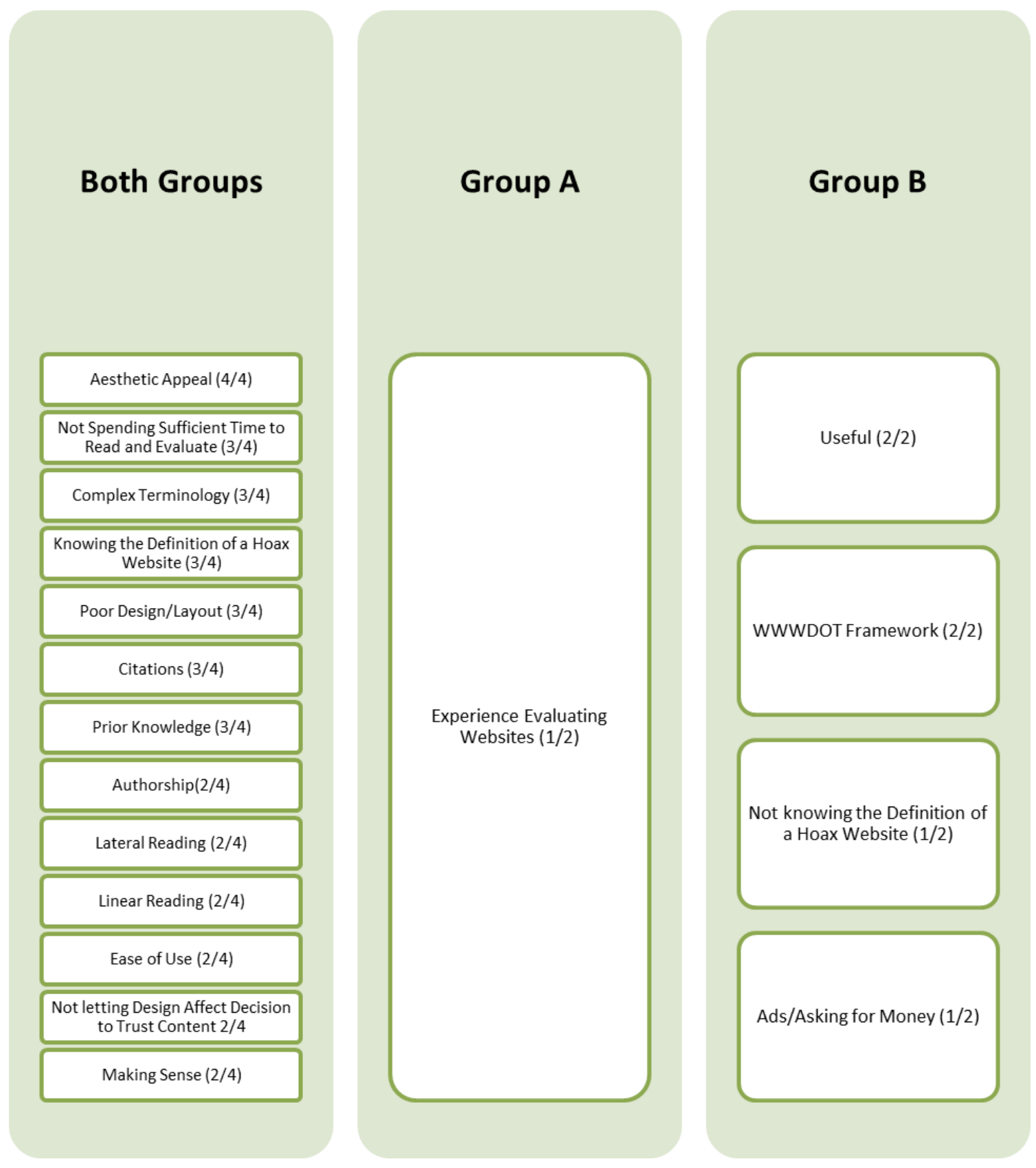

Figure 57. Web Evaluation Strategies for the Trusted One but Not the Other Category.

Interviewee \# 2 stated that she had experience evaluating websites through past classes taken where projects included having to evaluate websites. Group B had four 
sub-themes, which were WWWDOT Framework, useful, not knowing the definition of a hoax website and the presence of ads/asking for money. Table 65 below contains the statement made by interviewee \# 2:

Table 65

Trusted One-Experience Evaluating Websites

"Strategies that I have used have been based on my past classes Interviewee Group and all the websites I've actually done research on. Although some of them did have.org and the other ones I see those are educational websites I didn't really trust them because I found some information before they have not been honest and I've backed out backed it up with details so I just used past websites for my projects to evaluate."

Both Interviewees from Group B mentioned evaluating the websites based on whether they were useful. Interviewee \# 13 from Group B mentioned using the WWWDOT Framework. However, Interviewee \# 6 did not mention the WWWDOT Framework at all during the interview. Table 66 contains quotes related to useful and WWWDOT Framework: 
Table 66

Trusted One-Useful and WWWDOT Framework

Useful

Interviewee Group

"I would use the ones that I trust because they seem legit and if

6

B

it's useful for my class lesson, I would have my students

research on the topic."

"It depends on what I'm teaching. Definitely the water conservation one, which I did like because again it gave clear insight about everything and I would use that if that's the topic I'm talking about."

\section{WWWDOT Framework}

"I evaluated the websites by looking at who, when it was created, who created it and how it was created. That was like exactly what I looked for when I first go to a website that's exactly what I first see." Was this based on the WWWDOT framework?"Yeah"

What strategies did you use to evaluate the websites? "Well the WWW method, the framework."

What tools did you use to determine whether the information on the website was credible or not? "The WWW Framework is what I go by."

Interviewees \# 6 and 13 mentioned trusting the websites that they felt were useful. Interviewee \# 6 stated that if it is a legit and useful it would be trusted. Interviewee \# 13 trusted the credible website about water conservation and finds it useful to teach about that topic. Interviewee \# 13 also mentioned using the WWWDOT Framework. The following section includes the epistemic belief theme and the subthemes that resulted from the interviews.

Epistemic Beliefs. Below are the seven sub-themes that both Group A and Group B displayed in the epistemic beliefs theme:

1. Subjective View of Truth (4/4) 
2. Post-Truth Bias (4/4)

3. Empirical View of Knowledge (2/4)

4. Being Open-Minded and Aware of Own Bias (2/4)

5. Evidence-Based (2/4)

6. Political-Based (2/4)

All four interviewees mentioned statements related to a subjective view of truth. Table 67 below contains the statements made by the interviewees concerning the subjective view of truth sub-theme:

Table 67

Trusted One-Subjective View of Truth

"Truth means something that I researched, and I found and
whatever I think is correct."
"I feel that everybody has their own definition of the truth."
"Truth to me means something that has an answer you...
something you can prove and what mostly everyone believes."
And what is something you can prove? That's a chair.
So, something you see with your eyes? "Yes, and things like ...
sometimes books say, not limited to seeing, but believing."
"We go by the common opinion."
"The truth to me... Oh my God... (laughs). The truth to me is
whatever what is considered to be the right thing."
"What makes something true for me, I would say is something
that is backed up by any fact. Wait also by my feelings. I
realize that truth doesn't have to be just about facts it can also
be based on your beliefs."


Having a subjective view of truth is believing that truth can be based on opinions and that truth may vary from person to person. All of the above-mentioned statements express a subjective view of truth. Interviewee \# 2 admitted to being "a little bias" since if a website did not align with her beliefs, even if more research is done, the website would not be trusted. Interviewee \# 9 believes that everyone has a different definition of the term truth, which suggest a subjective view of truth. Interviewee \# 6 goes by the common opinion, or what most people believe, also by not just seeing, but by believing. Sometimes the common opinion is wrong, especially in this post-truth age were objective facts and evidence are not as influential compared to personal beliefs and feelings. Interviewee \# 13 also explains at the end, that truth could also be based on feelings and beliefs. Having a subjective view of truth was present in all of the individuals in this category. This sub-theme is a bit intertwined with the post-truth bias sub-theme. All interviewees said phrases that displayed a post-truth bias stance. Some of the quotes are repeated since they were a part of both the subjective view of truth sub-theme and the post-truth bias sub-theme. Table 68 below contains quotes that represent this sub-theme: 
Table 68

Trusted One-Post-Truth Bias

\begin{tabular}{|c|c|c|}
\hline & Interviewee & Group \\
\hline $\begin{array}{l}\text { "Truth means something that I researched, and I found and } \\
\text { whatever I think is correct. So, somebody can tell me } \\
\text { something and I won't believe it because it's not what I found." } \\
\text { "It (feelings, intuition, political stance) does affect me highly } \\
\text { because I'm raised in one way and I believe in very specific } \\
\text { ways and if a website says that this is the way I may not } \\
\text { believe it because that's not what I think is right and yes I can } \\
\text { do more research and everything, but if I and my belief I think } \\
\text { that it's correct this way, I'm not going to be using that website } \\
\text { so I'm technically a little bit biased to websites because I don't } \\
\text { believe in their ways. I'd rather believe in what I was brought } \\
\text { up to me and I've turned out fine. So, I rather be how I've } \\
\text { been." }\end{array}$ & 2 & $\mathrm{~A}$ \\
\hline $\begin{array}{l}\text { "Yeah like for me, I have never done drugs. I don't believe in it } \\
\text { so if there is a website that tells me that drugs are good, I will } \\
\text { not believe it because that is how I was raised." }\end{array}$ & & \\
\hline $\begin{array}{l}\text { "I don't usually believe a doctor that stands up on the stage and } \\
\text { says that this is the best way to cure any illness. I believe your } \\
\text { own research will conclude your information your own } \\
\text { beliefs." }\end{array}$ & & \\
\hline $\begin{array}{l}\text { "Back then Native Americans used weed to help compensate } \\
\text { any medical problem. I'm not for or against it, but that's how } \\
\text { they were brought up, so that's their belief. So, research, know } \\
\text { your stuff, be firm with yourself." }\end{array}$ & & \\
\hline $\begin{array}{l}\text { "For example, if my intuition says that it is right then I don't } \\
\text { have to evaluate it based on facts." }\end{array}$ & 9 & A \\
\hline $\begin{array}{l}\text { What makes something true for you? "We go by the common } \\
\text { opinion." }\end{array}$ & 6 & B \\
\hline $\begin{array}{l}\text { "Once you have experienced something, you feel comfortable } \\
\text { saying whether you believe it or not or what you're reading is } \\
\text { accurate or not." }\end{array}$ & & \\
\hline $\begin{array}{l}\text { "I realize that truth doesn't have to be just about facts it can } \\
\text { also be based on your beliefs." }\end{array}$ & 13 & B \\
\hline
\end{tabular}


Interviewee \# 2 explained that no matter the amount of facts/evidence for a website, if her beliefs are not aligned with the content, then the website would not be trusted. Based on the statements, it seems that if content does not align with that interviewee's beliefs, it is discarded regardless of the evidence. Interviewee \# 6 explains that truth is obtained by going with the common opinion (which is not always evidence-based or factual) and that experiencing something makes the person accept, or not accept the content. Interviewee \# 9 states that there is no need to evaluate based on facts if it is considered right based on intuition. This type of blind trust and priority given to intuition regardless of the facts, demonstrates how deep post-truth can run and how easily people can trust content based on emotions/feelings and intuition. Finally, Interviewee \# 13 stated that truth is not just based on facts but also on personal beliefs, which denotes a post-truth bias stance. Even though post-truth bias statements were present in these interviews, there were also statements related to being open-minded and aware of personal bias. Both Interviewee \# 2 and 13 explained the importance of not being biased, or at least of being aware of it. Table 69 below contains statements related to this: 
Table 69

Trusted One-Being Open-Minded and Aware of Own Bias

\begin{tabular}{l}
\hline \\
'Don't use only Wikipedia, use .org or use .edu and websites \\
that we've gone through that we know are trustworthy to show \\
them these are good websites for the research and not let them \\
just be biased to one opinion." \\
'I mostly use government or governmental websites even \\
though they are biased, but I also use .EDU websites because \\
that's usually teaching educational websites and resources that \\
I think that are true based on many websites that say the same \\
thing continuously to not be biased or not to be involved with \\
everything else." \\
'I base my evaluations on facts and evidence because even \\
though I am strong against drugs, if I see that somebody needs \\
the marijuana for medical reasons I am for it because that's \\
what it's going to help them. Not everything in the world is \\
bad, it's what we do when we use to abuse. So, if there's facts \\
to back it up and there's proven facts that support that then that \\
is what I see, it is true."
\end{tabular}

As seen above, Interviewee \# 2 stressed that even government websites can be biased and that it is important to not be biased to a single opinion and research various websites. Interviewee \# 2 demonstrates through the last statement above that even though 
drugs goes against her beliefs, being open minded can keep your own bias in check. This thought was shared by Interviewee \# 13, who stated that some websites are biased to their beliefs, that there are two sides to everything and most importantly that beliefs are not always right, therefore it is important to look beyond feelings and personal bias and review various websites. This sub-theme was interesting to find since it goes against the idea of the post-truth bias. The fourth sub-theme was having an empirical view of knowledge. Two interviewees thought that knowledge was based on experiences. Table 70 below contains the statements made by Interviewee \# 2 and 6:

Table 70

Trusted One-Empirical View of Knowledge

\begin{tabular}{lcc}
\hline "Knowledge is something that you earn while you are in school & Interviewee & Group \\
through experiences because yes there are some things that & & A \\
come to you naturally but if you don't go to school and you & & \\
don't experience it, you won't build upon the knowledge and & & \\
the more that you build upon, the more that you will learn, the & & \\
more that you will use in your life for better experiences." & 6 & B \\
"Our everyday lives. What we go through. What we learn from & 6 & \\
different experiences and things that we learn every day." & &
\end{tabular}

Interviewee \# 2 said that knowledge was obtained in school through experiences. Interviewee \# 6 also expressed an empirical view of knowledge since knowledge was described as different experiences that people go through every day. Sub-themes five and six were evidence-based and political-based epistemic beliefs. Table 71 below contains a few quotes on these epistemic beliefs: 
Table 71

Trusted One-Evidence-based and Political-Based

Evidence-Based
"What I believe credible will be facts, numbers, statistics. Not
always statistics are correct, but if I see that there's like an
even amount number ratio, then that would be credible for me.
I'm a very mathematical and analytical person, so if I see a
graph showing something based on theories and research that
have been proven like peer reviewed journals, I would think
that it is a credible website rather than just somebody just
writing out everything that they believe is right."

"Something that is true to me is based on research hard, hard research and like if there's a study being done about something and there's been many years that have been processed through that and other doctors who have tried it out and have come up with the same results then that is something true to me."

"I base my evaluations on facts and evidence because even though I am strong against drugs, if I see that somebody needs the marijuana for medical reasons I am for it because that's what it's going to help them. Not everything in the world is bad, it's what we do when we use to abuse. So, if there's facts to back it up and there's proven facts that support that then that is what I see, it is true."

"I think what makes information credible for me is making sure that there are facts. Like making sure that the website is backed up by the resources or the bibliography and it shows the sources where they got their information because you just don't come up with everything. You have to have sources for that stuff... for what you say."

\section{Political-Based}

"I think that your feelings and intuitions or political stance may persuade you to be against or for the credibility yeah."

'I don't know how to explain it that's just my belief, I think that politics is what draws the world basically we go by the common opinion."

"Because we believe facts by what we know and like I said politics is what we usually are around in our everyday lives and how we do things." 
This category had two interviewees with an evidence-based view of truth and two that had a political-based view. Clearly Interviewee \# 2 has an evidence-based view of truth. All of the quotes explain how truth and evaluations are based on facts, evidence, statistics and hard research. This concept is shared by Interviewee \# 13 which thinks that facts is what makes information credible as well as source to support it. Interviewee \# 6 and 9 agreed that politics can influence whether information is accepted, or not. What is interesting about Interviewee \# 2 is, that as seen in the post-truth sub-theme, a few of the statements previously made were giving more importance to feelings and beliefs compared to facts, or evidence and there was even an admittance of being a little biased. Specifically, Interviewee \# 2 changes her previous thoughts on the topic of drugs, which even though they go against her beliefs, if the facts and evidence support it, then she will be for it. This hints to the idea of how a person can easily change their mind depending on the situation. The next section contains sub-themes that only Group A, or Group B displayed.

Group A:

1. Feeling-Based $(2 / 2)$

2. Skeptical $(1 / 2)$

Group B:

1. Combination of Feeling and Evidence (2/2)

Both interviewees in Group A displayed feeling-based epistemic beliefs and one of the interviewees was skeptical. Two interviewees from Group B stated that they use a 
combination of feeling and evidence. Below is Figure 58 with the sub-themes for this category:
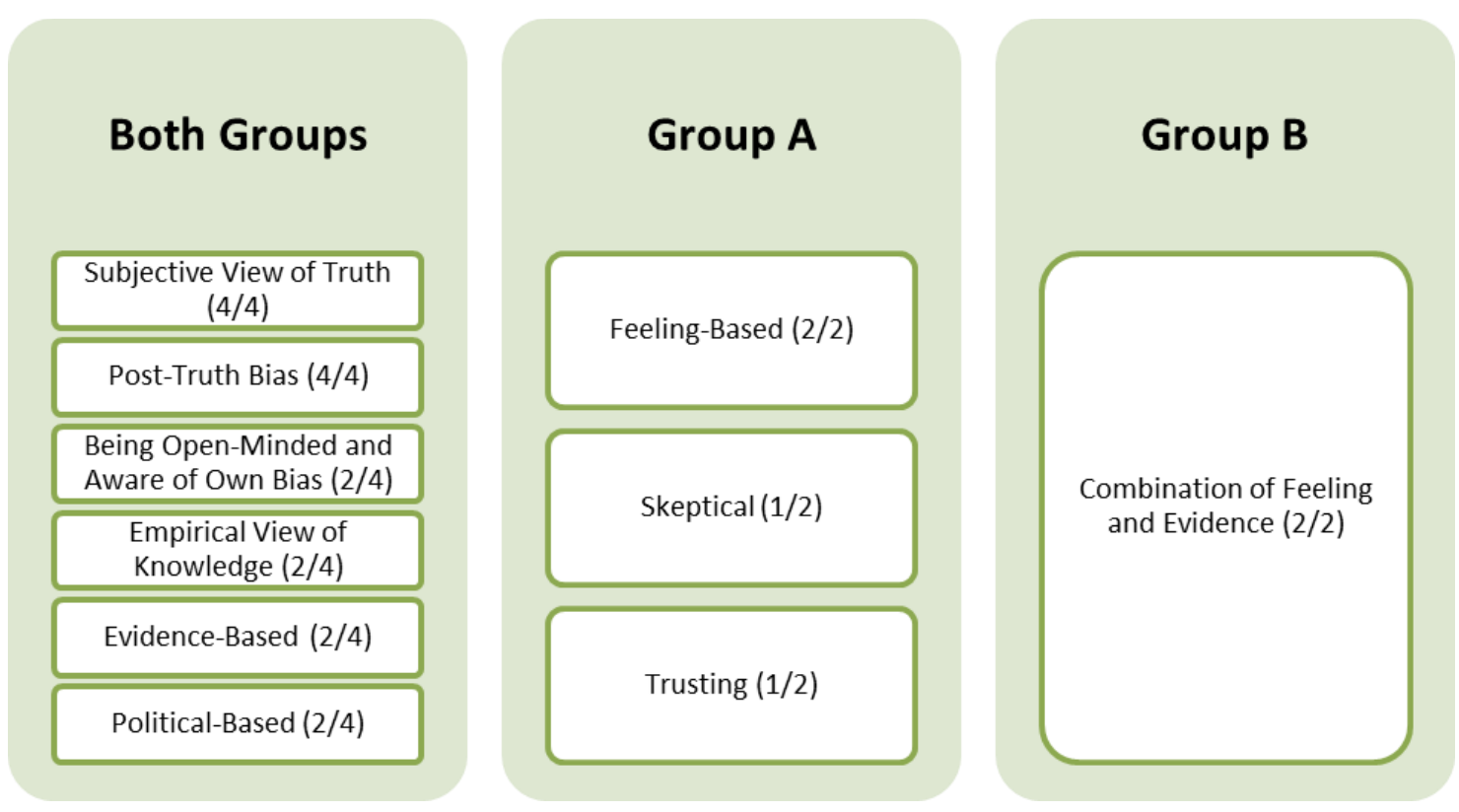

Figure 58. Epistemic Beliefs for the Trusted One but Not the Other Category.

It is interesting to note that both interviewees from Group A in the previous category (trusted hoax websites) and this one expressed statements related to having feeling-based epistemic beliefs. This aligns with the quantitative analysis of feelings having a statistically significant result in Group A. Table 72 below contains quotes that explain how feelings may affect whether a website is trusted, or not: 
Table 72

Trusted One-Feeling-Based

\begin{tabular}{|c|c|c|}
\hline & Interviewee & Group \\
\hline $\begin{array}{l}\text { 'It (feelings, intuition, political stance) does affect me highly } \\
\text { because I'm raised in one way and I believe in very specific } \\
\text { ways and if a website says that this is the way I may not } \\
\text { believe it because that's not what I think is right and yes I can } \\
\text { do more research and everything, but if I and my belief I think } \\
\text { that it's correct this way, I'm not going to be using that } \\
\text { website, so I'm technically a little bit biased to websites } \\
\text { because I don't believe in their ways. I'd rather believe in what } \\
\text { I was brought up to me and I've turned out fine, so I rather be } \\
\text { how I've been." }\end{array}$ & 2 & A \\
\hline $\begin{array}{l}\text { "For example, if my intuition says that it is right then I don't } \\
\text { have to evaluate it based on facts." }\end{array}$ & 9 & A \\
\hline
\end{tabular}

Interviewee \# 2 explained that feelings affect her tremendously in regard to trusting, or not trusting a website. This was the same interviewee that made multiple statements about having an evidence-based epistemic belief. This may be related to how some people may display a combination of epistemic beliefs depending on the situation. Interviewee \# 9 also believes that feelings and intuition take precedence over facts since according to her, there is no need to evaluate the website based on facts if your intuition tells you that it is right. Interviewee \# 2 expressed a skeptical mindset when it came to trusting websites. This differed from Interviewee \# 9, who expressed having a trusting personality since the statement below mentioned usually believing anything on the internet. Table 73 below contains the quotes provided: 
Table 73

Trusted One-Skeptical and Trusting

\begin{tabular}{lcc}
\hline Skeptical & Interviewee & Group \\
"Most of the time I do not believe everything at the website & 2 & A \\
because it was just brought up on me and I like to do my \\
research." \\
$\begin{array}{l}\text { Trusting } \\
\text { "I just need to be more careful because I usually believe } \\
\text { anything on the internet." }\end{array}$ & A \\
\hline
\end{tabular}

Interviewee \# 2 displayed a combination of epistemic beliefs such as evidence based, feeling based and skeptical. This is interesting since it is possible that some people display different epistemic beliefs depending on the situation, or how strongly they feel about a topic. The next sub-theme deals exactly with this concept. Some individuals expressed the idea that they use a combination of feeling and evidence based on the situation as is evident by the quotes in Table 74 below:

Table 74

Trusted One-Combination of Feeling and Evidence

\begin{tabular}{l} 
Trusted One-Combination of Feeling and Evidence \\
\hline $\begin{array}{l}\text { "Both (feelings and facts) depending on the topic or subject. } \\
\text { Evidence would be science and feelings would be believing }\end{array}$ \\
God." \\
"I use both. I use feelings and evaluation of facts and \\
evidence." \\
"What makes something true for me, I would say is something \\
that is backed up by any fact. Wait also by my feelings. I \\
realize that truth doesn't have to be just about facts it can also \\
be based on your beliefs."
\end{tabular}

Interviewee \# 6 explains that evidence is used for science and feelings for religious purposes. This idea was shared by two of the interviewees from the previous 
category (trusted hoax websites) and is also present in the other categories. Interviewee \# 13 stated that a combination of both feelings and facts are used to evaluate. It seems that people's epistemic beliefs may shift and change depending on the situation. More research should be done in this area to determine whether certain topics related to culture, religion, or humanities versus academics and science affect the decision of whether evidence, or feelings are used to evaluate what websites are trusted. The next category is composed of the interviewees that did not trust the hoax websites. These interviewees displayed a combination of sub-themes that were similar to the "Trusted One Hoax Website but not the Other," but differed significantly from the "Trusted Hoax Websites" category.

\section{Not Trusted Hoax Websites Category}

The following is a list of sub-themes mentioned that led interviewees $(1,8,10 \& 16)$ from this category to not trust both hoax websites within the web evaluation strategies theme. The sub-themes are ordered from the most mentioned to the least:

1. Lateral Reading (4/4)

2. Spending Sufficient Time to Read and Evaluate (4/4)

3. Aesthetic Appeal (3/4)

4. Authorship (3/4)

5. Ads/Asking for Money (3/4)

6. Not Making Sense (3/4)

7. Ease of Use (3/4)

8. Knowing the Definition of a Hoax Website (3/4)

9. Useful (3/4) 


\section{Prior Knowledge (3/4)}

\section{Experience Evaluating Websites (2/4)}

\section{Poor Design/Layout (2/4)}

Lateral reading was the main sub-theme mentioned by all the individuals that did not trust the hoax websites. Below is Table 75 with quotes based on the lateral reading sub-theme:

Table 75

Not Trusted-Lateral Reading

'Like for the tree octopus, I think one of the links didn't even Interviewee Group relate to a tree octopus and then I googled it."

"So, then I googled it. I went outside of the website. I googled it and then I saw that it was all a hoax."

"Finding multiple sources that said the same thing. So, if one and two are not good enough for me, I have to know that everybody's on a collective understanding."

"Well I think by searching more resources that pretty much says the same thing or gives a more solid foundation that the information is accurate or not accurate."

'I use like multiple resources. So, if I'm looking at a website, I would try to find other websites that support information that I see on that website."

"I would check out the resources to find out whether or not the website is legit. For example, I'd go to other websites to see if they had comparable information or if they had suggested certain like other websites that might have the same information or not and if it doesn't then that website is probably not as reliable, if the websites I looked up aren't showing the same information as what I am currently looking at." 
Interviewee \# 1 specifically stated that she googled to see if the website was a hoax since one of the links did not relate to the tree octopus. Interviewee \# 10 explained that multiple sources saying the same thing would be trusted. This idea of using multiple sources was also shared by Interviewee \# 8, who uses other websites to verify if the information is correct. Finally, Interviewee \# 16 also demonstrated lateral reading since the statement given refers to googling information on the side to evaluate the content. Lateral reading may be the most important sub-theme that determined whether a hoax website was not trusted. As mentioned earlier, all interviewees that trusted the hoax websites displayed linear reading compared to this category, who all displayed lateral reading. All Interviewees in this category also mentioned spending sufficient time to read and evaluate the content on the websites. Table 76 below contains statements for this sub-theme: 
Table 76

Not Trusted-Spending Sufficient Time to Read and Evaluate

\begin{tabular}{|c|c|c|}
\hline & Interviewee & Group \\
\hline $\begin{array}{l}\text { "I felt confident that I was able to distinguish something was } \\
\text { real or not and to take the time to see if any of the information } \\
\text { was true." }\end{array}$ & 1 & $\mathrm{~A}$ \\
\hline "I've always been told to really look for it." & & \\
\hline $\begin{array}{l}\text { "If I was familiar with the information, if it was true then I will } \\
\text { just agree to it and look for more, but if it was false I would } \\
\text { just have to question it and just do more follow up. I just won't } \\
\text { stop there and say OK I got it from that site it must be true, no I } \\
\text { have to do a little bit more groundwork and see if it's actually a } \\
\text { true statement." }\end{array}$ & 10 & A \\
\hline $\begin{array}{l}\text { "What led me not to accept it was if I had to do further research } \\
\text { on the information. I just don't trust everything I hear." }\end{array}$ & & \\
\hline $\begin{array}{l}\text { "I kind of looked at the things that I thought were interesting, } \\
\text { so I kind of went deeper into investigating those websites." }\end{array}$ & 8 & B \\
\hline $\begin{array}{l}\text { "It took me a while to figure it out because I had to make sure, } \\
\text { so I had to do research on the side, just to make sure that the } \\
\text { information was correct or at least to have an idea on what it } \\
\text { was." }\end{array}$ & 16 & B \\
\hline
\end{tabular}

Interviewee \# 1 stated that she was taught early on to "really look for it" and she felt confident by spending the time to distinguish if something was true or fake.

Interviewee \# 10 also said that it is important to follow up and do the groundwork to verify the information by doing further research. Going deep into investigating the websites was the comment made by Interviewee \# 8. Interviewee \# 16 said it took him a while to figure out if a website was credible or not by doing research on the side. All four interviewees expressed their thoughts regarding deep research and taking the time to evaluate the websites. Again, this differed from the individuals who trusted the hoax websites, who stated that they did not spend sufficient time to read and evaluate the 
websites. One of the sub-themes that both categories also shared was aesthetic appeal.

Table 77 below contains quotes about aesthetic appeal:

Table 77

Not Trusted-Aesthetic Appeal

"I paid attention to the layout and how easy it was to look at."

Interviewee Group

"Design, aesthetic and also if they were easy to use."

10

A

"So when I evaluate a website, the first thing I do is look at the

8

B appearance of the website to determine whether or not it's appealing."

Three out of four individuals paid attention to the aesthetic appeal of the websites. This was a recurring theme present in all of the categories. Some said that they paid attention to how it looked (Interviewee \# 1), others talked about the design and aesthetics (Interviewee \# 10) and finally about appearance (Interviewee \# 8) and if it was appealing or not. Authorship was the next sub-theme present. Three out of the four interviewees mentioned some sort of comment regarding the people who created the website and the expertise that came with it. Table 78 below contains a few quotes about authorship:

Table 78

Not Trusted-Authorship

"I would look at the tabs and if they had any information about Interviewee Group them, any way to contact them, if they had an address or not. Then, I would look at the actual information on the about us page to see who they are if they had pictures of themselves. If they had anyway to tell if it's a real person that's managing the website and basically that's it."

"I would tell teachers to see if the actual website is a popular credible website, so like the New York Post or maybe like the wildlife foundation, which everyone knows about it to see if it if they are the ones that are posting. If it is a random blog or a 
website made by just someone that's not even related to the fields then they should be worried."

"Check for links to see if any other person is talking about their website or the person that created that website see if you can actually contact them not just by emails but by phone or actual mail."

"So, what makes information credible to me would be if it's been reviewed by professionals in that field. If many people have recognized it. If it's been published in a credible source or actually if the person is even part of the field that they're writing about."

"To accept it, I would accept names and pictures of people that were involved."

"I believe that what counts as truth is defined by power

because in like certain instances people will rely on or trust people who have more power because they obviously have more experience and research, so for example like a scientist if he comes across a conclusion his answer will be more reliable than like somebody like me who hasn't had that much experience in that field, so the fact that he has more power makes his conclusions or response to the situation more reliable than mine that is why I believe that power would be like more a reliable source to define like concrete information."

"Credibility to me is like something that follows whether it is true, so I would say if somebody that I knew is an expert in that field post something on the Internet then I would say that they are credible because they are experts because they have years of experience they have a lot of information and prior knowledge they have a lot of most likely like life situations that they have been through to prove what they are putting on the website, so for me that is what is considered credible because they have truth behind whatever information they are giving."

"I guide myself based on how the website was constructed and then who wrote or typed the information. I guess that's my checklist, so to speak."

"So, the first thing I do is check to see the design and then after that who wrote the information." 
"Whenever I'm checking for the credibility of something, you could always base it off on authorship, who wrote it, are they an expert on the matter at hand."

Interviewee \# 1 was adamant about authorship. It seemed that authorship was one of the most important aspects of her website evaluation. All the five statements made by this interviewee mentioned who created the content and if it was from a real person or known professional group. Being able to contact the people who were behind the website was another major thing for Interviewee \# 1 . Interviewee \# 8 also had similar views to Interviewee \# 1 regarding the importance of authorship. The only difference was that Interviewee \# 8 regarded authorship and expertise with power. Lastly, Interviewee \# 16 stated that he guides himself based on how the website was built and the author. Another aspect that many interviewees in this category expressed was whether the website contained ads or was asking for money. Table 79 below contains the quotes regarding this sub-theme: 
Table 79

Not Trusted-Ads/Asking for Money

"The ads were another thing that I paid attention to. Websites Interviewee Group with ads just want to sell you things."

1 A

"To disregard it, ads for sure. When people are like showing ads they just want to sell you stuff or when their first page has links to ask you for your information that's also the reason why I don't trust some websites."

"They were telling you to donate money and start your own foundation about animals, but they weren't telling you why they're doing this, so there wasn't a really a good reason."

"So, some of the red flags that I noticed with the DHMO

websites to me the organization was not very well displayed. To me the information looked really cramped and it had a lot of advertisements."

"I disregarded that one (DHMO.org) because like I said the information seemed like it was easily edited by anybody there was a lot of advertisements."

"Some of the ways that teachers can learn about evaluating websites is paying attention to what is displayed on the website and how the display is, so if there's a lot of advertisements on the website if it's not easily navigational, if there's no like good like if it's not presented in an eye pleasing way then it shouldn't be considered like a very credible website because most websites that are credible are usually organized themselves and are easily navigated and don't have a lot of advertisements in there unless they're like advertising for like an organization that's a part of the website or related to the information on the website, so it's mostly the information that it's on the website that relates to what the website is about as a whole."

Why did you disregard the information? "Information that I didn't really was unfamiliar with and also if I felt like there were too many signs of pay here."

What is a hoax website? "A website that basically it's demanding some form of payment money you know or access to certain information and it doesn't have a lock on it." 
Three out of four interviewees mentioned that websites that had ads or asked for money should not be trusted. Interviewee \# 1 stated that one of the main reasons why she disregarded the information was due to websites containing ads. According to Interviewee \# 1, websites should not be trusted if they are also asking for donations, personal information or trying to sell you things. As for the DHMO.org website, Interviewee \# 8 stated that the main reason this website was disregarded or not trusted was because it contained many advertisements. Interviewee \# 8 did state that there could be an exception if the website is advertising for an organization that is part of the website. This suggests that certain advertisements could be acceptable if they are related to the website. In addition, Interviewee \# 10 did not trust websites that asked for money. Websites were not trusted if they contained advertisements and if they did not make sense. Three out of four interviewees stated that they did not trust the website if they found that the content did not make any sense. Table 80 below contains quotes about content not making sense: 
Table 80

Not Trusted-Not Making Sense

\begin{tabular}{|c|c|c|}
\hline & Interviewee & Group \\
\hline $\begin{array}{l}\text { "I remember going through the pages and something just } \\
\text { wasn't clicking. I don't know if it was that there was } \\
\text { information like news link or something like that, but I went } \\
\text { and I'm like wait a tree octopus, octopus live in oceans. So, } \\
\text { then I went is this real?" }\end{array}$ & 1 & A \\
\hline $\begin{array}{l}\text { "Like for the tree octopus, I think one of the links didn't even } \\
\text { relate to a tree octopus and then I googled it." }\end{array}$ & & \\
\hline $\begin{array}{l}\text { "One of the links did not have anything to do with the } \\
\text { information that was actually on the website." }\end{array}$ & & \\
\hline $\begin{array}{l}\text { "I noticed that the tree octopus website was a hoax mainly } \\
\text { because I know from an early age that octopus live in the ocean } \\
\text { and when you're eating seafood and there is octopus it's } \\
\text { coming from the sea. I was like wait this isn't right." }\end{array}$ & & \\
\hline "I would just make sure the information isn't like outlandish." & 8 & B \\
\hline $\begin{array}{l}\text { "Yes, the website about the octopus tree was definitely a hoax. } \\
\text { I mean common sense because that doesn't exist, but you could } \\
\text { always research it to make sure that it's not a hoax, but it was a } \\
\text { hoax." }\end{array}$ & 16 & $\mathrm{~B}$ \\
\hline $\begin{array}{l}\text { "I mean some of the things are common sense, for the website } \\
\text { like the tree octopus, I knew it was fake, but I did research just } \\
\text { to make sure anyways". }\end{array}$ & & \\
\hline
\end{tabular}

In regard to the Tree Octopus hoax website, Interviewee \# 1 did not trust it because it did not make sense to her that there could be an octopus that lived on a tree since octopus live in the ocean. Also, one of the links did not relate to the tree octopus. Interviewee \# 8 expressed that if the information was outlandish then it was not trusted. Interviewee \# 16 evaluated the websites based on common sense. The Tree Octopus website was deemed a hoax, due to it not making sense. It seems that these three interviewees used the notion of whether something just does not make sense as the first 
red flag on whether to trust a website or not. But it may be that the main reason why the website was determined to be a hoax or not was more based on using lateral reading as opposed to linear reading. Another aspect that the majority of interviewees in this category paid attention to was ease of use. Table 81 below contains the three individuals that made statement regarding this sub-theme:

Table 81

Not Trusted-Ease of Use

"First, I was looking at how easy it was to get through," Interviewee Group

"I looked through the tabs. I looked through the colors to see if it was easy to read."

How did you evaluate the websites? "Design, aesthetic and also if they were easy to use."

10

A

"Whether or not is easy to navigate because for me that is the 8 B most important thing for looking at a website and if I can't get through the website them I'm most likely not going to use it because it's not easy for me to manage or read, so that's the first thing I see when I look at the website."

"After I've determined that the website might be legit and that it's easy to navigate, I would just go through the website to see what other things I can get from that website."

What made you accept the content on the website? "The organization of it to see if like the separate links of the website were easily navigational and if they were easy for me to like access."

All three individuals above stated that one of the main things that they evaluate on a website is how easy it is to navigate and use. If it was easy to get through, to read, to use then it would be trusted and if it was not, then it would not be trusted. Interviewee \# 8 even said that ease of use was the most important thing when evaluating a website. Aside 
from ease of use, knowing the definition of a hoax website and whether a website was

useful was a sub-theme shared by three out of four individuals in this category. Table 82

below contains quotes on these two sub-themes:

Table 82

Not Trusted-Knowing the Definition of a Hoax Website and Useful/Applicable

Knowing the Definition of a Hoax Website

Interviewee

"A hoax website for me is a website that is trying to convince 1

Group

you of something that isn't true, trying to sell you something

that they're not going to give you or just asking for your

information to call you and harass you."

"A hoax website is a website that provides information that

8

B

might have truth facts on it but they may also have made up

information or made up images or like a lot of advertisements

in the margins or just like a lot of unnecessary unfactual

information on it that just doesn't support what they are giving

like they might have good information on it but the information

may not be true or credible in any manner."

'Isn't a hoax like a scam? As far as I am concerned, a hoax is something that is fake that was initially intended to trick or to fool people."

\section{Useful/Applicable}

"If it was something that I can apply in my life and I see the

results, it's still the same, so it has to be appliable. Do you mean applicable? "Yes, applicable."

"If I'm able to apply knowledge and I see the similar results"

"I would just go through the website to see what other things I

"Something is true to me if it can be applicable to the real things or the way you do things in the real world."

"This is a very philosophical question, but when it comes to truth you could say... this is a very deep question though, but 
you could work it around whether it is trustable. What you consider to be an appliable or applicable to life, I guess."

Interviewee \# 1,8 and 16 were able to provide an acceptable definition of a hoax website. All three mentioned that a website was a hoax if it contained fake information. The other aspect mentioned was if the website was useful. If the website was useful, then it was considered true. Interviewee \# 10 and 16 stated if the content can be applied or applicable, then it was true. Interviewee \# 8 talked about using it in the future and taking advantage of the knowledge. Prior knowledge was also mentioned by three of the interviewees. Table 83 below contains the prior knowledge quotes:

Table 83

Not Trusted-Prior Knowledge

"Past knowledge and what websites are supposed to look like Interviewee Group today in modern times."

"What led me to accept it was how it looked and if I were familiar with the information that was given."

What led you to disregard the information? "Information that I didn't really was unfamiliar with and also if I felt like there were too many signs of pay here."

"If I was familiar with the information, if it was true then I will just agree to it and look for more, but if it was false I would just have to question it and just do more follow up."

"For the tree octopuses it was just I kind of had prior 8 B knowledge. I had already seen that website before that's how I knew it wasn't real."

"I just kind of looked at the ones that were provided and used the prior knowledge that I had based of other websites."

"I would like read the information on the website to see if the information sounds like legit or if it sounds similar to 
something else I've read or relatable in any manner."

"Credibility to me is like something that follows whether it is true, so I would say if somebody that I knew is an expert in that field post something on the Internet then I would say that they are credible because they are experts because they have years of experience they have a lot of information and prior knowledge they have a lot of most likely like life situations that they have been through to prove what they are putting on the website, so for me that is what is considered credible because they have truth behind whatever information they are giving."

"In the same way, based on whatever you have experienced, or you have seen in your surroundings is going to give you a solid idea on how the world works. In that sense, everybody has a predisposition towards certain things or certain situations, in general. Definitely, the nature of your surrounding is going to affect how you see the world. The same thing with students that come from different backgrounds are going to have different predispositions for certain information or content areas in the class. I think that is how we might be affected by our previous knowledge. This is really philosophical."

Interviewee \# 10 explained that past knowledge helped her evaluate. Interviewee \# 8 had prior knowledge on the Tree Octopus and that is why it was not trusted. Based on the quotes above, it seems that if the interviewees used their prior knowledge to evaluate the websites and if they were familiar with the content, then there is a tendency to agree with it. Interviewee \# 10 did mention that if something was familiar, then she would agree but would still look for more. In addition, if the familiar information was false, then more research would need to be done as well. This suggests that even though content on a website could be familiar and align with prior knowledge, it is still important to research its credibility, despite of the usual tendency to agree with it. Interviewee \# 16 also explained how prior knowledge can give people certain predispositions towards content. Aside from prior knowledge, two out of the four interviewees actually had some 
experience evaluating websites. Table 84 below contains the statements for this

sub-theme:

Table 84

Not Trusted-Experience Evaluating Websites

"I think it comes from good education. I was always taught not Interviewee Group to believe the first thing someone told you because they could tell you the sky is green and it's definitely not green and make sure that's it that what you are reading is really true. I've always been told to really look for it."

"So, to use these websites, I would use a few of them just to show my students how to detect if they're reading real information or not because it is important now specially that they are talking about fake news and like random fake articles there's obviously going to be fake websites as well and try and sell them fake things and take their information or their money and that's important now to know."

"The thing is that back in high school, I did this week-long research project in my last year. So, they taught us all how to research, what to believe and not to believe."

'I mean it's something that I have been doing for a while, so it's not like it was surprising or eye opening its just, I go used to it."

Interviewee \# 1 expressed having a good education and being taught to really look for it. She also had knowledge of current trends of fake articles and the importance of using hoax websites to teach students. Interviewee \# 16 had also experience evaluating websites since high school thought a week-long research project that taught him how to evaluate websites. It seems that having experience evaluating websites helps prospective teachers in being able to determine if a website is a hoax or not. The last sub-theme that was mentioned by two of the four individuals in this category was poor layout. If a 
website had a poor design/layout it was not trusted. Please see Table 85 below with these quotes:

Table 85

Not Trusted-Poor Design/Layout

'Yes, I'm in art education, so if it doesn't look right, they Interviewee Group didn't spend the time or the money or the energy and the time that it takes to make it look right."

"Personally, I felt like some of them needed to be updated but, I was just like when I design my website is not going to look like a couple of these."

"So, some of the red flags that I noticed with the DHMO 8 B websites to me the organization was not very well displayed. To me the information looked really cramped."

"The DHMO website, that website was just poorly organized, and it seemed like anybody could've easily edit it and created their own website and just put it up for people to easily be confused or easily be like off-track whenever they misspelled or something it just didn't seem legit.

"It was literally one section of the website like the website didn't even fill out the whole screen, so it seemed poorly organized in my opinion."

A website that was poorly designed and organized was seen as a website that should not be trusted. Interviewee \# 10, who is an art education prospective teacher, said some of the websites were poorly designed and it was just a sign of not spending the money, time or energy to make it look right. Interviewee \# 8 specifically referred to the DHMO.org website, which did not fill up the entire screen, the information was cramped and poorly displayed and organized. There were a few sub-themes that were only present in Group A or Group B. Below is a list of them:

Group A: 
1. Citations $(1 / 2)$

2. Not knowing the definition of a hoax website $(1 / 2)$

\section{Group B:}

1. WWWDOT Framework (2/2)

2. Not Letting Design Affect Decision to Trust Content (2/2)

In Group A, one of the individuals stated that citations are important when it comes to trusting a website. In Group B, both individuals mentioned statements regarding the WWWDOT Framework and not letting design affect decision to trust content. Below is Figure 59, which sums up the web evaluation sub-themes present in this category by group: 


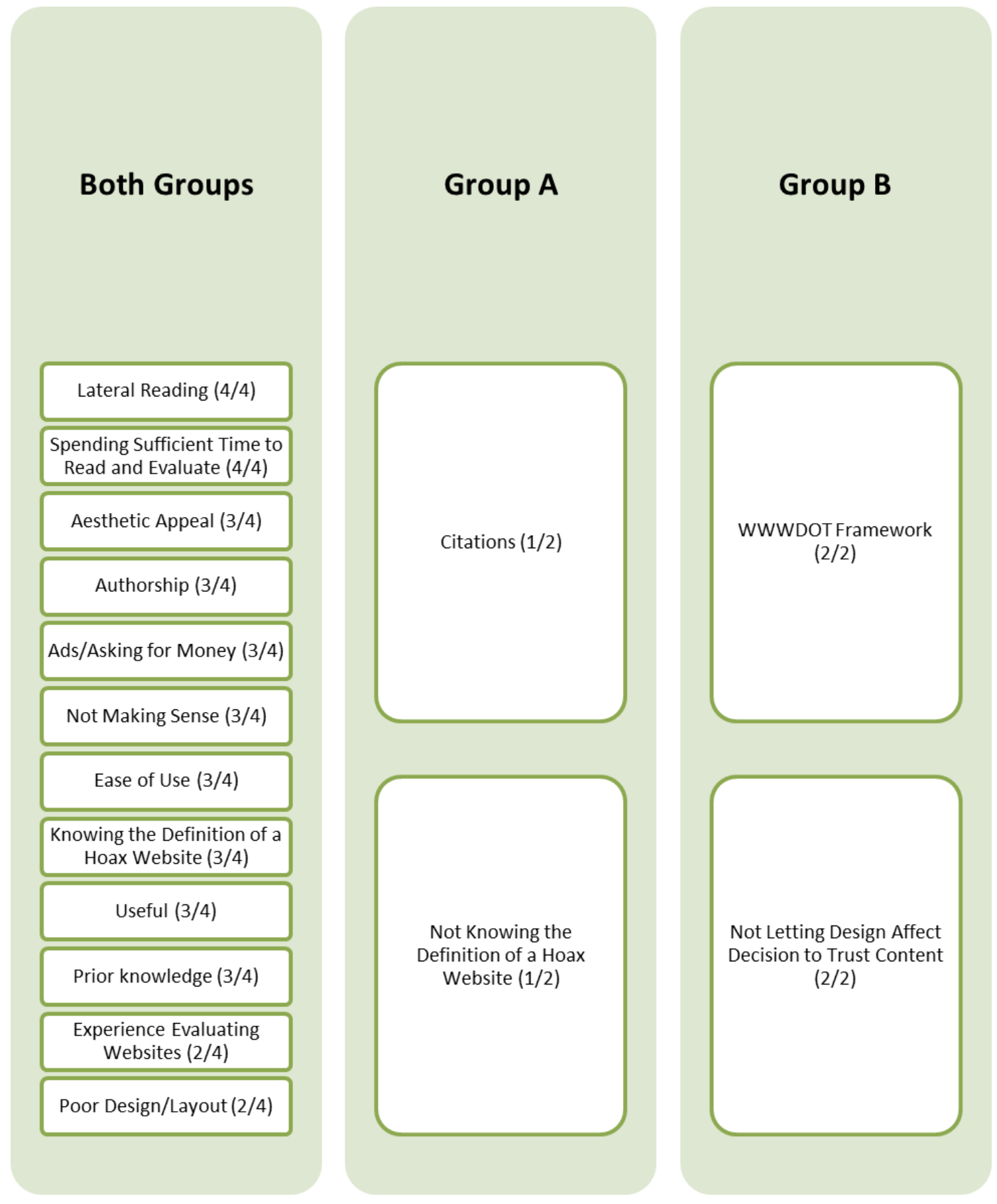

Figure 59. Web Evaluation Strategies for the Not Trusted Hoax Websites Category.

Interviewee \# 1 explained that she always uses websites that are well known and cite the information. Table 86 below contains the quote made by Interviewee \# 1: 
Table 86

Not Trusted-Citations

What sources do you use to verify the content on a website? "I mainly use the Internet because going to the library takes a lot of time, but I try to find websites that are credible and wellknown and cite where they got their information from."

The sub-theme "citations" was more prevalent in the trust one hoax but not the other category compared to this one. In this category, only one out of four mentioned websites that had citations compared to the "Trusted One Hoax but not the Other" category, where three out of four individuals mentioned it. This may be because some hoax websites might use citations to fool people and it may be more important to spend sufficient time to read and evaluate or read laterally compared to just relying on the presence of citations. One of the individuals from Group A also did not know the definition of a hoax website. Table 87 below contains the definition provided by Interviewee \# 10:

Table 87

Not Trusted-Not Knowing the Definition of a Hoax Website

"A website that basically it's demanding some form of Interviewee Group payment money you know or access to certain information and it doesn't have a lock on it."

Interviewee \# 10 did not mention anything about the website being false or fake, therefore it was considered incorrect. Only one of the individuals from this category did not know the definition. This differed from the Trusted hoax category, where most individuals did not know the definition. Both individuals from Group B mentioned using the WWWDOT Framework. This differed from the individuals from the "Trusted Hoax 
Websites" category, who stated that they did not use the framework at all. Please see

Table 88 to read the direct quotes provided on the WWWDOT Framework:

Table 88

Not Trusted-WWWDOT Framework

"I believe students can learn the same thing it's easy to Interviewee

Group

evaluate a website specially if use like a checklist the

WWW.framework and I think it's an easy like way to do it

because once you learn how to do it, you just do it

unconsciously, so it won't be hard for teachers or students to be

able to learn how to determine the credibility of a website they

just have to lay a little bit more attention to what they're

looking at."

"I evaluated the websites primarily off of the tips that you gave

us. I know it was like the dot com I believe that's what it was."

The WWWDOT Framework? "Yeah and I used that because I

looked at the way it was presented. I looked at the type of

information that was and like I couldn't really look at who

wrote it because it was a website, but I kind of used some of

my prior knowledge about what I knew and what sounded like

more legit, so I kind of used like the outline framework that

you gave us."

What tools did you use to evaluate the websites? "This is

probably going to be the same as before with the

WWW.framework because that literally is a checklist in and of

itself to help determine whether or not the website is legit. It

literally tells you to look at who wrote it the display of it, what

information is on there, like it literally tells you a breakdown of

how you're supposed to determine the credibility of the

website, so that's the that's the tools that I used"

"Well regarding the initial strategy (WWWDOT Framework) that you laid out at the beginning of the class or the survey, I think that in terms of trustable websites, you always go to the who did it because if the person or the company or the entity that created the website was, how do you call it, an expert in the topic, then you have a solid basis to trust the website. Now if you look into any random blog or a website that has that, whoever did it doesn't have a known person on it or knowledgeable person on the topic, then it's not a good website to trust. So, always go for who did it and then content wise, 
that is something that you can always research on the side like looking into books, articles or different sources that confirm the trustworthiness of the website."

Both Interviewee \# 8 and 16 mentioned that they used the WWWDOT Framework. Interviewee \# 8 liked that it provided a breakdown on what to look for in order to determine what is credible and what is not, which can be taught to teachers and students. Interviewee \# 16 said that he followed the framework to determine who created the website and when it came to the verification of the content, he said that it can be researched through books, articles and various sources, which suggests the importance of the lateral reading strategy. Lateral reading again seems like the most important strategy in determining the credibility of a website. Both individuals also made statements that even though they initially paid attention to the aesthetic appeal of the website, they ended up with not letting design affect their decision to trust the content. Below are statements related to this sub-theme in Table 89: 
Table 89

Not Trusted-Not Letting Design Affect Decision to Trust Content

"When I looked at it (Tree Octopus Website) the first time it
was appealing to see it was interesting to see that there
could've been a tree octopus but once I read it and once I went
through some of the information on there, it kind of proved to
not be as accurate or credible as some might think it is."
"The websites that I disregard, they just seemed to me like
easily like they just the tree octopus, it seemed like they made
it displayable for people to easily believe it, but they didn't put
good information on there that sound legit."
OK, so you said in the tree octopus that you knew that it was a
hoax website, but that people put stuff because it was meant to
deceive?
"Yeah like at the top there was a picture of the tree and an
octopus and it didn't look Photoshopped, so somebody
could've easily believed it."
"Definitely the design because I mean nowadays it is easy for
people to be fooled or tricked based off of appearance. So, for
example, if one of the websites were to be visually attractive,
then I am sure that somebody will like that website and trust it
even though the information could be right or wrong. So, the
first thing I do is check to see the design and then after that
who wrote the information."

Interviewee \# 8 said that even though the Tree Octopus website was appealing and contained images that did not look photoshopped, the content that was put in it was not good. Interviewee \# 16 also said that he paid attention to the design, however he also states that it is important to be aware that people may create visually attractive websites just to fool or trick others. Therefore, it is also important to check the author(s) of the website. Both individuals in Group B agreed that people need to go beyond just the aesthetic appeal of a website and do further research using the WWWDOT framework, 
lateral reading and a combination of other web evaluation strategies. The next theme in this category were the epistemic beliefs displayed.

Epistemic Beliefs. Below are the seven sub-themes that both Group A and Group B displayed in the epistemic beliefs theme:

1. Combination of Feeling and Evidence (4/4)

2. Evidence-Based (4/4)

3. Objective View of Truth (4/4)

4. Skeptical (3/4)

5. Multidimensional view of knowledge (3/4) or View that knowledge can be true, false or have various aspects.

6. Feeling-Based (2/4)

7. Empirical View of Knowledge (2/4)

8. Being Open-Minded and Aware of Own Bias (2/4)

All four interviewees mentioned statements that suggest using a combination of feelings and evidence as their epistemic beliefs. Below are the statements made by the interviewees concerning the first sub-theme: 
Table 90

Not Trusted-Combination of Feeling and Evidence

"As far as feelings, I've always been one to trust my gut and I Interviewee Group do believe that people know when something is wrong. It's human nature to like have an instinct of something is not going to happen in a good way. As far as intuition or political stance, I've always been open-minded, so I don't let that block me I'd rather look up to see if something is true or not through other sources that are credible."

"Double checking, as like you know, I really go with my gut instinct. I really do or just do further research and finding multiple sources that said the same thing, so if one and two are not good enough for me I have the know that everybody's on a collective understanding."

So, you kind of go first by intuition and then by research?

"Yeah if I'm interested then I'll do further research if not then OK they can have that."

"My feelings and intuition they affect the credibility of a website only slightly because I believe that like you have to have facts to prove that something is true and then your feelings my either support or might disagree with that but that doesn't really determine for me the credibility of a website it's either supporting facts or not it's just they are kind of."

"My feelings and intuition affect knowledge in a way that suggest that if I feel like the knowledge is inaccurate I might go and try to find like other information to prove that fact or that would prove that feeling but it won't be like determining whether I believe if it's actual knowledge because I think knowledge is stuff you have in your head you have it but I go out and find other resources to prove whether it's true or not or whether my instinct is something to rely on or not."

"I would say both (feeling and evidence). I mean it is very important to use facts and evidence and make sure that everything falls into place. But, at the same time, I think it is just human nature, you're going to evaluate things sometimes by guessing based on your intuition or feelings or what they call gut feeling. Two of the websites, I had a feeling that they were fake, so I researched them." 
Using a combination of feeling and evidence was displayed by all interviewees in this category. Although it seems that in this category, evidence is given a bit more priority than feelings. Both Interviewees \# 1 and 16 stated that it is part of "human nature" to use feelings, intuition or a gut feeling to evaluate, however, these feelings are used initially but precedence is given to evidence. Interviewee \# 10 said that she relied on her gut instinct but would also do further research from various sources. Interviewee \# 8 clearly believes that evidence is more important than feelings but does admit that feelings affect her slightly. Evidence seems more important to this category compared to the previous ones. Below are evidence-based quotes provided by individuals that did not trust the hoax websites: 
Table 91

Not Trusted-Evidence-Based

\begin{tabular}{|c|c|c|}
\hline & Interviewee & Group \\
\hline $\begin{array}{l}\text { "So, something that makes something true for me would be } \\
\text { seeing the evidence behind what someone is telling me it's } \\
\text { true." }\end{array}$ & 1 & $\bar{A}$ \\
\hline "I base my intuition on facts and evidence more than feeling." & & \\
\hline $\begin{array}{l}\text { "I just think it's important for people to really look at } \\
\text { information and see if there's any evidence to support it." }\end{array}$ & & \\
\hline $\begin{array}{l}\text { "Most of my evaluations are based on evidence and facts. I } \\
\text { personally think a lot and I know that I think a lot, so I ask a lot } \\
\text { of questions and I inquire about a lot of things, so if I feel in } \\
\text { some type a way my first instinct is to ask questions about it } \\
\text { like to figure out what the problem is and what I can do to } \\
\text { solve the problem and figure out how to get rid of like the first } \\
\text { thing I do is ask questions to figure out what to do next" }\end{array}$ & 8 & $\mathrm{~B}$ \\
\hline $\begin{array}{l}\text { 'Like I said prior, if I'm able to apply knowledge and I see the } \\
\text { similar results, so if I know if I go on a certain fact or } \\
\text { something I'm expecting a result or if you say for instance } \\
\text { mixing colors, but I know for a fact if I mix yellow and blue } \\
\text { together I'm going get green and I know for a fact if you do it } \\
\text { you're going to get green, so overall yellow and blue mix } \\
\text { green, so I just find those basic tools if everybody's getting the } \\
\text { same results then it's true they might have a lighter shade of } \\
\text { green or dark but it's still green. Everybody's got to come up } \\
\text { with the same answer.' }\end{array}$ & 10 & A \\
\hline $\begin{array}{l}\text { "If it's factual. If you can prove it. Even if it's something not } \\
\text { tangible, like a thought or an idea, how can you argue or } \\
\text { convince someone that your point of view is correct or the right } \\
\text { one." }\end{array}$ & 16 & B \\
\hline
\end{tabular}

The three statements made by Interviewee \# 1 were all about the belief that truth is determined by evidence. Interviewee \# 8, and 16 also made statements about relying on evidence, facts and proof. Interviewee \# 10 talked about getting equivalent results. Interviewee \# 10 explained this concept by providing an example of mixing yellow and 
blue to make green, where she expects everyone to have the same results even if it's a shade lighter or darker. Interviewees \# 1, 10, 8 and 16 also had an objective view of truth. Below are statements made on what truth meant to each of them:

Table 92

Not Trusted-Objective View of Truth

\begin{tabular}{|c|c|c|}
\hline & Interviewee & Group \\
\hline $\begin{array}{l}\text { "What truth means to me is that you can prove it and have } \\
\text { evidence to support what you were saying or showing." }\end{array}$ & 1 & $\mathrm{~A}$ \\
\hline $\begin{array}{l}\text { "Truth is something that is accurate that can be applied and that } \\
\text { has the same results constantly." }\end{array}$ & 10 & A \\
\hline $\begin{array}{l}\text { "The truth to me is something that can be proven, so if } \\
\text { somebody can show me or describe to me the proof then I will } \\
\text { be convinced that it is true regardless of what the proof is if } \\
\text { they can show me that the proof is legit then I would believe } \\
\text { whatever the proof is proving that it is true." }\end{array}$ & 8 & B \\
\hline $\begin{array}{l}\text { "Truth in the academic sense is that which you can prove. In } \\
\text { the same way, it is very important for students to know how to } \\
\text { prove things out, how to argue in favor or against something. } \\
\text { That was a very deep question, it really got me thinking." }\end{array}$ & 16 & B \\
\hline
\end{tabular}

Interviewee \# 1 and 8 said that truth must be proven and supported by evidence. Interviewee \# 10 discussed that truth needed to be accurate and when applied the results should be constantly the same. Interviewee \# 16 expressed that truth in the academic sense can be proven. In addition, Interviewee \# 16 expressed that through reason or discussion a person can defend non-tangible things, such as a thought or idea. This category differed from the rest since the other ones had a mostly subjective view of truth. There may be an association between having an objective view of truth and not trusting hoax websites. In addition, three of the four individuals also expressed being skeptical: 
Table 93

Not Trusted-Skeptical

\begin{tabular}{l}
\hline \\
"I think it comes from good education. I was always taught not \\
to believe the first thing someone told you because they could \\
tell you the sky is green and it's definitely not green and make \\
sure that's it that what you are reading is really true. I've \\
always been told to really look for it if there's any evidence to \\
support it." \\
'Personally, I feel uncertain because information can be lost \\
within the website because even though a website can have a \\
lock a secure lock, but somebody can still gain access to your \\
information or to what you do or what your interest is based \\
upon the sites you go to." \\
"Like I don't feel personally inside how can I find the words? I \\
feel pretty much detached you know as far as what I'm getting \\
from a website, so like no form of emotion like skeptical pretty \\
much even with social media like you have to be kind of on \\
guard dealing with the Internet or the media in that sense. It's \\
still a screen."
\end{tabular}

Interviewee \# 1 stated that she was taught to not believe the first thing someone tells you and to look for evidence that supports it. Interviewee \# 10 said she feels skeptical towards websites and social media in general. Lastly, Interviewee \# 16 provides his final thoughts on the interview by stating to be skeptical and question everything, since people can trick you and provide fake information. All three individuals above displayed skeptical notions. This differed from the "Trusted Hoax Websites" category, where individuals displayed a more trusting stance. Being skeptical seems like one of the 
most important epistemic belief when it comes to not trusting hoax websites. Aside from being skeptical, three out of four individuals had a multidimensional view of knowledge. Having a multidimensional view of knowledge is believing that knowledge has various dimensions or aspects and can be true or false. The following are statements related to a multidimensional view of knowledge:

Table 94

Not Trusted-Multidimensional View of Knowledge

\begin{tabular}{lcc}
\hline & Interviewee & Group \\
\hline "Knowledge can be true and can be factual. It just depends on & 10 & A \\
the perspective. You want knowledge to be accurate and true & & \\
and something that can be applied but... you can learn false & \\
knowledge." & B \\
"To me what constitutes knowledge is something that a person & 8 \\
can physically like mentally obtain although the knowledge & \\
may not be accurate, or it may not be true it could still be & B \\
knowledge for me. So, like if you have this information in your & \\
head like you have knowledge regardless of what the & \\
knowledge is about." & \\
"OK, so what constitutes knowledge is the world around us. & \\
Based on our environment, we construct knowledge out of it, & \\
so how we build up based upon that that's a different process. & \\
But we learn based on the environment around us. In the same & \\
way, students explore on their own to obtain knowledge either & \\
social knowledge, academic knowledge, symbolic knowledge, \\
whatever you want to call it. The nature of knowledge is \\
mostly based on our surroundings. Now if you want to go \\
deeper than that, it has the same foundations. This is getting \\
very philosophical (Laughs)."
\end{tabular}

Interviewees \# 10 and 8 explain that knowledge can be true or false. In other words, they believe that false or inaccurate knowledge as well as true and accurate knowledge can be learned. Interviewee \# 16 believes that there are diverse types of knowledge, such as social, academic, and symbolic which suggests a view of knowledge 
having multiple dimensions or aspects. It may be that having a multidimensional view of knowledge has some relationship with not trusting hoax websites since there is this acceptance that knowledge can be true, false or have various aspects. Despite of this category having a mostly evidence-based or combination of evidence based and feeling stance, two individuals mentioned relying on their instincts. Below are quotes on feeling-based epistemic beliefs:

Table 95

Not Trusted-Feeling-Based

"At first no I didn't know that any of the website was a hoax. I Interviewee Group just felt the type of energy when I went to visit those websites."

"I just relied on instinct."

"I just kind of used what I knew about websites to find out the 8 B credibility of it and just kind of relied on like my instincts a little bit."

Interviewee \# 10 felt a "type of energy" when she visited the websites and relied on instinct. Interviewee \# 8 also somewhat relied on instincts. I find this admission interesting since these two interviewees had previously stated having primarily evidence-based or a combination of both feeling and evidence epistemic beliefs. This demonstrates that feeling-based statements are present throughout all categories. Another sub-theme present in this category was having an empirical view of knowledge. Below are statements related to this: 
Table 96

Not Trusted-Empirical View of Knowledge

\begin{tabular}{lcc}
\hline & Interviewee & Group \\
\hline "The nature of knowledge comes from an interest in learning & 1 & A \\
and where you're learning from, so let's says if your & \\
grandparents have experienced something or your teachers that & \\
have studied another subject or yourself \\
experiencing something in person." \\
"OK, so what constitutes knowledge is the world around us. \\
Based on our environment, we construct knowledge out of it, \\
so how we build up based upon that that's a different process. \\
But we learn based on the environment around us." \\
"Based on whatever you have experienced, or you have seen in \\
your surroundings is going to give you a solid idea on how the \\
world works."
\end{tabular}

Interviewee \# 1 believes that not only your experiences give you knowledge but also the experiences of your family members and teachers. Interviewee \# 16 mentioned how the world around or the environment is what allows people to have experiences and understand how the world functions. Both interviewee \# 1 and 16 shared an experienced-based view of knowledge. This was similar to the previous categories where individuals had a view of knowledge coming from experiences. The only way that this category differed from the others was in the multidimensional view of knowledge.

Finally, the last sub-theme was being open-minded and aware of your own bias. Below is Interviewee's \# 1 statement:

Table 97

Not Trusted-Being Open-Minded and Aware of Own Bias

\begin{tabular}{lcc}
\hline & Interviewee & Group \\
\hline "As far as intuition or political stance, I've always been open- & 1 & A \\
minded, so I don't let that block me I'd rather look up to see if & & \\
something is true or not, through other sources that are & \\
credible."
\end{tabular}


Interviewee \# 1 said that she is open-minded and does not let intuition or political stance block her since she prefers to search whether things are true or not through credible sources. This concludes the sub-themes that both Group A and Group B displayed. However, there were a few sub-themes that were only present in Group A or Group B. Below is Figure 60, which summarizes the results of this category organized by group:
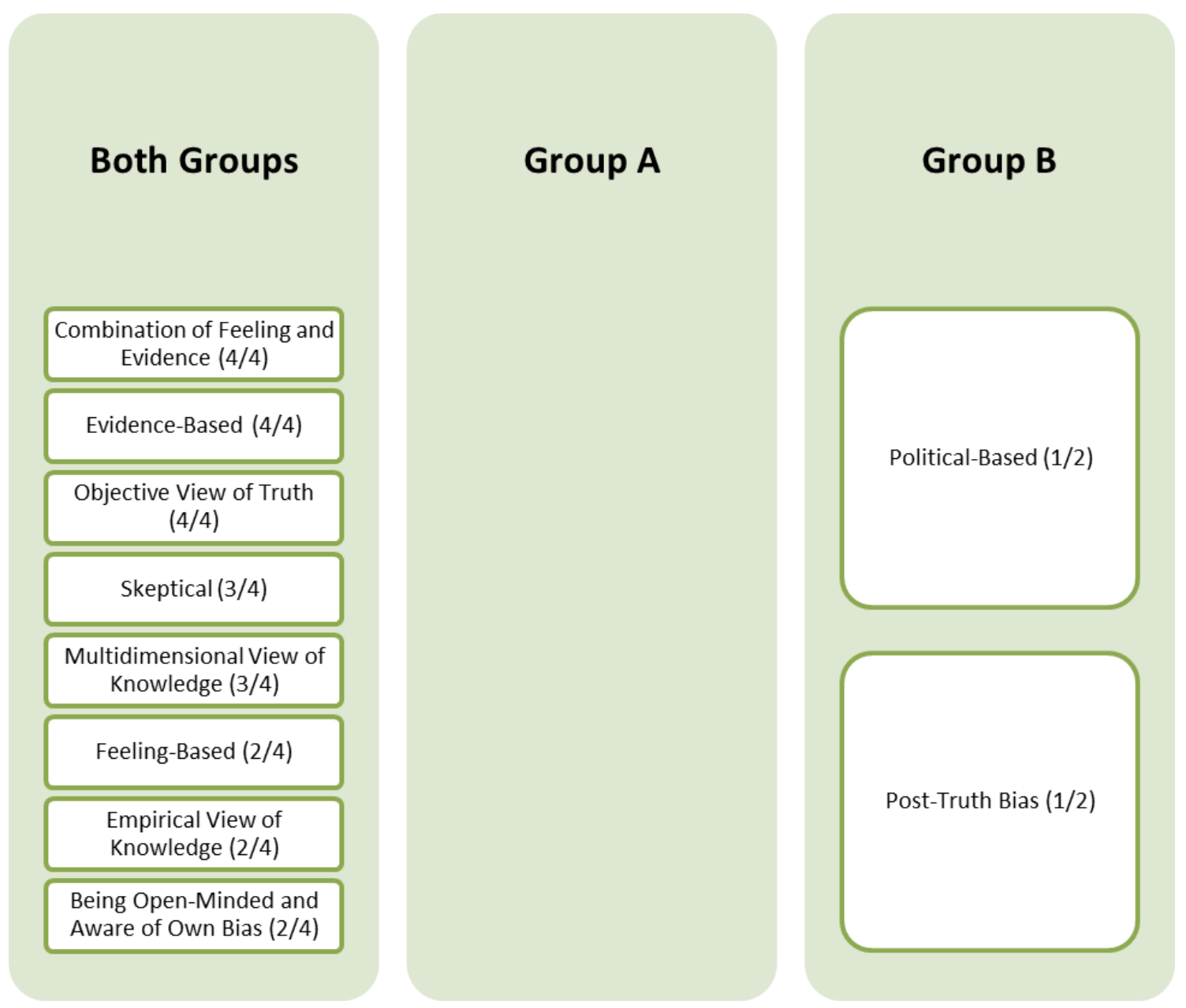

Figure 60. Epistemic Beliefs for the Not Trusted Hoax Websites Category. 
There were no unique sub-themes present only in Group A. One of the individuals in Group B had a political-based epistemic belief, which demonstrates that a political based view was present in all categories. Post-Truth bias was also present in Group B. Post- Truth bias was present in this category but only one of the individuals in Group B mentioned a comment related to it. This differed from the "Trusted Hoax Websites" category, where all individuals made post-truth bias statements. Below is the post-truth bias quote:

Table 98

Not Trusted-Post-Truth Bias

\begin{tabular}{lcc}
\hline & Interviewee & Group \\
\hline "Well they (Feelings, Intuition and Political Stance) definitely & 16 & B \\
affect my beliefs or anybody's beliefs on the credibility of a & \\
website or anything pretty much because either of those things, & \\
like intuition or political stance, gives people a predisposition & \\
towards things. So, for example, I don't really know much & \\
about politics in the US, but if I were a Republican and if I & \\
were to see a Democrat website, most likely, I would see it as \\
incorrect or false or something else. Definitely all that affects \\
our views because it gives us a predisposition to judge things." \\
\hline
\end{tabular}

Interviewee \# 16 believes that feelings, intuition or political stance can affect him and people in general due to the predispositions that they may have towards things. The example given was how Republicans would not trust information on a Democratic website due to their predispositions. This is interesting since it can also be referred to the idea of post-truth bias, mentioned earlier, where people will tend to trust content based on their views, beliefs, upbringing etc. despite of the evidence. Finally, interviewee \# 8 explained the belief of having a political based epistemic belief. 
Table 99

Not Trusted-Political-Based

"I believe that what counts as truth is defined by power

Interviewee Group

because in like certain instances people will rely on or trust

people who have more power because they obviously have

more experience and research, so for example like a scientist if

he comes across a conclusion his answer will be more reliable

than like somebody like me who hasn't had that much

experience in that field, so the fact that he has more power

makes his conclusions or response to the situation more

reliable than mine. That is why I believe that power would be

like more a reliable source to define like concrete information."

The neutral category also contained the two major themes of web evaluation strategies

and epistemic beliefs.

\section{Neutral Category (Neither Trusted or Not Trusted the Hoax Websites)}

The two major themes found within the neutral category were Web Evaluation

Strategies and Epistemic Beliefs. There was a total of four interviewees in this category, two from Group A and two from Group B. The section below contains information on the various sub-themes that arose from each theme:

Web Evaluation Strategies. The following is a list of the six major sub-themes mentioned under Web Evaluation Strategies that were mentioned by neutral interviewees $(5,11,14 \& 15)$ from both Group A and Group B.

1. Aesthetic Appeal (4/4)

2. Prior Knowledge (3/4)

3. No Prior Knowledge (2/4)

4. Not Making Sense (2/4)

5. Not Spending Sufficient Time to Read and Evaluate (2/4) 


\section{Poor Design/Layout (2/4)}

Just like in all the previous categories, the individuals that were neutral (Interviewees $5,11,14 \& 15)$ said that the aesthetic appeal was important. Below are statements made about evaluating based on the aesthetic appeal:

Table 100

Neutral-Aesthetic Appeal

"I think I evaluated it off of the looks. Yeah and how they Interviewee Group designed it." 5 A

What features did you pay attention to when evaluating the websites? "Pictures." Pictures? "Yeah the pictures and the colors. The colors are like cool. That's pretty much it."

What led you to accept or disregard the information posted on the websites?

"I don't even know. I think like the pictures and I think layout is like important."

"Usually when you want to evaluate a website a lot of the times design is very important because design shows that there was like intelligent thought and purpose behind the making of that website. Usually hoax websites don't have, lack very, very little design choice."

"The first thing I evaluate is the design." "Yeah, I studied graphic design in Miami Dade College, so that sort of allowed me to judge the look of the website and aside from that I'm also how text is laid out as well, that's another thing."

"I feel like a website should have an appealing look for it to have students or people adults engaged to what they want us to know."

What features did you pay attention to when evaluating the websites?

"Mostly the visual presentations like the pictures."

"So first as I said before, I used I looked at the content and then 
Every neutral interviewee evaluated the websites based on aesthetic appeal. Interviewee \# 5 evaluate the websites based on looks, colors used, pictures and layout. Interviewee \# 15 said that design is the first thing that he uses to evaluate the websites, especially since he studied Graphic Design and believes that colors, how text is laid out and overall design shows "intelligent thought" and the time spent to design it.

Interviewee \# 11 believes that websites need to have an appealing look and that the overall visual presentation and pictures were the features that she paid attention to when evaluating the websites. Interviewee \# 14 also looked at the pictures. Aesthetic appeal was a sub-theme present in all categories. Another sub-theme was knowing the definition of a hoax website. All interviewees knew the definition of a hoax website. Below are the definitions provided:

Table 101 Neutral-Knowing the Definition of a Hoax Website

\begin{tabular}{lcc}
\hline & Interviewee & Group \\
\hline "Probably something fake." & 5 & A \\
"A website that isn't doing or portraying what they are doing & 15 & A \\
or what they claim to be doing or portraying." & & \\
"A website that is not true that provides false information." & 11 & B \\
"A hoax website to me is one that's not credible also one for \\
$\begin{array}{l}\text { example the tree octopus to me was a hoax website because } \\
\begin{array}{l}\text { 've never heard about it before, so something that I don't have } \\
\text { any evidence to back it up." }\end{array}\end{array}$ & B \\
\hline
\end{tabular}

The definitions above explain that a hoax website is something fake (Interviewee \# 5), does not portray what it claims (Interviewee \# 15), contains false information (Interviewee \# 11), and is not credible (Interviewee \# 14). All of them display an understanding of the essence of a hoax website. It may be that knowing the definition of a 
hoax website may assist a person's chances to remain neutral on whether to trust the content or not. Another sub-theme in this category was prior knowledge. Some talked about evaluating the websites based on their prior knowledge. Below are statements made by interviewees 5,11 and 14 about prior knowledge:

Table 102

Neutral-Prior Knowledge Interviewee Group

"Previous knowledge was the big key that I used."

What resources did you use? "Prior knowledge, other websites, notes and that's really it."

5

11

B

'Like I said, like if I for so long I've learned about something and I've expanded like my research on something and I've gotten to know that topic or something and I come to a website and its telling me something completely different then I don't know, I don't know how to explain that one. Um" But would you accept it or not? "I think that would depend on the information that's being provided to me through the website." So, you would be resistant? "Yeah, I would be resistant."

"Something true for me would be that I know the information. I learned about it and I know that I can use it in the future."

"I evaluated the websites by first scrolling through and looking at the content and reading and then I would try and remember if I ever learned anything about the information that was given." So, you used prior knowledge? "Yeah."

Interviewee \# 5 said that she used her prior knowledge has the main thing when evaluating the websites. Prior knowledge was also mentioned as a resource that was used by Interviewee \# 11 and that she would be resistant if the website did not align with her prior knowledge. Interviewee \# 14 referred to prior knowledge in the context of defining truth. Truth is related to whether something is known, and the websites were evaluated 
based on prior knowledge. Some also talked about how the lack of prior knowledge

affected whether a website was trusted or not. Below are quotes made by Interviewee \# 5

and 14 in regard to having no prior knowledge:

Table 103

Neutral-No Prior Knowledge

"If I don't know much about the topic, I don't want to say I
trust it because they can be getting the information like from
Wikipedia."
"I don't know much about any of the topics, other than what I
saw on the websites."
"Well it depends on the topic. I think like if it's science, I don't
know much about science, so I'm not going to sit there."
"My favorite one was probably the tree octopus because it was
kind of interesting to see something that I've never heard about
never actually learned about it, so it was about new
information."
"So, the tree octopus I know that it wasn't real, so it definitely
stood out for me because I've never heard of it before."
"The content that led me to believe that it wasn't true was the
fact that I've never heard of a tree octopus was before."

Based on the quote above, it seems that if there is no prior knowledge on the website's content, then Interviewee \# 5 would not trust it and just remain neutral. Interviewee \# 14 said something similar regarding the Tree Octopus websites. She stated that she had never heard about a tree octopus before, therefore she did not trust it. Although in the questionnaire, she remained neutral regarding the trust level. Another important aspect that led interviewees to remain neutral as when the websites did not make sense. Below are two quotes by Interviewee \# 15 and 14 regarding this sub-theme: 
Table 104

Neutral-Not Making Sense

\begin{tabular}{lcc}
\hline & Interviewee & Group \\
\hline "The octopus website, that's that was a very random website. I & 15 & A \\
don't know why would anybody would make a website just & & \\
devoted to octopi." & & B \\
"The content that led me to believe that it wasn't true was the & 14 & \\
fact that I've never heard of a tree octopus was before. I knew & \\
the octopuses can't live in trees."
\end{tabular}

Both statements above were regarding the Tree Octopus website not making sense. Interviewee \#15 described it as random and not making sense that there would be a website just about octopi. Interviewee \# 14 said that octopuses are not able to live in a tree. Based on the last two sub-themes. The interviewees remained neutral because the websites did not make sense and there was not prior knowledge on the content. Another aspect was not spending sufficient time to read and evaluate. Table 105 contains a few quotes on this sub-theme:

Table 105

Neutral-Not Spending Sufficient Time to Read and Evaluate

\begin{tabular}{|c|c|c|}
\hline $\begin{array}{l}\text { "First, I went to the website and I looked at the homepage and } \\
\text { saw what was on there first and I kind of clicked each of the } \\
\text { tabs and scrolled down and read some stuff and then got bored } \\
\text { and then left it. (Laughs)" }\end{array}$ & 5 & $\mathrm{~A}$ \\
\hline $\begin{array}{l}\text { "If you give me like a day, I probably would have like } \\
\text { researched it and then know more about the topics and } \\
\text { evaluating them." }\end{array}$ & & \\
\hline $\begin{array}{l}\text { Did you notice any hoax websites? } \\
\text { "No." What about the one that you googled the tree octopus } \\
\text { one?" Oh well yeah, I did, but after reading it a couple of times } \\
\text { and discussing it with my classmates but at first, I thought it } \\
\text { was true. I was like wow there really is such a thing." }\end{array}$ & 11 & B \\
\hline
\end{tabular}


Interviewee \# 5 said that after reading some stuff, "she got bored and left it." She also stated that if more time was given to her like, for example a day, then she would have researched and evaluated the websites. Interviewee \# 11 remained neutral regarding the Tree Octopus website and did not find out it was a hoax until after the questionnaire was completed and additional time was spent researching and discussing it with her classmates. It may be that if additional time was spent by both of the interviewees above, then they would have most likely made a choice as to whether they trusted or not trusted the websites and not remain neutral. The last sub-theme present in both Group A and Group B was evaluating based on poor design/layout. It seems that if the websites were poorly designed, it was seen as antiquated and a red flag. Below are statements made by Interviewees \# 15 and 11 regarding the poor design and layout:

Table 106 Neutral-Poor Design/Layout

\begin{tabular}{|c|c|c|}
\hline & Interviewee & Group \\
\hline $\begin{array}{l}\text { "Also, some of them seemed very, very, very antiquated. } \\
\text { Didn't have really any tabs or any search fields or anything like } \\
\text { that, and then some of them did have some of those things, but } \\
\text { they barely had any information besides maybe a contact list." }\end{array}$ & 15 & A \\
\hline $\begin{array}{l}\text { "There were very few that were very well organized and } \\
\text { appealing to the eye. My thing is that most of them were kind } \\
\text { of bad designed, were kind of random websites that really } \\
\text { nobody goes to." }\end{array}$ & & \\
\hline $\begin{array}{l}\text { What red flags did you noticed when evaluating the websites? } \\
\text { "Some of them were disorganized." Would that be a red flag? } \\
\text { Yes, did you notice anything else? "Not that I can remember. } \\
\text { Not all of them. The design and whether they were } \\
\text { disorganized or not." }\end{array}$ & 11 & B \\
\hline
\end{tabular}

Interviewee \# 15, who had previously mentioned having studied graphic design, described some of the websites as antiquated and badly designed. This led him to remain 
neutral regarding whether to trust it or not. Poor design and disorganization were seen as red flags by Interviewee \# 11. Aesthetic Appeal, Prior Knowledge, No Prior Knowledge, Not Making Sense, Not Spending Sufficient Time to Read and Evaluate, and Poor Design/Layout were the sub-themes that led the interviewees to remain neutral in regard to trusting the websites by interviewees from both Group A and Group B. The next section reviews the web evaluation strategies present only in Group A or Group B. Below are the sub-themes present only in Group A or Group B:

Group A:

1. Linear Reading (2/2)

2. Authorship (1/2)

3. Ads/Asking for Money (1/2)

4. Complex Terminology (1/2)

5. Not Useful $(1 / 2)$

Group B:

1. Lateral Reading (2/2)

2. WWWDOT Framework (2/2)

3. No experience Evaluating Websites (1/2)

4. Ease of Use (1/2)

5. Useful $(1 / 2)$

These are graphically represented in Figure 61: 

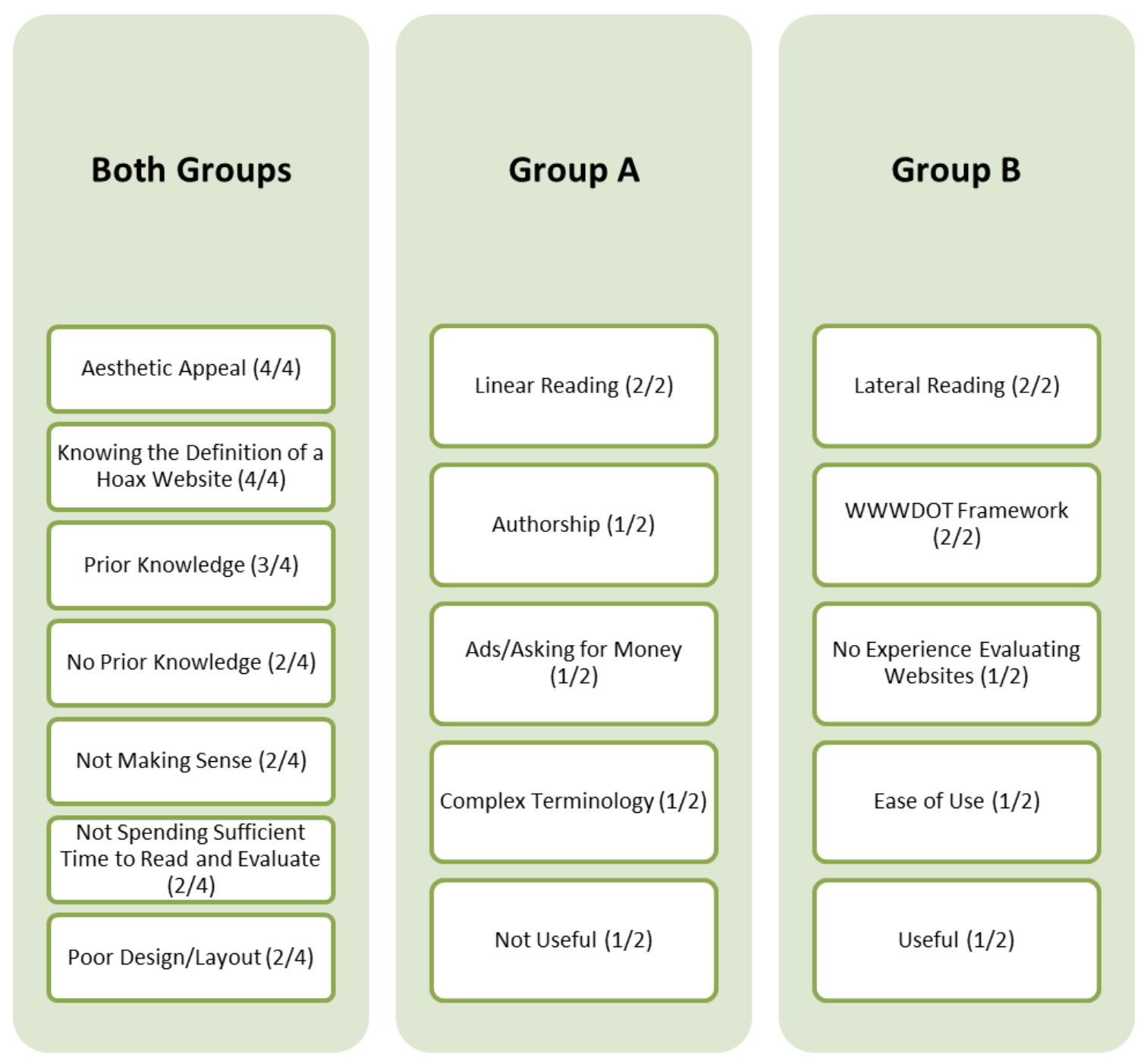

Figure 61. Web Evaluation Strategies for the Neutral Category.

Both interviewees from Group A read the content on the websites linearly, which meant that they stayed within the websites. Below are statements made by Interviewee \# 5 and 15: 
Table 107

Neutral-Linear Reading

\begin{tabular}{lcc}
\hline & Interviewee & Group \\
\hline "I don't think. I don't know much about any of the topics, & 5 & A \\
other than what I saw on the websites. If you give me like a \\
day, I probably would have like researched it and then know \\
more about the topics and evaluating them." \\
$\begin{array}{l}\text { What sources did you use? No, I didn't think it was necessary. } \\
\text { I didn't have to." }\end{array}$
\end{tabular}

Interviewee \# 5 did not use other websites and said that she would need at least a day to properly evaluate them. No sources were used by Interviewee \# 15, who said that he did not thought it was necessary. This suggests that they both remained neutral in regard to trusting the content since no in-depth research was conducted or any sources were used. Interviewee \# 5 also mentioned a few sub-themes such as authorship, ads/asking for money and complex terminology as possible reasons as to why the information was neither trusted or not trusted. These sub-themes match statements made by other interviewees in previous categories. Below are the statements made by Interviewee \# 5: 
Table 108

Neutral-Authorship. Ads/Asking for Money and Complex Terminology

\begin{tabular}{|c|c|c|}
\hline & Interviewee & Group \\
\hline $\begin{array}{l}\text { Authorship } \\
\text { What do you think you would've pushed you to trust or not } \\
\text { trust it? I think if there was a teacher there telling me that they } \\
\text { trust that website. So, expertise and knowledge in the area? } \\
\text { Yeah }\end{array}$ & 5 & $\mathrm{~A}$ \\
\hline $\begin{array}{l}\text { "Knowing more about the company that's making the website } \\
\text { and the purpose of it. Some of the people that sponsor them." }\end{array}$ & & \\
\hline Ads/Asking for Money & & \\
\hline $\begin{array}{l}\text { Would you use any of the websites in the future? } \\
\text { "Probably not because some of the websites had advertisement } \\
\text { and stuff and that's always a bad sign." }\end{array}$ & 5 & A \\
\hline $\begin{array}{l}\text { I think I evaluated it off of the looks. Yeah and how they } \\
\text { designed it the organization levels and the advertisements." }\end{array}$ & & \\
\hline $\begin{array}{l}\text { Did you notice any red flags? "The advertisements... that's } \\
\text { pretty much it." }\end{array}$ & & \\
\hline $\begin{array}{l}\text { "Other times they had supporters or people who got paid for } \\
\text { the site, which is iffy. Why are they paying for the website?" }\end{array}$ & & \\
\hline Complex Terminology & & \\
\hline $\begin{array}{l}\text { "I think the way they worded the information it sometimes } \\
\text { throws me off." }\end{array}$ & 5 & A \\
\hline
\end{tabular}

It seems that if Interviewee \# 5 had someone, such as an expert that is knowledgeable in the area, telling her that the website was true then it would have pushed her to trust it. Also, if she knew more about the company who made the website, its purpose or the people that sponsor it, then she would have felt more comfortable trusting the content. Ads and asking for money was the main red flag that led her to remain neutral as well as complex wording, which threw her off sometimes. The final sub-theme 
in Group A was finding the websites as not being useful. This was expressed by

Interviewee \# 15. Below are his statements:

Table 109

Neutral-Not Useful

"The information seemed like miscellaneous. In the sense that

Interviewee

Group it really has nothing to do with anything that I'm studying or anything pertaining to me, so it may be true information or maybe false, but there's no way that I can make a statement. I can't conclude on a response because I have to, I need to prove my own statements so that the evidence isn't inconclusive."

It may be that Interviewee \# 15 remained neutral since he did not find the websites to be useful. The websites were described as miscellaneous and not applicable to his life. The following sections contains the web evaluation sub-themes that were only present in Group B.

Group B differed from Group A since the interviewees read laterally instead of linearly. Interviewee \# 11 and 14 also used the WWWDOT Framework. Below are the statements made for these two sub-themes: 
Table 110

Neutral-Lateral Reading and WWWDOT Framework

Lateral Reading

Interviewee Group

Why did you believe some websites and not the others?

11

B

"Because they sounded convincing. That's why at first like for the first, like the Tree Octopus, at first it sounded convincing. It got to the point where it led me to search if it was true or not because I wanted to see if there was such a thing as an octopus living on a tree."

What resources do you use to verify whether information is credible? "Prior knowledge, other websites, notes and that's really it."

"For the tree octopus one I went to go to see if it was fake on google."

"So, for the tree octopus for example I tried to Google it to see not."

\section{WWWDOT Framework}

"I did use the who, what, when. I started looking when was it published, who was it published by, their purpose of why publishing the websites. That's what I would really look for in the websites. So, then you did use the www framework? Now that you broke it up, I do remember using that the who, the what and the when in regards to that."

'Like I know how to evaluate websites now. Cause I didn't even know there was such a thing as doing that." Do you think the WWW DOT framework helped you a little? "Yeah it did."

"For the tree octopus one I went to go to see if it was fake on google. Was that based on the WWW DOT Framework? "Yes." So for strategies, I did use the 5W's, so I didn't, I didn't look at the who, but I did look at what it was and why it's there and what the animal one does. For example, about the one about the tree octopus

"I know that now, from now on, when I look at websites, I have to make sure that that they are credible sources by looking at the date, the publisher, etc." 
Interviewee \# 11 looked at other websites to make sure if the Tree Octopus was true or not since it sounded convincing to her. Interviewee \# 14 used google to check if the information was real or not. Both of them also used the WWWDOT Framework. Interviewees \# 11 and 14 both focused on the W's (Who, what, when) and it may have helped in allowing them to at least remain neutral in regard to trusting the content.

Interviewee \# 11 also mentioned that aside from this experience, she had never evaluated a website before and that it is important that the websites are easy to use and accessible.

Below are her statements regarding these two sub-themes:

Table 111

Neutral-No Experience Evaluating Websites and Ease of Use

No Experience Evaluating Websites Interviewee Group

'Like I know how to evaluate websites now. Cause I didn't 11 B even know there was such a thing as doing that."

Ease of Use

Would you use these websites in the future? "I would. They

11

B were very accessible, so I feel like my students would gain a lot out of them."

Finally, Interviewee \# 14 mentioned that something is true if it is useful. This aligns with the quantitative results:

Table 112

Neutral-Useful Applicable

"Something true for me would be that I know the information. I Interviewee Group learned about it and I know that I can use it in the future."

Aside from the web evaluation strategies theme, the other theme present in this category was epistemic beliefs. The following section contains the epistemic beliefs that resulted from the interviews in the neutral category. 
Epistemic Beliefs. The following is a list of the five major sub-themes mentioned under Epistemic Beliefs displayed by both Group A and Group B in the neutral category:

1. Evidence-Based (4/4)

2. Combination of Feelings and Evidence (4/4) Using feelings initially and feelings with academic and evidence for science

3. Post-Truth Bias $(2 / 4)$

4. Feeling-Based (2/4)

5. Subjective View of Truth $(2 / 4)$

6. Objective View of Truth $(2 / 4)$

All four individuals in the neutral category made statements that were

evidence-based. Table 113 contains all of the evidence-based quotes from this category:

Table 113

Neutral-Evidence-Based

"I think the research to back up the statement makes it the Interviewee truth."

'I can't conclude on a response because I have to, I need to 15 A prove my own statements so that the evidence isn't inconclusive."

"Truth is basically a synonym of fact. It needs to be demonstrable with proof that has proof that has evidence that is not only like I said demonstrable but also verifiable."

"I need to have evidence backing it up such as maybe video, audio, other peers stating the same thing or a published work."

What makes something true for you? "If I can prove it if I have enough evidence to conclude that it's true."

What makes information credible for you? "If it has something to back it up." 
What makes something true to you?" If I can see proof'

For example?

"For example, if a website is telling me that there is such a

thing as goldfishes and I go to the river and I see goldfishes

that'll help me find out what's true."

"I don't think I would use the websites because when I looked

at them the information didn't seem accurate enough like there was no evidence to back it up."

Interviewee \# 5 talked about how backing up statements with research makes it the truth. The statements made by Interviewee \# 15 were all about facts, demonstrable, proof, and evidence. Interviewee \# 11 also talked about the importance of proof and Interviewee \# 11 mentioned evidence to back up the content on websites. It may be that they all remained neutral due to their strong evidence-based epistemic beliefs. All these individuals also mentioned using a combination of feelings and evidence. This was similar to other categories. Table 114 contains the statements made about using a combination of feelings and evidence:

Table 114

Neutral-Combination of Feelings and Evidence

\begin{tabular}{l}
\hline \\
"I think a little of both (feelings and facts) because sometimes \\
evidence doesn't really support the claim you are trying to \\
make."
\end{tabular}


"So, feelings intuition or political stance should have no effect at all on fact or truth, but one sometimes you need to draw a conclusion to come to an answer that based on the information given, you need to use some form of feeling and feeling sometimes it's connected to usually what can let's say one piece of evidence plus another piece of evidence can conclude on."

"The way it affects me is what I've already said you need to have facts or evidence, so that you can come to a conclusion for an answer. Sometimes you're not going to have the exact information you need to come to a conclusion, so all you can do is try to speculate."

"Both. Feelings and intuition facts and evidence." Can you give me an example as to when you use feelings and intuition or facts and evidence?

"Evidence I would say like I use evidence on a daily basis. Like for example, in school for example like if I'm taking a test or something and I need evidence on what my answer is going to be or something, I can always go back to the textbook and find out the facts of something, so I will obviously not get the answer wrong and for feelings, feelings I would say past experience on something."

"I used my intuition, but I mostly, I based it on if I knew it with evidence. So, if I didn't know any evidence that backed it up, then I knew that it wasn't real."

Interviewee \# 5 admitted to using both feeling and facts since sometimes evidence is not able to support what you are trying to claim. This remark is also related to post-truth bias since it seems that if the evidence or facts do not support the claim or belief then she would rely on instead on her feelings. Interviewees \# 15 and 11 also said that they use a combination of feeling and evidence depending on the situation. In addition, they stated that evidence and facts are used more for academic purposes and feelings for "social family things" and "life decisions" (Interviewee \#15) or "past experiences" (Interviewee \# 11). Interviewee \# 14 stated that she used her intuition but 
mainly used evidence to evaluate the websites. All of the neutral interviewees relied on a combination of feelings and evidence. Some seemed to lean more towards the evidence side, such as Interviewee \# 14 and 11, and others leaned more towards the feeling side, such as Interviewees \# 5 and 14. Below are statements made by these interviewees regarding feeling-based epistemic beliefs:

Table 115

Neutral-Feeling-Based

"I don't know from past websites that I have seen like that it just gives me like a bad feel."

Interviewee Group

So, you don't think that knowledge can influence whether you

believe in something or not? It's just more based on feeling?

"Yeah, I think so"

"I felt more confident with myself and my decisions and I

know that I can trust my intuition."

"I think with my intuition and my gut feelings I think I can tell in the future what I can trust and what I can't trust."

Interviewees \# 5 said that one of the websites gave her a bad feeling. This may be why she remained neutral regarding whether to trust the hoax websites or not. In addition, she confirmed that she thinks that feelings can influence whether you believe in something or not. Interviewee \# 14 stated that she uses her intuition and gut feeling to determine whether a website can be trusted or not and felt confident using this strategy. Although in this situation, no decision was made regarding whether the websites were trusted or not since Interviewee \# 14 remained neutral. Interviewee \# 5 and 11 also made various statements that suggested a post-truth bias position. Below are the post-truth bias statements made by these two individuals: 
Table 116

Neutral-Post-Truth Bias

"If I don't agree with something, I'm going to be like, they Interviewee Group didn't do the research and shut it down."

'Well it depends on the topic. I think like if it's science, I don't know much about science, so I'm not going to sit there, but if it's like something to do with disabilities or something, I'd probably be like you don't know what you're talking about, if I see something that I find wrong."

So, something that you are passionate about? "Yes, versus something ... that I don't really care for."

"So, if I don't believe the evidence, then that's it it's not going to be something I think is credible."

"I think a little of both (feelings and facts) because sometimes evidence doesn't really support the claim you are trying to make."

Do feelings affect the credibility of a website? 'It would affect it because let's say if I believed in something for so long that was true, and I come to a website and it tells me something different. It does affect it because for so long I believed in something and then I come to find out through a website that it is probably not true."

How does it affect? "My beliefs?" Yeah how? "Yeah probably like lose hope or something." So, you would be disappointed? "Disappointed there you go. So, you would like to find a website that aligned with what you believed? "Yeah" Even if it's true or not because you believed it for so long you have so much conviction on it? "Yeah."

'Like I said, like if I for so long I've learned about something and I've expanded like my research on something and I've gotten to know that topic or something and I come to a website and its telling me something completely different then I don't know, I don't know how to explain that one. Um" But would you accept it or not? "I think that would depend on the information that's being provided to me through the website." So, you would be resistant? "Yeah, I would be resistant." 
Interviewee \# 5 said that if she did not agree with something, then she would not accept it and think that they did not do the research; furthermore, the website was rejected or accepted depending on the subject. For example, Interviewee \# 5 could remain neutral about a subject such as science since she did not know much about, but if it had to do with disabilities then she would not trust it. This was especially true if it was based on something she finds wrong. Interviewee \# 5 explains that the subject of disabilities is something that she is passionate about. Interestingly, she also stated that if she did not believe the evidence, then she would not think that it was credible and that she relies on feelings sometimes when the evidence does not support the claim that she is trying to make.

All of these statements are related to post-truth bias since it seems that she is trying to justify not following evidence and using feelings instead when the content on the website does not align with personal beliefs. Interviewee \# 11 made a remark about losing hope if a website did not align with previous beliefs. She stated that feelings affect the credibility of a website since if something was believed for a long time and a website says that it is not true, then she would lose hope and be disappointed. She concludes that she would be resistant if the website did not align with her beliefs and prior knowledge. In previous categories, post-truth bias was associated with trusting hoax websites, especially if the content aligned with previous beliefs. It may be that in this category, the interviewees remained neutral since the content on the websites may not have appealed to their feelings. The last sub-theme that was present in both Group A and Group B was having a subjective view of truth. Below are remarks made by Interviewee \# 5 and 14: 
Table 117

Neutral-Subjective View of Truth

\begin{tabular}{|c|c|c|}
\hline & Interviewee & Group \\
\hline $\begin{array}{l}\text { "So, a website is just someone's beliefs or thoughts on the } \\
\text { topic. So, you just have to agree with them or not, to believe it's } \\
\text { true." }\end{array}$ & 5 & $\mathrm{~A}$ \\
\hline $\begin{array}{l}\text { "Truth to me is something that's there. Something that I } \\
\text { believe." }\end{array}$ & 14 & B \\
\hline
\end{tabular}

Interviewees \# 5 said that something is true if you agree or not with the beliefs or thoughts of the person who created the website. Interviewee \# 14 displayed a subjective view of truth since truth was defined simply as something that she believes. Having a subjective view of truth seems generally associated with trusting a hoax website since it was present in all of the categories, except the not trusted hoax websites category. Having a subjective view of truth constitutes the belief that anything can be considered true even if it is just based on opinions and thoughts. In this case, both interviewees remained neutral even though they both displayed a subjective view of truth. The other two neutral individuals displayed an objective view of truth. Below are their statements:

Table 118

Neutral-Objective View of Truth

"Truth means to me like ... to me the truth is more something Interviewee Group that I have. It has a big value to me. The truth is something that 11 B has value to it, it has meaning to it and it can't be fake, it needs to be realistic."

"Truth is basically a synonym of fact. It needs to be 15 A demonstrable with proof that has proof that has evidence that is not only like I said demonstrable but also verifiable."

Interviewees \# 11 and 15 had an objective view of truth. Truth was described as having to be realistic and not fake by Interviewee \# 11 and as being a "synonym of fact" 
by interviewee \# 15. In the trusted hoax websites category, most individuals had a subjective view of truth. In contrast most individuals had an objective view of truth in the not trusted hoax websites category. The neutral category had a balanced number of objective and subjective view of truth. The next section contains sub-themes that were only present in Group A or Group B. Below Figure 62, which summarizes the results of this category organized by group:
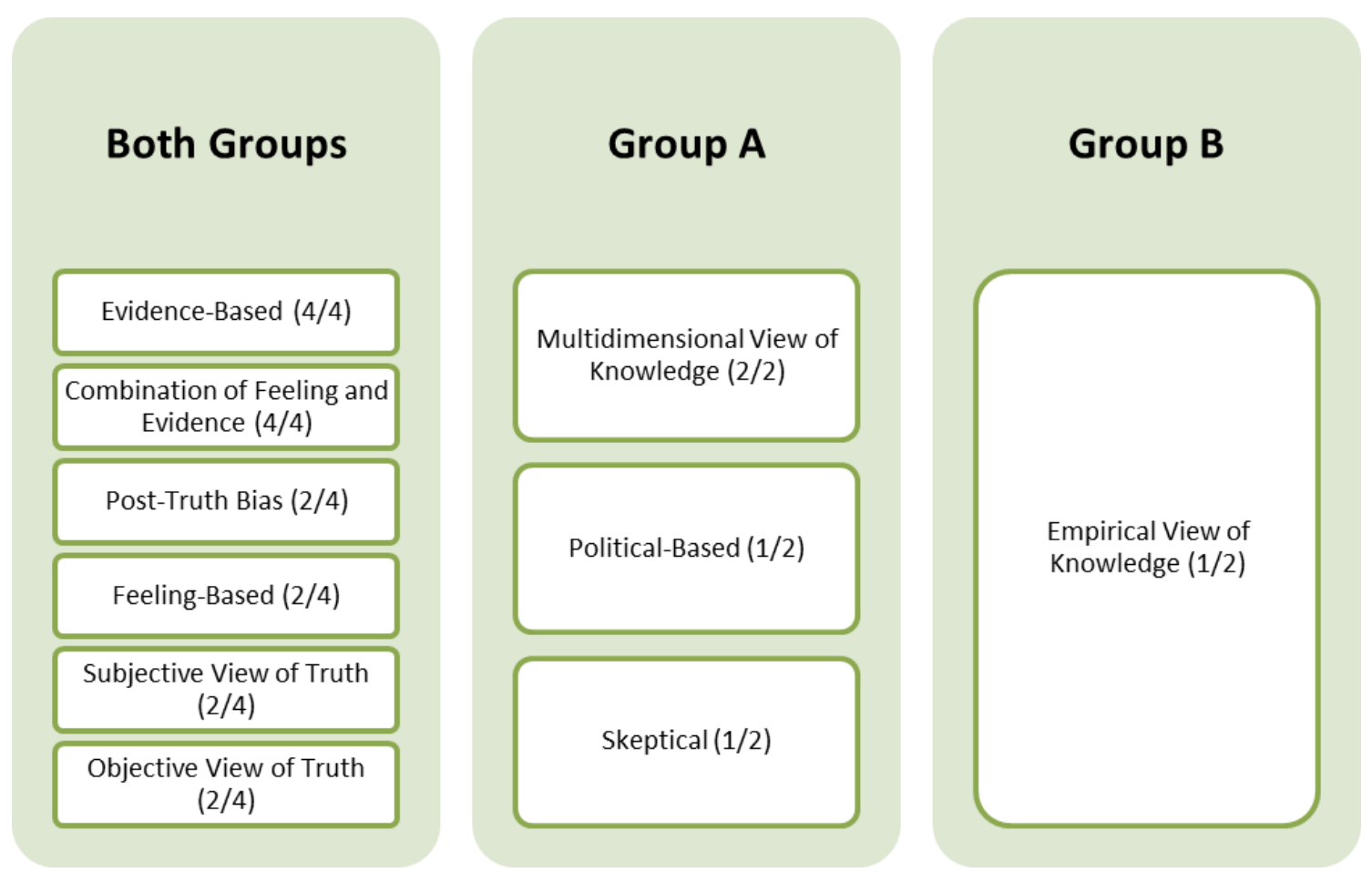

Figure 62. Epistemic Beliefs for the Neutral Category.

Both individuals from Group a had a multidimensional view of knowledge, which meant that they thought that knowledge could be true or false and can contain various aspects. One displayed political based epistemic beliefs and made skeptical remarks. An individual from Group B had an empirical view of knowledge and another had an objective view of truth. Below are the sub-themes by Group: 
Group A:

1. Multidimensional View of Knowledge (2/2)

2. Political-Based (1/2)

3. Skeptical $(1 / 2)$

Group B:

1. Empirical View of Knowledge (1/2)

Both Interviewee \# 5 and 15 displayed a multidimensional view of knowledge. Below are the statements made by these individuals:

Table 119

Neutral-Multidimensional View of Knowledge

\begin{tabular}{lcc}
\hline & Interviewee & Group \\
\hline "I think that depends on the person. Right? I mean knowledge & 5 & A \\
is just different for everyone, like street smarts and book & & \\
smarts, I think." & & A \\
"Knowledge can be gained through two different ways. Either & 15 & \\
through other people or directly from observation. So, therefore & & \\
knowledge can be objective or possibly or subjective." &
\end{tabular}

Interviewee \# 5 said that the definition of knowledge was different for everyone and that there are various kinds or aspects of knowledge such as book and street smarts. Interviewee \# 15 believes that knowledge can be objective and subjective and can be gained through other people or from observation. It may be that having a multidimensional view of knowledge led these individuals to remain neutral regarding whether to trust it or not since this sub-theme was also present in the not trusted hoax websites category. Interviewee \# 5 from Group A also displayed a political-based epistemic belief and made a few skeptical remarks. Below are the statements made of Interviewee \# 5: 
Table 120

Neutral-Political-Based and Skeptical

\begin{tabular}{lcc}
\hline & Interviewee & Group \\
\hline Political-Based & 5 & A \\
"I think I'm a very opinionated person when it comes to certain & & \\
things. So, I think the political stance takes a lot." & & \\
\hline Skeptical & 5 & A \\
"Websites are iffy because you can't always trust people to & \\
write down the correct information." & \\
'I feel like I need to do more research on topics I don't & \\
understand because when people put websites in front of me, I \\
don't want to trust them, but I want to because someone is \\
showing it to me, but I should probably look at more stuff."
\end{tabular}

Interviewee \# 5 considers herself an opinionated person and believes that her political stance influences a lot whether to trust or not a website. Political-based remarks were present in all the categories and therefore not associated with a particular category. These results align with the quantitative data of political-based epistemic beliefs not being statistically significant. The last two epistemic beliefs present in Group B only were having an empirical view of knowledge and an objective view of truth. Below are statements made by Interviewees \#15 and 11 regarding these two sub-themes:

Table 121

Neutral-Empirical View of Knowledge

\begin{tabular}{lcc}
\hline "So, as I said before, knowledge is gained through experience. & Interviewee & Group \\
That shows me that information will be true on a website & B \\
because I would I would know it from the past. I would know it & \\
if it existed from the past." So, your past experiences? "Yes." & \\
"I believe that knowledge is gained through experience and & \\
through studies."
\end{tabular}

As is evident by the statements above, Interviewee \# 14 believes that knowledge is passed on past experiences. The empirical view of knowledge sub-theme was present 
in all of the previous categories and may not be associated with a particular one however it was a bit more prevalent in the trusted hoax websites category compared to the others. The following section contains a holistic general view of the results from the sixteen interviews.

\section{Overview of All Categories}

This section contains a holistic overview of the qualitative results of the interviews for all the categories. This section is divided by the themes web evaluation strategies and epistemic beliefs.

Web Evaluation Strategies

Aesthetic appeal was the main web evaluation strategy used to evaluate the websites that was mentioned by the interviewees from all the categories. As is evident from the bar graph below all the interviewees from each category, except the "Not Trusted Hoax Websites" referred to aesthetic appeal. However, 75\% of the "Not Trusted Hoax Websites" category also mentioned aesthetic appeal. Below is Figure 63, which illustrates this: 


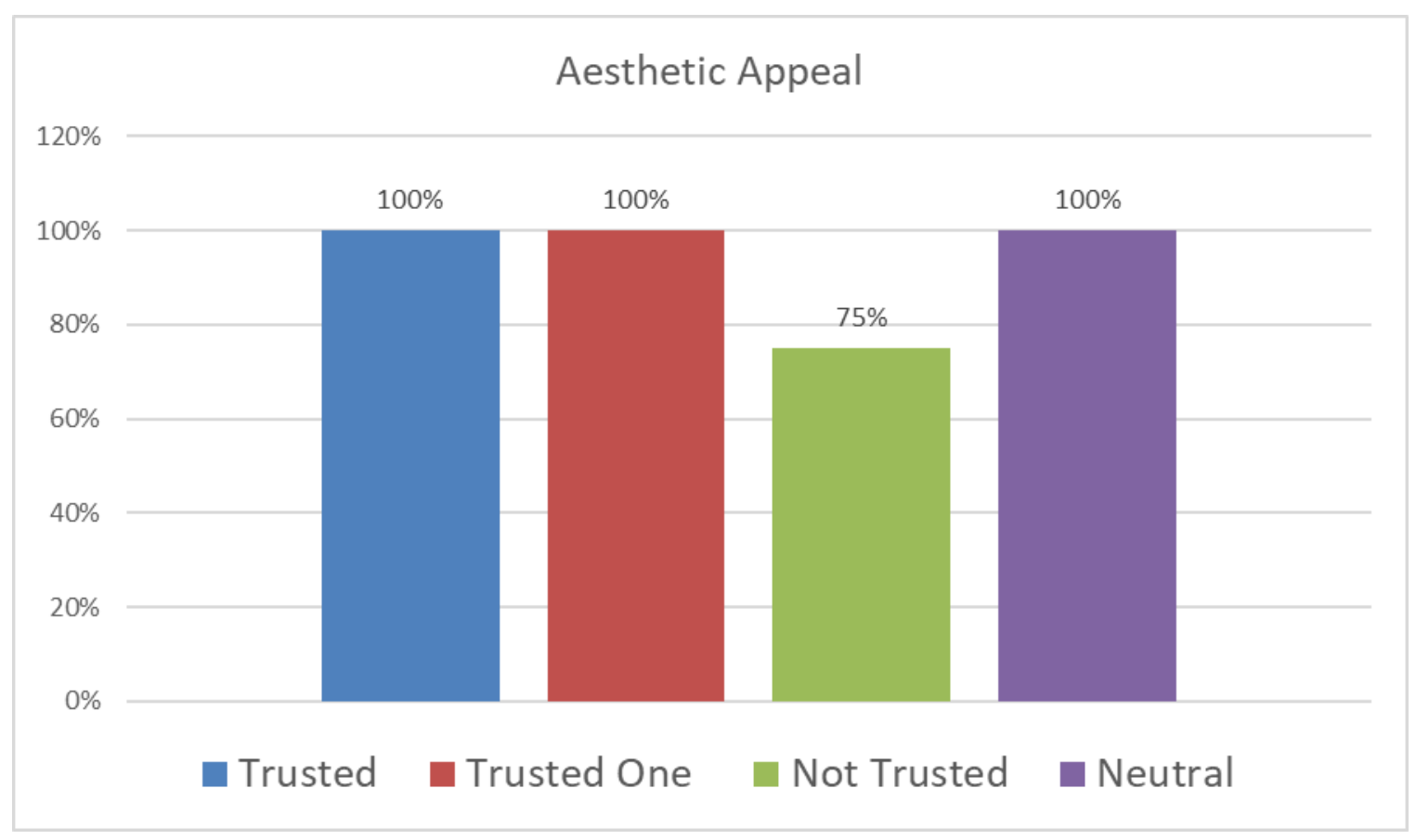

Figure 63. Aesthetic appeal for all categories.

The second aspect mentioned by the interviewees was time. More specifically, spending sufficient time to read and evaluate compared to not spending sufficient time. All the interviewees that trusted the hoax websites explained that they did not spend sufficient time evaluating them. In contrast, all the interviewees that did not trust the hoax websites stated that they spent sufficient time to read and evaluate the information. Of the individuals in the neutral category, $50 \%$ of them admitted to not spending sufficient time evaluating. In addition, $75 \%$ of the Trusted One Hoax but Not the Other category stated that they did not spend sufficient time evaluating either. Figures 64 and 65 below show the difference between the categories regarding this aspect: 


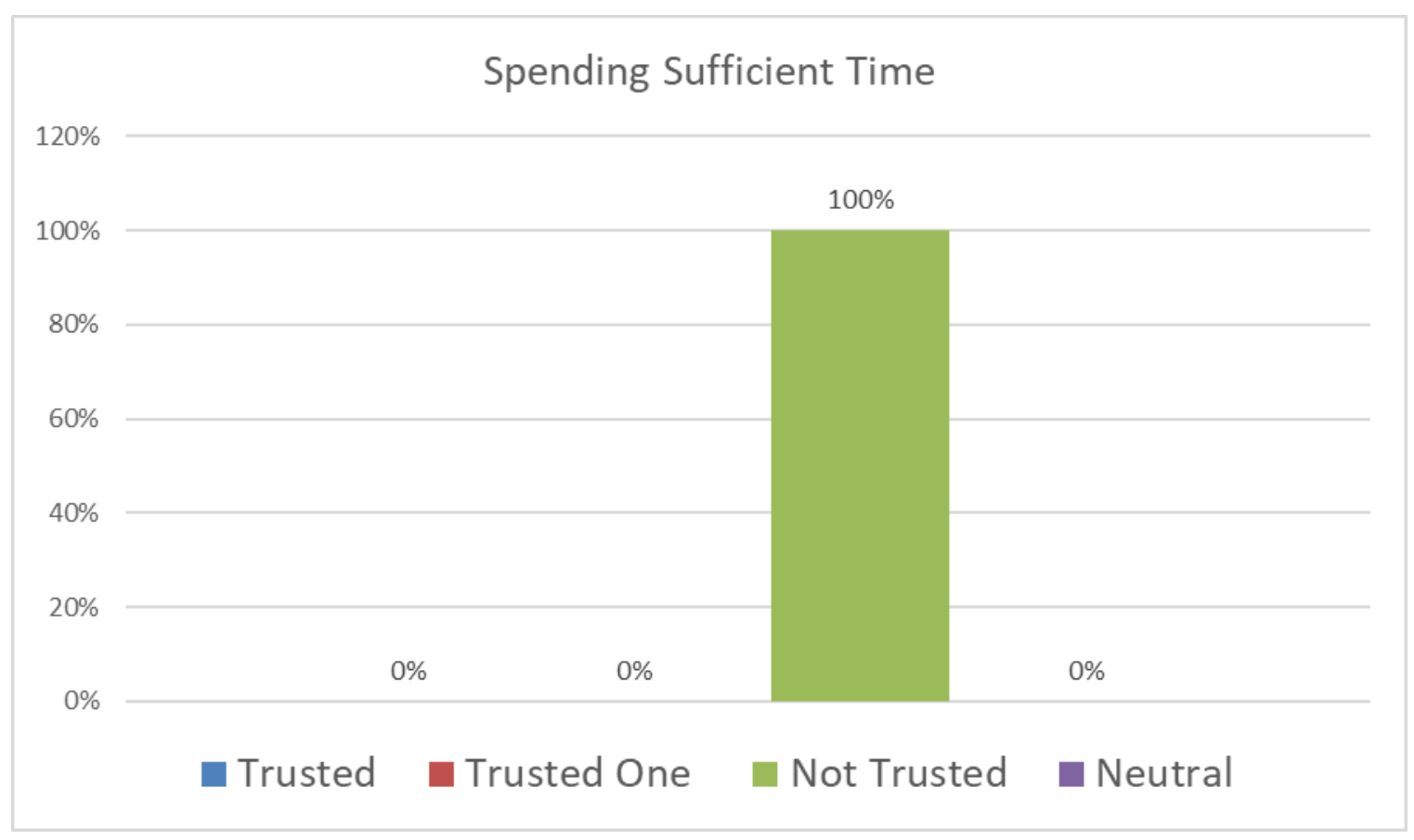

Figure 64. Spending Sufficient Time for all categories.

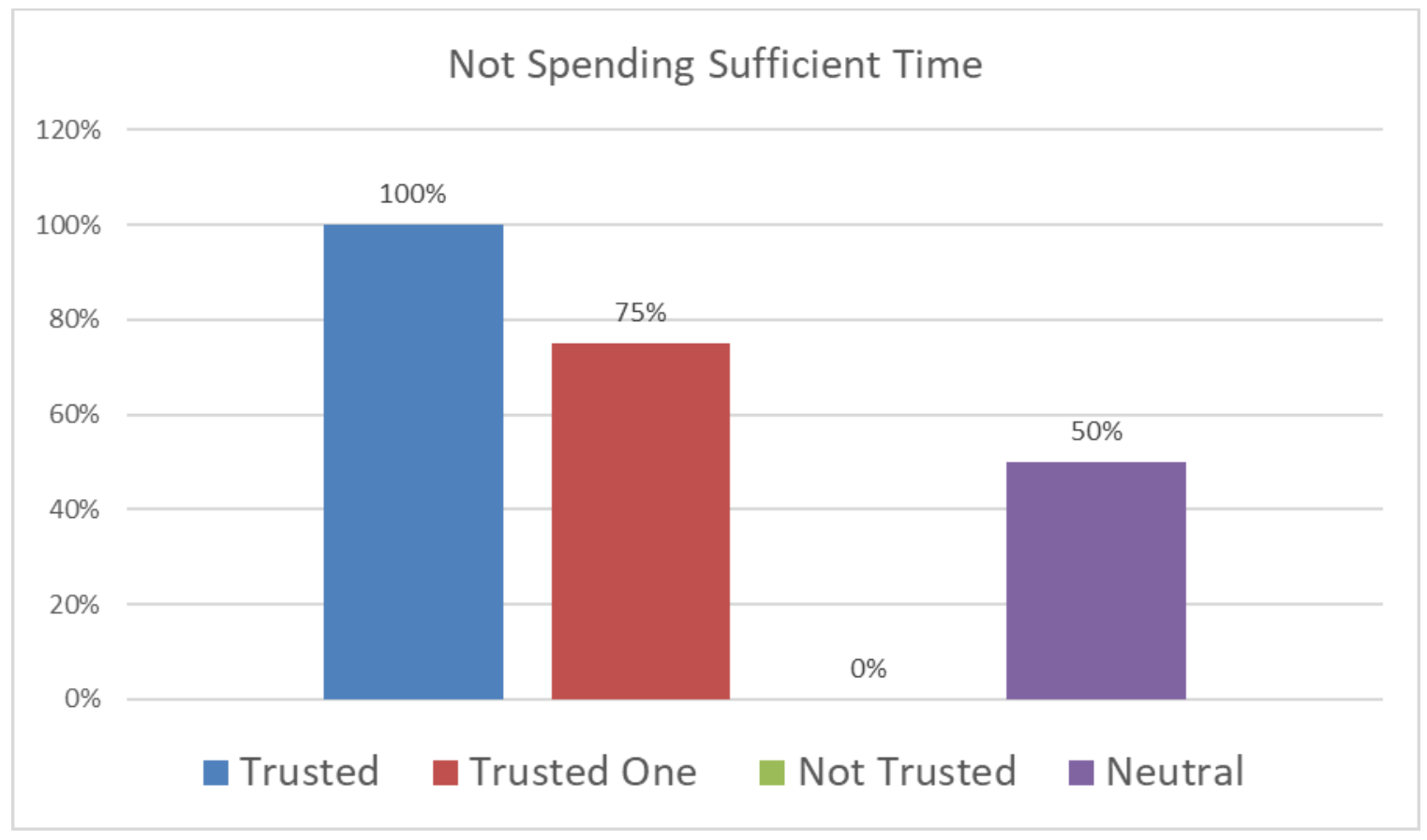

Figure 65. Not Spending Sufficient Time for all categories.

Another important aspect was lateral reading, especially among those that did not trust the hoax websites. In contrast, linear reading was displayed mostly by those that 
trusted the hoax websites. Below are Figures 66 and 67 that show the differences among the categories for lateral and linear reading:

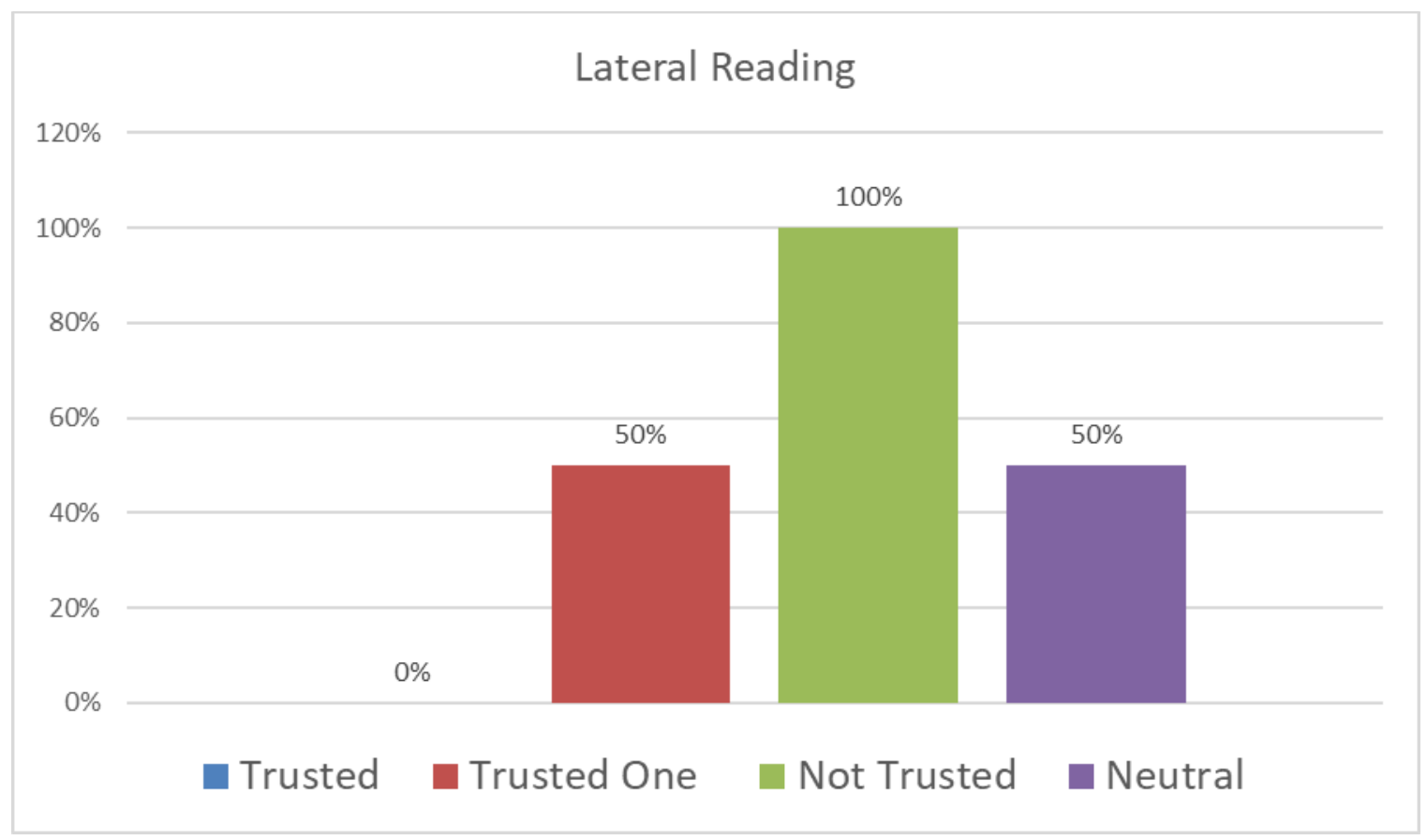

Figure 66. Lateral reading for all categories.

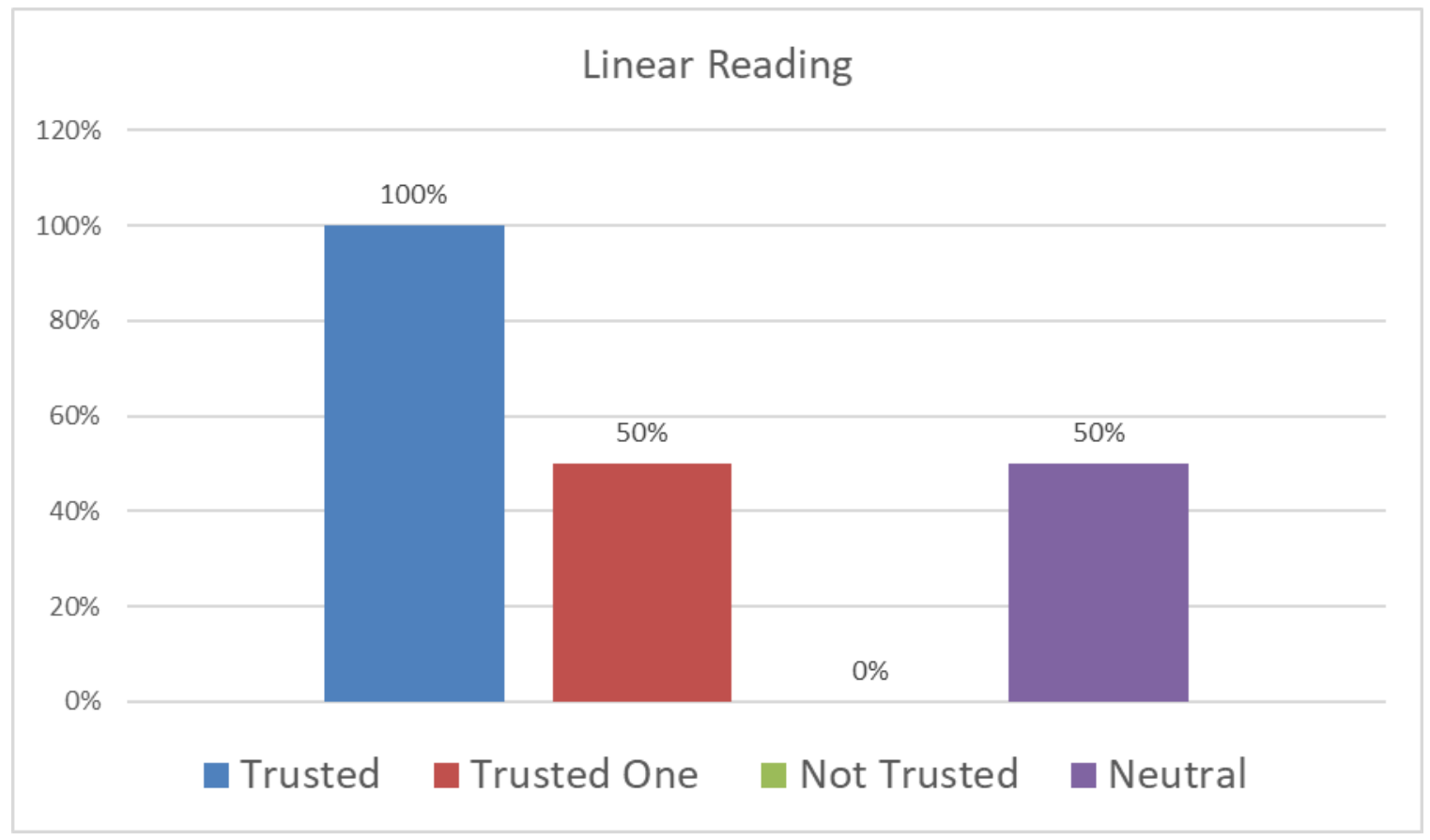

Figure 67. Linear reading for all categories. 
All the individuals from the "Not Trusted Hoax Websites" category practiced lateral reading, which means that they researched other websites and googled the information. In contrast, all the interviewees from the "Trusted Hoax Websites" category read linearly, which means that they read within the same website. The individuals that were a part of the "Neutral" and "Trusted One Hoax Website but Not the Other" categories were balanced between lateral and linear reading with half of them belonging to each one. Another sub-theme present was whether they knew the definition of a hoax website or not.

Most of the individuals that trusted the hoax websites did not know the definition. In contrast, many of the individuals in the other categories did know the definition. More specifically, $75 \%$ of the "Trusted Hoax Websites" category did not know the definition. Conversely, all the individuals in the neutral category, $75 \%$ of the "Trusted One Hoax but Not the Other" category, and $75 \%$ of the "Not Trusted Hoax Websites" category did know the definition of a hoax website. It may be that knowing the definition of a hoax website might increase the chances to not trust hoax websites. Below are Figures 68 and 69 with the results: 


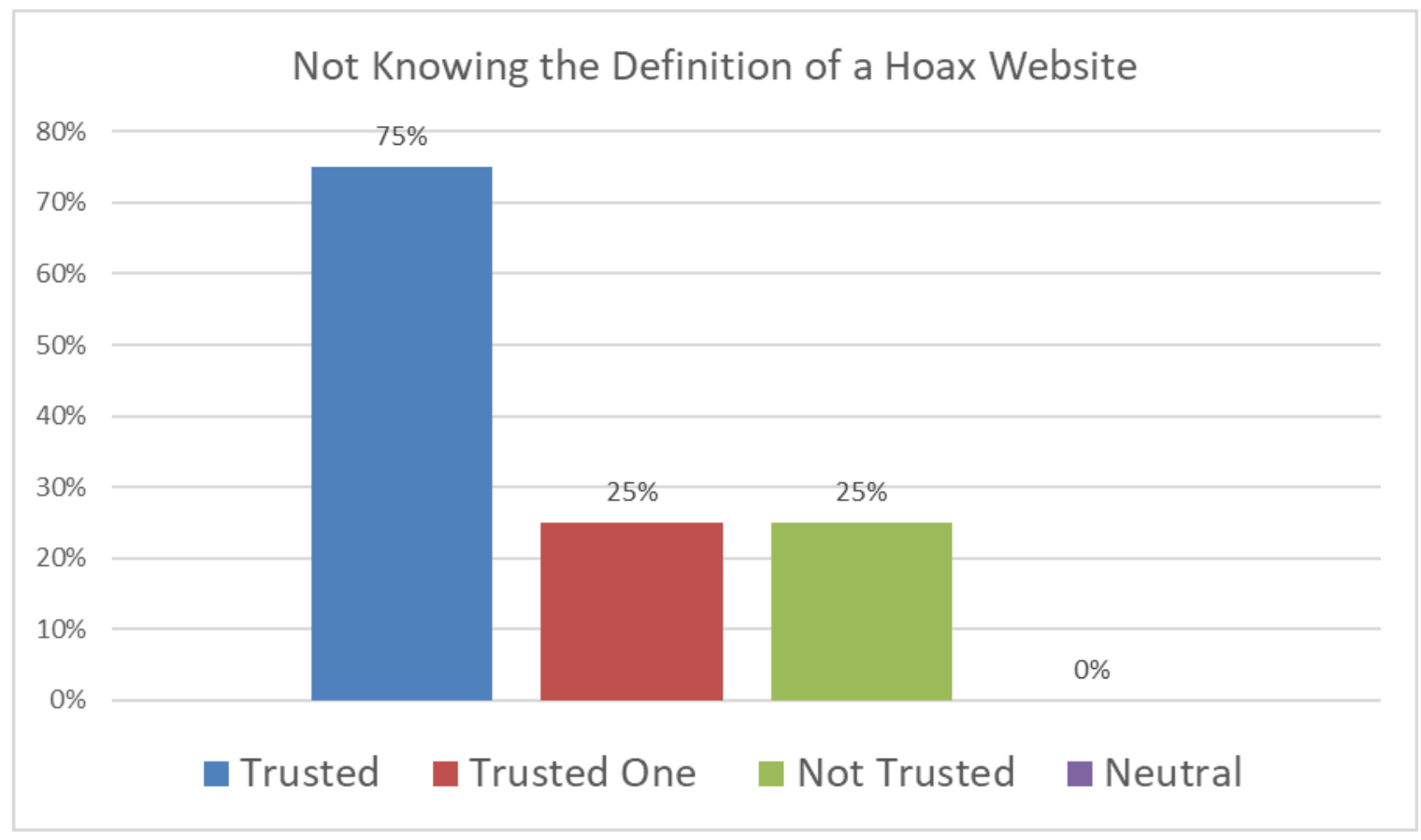

Figure 68. Not Knowing Definition of a Hoax Website for all categories.

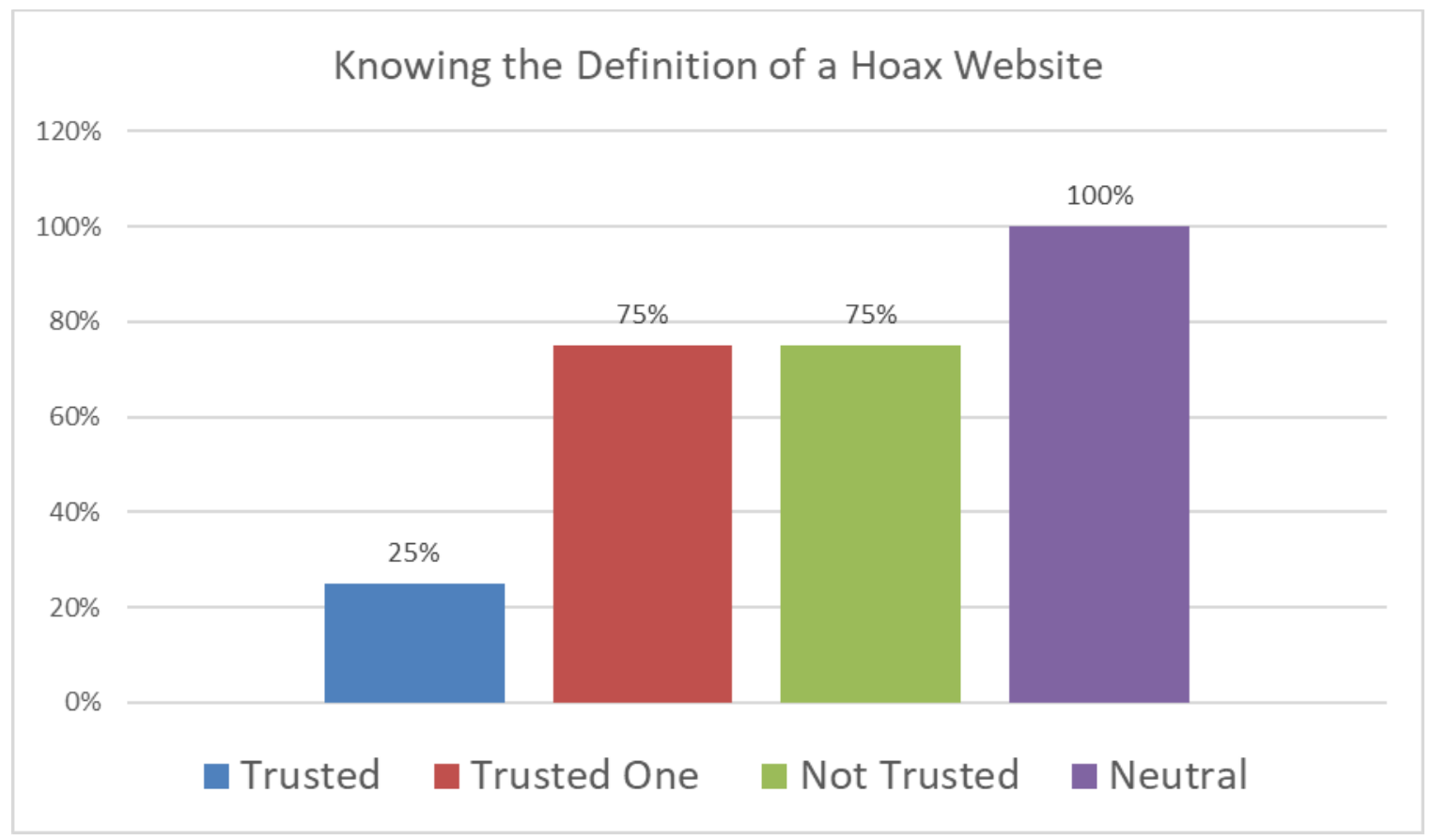

Figure 69. Knowing the Definition of a Hoax Website for all categories. 
Several reasons were given as to why the hoax websites were trusted. Those that trusted the Tree Octopus and DHMO.org hoax websites based their evaluations mostly on aesthetic appeal, not spending sufficient time to read and evaluate, performed linear reading and were influenced by the presence of complex terminology. In addition, the individuals from Group B that trusted the hoax websites admitted to not using the WWWDOT Framework.

In contrast, all the individuals that did not trust the hoax websites spent sufficient time reading and evaluating the content. The individuals that did not trust the hoax websites also read laterally; furthermore, $75 \%$ of the participants that did not trust the hoax websites evaluated using the following: aesthetic appeal, prior knowledge, presence of ads/asking for money, not making sense, authorship, and ease of use. All the individuals from Group B that did not trust the hoax websites used the WWWDOT Framework. The not making sense comments were mostly about the Tree Octopus websites since many said that the website was not trusted because the content did not make sense. The DHMO.org website was considered poorly designed and organized by the interviewees and was hardly trusted. The ones that did trust the DHMO.org website was based on the complex terminology, linear reading and lack of knowledge on the subject. Experience evaluating websites was also mentioned. Half of the people who did not trust the hoax websites had experience evaluating them compared to $25 \%$ of them from the trusted hoax websites category, who had no experience.

The individuals that trusted one hoax but not the other evaluated the websites based mostly on aesthetic appeal, $75 \%$ used prior knowledge, the presence of citations, knew the definition of a hoax website, described the hoax websites as being poorly 
designed/organized, stated that the websites had complex terminology and did not spend sufficient time to read and evaluate the content. In addition, $50 \%$ of the participants said that they evaluated based on ease of use, usefulness, authorship and making sense. The participants that trusted one hoax but not the other were balanced in reading linearly and laterally, since as previously mentioned, half of them fell into each category. All individuals from Group B, who trusted one hoax but not the other, used the WWWDOT Framework. This category was like the neutral category since half of them read linearly and the other half read laterally, as well. The people who remained neutral all knew the definition of a hoax website, $75 \%$ used prior knowledge, $50 \%$ mentioned the presence of a poor design/layout, content not making sense and not spending sufficient time to read and evaluate the content. All individuals from Group B that were neutral used the WWWDOT Framework. The other theme analyzed included epistemic beliefs. The next section contains the overall qualitative results based on the epistemic beliefs from all the categories.

\section{Epistemic Beliefs}

All the individuals from the neutral and not trusted hoax categories displayed a combination of feeling and evidence-based epistemic beliefs. Half of the individuals who trusted the hoax websites or trusted one but not the other also displayed a combination of feeling and evidence. It seemed by the comments made that using feelings or evidence depended on the situation. Interestingly, science and academia were mostly associated with evidence and social, life decisions and cultural aspects were associated with feelings and intuition. Below is Figure 70 with this sub-theme: 


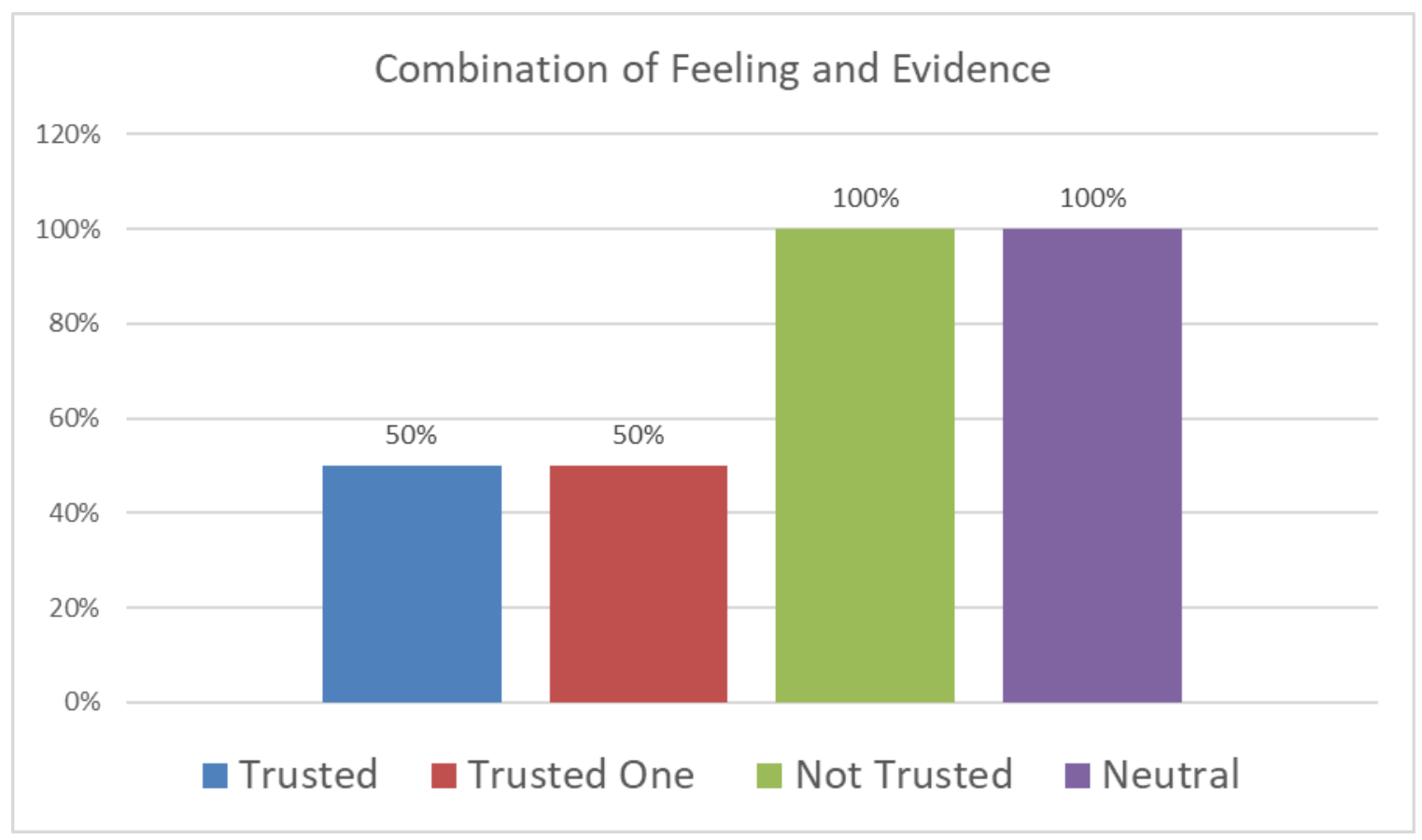

Figure 70. Combination of feeling and evidence for all categories.

Evidence, feelings and political-based epistemic beliefs were also used by some interviewees across all groups. All the individuals from the neutral category mentioned evidence-based epistemic beliefs. This was followed by $75 \%$ of the people who did not trust the hoax websites, $50 \%$ of the individuals that trusted one hoax but not the other and $25 \%$ of those that trusted the hoax websites. The top two categories that were evidence-based were the neutral and the not trusted hoax websites. Below is Figure 71 with these percentages: 


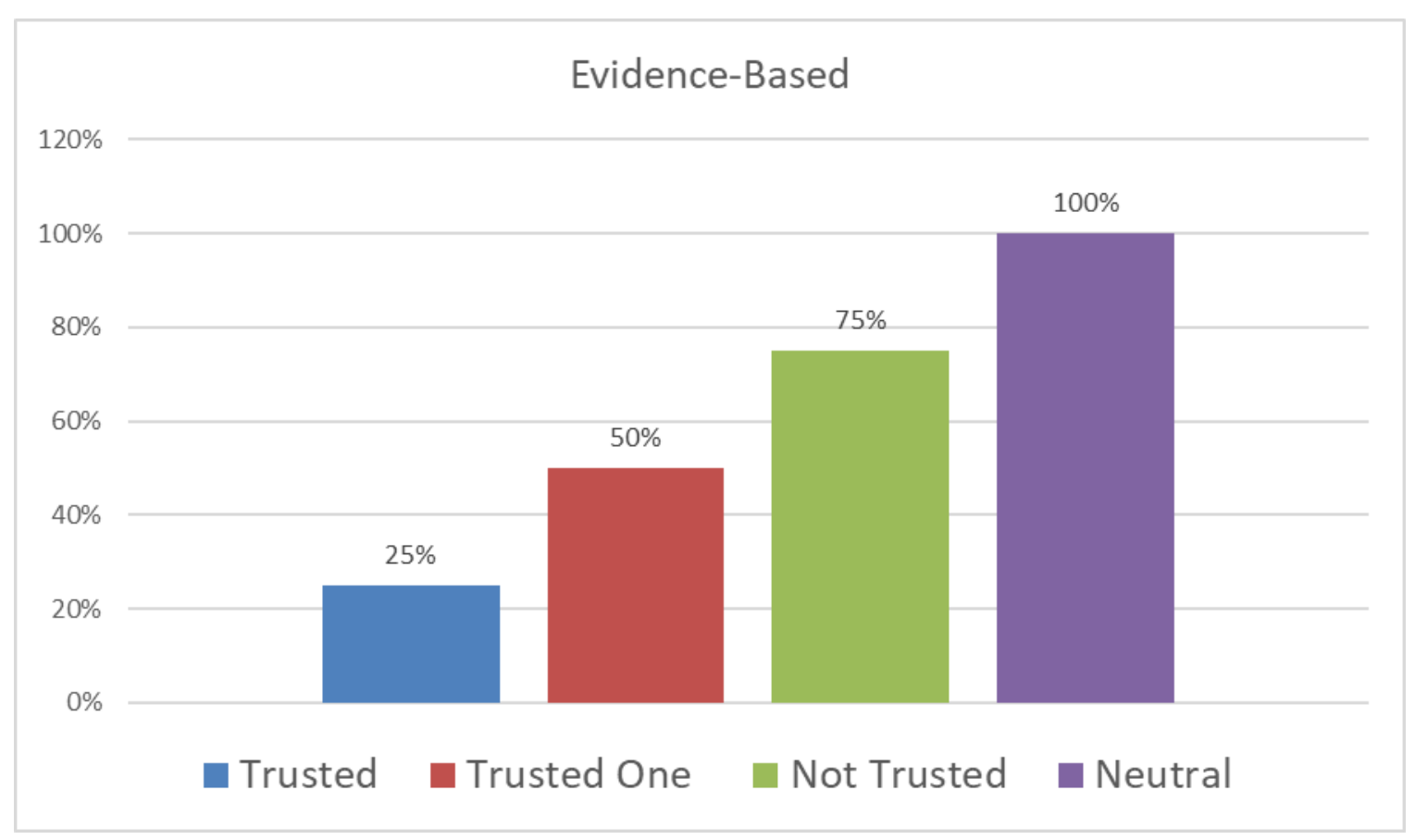

Figure 71. Evidence-Based for all categories.

Most of the individuals that trusted the hoax websites displayed feeling-based epistemic beliefs. These results are consistent with the quantitative data. A total of $75 \%$ of the interviewees that trusted the hoax websites made statements related to feelings, however $50 \%$ of the individuals from each of the other categories also made feeling-based statements. Figure 72 below contains the results for the feeling-based epistemic belief: 


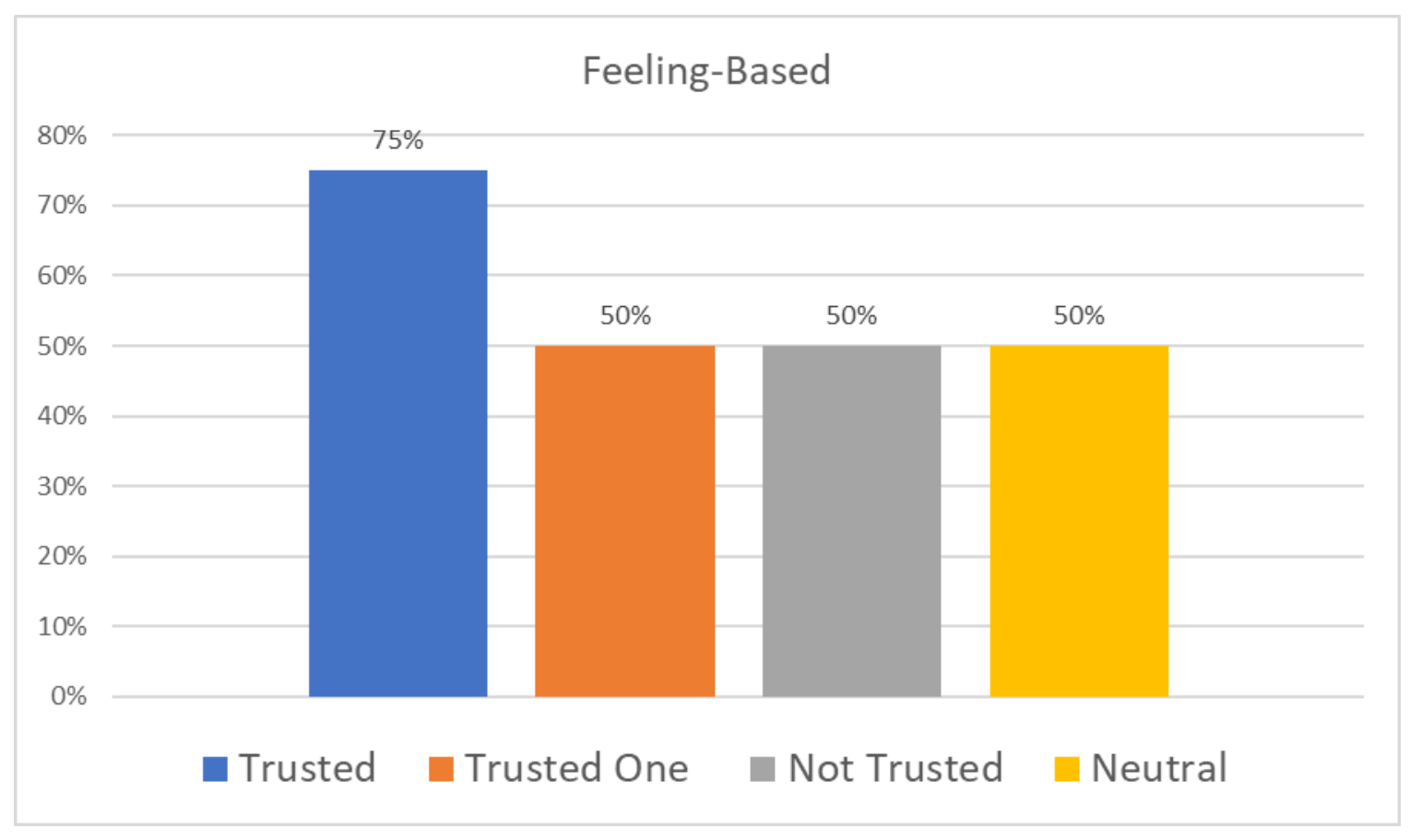

Figure 72. Feeling-Based for all categories.

Political-based epistemic beliefs were present throughout all the categories as well. Half of the individuals who trusted the hoax websites or trusted one but not the other displayed political-based comments. On the other hand, $25 \%$ of the individuals who did not trust the hoax websites or remained neutral made political-based comments. Below is Figure 73 with the political-based results: 


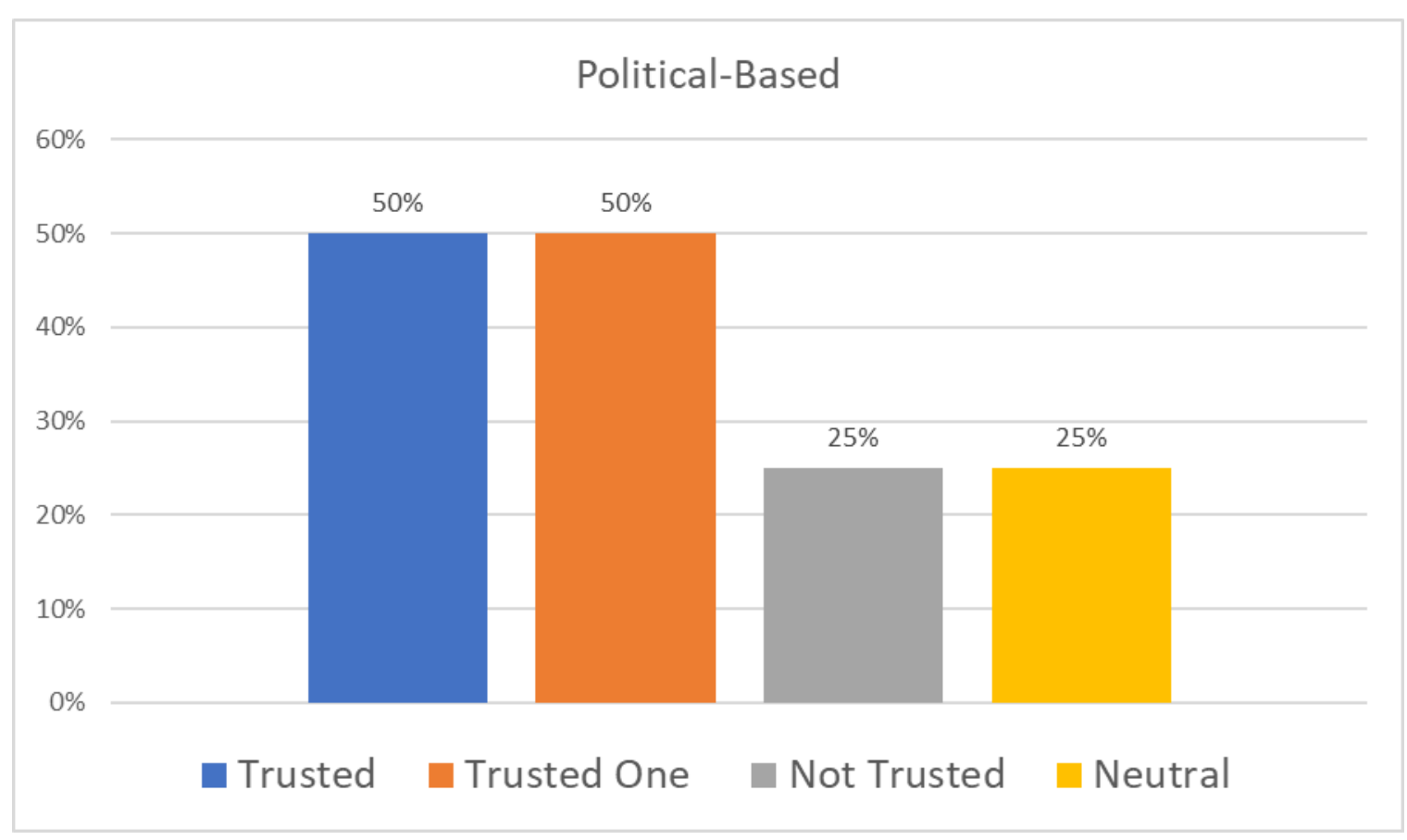

Figure 73. Political-Based for all categories.

There does not seem to be too much of a difference in regard to political-based epistemic beliefs although this may be due to the fact that the websites evaluated did not contain any political content. Another epistemic belief that was displayed was in regard to the definition of truth. Some individuals had an objective view of truth and others had a subjective view of truth. An objective view of truth is defined as evidence-based, factual, realistic, provable and consistent. A subjective view of truth is defined as truth based on perceptions, opinions, beliefs and multiple truths. All the people who did not trust the hoax websites displayed an objective view of truth. In contrast, all the individuals that trusted the hoax websites or trusted one but not the other, had a subjective view of truth. Half of the individuals in the neutral category also had an objective view of truth and the other half had a subjective view of truth. Figures 74 and 75 represent these two views of truth by category: 


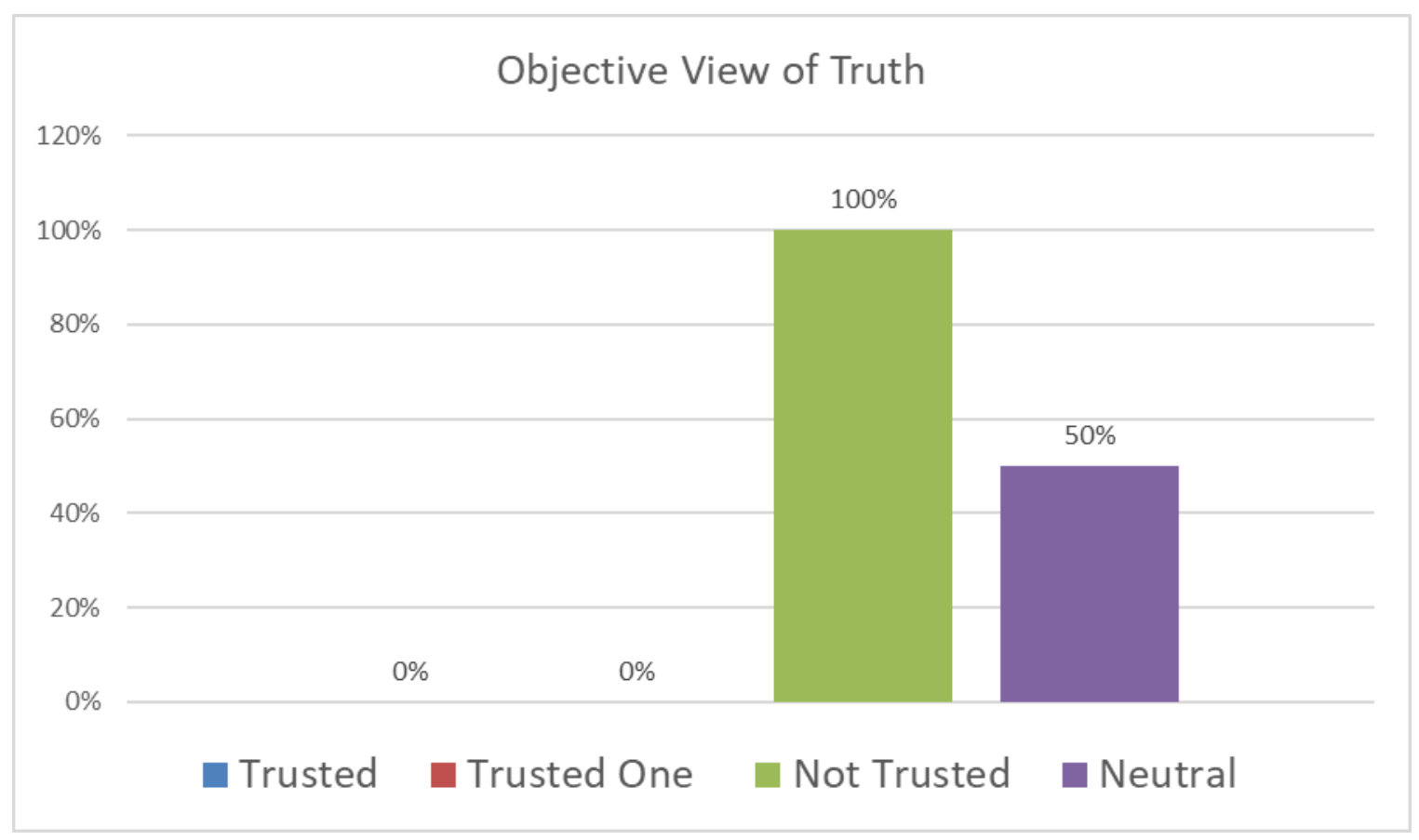

Figure 74. Objective View of Truth for all categories.

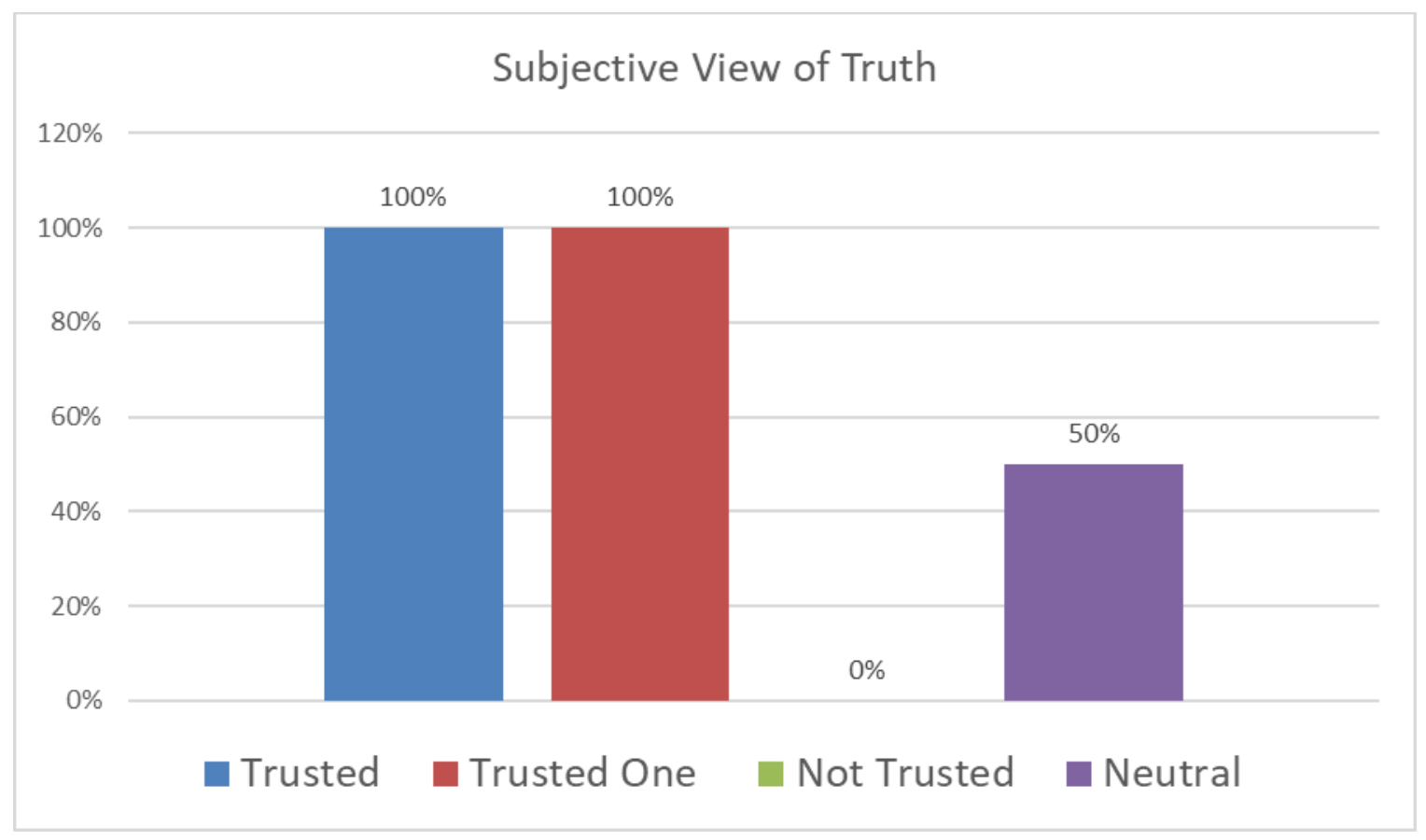

Figure 75. Subjective View of Truth for all categories.

It may be that having an objective view of truth leads to not trusting a hoax website and having a subjective view of truth leads to trusting hoax websites. Further 
research should be conducted in this area. Another interesting epistemic belief that was not a part of the original questionnaire or structure interview questions but resulted based on the responses was whether the individual was trusting or skeptical. Most of the people that trusted the hoax websites, specifically $75 \%$, said that they were trusting. In contrast, $75 \%$ of the people that did not trust the hoax websites said that they were skeptical. Below Figures 76 and 77 with the results by category based on whether they were trusting or skeptical:

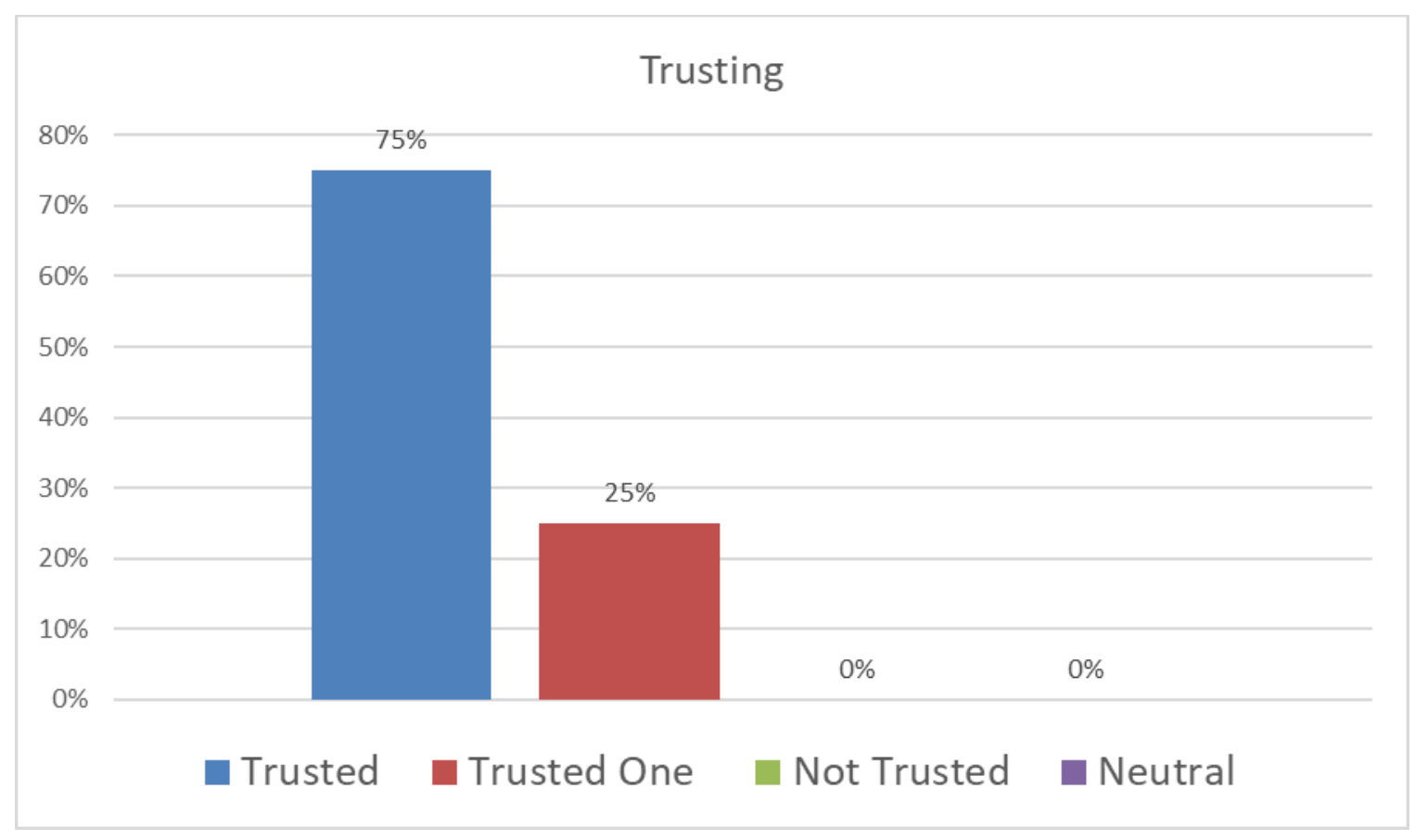

Figure 76. Trusting for all categories. 


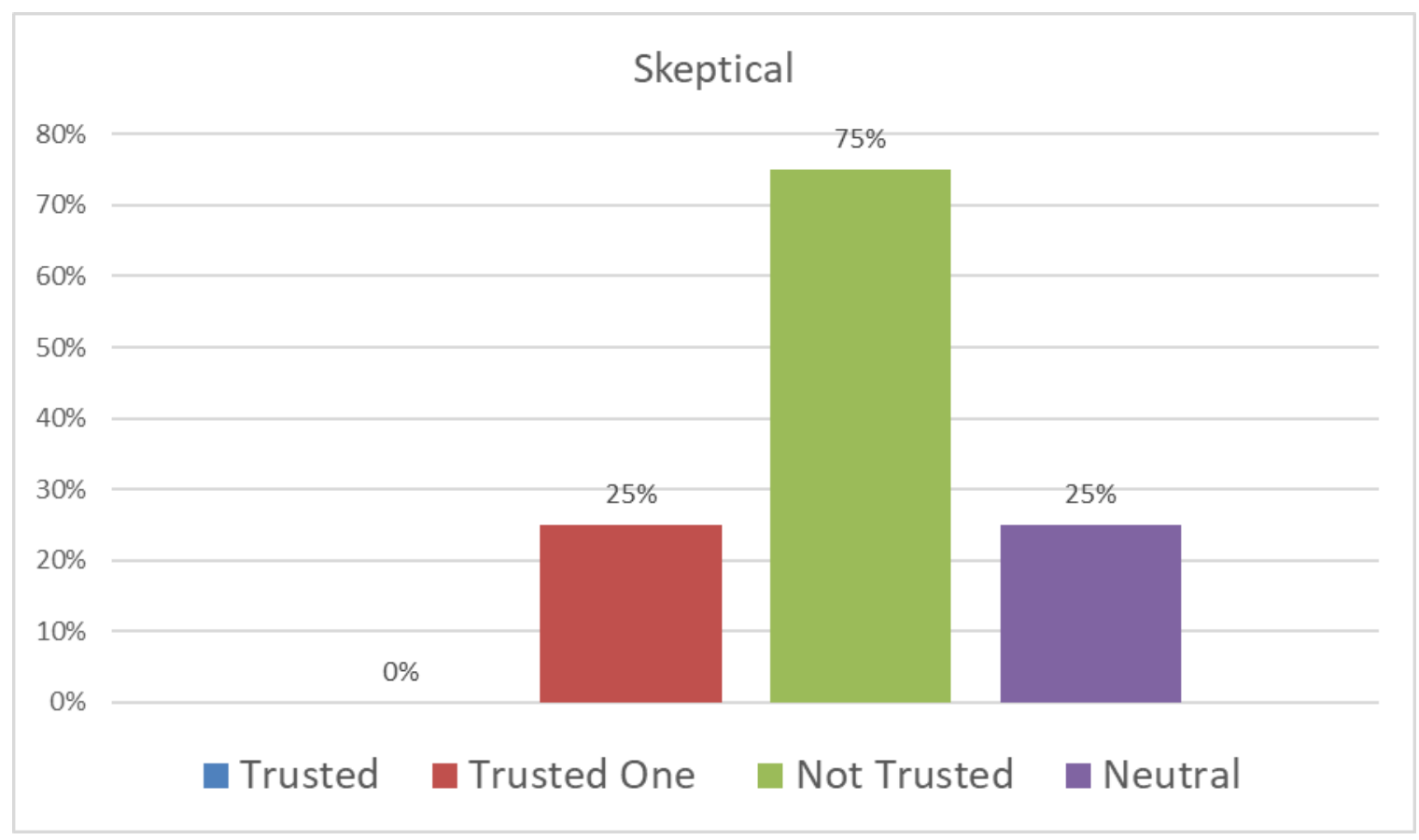

Figure 77. Skeptical for all categories.

One of the most surprising results was how many interviewees that trusted the hoax websites mentioned their justification or reasoning to trust content on websites that confirms their preconceptions, beliefs or upbringing regardless of whether the content contains factual, evidence-based information or not (post-truth bias). Post-truth bias was $100 \%$ present in the trusted hoax websites and trusted one hoax but not the other categories. The neutral category contained $50 \%$ post-truth and the no trusted hoax website category contained $25 \%$. Post-truth bias was predominant in the categories where the hoax websites were trusted. However, $50 \%$ of the interviewees from all groups, expect neutral stated the need to be aware of your own bias and being open-minded. Below are Figures 78 and 79 with these results: 


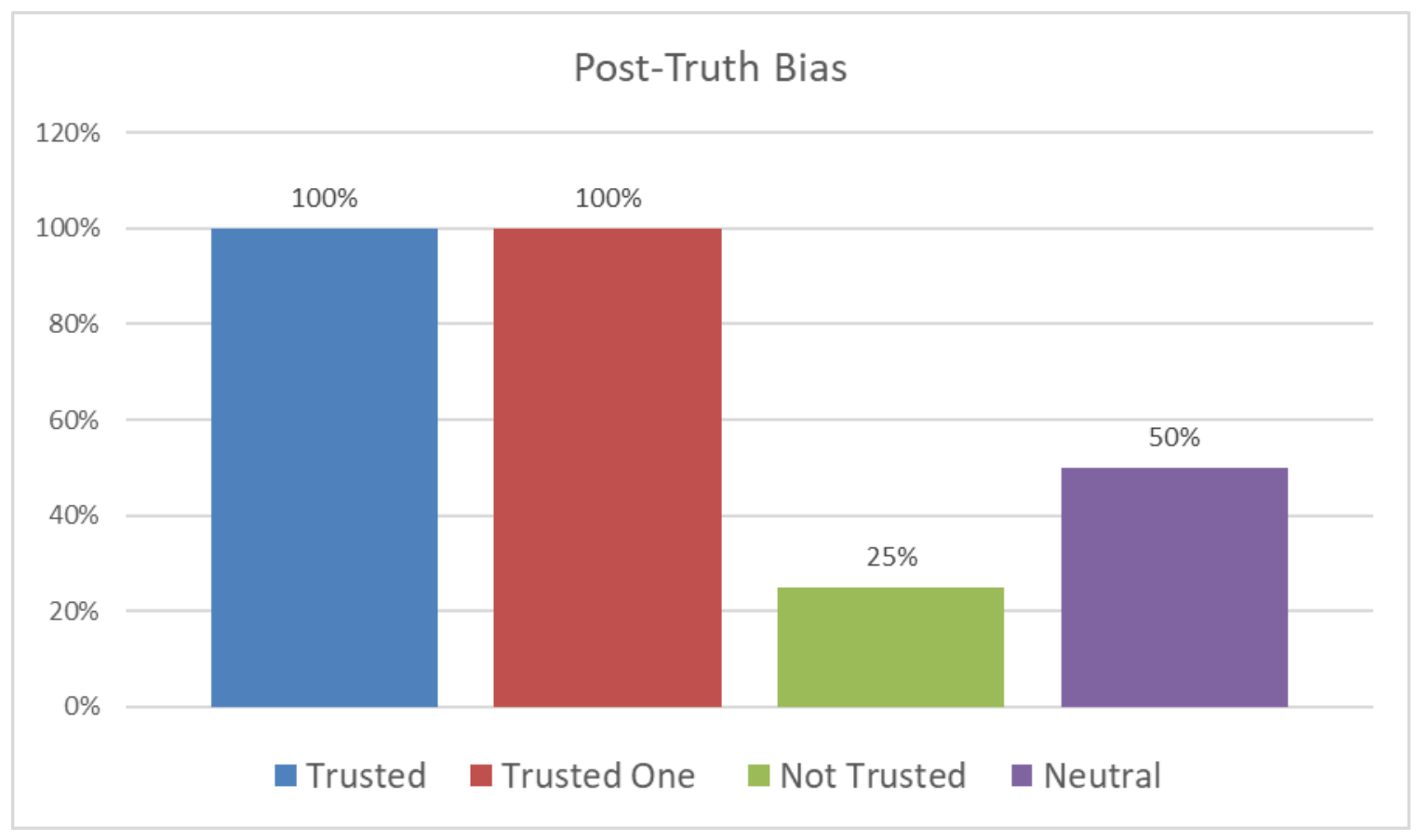

Figure 78. Post-Truth Bias for all categories.

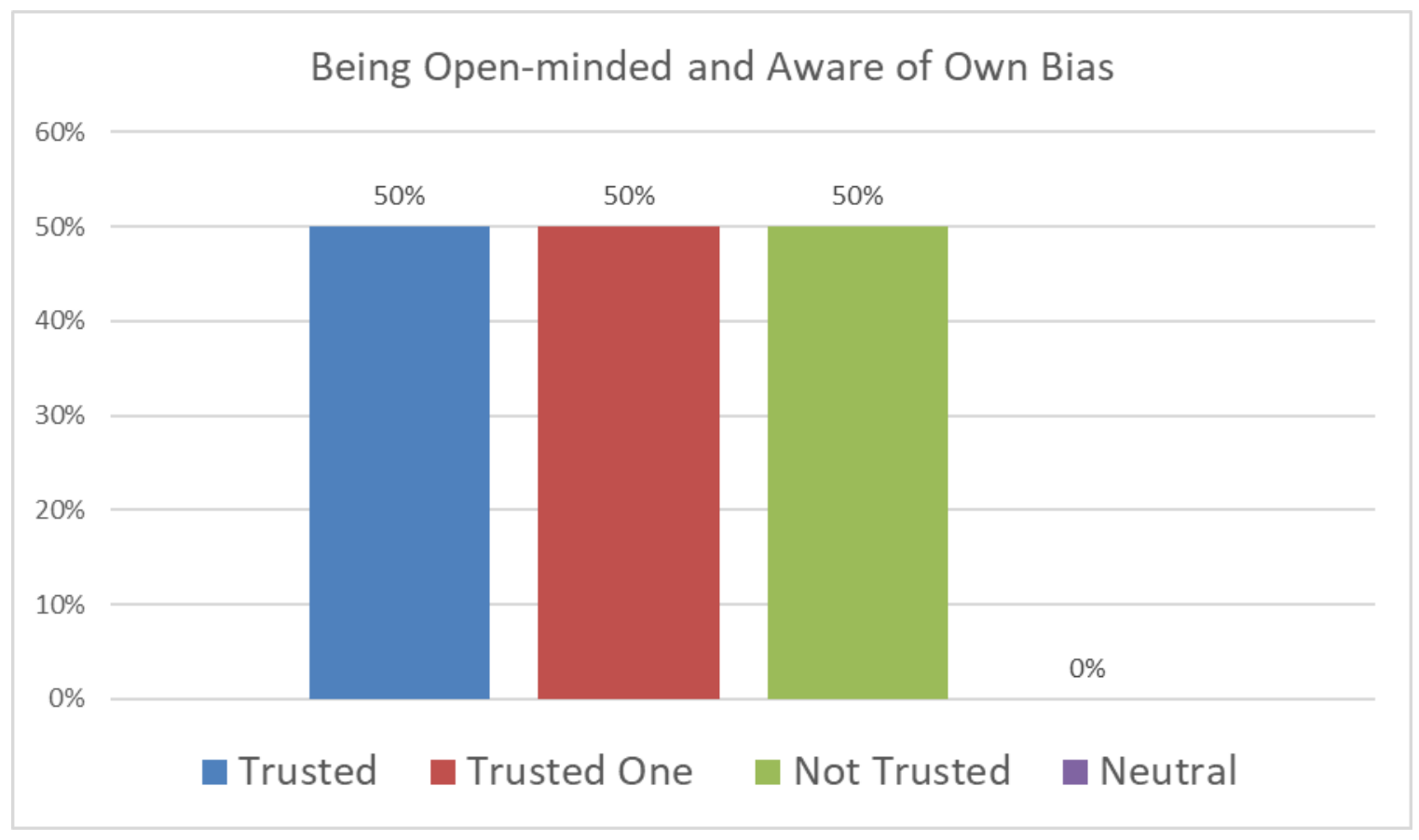

Figure 79. Being Open-minded and Aware of Own Bias for all categories. 
Finally, knowledge was described as multidimensional and empirical. A Multidimensional view of knowledge is defined as viewing knowledge as being able to be true or false or have various aspects. The empirical view of knowledge is defined as being based on experiences. Most of the individuals who did not trust the hoax websites, specifically $75 \%$, displayed a multidimensional view of knowledge. Half of the individuals in the neutral category also displayed this view of knowledge. In contrast, most of the individuals who trusted the hoax websites, precisely $75 \%$ said that knowledge was primarily based on experiences and therefore had an empirical view of knowledge. It is also interesting to note that half of the individuals that trusted one hoax but not the other and that did not trust the hoax websites also said that knowledge is based on experiences. Additional research should be performed in this area. Below are Figures 80 and 81 , which illustrates these results:

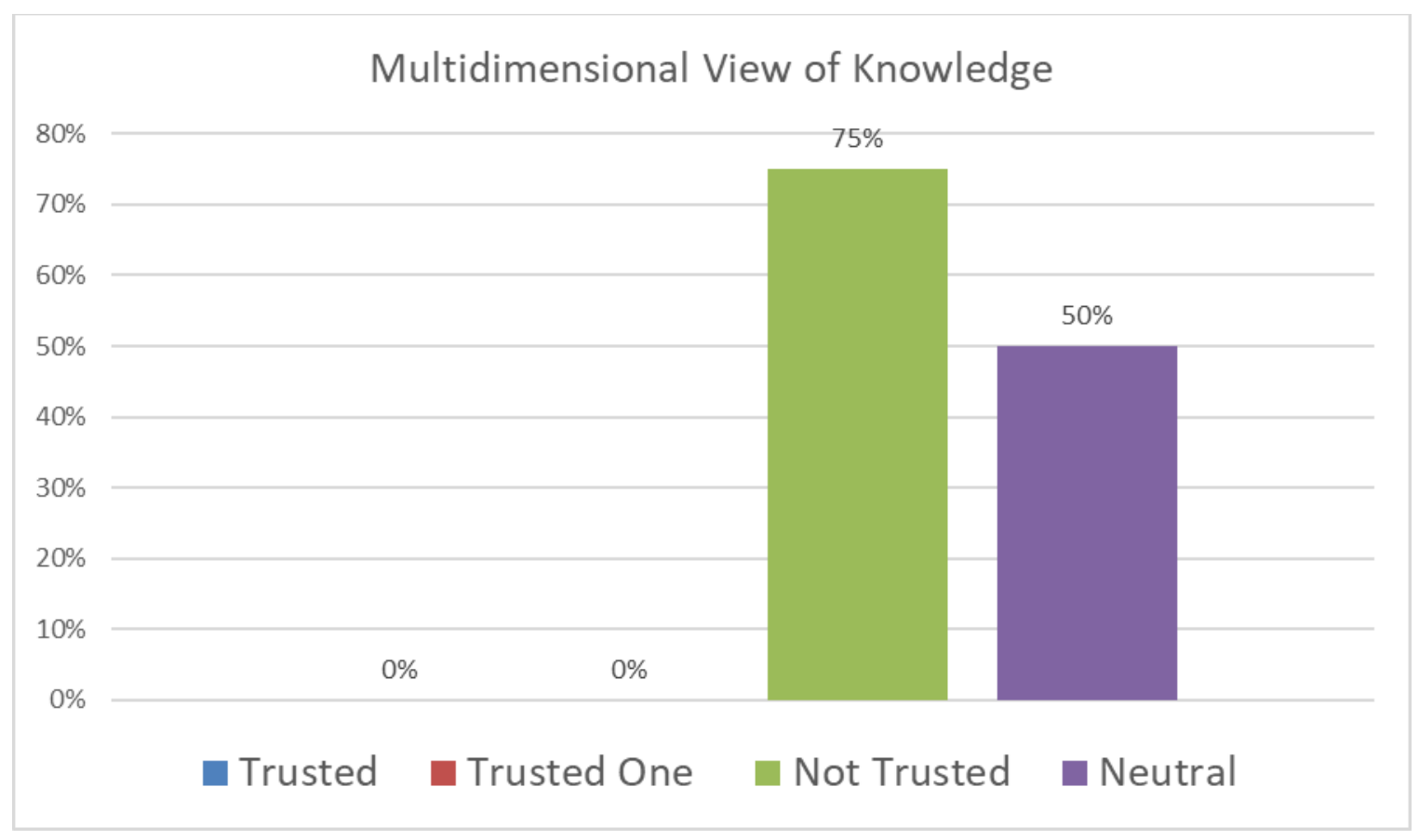

Figure 80. Multidimensional View of Knowledge for all categories. 


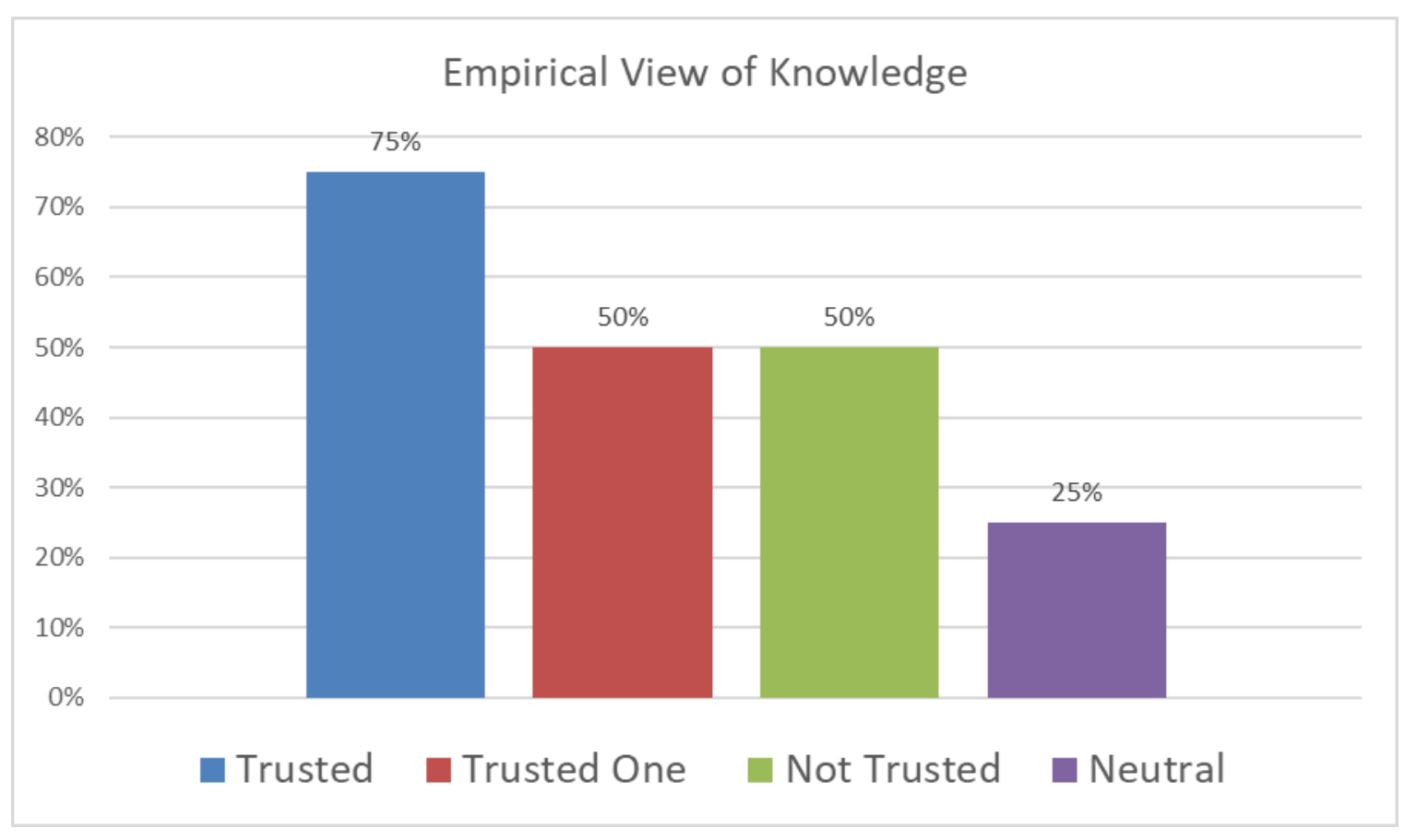

Figure 81. Empirical View of Knowledge for all categories.

\section{Suggestions for Learning Web Evaluations Strategies}

All the individuals made suggestions for learning web evaluation strategies. All sixteen said that they think that prospective teachers need to be provided with guidance on web evaluation strategies. Below is a graph with the suggestions based on frequency counts on the number of people that mentioned it. There were ten suggestions:

1. Provide Guidance (16)

2. Class on Web Evaluation (5)

3. Visit Websites (Hoax, Credible and Web Evaluation) (3)

4. Videos (2)

5. Teach Lateral Reading (2)

6. Workshops (1) 
7. Regulate the Internet (1)

8. Spending Sufficient Time to Read and Evaluate (1)

9. Computer Game (1)

10. Hands-On Activities (1)

All interviewees agreed that prospective teachers should be provided with guidance regarding web evaluation. The main reason provided was that students rely on teachers and therefore it is important for them to be able to identify credible and fake information on the web since teachers are expected to teach students accurate information and how to evaluate content on websites (Interviewees \# 1, 3, 4, 5, 9, 10, 11, 14). Some said that web evaluation should be a part of the teacher's professional training (Interviewees \# 3,6) or even be taught in high school (Interviewee \# 3). Others would like guidance since they had no experience evaluating websites and enjoyed the experience (Interviewees \# 6 \& 7). Teachers need to use technology and websites and therefore need guidance evaluating websites (Interviewee \# 2, 8, 13, 16). Interviewee \# 4 stated that teachers should be provided with guidance but that they should not have to agree, or change based on the responses received. It seems that she did not want to be told what to believe or not, only how to evaluate information. Interviewee \# 10 initially said that teachers should be taught what to believe or not but then said that it should be more on a deeper level. This deep level was regarding teaching "how to evaluate not so believe because they could probably believe in something and it could, or no be true, however it's how they come to the conclusion whether they can gain from it and if it is beneficial to them in their life and in their students' life." This suggest that some prospective teachers do not like to be told what to believe just how to evaluate. Finally, 
Interviewee \# 15 said that teachers need to be provided guidance on web evaluation since they need a "standardized way of approaching decision making" and should be more of a strict and thought out process (Interviewee \# 16). In conclusion, prospective teachers would like guidance on web evaluation. Table 122 below contains all of the quotes provided by the interviewees regarding this suggestion:

Table 122

Provide Guidance

"I do believe teachers should be taught how to evaluate websites Interviewee Group because they sometimes do use external links to teach their students and find like resources that may help students and some of those websites might not really have good information or enough to show that it might help the students as well as teaching their own students how to evaluate a website when they're doing papers or research because teachers are always giving projects to students."

"I think students should be the same if not more careful about what websites they are going on. Especially because they might not know if they should or shouldn't add their information why something may be asking them or showing them, teaching them something that maybe isn't true. That way they can learn to listen to credible information."

"They should be provided with a lot of guidance because we are blunt to these ideas we are only taught through the textbook and only the textbook and we believe the textbook is the only thing that's correct but now I do use technology. It's been such an influence in teaching that we are in the old-school type still that we do not know how to incorporate everything and when they say teach them with this website we might just believe it's true because we don't know that much, so there should be a lot of assistance for us in learning new ways to teach and using different research methods." 
'I think it's a lot of the same thing with the teachers but in a way we kind assume and rely on our teachers to be like you know what you should and shouldn't be looking at like with Wikipedia its not the best source for information if you're looking for a research paper or something, so students it's more like what's like in the books and we use google scholar, too, so anything that we know and that teachers have told us are credible sources and certain teachers will tell us specific places to go like in this class, so it really depends on our prior knowledge of different research projects that we've had and like what teacher's tell us for each assignment."

"I think teachers should be provided guidance in like I guess as part of their training to be like make sure you know this is how you research, this is how you need your students to research and things like that. A lot of people nowadays don't necessarily know the right ways to go about finding reliable sources and things like that, so especially like going into teaching. Like some teachers don't necessarily relay the information that they know or if they don't even know at all, so I think it's definitely important for that."

"I believe that students can learn more about credible websites from the teachers basically teachers giving them websites that they know have real facts and not... like encyclopedia or anything."

"I believe that teachers should be provided with guidance, but I don't believe that they should necessarily have to agree, or change based off the responses that they receive."

"I think that prospective teacher should have a class on how to evaluate websites just because you're giving the information to students and the students are going to go based on what you tell them, so it's good to know that you are telling your students correct information rather than wrong."

"They should be provided with guidance." Why? "Because I think they should know because they are teaching students and they should know if the information is credible or not." 
"Well students can basically rely or find credible sources as a go

to as a safety net and then always double check with their

teachers or someone that is knowledgeable in the field to make sure that they're getting the right information."

"Yes, I definitely think teachers should be taught guidance as far as what to believe or what not but even on a deeper level like how to evaluate not so believe because they could probably believe in something and it could or no be true, however it's how they come to the conclusion whether they can gain from it and if it is beneficial to them in their life and in their students' life."

"Yes, because teachers need to have a standardized way of approaching decision making."

"Paying attention in class to the teacher when the teacher talks about this. There are certain classes that will have this in the curriculum, like I said before and you could also have like specific education on this as well because usually the hoax websites is more about where to get information to prepare for academic use rather than necessarily for websites that are stealing personal information. For that usually students just go on their own on the Internet and find out either the hard way on their own like many other things that academic academia doesn't obviously teach you."

"I believe they should be trained and knowing how to determine if the website is credible or not, not only by their common sense, but professional wise."

"I liked the experience of not only looking for information but how the resources I would have ... get to experience what's true or not because we always believe that whatever, whatever is on the internet whatever link we open is going to be the answer." So, would you like more guidance and more instruction in that at the school at the university level? "Yes." 
"I think that teachers should be given guidance to evaluate websites. I mean before taking this survey or interview, I never really thought about evaluating websites and obviously I know that everything on the website anybody can just put on, but I don't think I've ever looked at the website and be like this may not be true. I think it's important."

"I think that this should be made of an awareness more because like I said, I never really thought about evaluating content of information on websites until now and I'm on my junior year of college. So, I feel like this information, strategies to evaluate websites should be taught earlier on, maybe even in high school."

"I think teachers should be provided with guidance because there's so many ways that people can easily create their own websites and organize it in manners that could be very appealing and have slightly truthful information but a lot of non-factual information, so they are easy ways to be misguided when looking at websites, so I think it is important for teachers to be able to learn how to like figure out how these websites work especially with technology being such a big factor in schools, so I think this is very important because a lot of teachers rely on technology inside their classrooms nowadays."

"Yes I do because these websites are being used by the students and teachers need to know what websites to use or not use because then students end up learning like the right thing or the wrong thing and then once they move onto like the next grade or something they're going with the knowledge of a website that probably wasn't true, so then you're going to be moving onto the next step and it was never true something like that."

"They should be taught about evaluating websites."

"Students I think the same that they should learn the same way as teachers. I think that they should listen to experts as well." "Definitely, I think teachers should be provided with guidance on evaluating websites because teachers do use a lot of websites. Every teacher I ever think of or that I've ever had has shown me websites or videos on something and if that's not credible then they should know." 
"I think teachers should be provided with guidance, so that they know what they're doing when they're in front of the students in the classroom and then and they know what to expect from their students."

"Yes, definitely. I mean as we advance in a technological world, the more immersed we are with technology. So, that is definitely a must with educators, so that they are certified or educated on how to use technology properly including things like that like assessing websites. I mean it's logical."

"It should be a more thought out process. As we were talking about before, when it comes to educating professionals or teachers there should be a more strict process for them to know this kind of stuff because if the teacher, who is the one that's sort of gives the information, is wrong and it's going to be wrong for the students as well, so they should be more strict with that."

The second suggestion was offering a class on web evaluation. Five of the interviewees mentioned that a class would be ideal for learning web evaluation. Interviewee \# 2 said that a more in-depth class on web evaluation with more than just a single lesson on hoax websites would be better. Interviewees \# 5, 12 \& 15 also suggested a class on web evaluation. Interviewee \# 12 thought that the WWWDOT Framework was not enough and that teachers could benefit more from a class or workshop. Interviewee \# 14 said that a class could be provided at the schools where the students are located. Below are quotes provided on this suggestion: 
Table 123

Class on Web Evaluation

\begin{tabular}{|c|c|c|}
\hline & Interviewee & Group \\
\hline $\begin{array}{l}\text { "Teachers should be informed about having a more in-depth } \\
\text { class about technology because all this technology that we're } \\
\text { learning about what we can use inside a classroom has been very } \\
\text { beneficial towards me and becoming a better teacher. not just } \\
\text { one class about hoax and one lesson they should show us what is } \\
\text { a fake website and what is not a fake website, so we can use it. } \\
\text { The most accurate facts for teaching the subjects and know as } \\
\text { much as possible for the children, so later in the future school } \\
\text { will be easier for them." }\end{array}$ & 2 & $\mathrm{~A}$ \\
\hline $\begin{array}{l}\text { 'I think that prospective teacher should have a class on how to } \\
\text { evaluate websites just because you're giving the information to } \\
\text { students and the students are going to go based on what you tell } \\
\text { them, so it's good to know that you are telling your students } \\
\text { correct information rather than wrong." }\end{array}$ & 5 & A \\
\hline $\begin{array}{l}\text { "I would suggest having certain classes that have that in the } \\
\text { curriculum, which most classes already do." }\end{array}$ & 15 & A \\
\hline $\begin{array}{l}\text { "Taking a class on it would be good or workshops that they } \\
\text { have. Teachers can add that in there, so if they have students that } \\
\text { do like research and they will know the exact websites they want } \\
\text { them to be on." OK, so you think it should be more than just } \\
\text { teaching the WWW DOT Framework? "Yes, definitely I think it } \\
\text { should be like a class or a workshop." }\end{array}$ & 12 & B \\
\hline $\begin{array}{l}\text { "Maybe the schools that the students are at they can make a } \\
\text { class about learning about websites." }\end{array}$ & 14 & B \\
\hline
\end{tabular}

The third suggestion was providing and visiting websites that had to do with web evaluation. Three of the interviewees mentioned this idea. Interviewee \# 9 stated that visiting websites that talk about hoaxes can help prospective teachers learn web evaluation. Interviewee \# 8 and 16 would use hoax websites, such as the Tree Octopus, to demonstrate to students that not everything on the internet is true. Below are the quotes on visiting websites: 
Table 124

Visit Websites

\begin{tabular}{lcc}
\hline & Interviewee & Group \\
\hline "Going on other websites that talk about hoaxes, like how to & 9 & A \\
spot the signs and maybe watching videos." & \\
"Maybe the same way as above. Like videos and websites." & 8 & B \\
"I might use some of the websites like the octopus one just to & \\
like show some of the students that all the things that you view \\
on the Internet may not be accurate or may not be truthful." \\
$\begin{array}{l}\text { "Yes, I would. I think it's very important for students to know } \\
\text { where they're looking into because if they start researching fake }\end{array}$ \\
websites, they are going to get fake information in the end, so \\
yes I would use one of the websites especially fake websites for \\
them to know kind of like what a fake website looks like."
\end{tabular}

Watching videos was the fourth suggestion made by two of the Interviewees. Interviewee \# 9 stated that watching videos could be a way for prospective teacher to learn more about web evaluation. Interviewees \# 13 specifically mentioned TED talk videos. Videos could be a viable way to teach prospective teachers. Below are the two quotes on this suggestion:

Table 125

Videos

Videos

"Maybe the same way as above. Like videos and websites." Interviewee Group

"Going on other websites that talk about hoaxes, like how to 9 A spot the signs and maybe watching videos."

'Like I said earlier, I would I would I think it's very important 13 B even just now doing the survey how bad I am at evaluating websites looking back at websites, so I think I would love to attend a workshop or just look at a video TED talk whatever of someone teaching more about believing websites or not what to believe and not to believe." 
The fifth suggestion was teaching lateral reading. Both Interviewee \# 2 and 7 explained the importance of visiting other websites to verify the information and fact check. Interviewee \# 2 said that she used to rely on just the first website, usually Wikipedia and that this is not a reliable source since the proper thing is to look at various websites. Interviewee \# 7 talked about going outside of the website and researching what others think of it by fact checking. Below are the statements made by Interviewees \# 2 and 7:

Table 126

Teach Lateral Reading

"Students should be open to seeing more websites not just rely on Interviewee Group the first website that they see because most of the times I was one of the students when I was younger that I would just research about Abraham Lincoln, let's say and the first website that would come up would be Wikipedia and I would use it, but Wikipedia I later found out that many authors can use it and just manipulate what they say, so the more that we teach them."

"Teachers could use further research on the website. Like by 7 B going outside of the website and researching other thoughts on it. You could probably avoid like getting a hoax website by going through scholarly journals and articles and things to find real content."

"Maybe actually fact check it or go back and compare it to some of the other websites and you know actually analyze it."

The last remaining five suggestions were given by a single interviewee. The suggestions were taking a workshop, regulating the internet, spending sufficient time to read and evaluate, computer game and hands-on activities. Below are the statements made about these suggestions: 
Table 127

Workshops, Regulate the Internet, Spending Sufficient Time to Read and Evaluate, Computer Games, and Hands-On Activities

\section{Workshops}

Interviewee Group

"Yes attending workshops and hearing from people that do that I

guess like uh.. someone that's... that's their job that they look

... Like experts? Yes (Laughs) experts (laughs) I know I suck at

this. Attend workshops and listen to experts about what they

know about credible websites or not."

'Looking back now, I haven't realized certain things are looked into websites that much, but now after talking about it and looking back on it now I think I've learned definitely I need to make sure about where the sources are coming from, from websites and I think it's important that people attend workshops and students and teachers attend workshops to learn about the credible websites."

'Like I said earlier, I would I would I think it's very important even just now doing the survey how bad I am at evaluating websites looking back at websites, so I think I would love to attend a workshop or just look at a video TED talk whatever of someone teaching more about believing websites or not what to believe and not to believe."

\section{Regulate the Internet}

"My concerning thought is that they should fix the Internet world web all-around like before it was the encyclopedia it was only about true facts. The world web is very, very dangerous for these children that don't even know anything about it. Luckily, we grew up in an age using textbooks, so we know still what could be true and what could not be true and it's too much out there. They should start reducing things and start evaluating what should be on the web and what should not be on the web."

\section{Spending Sufficient Time to Read and Evaluate}

'I don't know. Looking more into it? Deep research. I think it would be a way teachers can learn and know more about websites."

\section{Computer Game}

"Maybe computer games and programs that help them identify hoax and credible websites. I think that was much easier... thinking about the students." 


\section{Hands-On}

"Same thing. I think that when it comes to these types of

exercises, all that are hands-on activities, I mean if they do it by

themselves, it's going to be easier for them to learn. So, it's

going to be easier for them to evaluate how to identify fake or

credible information. Like I was telling you before back when I

did the research project in high school, I would be looking at

primary sources all day long, different books, different

research."

"I think that a way for teachers to train themselves into

identifying hoaxes and fake websites could be probably using surveys like these and having them evaluate different websites to figure out if they are trustable or not. We can start from there. Just teaching them, hey this is how you evaluate a website, this is the process, and these are the steps. That could be a tool or a way for teachers to assess the different website that they use."

Interviewee \# 13 suggested that attending a workshop and listening to experts would be a way to learn about web evaluation. Interviewee \# 2 talked about the possibility of regulating the internet since she believes it needs to be fixed by determining what should stay and what should be removed. Interviewee \# 11 had two suggestions one was spending sufficient time to read and evaluate through deep research and the other was the creation of a computer game in order to make it easier for the students. These are two great suggestions since based on this study spending sufficient time to read and evaluate was a major sub-theme within the individuals that did not trust the hoax websites. In addition, the computer game would indeed be helpful for students to learn about web evaluation in a fun and interactive way. Finally, interviewee \# 16 suggested giving prospective teachers hands-on activities to learn web evaluation. This suggestion was based on a research project he did in high school where he had to research and 
evaluate various sources. Interviewee \# 16 added that visiting websites as he did with the survey used in this study and explaining the process could be a way that teachers learn web evaluation, especially because it is hands-on and serves as a good starting point. Below is Figure 82 with the suggestions for learning web evaluation:

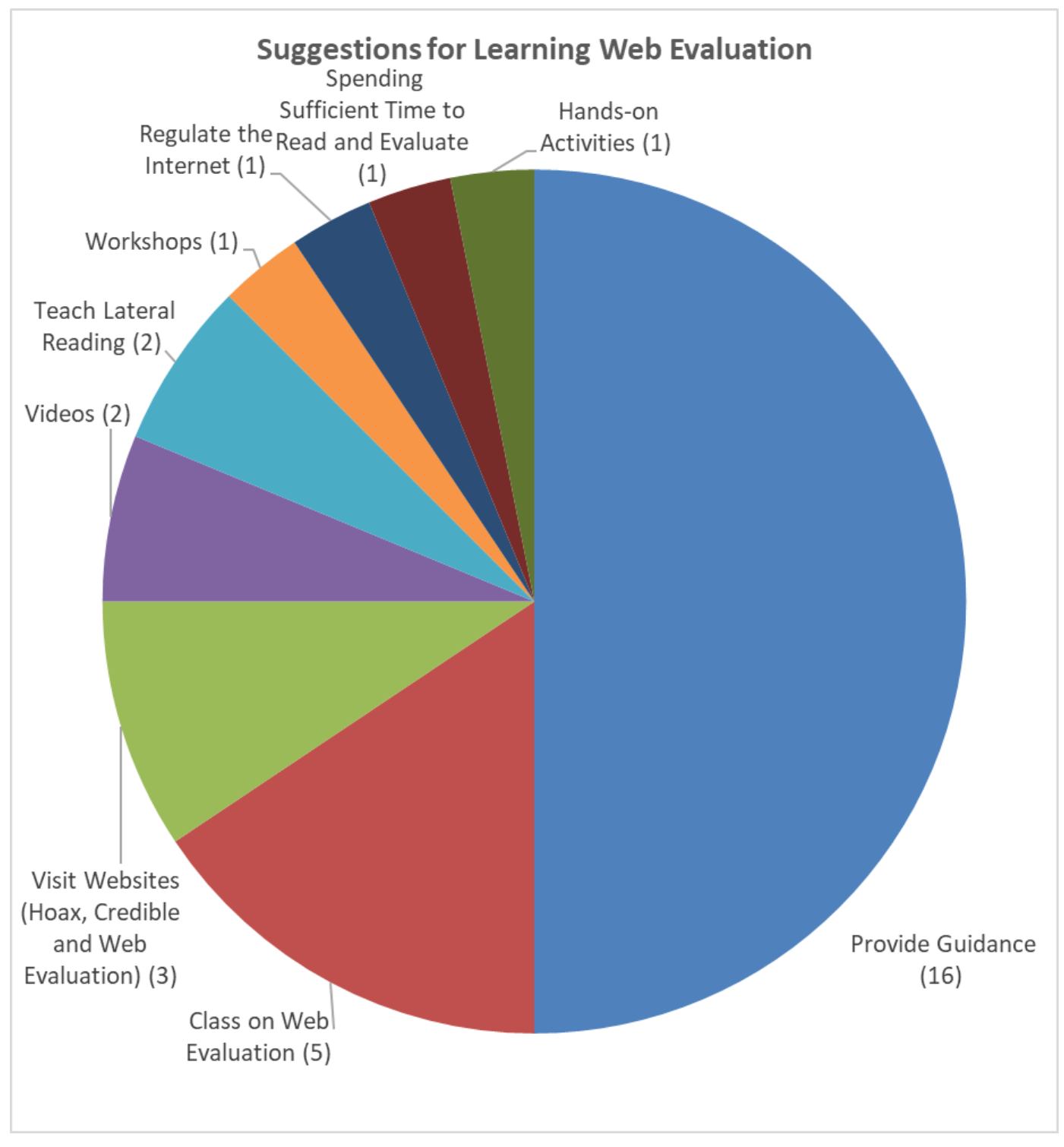

Figure 82. Suggestions for learning web evaluation. 


\section{Results for Research Question \#1}

The first research question was "What percentage of prospective teachers trust the content on hoax websites?" This research question was analyzed using the quantitative data from the questionnaire. Of the 72 participants, 35 of them trusted a hoax website, regardless of whether they were in Group A or Group B. That means that 48.6\%, almost half of the participants, trusted at least one of the hoax websites. This percentage (33\%) was chosen in order to take into consideration the three trust levels (not trust, neutral and trust). In Group A, 21 of the 36 participants trusted a hoax website, which means that 58.3\% of the participants from Group A, trusted at least one hoax website. In contrast, 14 out of 36 participants in Group B trusted a hoax website, which is $38.9 \%$. The hypothesis that the percentage of prospective teachers that trust a hoax website is less than $33 \%$ is rejected. Interestingly, the results varied between the DHMO.org and the Tree Octopus hoax websites.

Of the 72 participants, $43.1 \%$ did not trust the content on the DHMO.org website, $26.4 \%$ trusted the content and $30.6 \%$ neither agreed or disagreed with trusting the content. The present study fails to reject hypothesis number one regarding the DHMO.org hoax website. The hypothesis that the percentage of prospective teachers that trust a hoax website is less than $33 \%$ regarding the DHMO.org website is rejected. It may be that the DHMO.org website was not trusted in general due to it being non-aesthetically appealing. Nevertheless, the majority did not trust the DHMO.org website. In Group A, 27.8\% trusted the DHMO.org website and 25\% in Group B. The WWWDOT framework helped lower the number of participants that trusted the hoax website by a bit. However, the number was not statistically significant. 
As for the Tree Octopus website, $45.8 \%$ did not trust the content on the Tree Octopus website, $37.5 \%$ trusted the content and $16.7 \%$ neither agreed or disagreed with trusting the content. In this case, hypothesis number one is rejected. The present study rejects the hypothesis that the percentage of prospective teachers that trust a hoax website is less than $33 \%$ regarding the Tree Octopus Website. However, there were significant differences between Group A and Group B regarding the level of trust. It is important to note that $50 \%$ of the participants in Group A, trusted the Tree Octopus hoax website compared to $25 \%$ from Group B. In other words, most of the participants from Group A trusted the Tree Octopus hoax website. The opposite is true for Group B since most of the participants did not trust it. This suggests that the WWWDOT Framework was effective in reducing the percentage of participants that trusted the Tree Octopus hoax website.

\section{Results for Research Question \#2}

The second research question was "What web evaluation strategies do prospective teachers report using regarding hoax websites? The sub-question included the suggestions that prospective teachers had regarding learning web evaluation strategies. The main research question was analyzed using quantitative and qualitative data.

Based on the quantitative data, the web evaluation strategies that prospective teachers reported regarding the DHMO.org website were the website not being aesthetic appealing, not organized, and useful. As for the Tree Octopus website, the main web evaluation strategies consisted of it being described as aesthetically appealing, organized and useful. The qualitative data provided additional insights regarding the web evaluation strategies prospective teachers reported regarding the hoax websites. 
The qualitative data demonstrated that aesthetic appeal was the main web evaluation strategy used to evaluate the websites that was mentioned by the interviewees from all the categories. The second aspect mentioned by the interviewees was time. More specifically, spending sufficient time to read and evaluate compared to not spending sufficient time. Another important aspect was lateral reading and in contrast linear reading. Some knew the definition of a hoax website and some did not. Most of the participants evaluated the websites using the following: prior knowledge, presence of ads/asking for money, if the content made sense, authorship, ease of use, presence of complex terminology, the presence of citations, and usefulness.

A sub-question included what suggestions prospective teachers provided about learning web evaluation strategies. The main suggestion was that prospective teachers need and want to be provided with guidance on learning web evaluation strategies. In addition, they suggested to take a web evaluation class, visit websites, watch videos, teach lateral reading, attend workshops, regulate the internet, spend sufficient time to read and evaluate and do hands-on activities. Research question number three contains which of the web evaluation strategies mentioned at the beginning of this section were predominant in each trust level category.

\section{Results for Research Question \#3}

The third research question was "What led prospective teachers to trust, remain neutral or not trust information posted on hoax websites?" The sub-questions included the following:

a. How does teaching a specific web evaluation strategy (the WWWDOT Framework) to prospective teachers help them identify hoax websites? 
b. How do the epistemic beliefs of prospective teachers correlate to their tendency to trust or not trust information posted on hoax websites?

c. What web evaluation strategies led prospective teachers to trust or not information posted on hoax websites?

These questions were analyzed using quantitative and qualitative data. Below are the results for each of the three sub-questions above organized by WWWDOT Framework, epistemic beliefs and web evaluation strategies.

\section{WWWDOT Framework- Sub-Question A}

The first sub-question was how does teaching a specific web evaluation strategy to prospective teachers help them identify credible and hoax websites. The WWWDOT Framework was the web evaluation strategy used. The WWWDOT Framework was statistically significant for the Tree Octopus website, but not for the DHMO.org website. Therefore, for the Tree Octopus website, null hypothesis number two is rejected. The present study rejects the null hypothesis that there is no relationship between teaching the WWWDOT Framework to prospective teachers and their trust level (trust, neutral, not trust) concerning the hoax website regarding the Tree Octopus website. However, for the DHMO.org website, the present study fails to reject null hypothesis number two. Based on the qualitative and quantitative data, prospective teachers tended to not trust websites that are not aesthetically appealing. Since the DHMO.org website was not aesthetically appealing it was not trusted in general, regardless of the WWWDOT Framework. However, the WWWDOT Framework did help prospective teachers identify the Tree Octopus hoax website since the number of participants that did not trust it in Group B 
was much higher compared to Group A. The qualitative data also provided additional insights concerning the use of the WWWDOT Framework.

The qualitative data suggests that the WWWDOT Framework was used by the prospective teachers that trusted one hoax but not the other, were neutral or did not trust the hoax websites. All the prospective teachers that trusted the hoax websites, admitted to not using the WWWDOT Framework at all. Not using the WWWDOT Framework led the prospective teachers from Group B to trust the hoax websites. The second sub-question dealt with how the epistemic beliefs of prospective teachers correlated to their tendency to trust or not trust a hoax website.

\section{Epistemic Beliefs-Sub-Question B}

Of the three epistemic beliefs (feeling, evidence and political), the only one that was statistically significant was feeling-based among those that were not taught the WWWDOT Framework for the Tree Octopus website. In other words, prospective teachers from Group A, who had predominant feeling-based epistemic beliefs, were more likely to trust the Tree Octopus website. Therefore, the present study rejects null hypothesis number three since zero order correlations (Bivariate Pearson Correlation) tests were significant for feeling-based epistemic beliefs and the trust level variable in Group A. Null hypothesis number three states that there is no relationship between epistemic beliefs and prospective teachers' trust level (trust, neutral, not trust) concerning the hoax website, which is rejected for the Tree Octopus website. However, it is important to note that the other epistemic beliefs (evidence and political) were not statistically significant. The epistemic beliefs were also not statistically significant regarding the trust level of the DHMO.org website. Therefore, the present study fails to 
reject null hypothesis number three regarding the DHMO.org website. Qualitative data also provided additional insights concerning epistemic beliefs.

The qualitative data suggests that feeling-based epistemic beliefs, a subjective view of truth, being trusting, displaying post-truth bias, and having an empirical view of knowledge led prospective teachers to trust the hoax websites. What led prospective teachers to trust one hoax but not the other were having a subjective view of truth and displaying post-truth bias. The ones that remained neutral were due to having a combination of feeling and evidence-based epistemic beliefs, and evidence-based epistemic beliefs. The following led prospective teachers to not trust the hoax websites: having a combination of feeling and evidence-based epistemic beliefs, evidence-based epistemic beliefs, having an objective view of truth, being skeptical, and having a multidimensional view of knowledge. Some prospective teachers displayed a combination of epistemic beliefs. This was evident in the quantitative and qualitative data since some prospective teachers had more than one predominant epistemic belief and a few said they switched between them depending on the situation. Future research should be performed in this area.

\section{Web Evaluation Strategies- Sub-Question C}

The quantitative data demonstrated that aesthetic appeal, organization, planning to visit the website in the future, and usefulness led prospective teachers to trust the hoax website in general. Conversely, if participants thought the website was not aesthetically appealing, disorganized, were not planning on visiting it in the future and not useful, then they tended no to trust it. All of the above-mentioned variables, were statistically significant based on Pearson Chi-Square Tests or Fisher's Tests, as applicable. Therefore, 
the present study rejects null hypothesis number four that there is no relationship between web evaluation strategies and prospective teachers' trust level (trust, neutral, not trust) concerning the hoax website.

The qualitative data suggests that aesthetic appeal, not spending sufficient time to read and evaluate, linear reading, and not knowing the definition of a hoax website, led prospective teachers to trust the hoax websites. What led prospective teachers to trust one hoax but not the other were aesthetic appeal, prior knowledge, complex terminology, not spending sufficient time to read and evaluate, and knowing the definition of a hoax website. The ones that remained neutral were due to aesthetic appeal, knowing the definition of a hoax website, and prior knowledge.

The following led prospective teachers to not trust the hoax websites: not letting design influence decision to trust content, spending sufficient time to read and evaluate, lateral reading, knowing the definition of hoax website, authorship, presence of ads/asking for money, not making sense, usefulness, prior knowledge, and ease of use. A few specific things led prospective teachers to trust or not the DHMO.org and Tree Octopus websites.

Complex terminology and linear reading was what led prospective teacher to trust the DHMO.org website in general. The prospective teachers that did not trust the DHMO.org website read laterally and said they did not trust it due to the poor design/layout. The Tree Octopus was trusted in general due to the aesthetic appeal, complex terminology and linear reading. The ones that did not trust it said it was because of the website not making sense, not letting design influence decision to trust the content and lateral reading. 


\section{Summary}

The results of this mixed method study were presented in this chapter. The chapter contained demographic information about the participants, quantitative analysis of the questionnaire data, qualitative analysis of the interview data, and the results for the three research questions.

Almost half of the participants $(48.6 \%)$, trusted at least one of the hoax websites. In response to research question number one, the percentage that trusted the DHMO.org website was $26.4 \%$ and $37.5 \%$ trusted the Tree Octopus website. Research question number two contained the web evaluation strategies that prospective teachers reported using and suggestions for learning them. The qualitative data demonstrated that aesthetic appeal was the main web evaluation strategy used, this was followed by spending sufficient time to read and evaluate compared to not spending sufficie nt time, using linear or lateral reading, knowing the definition of a hoax website, prior knowledge, presence of ads/asking for money, if the content made sense, authorship, ease of use, presence of complex terminology, the presence of citations, and usefulness. The suggestions for learning web evaluation strategies were to be provided with guidance, taking a web evaluation class, visiting websites, watching videos, teaching lateral reading, attending workshops, regulating the internet, spending sufficient time to read and evaluate and hands-on activities. Finally, research question number three contained what led prospective teachers to fall into each trust level category.

The quantitative data consisted of the dependent variable, which was the trust level (not trust, neutral and trust) and the independent variables which were whether they were given the WWWDOT Framework or not (determined by the group), epistemic 
beliefs, aesthetic appeal, organization, visit in the future, and usefulness. The WWWDOT Framework was statistically significant regarding the Tree Octopus website. The prospective teachers that were given the WWWDOT Framework (Group B) were able to identify the Tree Octopus as a hoax website at a much higher rate than Group A. The WWWDOT Framework was not statistically significant for the DHMO.org website since prospective teachers in general did not trust it based on its aesthetically unappealing design. As for the epistemic beliefs, feelings were statistically significant, but the others (evidence and political) were not.

Having feeling-based epistemic beliefs was statistically significant for Group A regarding the Tree Octopus website. Most of the prospective teachers in Group A that had feeling-based epistemic beliefs, trusted the Tree Octopus website. Aesthetic appeal, organization, visit in the future and usefulness were all statistically significant in general. The qualitative data provided insight on how certain things led prospective teachers to trust or not the content on a hoax website.

For the most part aesthetic appeal, not spending sufficient time to read and evaluate, linear reading, not knowing the definition of a hoax website, feeling-based epistemic beliefs, a subjective view of truth, being trusting, displaying post-truth bias, and having an empirical view of knowledge led prospective teachers to trust the hoax websites. In contrast, the following led prospective teachers to not trust the hoax websites: not letting design influence decision to trust content, spending sufficient time to read and evaluate, lateral reading, knowing the definition of hoax website, authorship, presence of ads/asking for money, not making sense, usefulness, prior knowledge, ease of use, having a combination of feeling and evidence-based epistemic beliefs, 
evidence-based epistemic beliefs, having an objective view of truth, being skeptical, and having a multidimensional view of knowledge.

The following chapter contains the restatement of the problem, summary of the study, discussion of the results, practical implications, limitations, recommendations for future research and a conclusion. 


\section{CHAPTER V: DISCUSSION}

This chapter provides a restatement of the problem, summary of the study, and a discussion of the results. In addition, it contains practical implications, limitations, recommendations for future research and a conclusion.

\section{Restatement of the Problem}

Numerous studies suggest that there is a deficiency in evaluating the trustworthiness of a website among students (Asher \& Duke, 2011; Brem, Russell, \& Weems, 2001; Clark \& Slotta 2000; Gasser, Cortesi, Malik \& Lee, 2012; Hirsh, 1999; Wineburg \& McGrew, 2017). These studies indicate that students and some teachers show little reflective activity when evaluating the credibility of websites and/or do not distinguish conflicting information sometimes even abandoning searches after not obtaining the results they desired. Even undergraduate university students and history teachers with Ph.Ds. have fallen victim and been easily deceived by websites containing official looking logos and domain names (Wineburg \& McGrew, 2017).

Due to the amount of hoax websites and fake news that currently exists, there is a need for teachers to effectively evaluate websites and be aware of how their epistemic beliefs may influence their decision to trust a hoax website since students rely on them. This mixed method study aimed to enrich the literature on web evaluation strategies and epistemic beliefs for prospective teachers and provide a more empirical understand ing of the evaluation of hoax websites that go beyond quantitative methods.

\section{Summary of the Study}

This mixed method study investigated how teaching a specific web evaluation strategy (WWWDOT Framework) to prospective teachers, enrolled in undergraduate 
education courses, influence their trust level regarding the review of two hoax websites, what web evaluation strategies were used and how their epistemic beliefs may have influenced their evaluation. The three research questions that were answered as the result of this mixed method study are:

1. What percentage of prospective teachers trust the content on hoax websites?

2. What web evaluation strategies do prospective teachers report using regarding hoax websites?

a. What suggestions do prospective teachers have about learning web evaluation strategies?

3. What led prospective teachers to trust or not trust information posted on hoax websites?

a. How does teaching a specific web evaluation strategy (the WWWDOT Framework) to prospective teachers help them identify credible and hoax websites?

b. How do the epistemic beliefs of prospective teachers correlate to their tendency to trust or not trust information posted on hoax websites?

c. What web evaluation strategies led prospective teachers to trust or not information posted on hoax websites?

\section{Discussion of the Results}

The following section summarizes the results presented in Chapter four and provides a brief discussion for each research question. 


\section{Summary and Discussion of Results for Research Question \# 1}

Almost half of the participants (48.6\%), trusted at least one of the hoax websites. These results were consistent with numerous studies that suggest that there is a deficiency in evaluating the trustworthiness of a website among students (Asher \& Duke, 2011; Brem, Russell, \& Weems, 2001; Clark \& Slotta 2000; Gasser, Cortesi, Malik \& Lee, 2012; Hirsh, 1999) including undergraduate university students and history professors with Ph.Ds. who have trusted hoax websites (Wineburg \& McGrew, 2017).

\section{Summary and Discussion of Results for Research Question \# 2}

The qualitative data demonstrated that aesthetic appeal was the main web evaluation strategy used. This was followed by spending sufficient time to read and evaluate compared to not spending sufficient time, using linear or lateral reading, knowing the definition of a hoax website, prior knowledge, presence of ads/asking for money, if the content made sense, authorship, ease of use, presence of complex terminology, the presence of citations, and usefulness. Some were consistent with known web evaluation models, such as lateral reading (Wineburg \& McGrew, 2017), the Big6 (Eisenberg, 2003), WWWDOT Framework (Zhang \& Duke, 2011), AAOCC (Tate \& Alexander,1996; Gardner, 1999), A.S.A.P., A.S.P.E.C.T. (Clark Librarians from the Clark College Libraries (2017), etc. However, there were a few new aspects that add to the literature such as spending sufficient time to read and evaluate and knowing the definition of a hoax website. A sub question included suggestions for learning web evaluation strategies.

The suggestions for learning web evaluation strategies were to be provided with guidance, taking a web evaluation class, visiting websites, watching videos, teaching 
lateral reading, attending workshops, regulating the internet, spending sufficient time to read and evaluate and hands-on activities. These results add to the literature that prospective teachers would like to be provided with guidance through additional training in this area.

\section{Summary and Discussion of Results for Research Question \# 3}

The discussion for research question number three is organized by the WWWDOT Framework, epistemic beliefs and web evaluation strategies.

WWWDOT Framework. The WWWDOT Framework was statistically significant regarding the Tree Octopus website. The prospective teachers that were given the WWWDOT Framework (Group B) were able to identify the Tree Octopus as a hoax website at a much higher rate than Group A. The WWWDOT Framework was not statistically significant for the DHMO.org website since prospective teachers in general did not trust it based on its aesthetically unappealing design. These results add to the literature that prospective teachers may tend to not trust non-aesthetically appealing websites in general. However, a web evaluation strategy such as the WWWDOT Framework does help them identify hoax websites that are aesthetically appealing, which otherwise they would have most likely trusted.

Epistemic Beliefs. As for the epistemic beliefs, feelings were statistically significant, but the others (evidence and political) were not. Having feeling-based epistemic beliefs was statistically significant for Group A regarding the Tree Octopus website. Most of the prospective teachers in Group A that had feeling-based epistemic beliefs, trusted the Tree Octopus website. These results are consistent with Garrett and Weeks, (2017) study that confirms that epistemic beliefs have important implications for 
what is perceived as true and those who base themselves on intuition are likely to exhibit conspiracist ideation (belief of conspiracy theories). However, this study demonstrates that teaching a web evaluation strategy such as the WWWDOT Framework helps in lowering the effects of epistemic beliefs when it came to feelings and an aesthetically appealing website such as the Tree Octopus. The evidence and political epistemic beliefs were not statistically significant, these results were not consistent with Garret and Weeks (2017) study, who confirmed that individuals who maintained that beliefs should be based on evidence, were less likely to accept conspiracy theories and other falsehoods. It is possible that the evidence epistemic beliefs would have been statistically significant if the sample size would have been larger since this study had 72 participants and Garrett and Weeks' study had 510 respondents. It may also be that the political epistemic beliefs were not statistically significant because the content on the hoax websites selected were not political. Nevertheless, epistemic beliefs and web evaluation should be explored further.

Based on the interviews, a few other epistemic beliefs were displayed by prospective teachers that did not trust the hoax websites. These epistemic beliefs were having an objective view of truth, being skeptical and having a multidimensional view of knowledge. In contrast, prospective teachers that trusted the hoax websites displayed a subjective view of truth, were trusting, and had post-truth bias. These add to the literature of epistemic beliefs and web evaluation. However, the post-truth bias displayed by all the individuals who trusted the hoax websites is consistent with the notion provided by Garret and Week (2017). Garret and Week (2017 concluded that individuals tend to maintain beliefs that are aligned with their political ideology, financial view of the world, 
and ethical standards, which can influence their inclination to accept claims with little or no empirical evidence. In other words, individuals tend to maintain beliefs that are aligned with their political ideology, financial view of the world, and ethical standards, which can influence their inclination to accept claims with little or no empirical evidence (Garrett \& Weeks, 2017).

Web Evaluation Strategies. The quantitative data confirms that aesthetic appeal, organization, planning to visit the website in the future and usefulness were all statistically significant in general. However, the qualitative data provided additional insights on how certain factors led prospective teachers to trust or not the content on a hoax website. For the most part aesthetic appeal, not spending sufficient time to read and evaluate, linear reading, and not knowing the definition of a hoax website, led prospective teachers to trust the hoax websites. In contrast, the following led prospective teachers to not trust the hoax websites: not letting design influence decision to trust content, spending sufficient time to read and evaluate, lateral reading, knowing the definition of hoax website, authorship, presence of ads/asking for money, not making sense, usefulness, prior knowledge, and ease of use. The presence of ads as a factor that led individuals to not trust a website is consistent with Fogg's et al. (2002) study, who found that ads and advertising damaged the credibility of the website. Those that did not trust the hoax websites read laterally this is consistent with Wineburg and McGrew (2017), who noticed in their study that fact checkers tend to read laterally and are able to identify hoax websites at a much higher rate compared to those that read linearly or vertically. 


\section{Summary and Discussion of Hoax Websites}

Two hoax websites were selected for this study. They were the DHMO.org and the Tree Octopus website. The DHMO.org website was selected since it was created to promote media and information literacy (Watley, 2004) and the design was outdated and not aesthetically appealing. The Tree Octopus was selected because it has been used in previous studies (Krane, 2006; Baildon \& Baildon, 2012; Heine \& O’Connor, 2014; Palmer, 2014) and it is aesthetically appealing. It would have been interesting to have selected hoax websites that contained political content to see if the other epistemic beliefs (evidence and political) would have been influential in swaying participants to trust or not the content on the hoax websites.

\section{Practical Implications}

This study has practical implications for educators, students, curriculum developers, administrators and policymakers who are interested in improving prospective teachers' identification of hoax and credible websites, web evaluation strategies and the influence of their epistemic beliefs. The quantitative and qualitative results of this study provide various practical recommendations.

Based on the quantitative results, aesthetic appeal, organization, planning to visit the website in the future and usefulness were statistically significant in general. In other words, prospective teachers tended to trust websites that were described as such. The practical implication is that educators should be aware of this and teach students that some websites can be aesthetically appealing, organized, and considered useful, like the Tree Octopus, but are still a hoax. Therefore, evaluating solely by using these variables is not enough and students should be taught additional web evaluation strategies. 
The group variable was statistically significant for the Tree Octopus website. Basically, most prospective teachers in Group B did not trust it compared to Group A since they were taught the WWWDOT Framework. Based on the interviews, some said that web evaluation should be a part of the teacher's professional training (Interviewees \# 3,6 ) or even be taught in high school (Interviewee \# 3). It is recommended that a specific web evaluation strategy such as the WWWDOT Framework be taught at the undergraduate level and possibly earlier. It is suggested that curriculum developers should add the WWWDOT Framework to the general education undergraduate curriculum.

The quantitative results of the epistemic beliefs were that prospective teachers, who had feeling-based epistemic beliefs and were not taught the WWWDOT Framework, trusted the Tree Octopus website. The feeling epistemic beliefs variable was statistically significant in this case. This practical implication is that teaching the WWWDOT Framework to prospective teachers may assist those that have feeling-based epistemic beliefs to not trust hoax websites. There is also an implication for adding another component to the notion of epistemic beliefs since such beliefs by themselves do not completely explain why people trust or do not trust hoax websites. The findings of this study suggest that exposure to web evaluation strategies also plays an important part in determining whether people trust or do not trust hoax websites. Below is Figure 83 with an addition to the idea of epistemic beliefs: 


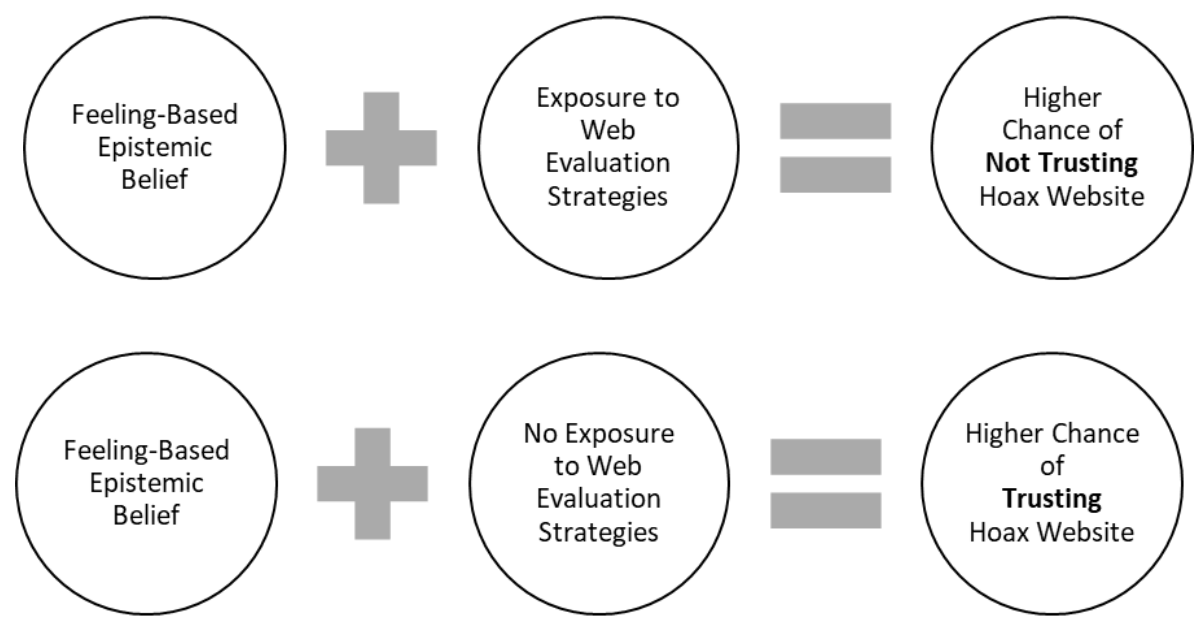

Figure 83. Epistemic Beliefs and Exposure to Web Evaluation Strategies.

Based on the interviews a few other epistemic beliefs were displayed by prospective teachers that did not trust the hoax websites. These epistemic beliefs were having an objective view of truth, being skeptical and having a multidimensional view of knowledge. In contrast, prospective teachers that trusted the hoax websites displayed a subjective view of truth, were trusting, and had post-truth bias. Educators, administrators and curriculum developers could revise web evaluation frameworks by adding a section explaining the differences between having an objective and a subjective view of truth, being skeptical instead of trusting, understanding that there are various types of knowledge, which can be true, false or have various aspects (multidimensional view of knowledge), and the effects of post-truth bias.

The interview data demonstrated that all the prospective teachers that did not trust the hoax websites practiced lateral reading, spent sufficient time reading and evaluating and most knew the definition of a hoax website. The opposite was true for those who trusted the hoax websites since they displayed linear reading, did not spend sufficient time reading and evaluating and did not know the definition of a hoax website. The 
practical implication is that educators should evaluate websites by reading laterally and should model and teach this to their students. In addition, students need to be taught to spend sufficient time to read and evaluate and know the definition of the hoax website. Curriculum designers can incorporate the definition of a hoax website, lateral reading and the importance of spending sufficient time to read and evaluate into the curriculum. There is also an implication for a proposed model of web evaluation. Below is Figure 84 with the Reading, Time and Definition (RTD) model:

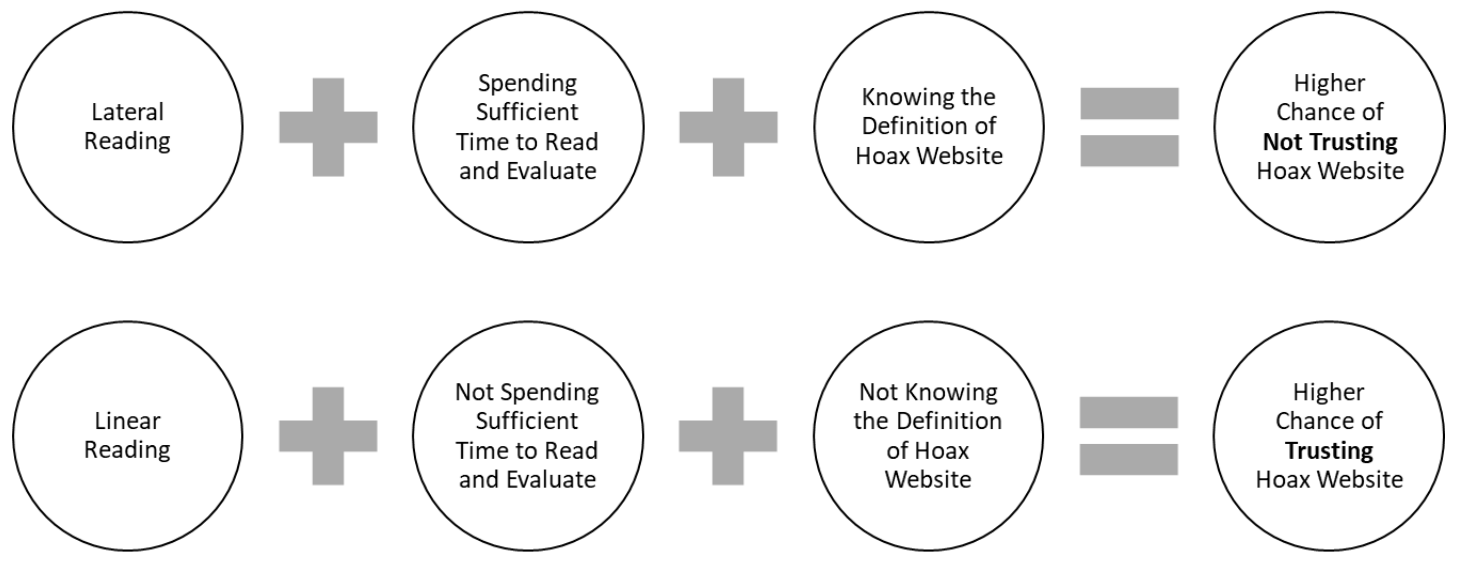

Figure 84. RTD Web Evaluation Model.

Finally, all interviewees agreed that prospective teachers should be provided with guidance regarding web evaluation and gave suggestions on learning it. These suggestions were taking a web evaluation class, visiting websites, watching videos, teaching lateral reading, attending workshops, regulating the internet, spending sufficient time to read and evaluate and hands-on activities. The practical implication is that prospective teachers should be provided with guidance regarding web evaluation by providing opportunities for them to practice their suggestions. Professional development training should be provided to teachers regarding web evaluation. Administrators and 
policymakers can organize web evaluation workshops or classes for prospective teachers at the high-school or university level. Also, these suggestions can be incorporated into the curriculum by curriculum developers. The next section contains the limitations of the study.

\section{Limitations}

The purpose of this mixed-method study was to analyze how teaching a specific web evaluation strategy (WWWDOT Framework) to prospective teachers, enrolled in undergraduate education courses, influence their trust level regarding the review of two hoax websites, what web evaluation strategies prospective teacher report using and how their epistemic beliefs may have influenced their evaluation. However, there are a few factors that may have limited the study.

This study had the following limitations:

1. The results may be partially generalizable since the participants were predominantly females taking an undergraduate education course. The results might only be generalizable to females with similar backgrounds, who are also studying to be teachers.

2. The study was limited to the field of education.

3. The majority of the participants in this study were white, although it is important to note that $67 \%$ of the University's undergraduate population, where the study took place, is Hispanic/Latino (National Center for Education Statistics, 2017). Since there was no Hispanic option in the questionnaire and participants had to type it in the "other" field, it may be that a few White/Hispanic participants simply chose the White option. In addition, race and ethnicity were combined into 
a single question on the online questionnaire. In hindsight, it would have been better to have had a question on race and a separate question on ethnicity asking specifically whether the participants were Hispanic/Latino.

4. Setting of the study. Although most participants evaluated the websites using the desktops from the university's computer lab, a few used their laptops and smartphones. There may have been some differences on how the website was displayed depending on the technology used.

Even though the study contained some limitations, this mixed-method study contributed to the knowledge base of web evaluation education. Future research should be conducted on this topic.

\section{Recommendations for Future Research}

Future research should be conducted on males and diverse ethnic groups since this study mostly had females. Future studies could contain other age groups such as K-12 grade levels. This type of research could also be expanded to other majors outside of education.

Another future study could focus on epistemic beliefs and web evaluation, by incorporating diverse hoax websites that contain political or controversial topics to see if there is a statistically significant result concerning feeling, evidence and political epistemic beliefs. This future study should consider the concept that some people in this study displayed a combination of equally predominant epistemic beliefs depending on the situation. Future research should be done to determine whether certain topics related to culture, religion, or humanities versus academics and science affect the decision of whether evidence, or feelings are used to evaluate and trust websites. Future research 
could be performed to find out what specific situations motivate them to shift between the various epistemic beliefs.

Other interesting concepts that arose from the qualitative data were the multidimensional view of knowledge and post-truth bias. These areas should be explored further in future research. Additional research could be done on the concept of post-truth bias and its effect on trusting hoax websites. A quantitative study could be done to compare it to the qualitative results of this study.

Finally, this study focused on teaching the experimental group the WWWDOT Framework, a future study could focus on other web evaluation strategies, such as lateral reading, or even information literacy in general.

\section{Conclusion}

First, this mixed method study attempted to find what percentage of prospective teachers trusted a hoax website. This study found that $48.6 \%$, almost half of the prospective teachers trusted a hoax website. It is concluded that web evaluation training and additional research is vital to possibly reduce the number of prospective teachers that trust hoax websites.

Second, this mixed method study looked at what web evaluation strategies prospective teachers reported using and suggestions they had to learn web evaluation in general. The web evaluation strategies that were statistically significant were aesthetic appeal, organization, planning to visit the website in the future and usefulness. It can be concluded that prospective teachers will tend to trust websites that are described as such and evaluating solely by using these variables is not enough. 
The interview data demonstrated that all the prospective teachers that did not trust the hoax websites practiced lateral reading, spent sufficient time reading and evaluating and most knew the definition of a hoax website. It is concluded that prospective teachers should practice lateral reading, spend sufficient time reading and evaluating and should know the definition of a hoax website to increase their chances of not trusting hoax websites.

All interviewees agreed that prospective teachers should be provided with guidance regarding web evaluation and gave suggestions on learning it. These suggestions were taking a web evaluation class, visiting websites, watching videos, teaching lateral reading, attending workshops, regulating the internet, spending sufficient time to read and evaluate and hands-on activities. It is concluded that teachers should be provided with guidance on web evaluation since they all stated that it was something they desired and needed.

Third, quantitative data and qualitative data was obtained to understand what led prospective teachers to trust, or not the content on the hoax websites. This led to finding out how their epistemic beliefs may have influenced their evaluation and how teaching a specific web evaluation strategy (WWWDOT Framework) to prospective teachers, enrolled in undergraduate education courses, influenced their trust level regarding the review of two hoax websites (DHMO.org and Tree Octopus).

Feeling-based epistemic beliefs were statistically significant for the Tree Octopus hoax website. It can be concluded that prospective teachers that have predominantly feeling-based epistemic beliefs and have not been exposed to a web evaluation strategy, 
such as the WWWDOT Framework, will tend to trust hoax websites. This can be overcome by teaching the WWWDOT Framework to prospective teachers.

A few other epistemic beliefs were displayed by prospective teachers that did not trust the hoax websites. It is concluded that having an objective view of truth, being skeptical and having an understanding that there are various types of knowledge, which can be true, false, or have various aspects (multidimensional view of knowledge) will increase the chances for prospective teachers to not trust hoax websites.

Finally, it is important to note that most prospective teachers tended to not trust hoax websites that were not aesthetically appealing, such as the DHMO.org website and teaching them the WWWDOT Framework did not have an effect. However, when it came the Tree Octopus hoax website, which was considered aesthetically appealing, the WWWDOT Framework was statistically significant and reduced the number of people that trusted it. It can be concluded that prospective teachers will tend to not trust websites that are not aesthetically appealing, but the WWWDOT Framework will help them not trust websites that are aesthetically appealing, which otherwise they would have most likely trusted. 


\section{REFERENCES}

@ realDonaldTrump. (2017, February 17). The FAKE NEWS media (failing @ nytimes, @NBCNews, @ $\mathrm{ABC}$, @CBS, @CNN) is not my enemy, it is the enemy of the American People! [Tweet]. Retrieved from https $/ /$ twitter.com/realdonaldtrump/status/832708293516632065?lang=en

Amacher, R. (1975). Humor in Franklin's Hoaxes and Satires. Studies in American Humor, 2(1), 4-20. Retrieved from http://www.jstor.org.ezproxy.fiu.edu/stable/42573065

American Library Association (1989). Presidential Committee on Information Literacy. Final Report. Retrieved from http://www.ala.org/acrl/publications/whitepapers/presidential.cfm

Asher, A. D., \& Duke, L. M. (2011). Searching for answers: Student research behavior at Illino is Wesleyan University. In L. M. Duke \& A. D. Asher (Eds.), College libraries and student culture: What we now know (pp. 71-86). Chicago, IL: ALA Editions.

Azzouni, J. (2010). Ontology and the word 'exist': Uneasy relations. Philosophia Mathematica (III), 18(1), p. 74-101. Retrieved from: http://web.ebscohost.com

Bacon, F., ed. by Joseph Devey, M.A. (1620). Novum Organum. New York: P.F. Collier. Retrieved from https:/books.google.com/books? id=Xc9xDgHgva YC\&printsec $=$ frontco ver \&sour

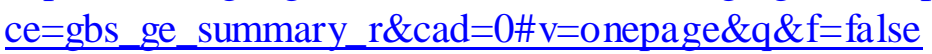

Baildon, M., \& Baildon, R. (2012). Evaluating online sources: Helping students determine trustworthiness, readability, and usefulness. Social Studies and the Young Learner, 24(4), 11-14. Retrieved from http://ezproxy.fiu.ed u/login?url=https://search-proquestcom.ezproxy.fiu.edu/doc view/1361856590?accountid=10901

Bandura, Albert. (1977). Social learning theory. Englewood Cliffs, N.J : Prentice Hall

Barthel, M., Mitchell, A., Holcomb, J. (2016). More Americans believe fake news is sowing confusion. Pew Research Center. Retrieved from http://www.journalism.org/2016/12/15/many-americans-believe-fake-news- issowing-confusion/

Boghossian P. (2016). Fear of knowledge: Against relativism and constructivism. Oxford: Clarendon Press. 
Brem, S. K., Russell, J., \& Weems, L. (2001). Science on the web: Student evaluations of scientific arguments. Discourse Processes, 32, 191-213.

Bristor, V. J., \& Drake, S. V. (1994). Linking the language arts and content areas through visual technology. T.H.E. Journal, 22(2), 74-77. Retrieved from

http://ezproxy.fiu.edu/login?url=https://search-proquestcom.ezproxy.fiu.edu/doc view/62715883?accountid=10901

Browning, N. (2017). Qatar investigation finds state news agency hacked: foreign ministry. Reuters. Retrieved from https://www.reuters.com/article/us-gulf-qatarcybercrime/qatar-investigation-finds-state-news-agency-hacked-foreign-ministryidUSKBN18Y2X4

Bryman, A. (2006). Integrating quantitative and qualitative research: How is it done? Qualitative Research, 6(1), 97-113. Retrieved from https//doi.org/10.1177/1468794106058877

Christian, J. (2017). Is There Any Hope for Facebook's Fact-Checking Efforts? The Atlantic. Retrieved from https $/ /$ www.theatlantic.com/technology/archive/2017/09/facebook-fact-checkingchallenges/540192/

Clark College Libraries (2017). Evaluating Information: A.S.A.P. and W5 for W3: A guide to evaluating information designed and created by Clark Librarians. Clark College Libraries. Retrieved from http://libraryguides.library.clark.edu/e valuating-information

Clark, D. B., \& Slotta, J. D. (2000). Evaluating media-enhancement and source authority on the Internet: The Knowledge Integration Environment. International Journal of Science Education, 22, 859-871.

Committee on Information Technology Literacy (1999). Being Fluent with Information Technology. Retrieved from www.nap.edu/openbook.php?record_id=6482

Creswell, J.W. (2008). Educational research: Planning, conducting, and evaluating quantitative and qualitative research, $3 r d$ Ed. Upper Saddle River, NJ: Pearson.

Creswell, J. W., \& Plano Clark, V. L. (2010). Designing and conduction mixed methods research. Thousand Oaks, CA: Sage.

Critical Thinking. (2017). In Oxford Dictionaries. Retrieved from https $/ /$ en.oxforddictionaries.com/definition/critical_thinking 
Crocco, M., Halvorsen, A., Jacobsen, R., \& Segall, A. (2017). Teaching with evidence. Phi Delta Kappan, 98(7), 67-71. Retrieved from http://journals.sagepub.com/doi/10.1177/0031721717702635

De Groote, I. et al. (2012). New genetic and morphological evidence suggests a single hoaxer created 'Piltdown man.' The Royal Society Publishing. Retrieved from http://rsos.royalsocietypublishing.org/content/3/8/160328

Deering, M., \& Eng, T. (1999). Published criteria for evaluating health related web sites: review. BMJ, 318, 647-649.

Dorman, W. A. (1992). Beyond reason: The media, politics, and public discourse. draft Retrieved from http://files.eric.ed.gov/fulltext/ED379167.pdf

Eaton, G., \& Hoose, P. (2016). A History of Ambition in 50 Hoaxes. Tilbury House Publishers.

Ebbinghouse, C. (1998). Frauds, hoaxes, myths, and chain letters: Or, what's this doing in my E-mail box? Searcher, 6(4), 50-53+. Retrieved from http://ezproxy.fiu.edu/login?url=https://search-proquestcom.ezproxy.fiu.edu/doc view/221074349?ac countid=10901

Eisenberg, M. B. (2003). Technology for a purpose: Technology for information problem-solving with the Big6R]. TechTrends, 47(1), 13-17. Retrieved from http://ezproxy.fiu.edu/login?url=https://search-proquestcom.ezproxy.fiu.edu/doc view/62171220?accountid=10901

Emery, D. (2017). Don't Be Fooled! A Guide to Fake News websites. ThoughtCo. Retrieved from https://www.thoughtco.com/guide-to-fake-news-websites$\underline{3298824}$

Epistemic. (2017). In Oxford Dictionaries. Retrieved from https:/en.oxforddictionaries.com/definition/epistemic

Epistemology. (2017). In Oxford Dictionaries. Retrieved from https//en.oxforddictionaries.com/definition/epistemology

Fake News. (2017). In Macquarie Dictionary. Retrieved from https $/ /$ www.macquariedictionary.com.au/resources/view/word/of/the/year/

Fallis, D. (2015). What is disinformation? Library Trends, 63(3), 401-426. Retrieved from http://ezproxy.fiu.edu/login?url=https://search-proquestcom.ezproxy.fiu.edu/doc view/1675007606?ac countid=10901 
Fidel, R., Davies, R. K., Douglass, M. H., Holder, J. K., Hopkins, C. J., Kurshner, E. J., et al. (1999). A visit to the information mall: Web searching behaviour of high school student. Journal of American Society for Information Science, 50, 24-37.

Fiegerman, S. (2017). Facebook's global fight against fake news. CNNtech. Retrieved from http://money.cnn.com/2017/05/09/technology/facebook-fake-news/

File, T. \& Ryan, C. (2014). Computer and Internet use in the United States: 2013. U.S. Census Bureau. Retrieved from https $/ /$ census.gov/content/dam/Census/library/publications/2014/acs/acs-28.pdf

Fisher, R. A. (2006). Statistical methods for research workers. Genesis Publishing Pvt Ltd.

Flavell, J. H. (1979). Metacognition and cognitive monitoring: A new area of cognitivedevelopmental inquiry. American Psychologist, 34(10), 906-911. Retrieved from http://psycnet.apa.org.ezproxy.fiu.edu/fulltext/1980-09388-001.pdf

Fogg, B.J. (2002). Stanford Guidelines for Web Credibility. A Research Summary from the Stanford Persuasive Technology Lab. Stanford University. Retrieved from https:/credibility.stanford.edu/guidelines/

Fogg, B.J., Kameda, T., Boyd, J., Marshall, J., Sethi, R., Sockol, M., and Trowbridge, T. (2002). Stanford-Makovsky Web Credibility Study 2002: Investigating what makes Web sites credible today. A Research Report by the Stanford Persuasive Technology Lab \& Makovsky \& Company. Stanford University. Retrieved from http://credibility.stanford.edu/pdf/Stanford-Mako vskyWebCredStudy2002prelim.pdf

Framework for information literacy for higher education (2016). Retrieved from http://www.ala.org/acrl/sites/ala.org.acrl/files/content/issues/infolit/Framework_I LHE.pdf

Frey, S. M. (2011). Facilitating critical thinking and self-reflection: Instructional strategies for strengthening students' online research skills. Indiana Libraries, 30(1), 49-56.

Gardner, S. A., Benham, H. H., \& Newell, B. M. (1999). Oh, what a tangled web we've woven! helping students evaluate sources. English Journal, 89(1), 39-44. Retrieved from http://ezproxy.fiu.edu/login?url=https://search-proquestcom.ezproxy.fiu.edu/doc view/237278177? ac countid=10901

Garrett, R.K., Weeks, B.E. (2017). Epistemic beliefs' role in promoting misperceptions and conspiracist ideation. PLOS ONE, 12(9): e0184733. Retrieved form https:/doi.org/10.1371/journal.pone.0184733 
Gasser, U., Cortesi, S., Malik, M., \& Lee, A. (2012). Youth and digital media: From credibility to information quality. Berkman Center for Internet \& Society. Retrieved from http://ssrn.com/abstract=2005272.

Greene, J.C., Caracelli, V.J., \& Graham, W.F. (1989). Toward a conceptual framework for mixed-method evaluation designs. Educational Evaluation and Policy Analysis, 11(3), 255-274.

Griffiths, M. D. (2017). The psychology of hoaxing: Why do individuals deliberately try to mislead others? Psychology Today. Retrieved from https //www.psychologytoday.com/blog/in-excess/201705/the-psychologyhoaxing

Gurak, L. J. (2001). Cyberliteracy: Navigating the Internet with awareness. New Haven Conn.; London: Yale University Press.

Halverson, K. L., Siegel, M. A., \& Freyermuth, S. K. (2010). Non-science majors' critical evaluation of websites in a biotechnology course. Journal of Science Education and Technology, 19(6), 612-620. Retrieved from http://ezproxy.fiu.edu/login?url=https://search-proquestcom.ezproxy.fiu.edu/doc view/822505379?ac countid=10901

Hamilton, C. (1991a). Hitler's Diaries in the Headlines. In The Hitler Diaries: Fakes that Fooled the World, 66-74, University Press of Kentucky. Retrieved from http://www.jstor.org.ezproxy.fiu.edu/stable/j.ctt130jfw9.14

Hamilton, C. (1991b). The Quest for Kujau. The Hitler Diaries: Fakes that Fooled the World, 24-32, University Press of Kentucky. Retrieved from http://www.jstor.org.ezproxy.fiu.edu/stable/j.ctt130jfw9.9

Hamilton, C. (1991c). The Selling of Adolf Hitler. In The Hitler Diaries: Fakes that Fooled the World, 48-59, University Press of Kentucky. Retrieved from http://www.jstor.org.ezproxy.fiu.edu/stable/j.ctt130jfw9.12

Heine, C. \& O'Connor, D. (2014). Teaching information fluency: How to teach students to be efficient, ethical, and critical information consumers. The Scarecrow Press, Inc, Lanham, Toronto, Lymouth, UK.

Hernon, P. (1995). Disinformation and misinformation through the Internet: Findings of an exploratory study. Government Information Quarterly, 12(2), 133-139. Retrieved from http://ezproxy.fiu.edu/login?url=https://search-proquestcom.ezproxy.fiu.edu/doc view/57371103?accountid=10901

Heyd, T. (2012). The metapragmatics of hoaxing tracking. Investigations Into the Metacommunicative Lexicon of English: A Contribution to Historical Pragmatics, 220, 
129. Retrieved from

https:/books. google.com/books?hl=en\&lr=\&id=u6pTtVkpebIC\&oi=fnd\&pg=PA $129 \& \mathrm{dq}=$ The+metapragmatics+of+hoaxing+tracking. + \&ots=JbS v6QaZeX\&sig= p_RqV-

dF1MGKsdcNwSeAHiwBpbA\#v=onepage \&q=The $\% 20$ metapragmatics $\% 20 \mathrm{of} \% 2$ 0hoaxing\%20tracking. \& $\mathrm{f}=$ false

Hirsh, S. G. (1999). Children's relevance criteria and information seeking on electronic resources. Journal of the American Society for Information Science, 50, 12651283.

Hoax. (2017). In Merriam-Webster.com. Retrieved from https://www.merriamwebster.com/dictionary/hoax

Hoax. (2017). In Oxford Dictionaries. Retrieved from https//en.oxforddictionaries.com/definition/hoax

Hobart, M. (2013). My best friend's brother's cousin knew this guy who?...?: Hoaxes, legends, warnings, and fisher's narrative paradigm Routledge. Communication Teacher, 27(2), 90-93. Retrieved from http://ezproxy.fiu.edu/login?url=https://search-proquestcom.ezproxy.fiu.edu/doc view/1509080578?accountid=10901

Hofer, B.K. (2001). Personal epistemology research: Implications for learning and teaching. Educational Psychology Review, 13, 353-383. Retrieved from https//doi.org/10.1023/A:1011965830686

Hofer, B.K., \& Pintrich, P.R. (1997). The development of epistemological theories: Beliefs about knowledge and knowing and their relation to learning. Review of Educational Research, 67, 88-140.

Hofer, B. K., \& Pintrich, P. R. (2002). Personal epistemology: The psychology of beliefs about knowledge and knowing. Mahwah: Lawrence Erlbaum Associates.

Hull, G. A., Mikulecky, L., St. Clair, R., \& Kerka, S. (2003). Multiple literacies. A compilation for adult educators. Ohio: CETE, Retrieved from https//eric.ed.gov/?id=ED482361

Information literacy competency standards for higher education (2000). Retrieved from https $/ /$ alair.ala.org/bitstream/handle/11213/7668/ACRL\%20Information\%20Liter acy\%20Competency $\% 20$ Standards $\% 20$ for $\% 20$ Higher $\% 20$ Education.pdf? sequenc $\underline{\mathrm{e}=1 \text { \&isAllowed }=\mathrm{y}}$ 
International ICT Literacy Panel. (2002). Digital transformation: A framework for ICT literacy (A report of the International ICT Literacy Panel). Princeton, NJ: Educational Testing Service. Retrieved from http://www.ets.org/Media/Research/pdf/ICTREPORT.pdf

Jackman, L.W., Weiner, S.A. (2016). The rescinding of the ACRL 2000 information literacy competency standards for higher education... really??. Libraries Faculty and Staff Scholarship Research. Paper 146. Retrieved from http://docs. lib.purdue.edu/cgi/viewcontent.cgi? article $=1155 \&$ context=lib_fsdocs

Jacobson, T. E., \& Mackey, T. P. (2013). Proposing a metaliteracy model to redefine information literacy. Communications in Information Literacy, 7(2), 84-91. Retrieved from http://ezproxy.fiu.edu/login?ur=https://search-proquestcom.ezproxy.fiu.edu/doc view/1826519855?accountid=10901

Jacobson, T. E., \& O'Keeffe, E. (2014). SEEKING-AND FINDING-authentic inquiry models for our evolving information landscape. Knowledge Quest, 43(2), 26-33. Retrieved from http:/ezproxy.fiu.edu/login?ur=https://search-proquestcom.ezproxy.fiu.edu/doc view/1620880391?accountid=10901

Jamieson, K.H. (2015). Implications of the demise of "fact" in political discourse. Proceedings of the American Philosophical Society. 159(1), 66-84. Retrieved from https://amphilsoc.org/sites/default/files/proceedings/Jamieson.pdf

Kang, C., Goldman, A. (2016). In Washington pizzeria attach, fake news brought real guns. The New Your Times, Retrieved from https:/www.nytimes.com/2016/12/05/business/media/comet-ping-pong-pizzashooting-fake-news-consequences.html

Kata, A. (2012). Anti-vaccine activists, Web 2.0, and the postmodern paradigm-An overview of tactics and tropes used online by the anti-vaccination movement. Vaccine. 30(25), 3778-3789. Retrieved from http://www.sciencedirect.com/science/artic le/pii/S0264410X11019086?via\%3Dih $\underline{\mathrm{ub}}$

Kerka, S. (1999). Consumer education for the information age. practice application brief no. 4 Retrieved from http://ezproxy.fiu.edu/login?url=https://search-proquestcom.ezproxy.fiu.edu/doc view/62384794?accountid=10901

Kiely, E., Robertson, L. (2016). How to spot fake news. FactCheck.org. Retrieved from http://www.factcheck.org/2016/11/how-to-spot-fake-news/

Krane, B. (2006). Researchers find kids need better online academic skills. University of Connecticut Advance. Retrieved from http:/advance.uconn.edu/2006/061113/06111308.htm 
Kumar, S. (2017). Characterization and detection of malicious behavior on the web (Order No. 10269027). Available from ProQuest Dissertations \& Theses A\&I; ProQuest Dissertations \& Theses Global. (1927904003). Retrieved from http://ezproxy.fiu.edu/login?url=https://search-proquestcom.ezproxy. fiu.edu/doc view/1927904003? accountid=10901

LaCapria, K. (2016). 6 Quick Ways to Spot Fake News. Snopes.com. Retrieved from http://www.snopes.com/2016/01/21/6-quick-ways-spot-fake-news/

LaCapria, K. (2017). Snopes' field guide to fake news sites and hoax purveyors. Snopes.com Retrieved from http://www.snopes.com/2016/01/14/fake-news-sites/

Langmuir, I. (1953). Pathological science. Colloquium at the Knolls Research Laboratory. Transcribed and edits by R. N. Hall. Retrieved from https $/ /$ www.cia.gov/library/readingroom/docs/CIA-RDP9600791R000100490001-4.pdf

Lewison, M., Leland, C., \& Harste, J. (2008). Creating critical classrooms: K-8 reading and writing with an edge. New York: Lawrence Erlbaum Associates.

Livingstone, S. (2004). Media literacy and the challenge of new information and communication technologies. The Communication Review, 7, 3-14.

Locke, R. A. (1975). The moon hoax: Or, a discovery that the moon has a vast population of human beings, Boston, MA: Gregg Press. This is a reprint of the original issue of 1835 .

Loxton, D., \& Prothero, D. (2013). Nessie: The loch ness monster. In Abominable Science!: Origins of the Yeti, Nessie, and Other Famous Cryptids, 118-175, Columbia University Press. Retrieved from http://www.jstor.org.ezproxy.fiu.edu/stable/10.7312/loxt15320.9

Ludlum, P. M. (1993). The evolution of parody from miss wyoming to andrea dworkin. Retrieved from http://ezproxy.fiu.edu/login?url=https://search-proquestcom.ezproxy.fiu.edu/doc view/62780508?accountid=10901

Mackey, T. P., \& Jacobson, T. D. (2014). Metaliteracy: Reinventing Information Literacy to Empower Learners. Chicago: ALA/Neal-Schuman.

Mackey, T. P., \& Jacobson, T. E. (2011). Reframing information literacy as a metaliteracy. College \& Research Libraries, 72(1), 62-78. Retrieved from http://crl.acrl.org/index.php/crl/article/view/16132 
Mackey, T. P., \& Jacobson, T. D. (2016). How can we learn to reject fake news in the digital world? The Conversation. Retrieved from

https $/ /$ theconversation.com/how-can-we-learn-to-reject- fake-news-in-the-digitalworld-69706

Martinich, A.P., Stroll, A. (2017). Epistemology. Encyclopaedia Britannica. Retrieved from https://www.britannica.com/topic/epistemology

Mason, L., Boldrin, A., \& Ariasi, N. (2010). Epistemic metacognition in context: Evaluating and learning online information. Metacognition and Learning, 5(1), 67-90. Retrieved from http://ezproxy.fiu.edu/login?url=https://search-proquestcom.ezproxy.fiu.edu/doc view/61799623?accountid=10901

McClure, R. C. (1994). Network literacy: a role for libraries? Information Technology and Libraries, 13(2), 116-117.

McDonough, B. A. (2014). Critical information literacy in practice: An interpretive synthesis Available from ERIC. (1651831278; ED545370). Retrieved from http://ezproxy.fiu.edu/login?url=https://search-proquestcom.ezproxy.fiu.edu/doc view/1651831278?accountid=10901

McFarland, J., Hussar, B., de Brey, C., Snyder, T., Wang, X., et al. (2017). The condition of education 2017. NCES 2017-144. National Center for Education Statistics. Retrieved from https://nces.ed.gov/pubs2017/2017144.pdf

McGrane, S. (2013). Diary of the Hitler diary hoax. The New Yorker. Retrieved from https $/ /$ www.newyorker.com/books/page-turner/diary-of-the-hitler-diary-hoax

Metcalfe, J., \& Shimamura, A. P. (1994). Metacognition: knowing about knowing. Cambridge, MA: MIT Press.

Mikkelson, B. (2011). Carmex Addiction: Does the lip balm Carmex contain ground glass? Snopes.com. Retrieved from http://www.snopes.com/business/secret/carmex.asp

Mikkelson, D. (2016). We have a bad news problem, not a fake news problem. Snopes.com. Retrieved from http://www.snopes.com/2016/11/17/we-have-a-badnews-problem-not-a-fake-news-problem/

Morgan, G. Leech, N., Gloeckner, G. Barrett, K. (2007). SPSS for introductory statistic, use and interpretation ( $3^{\text {rd }}$ ed.) Mahwah, New Jersey: Lawrence Erlbaum Associates. 
Morson, G. S. (1979). The war of the well(e)s. Journal of Communication, 29(3), 10-20. Retrieved from http://ezproxy.fiu.edu/login?url=https://search-proquestcom.ezproxy.fiu.edu/doc view/63719832?accountid=10901

National Center for Education Statistics. (2017). College navigator. Washington, D.C.: U.S. Dept. of Education, Institute of Education Sciences, National Center for Education Statistics. Retrieved from https $/ /$ /nces.ed.gov/collegenavigator/?q=Florida+international+university $\& s=a l l \&$ $\underline{\mathrm{id}=133951 \text { \#programs }}$

New Literacies Research Team \& Internet Reading Research Group. (2006). Results summary report from the Survey of Internet Usage and Online Reading for School District 10-C (Research Report No. 1), University of Connecticut, New Literacies Research Lab.

Nigohosian, R. H. (1996). Scholarly Internet research: Is it real? Retrieved from http://files.eric.ed.gov/fulltext/ED404985.pdf

Palmer, E. (2014). Teaching the Core Skills of Listening and Speaking. ASCD, Alexandria, VA. Retrieved from https//books.google.com/books? id=tBRRBAAAQBAJ\&pg=PA76\&lpg=PA76\&d q=tree+octopus+created+by+zapato+facts \&source=bl\&ots=3wFMQd6RPy\&sig= EsBjDF7wefgWmXK9YbAs32cyUFw\&hl=en\&sa=X\&ved=0ahUKEwjhhP3frLX WAhVX1GMKHcXxDMc4FBDoAQ g4MAQ\#v=onepage $\& \mathrm{q}=$ tree\%20octopus\% 20created $\% 20$ by $\% 20$ zapato $\% 20$ facts $\& \mathrm{f}=$ false

Peltier-Davis, C. (2009). Web 2.0, library 2.0, library user 2.0, librarian 2.0: Innovative services for sustainable libraries. Computers in Libraries, 29(10), 16-21. Retrieved from http://ezproxy.fiu.edu/login?url=https://search-proquestcom.ezproxy.fiu.edu/doc view/61835010?accountid=10901

Pennycook, G. \& Rand, D. G. (2017). Assessing the Effect of 'Disputed' Warnings and Source Salience on Perceptions of Fake News Accuracy. SSRN. Retrieved from https $/ /$ papers.s srn.com/sol3/papers.cfm?abstract_id=3035384

Perry, W. G., Jr. (1970). Forms of intellectual and ethical development in the college years: A scheme. New York: Holt, Rinehart and Winston.

Pintrich, P. R. (2002). Future challenges and directions for theory and research on personal epistemology. In: BK Hofer and PR Pintrich (eds) Personal Epistemology: The Psychology of Beliefs about Knowledge and Knowing. Mahwah, NJ: Lawrence Erlbaum Associates, pp. 389-414. 
Piper, P. S. (2000). Better read that again: Web hoaxes and misinformation. Searcher, 8(8), 40-49. Retrieved from http://ezproxy.fiu.edu/login?url=https://searchproquest-com.ezproxy.fiu.edu/doc view/221037356?accountid=10901

Plous, S. (1993). The psychology of judgment and decision making. New York: McGraw Hill.

Post-Truth. (2017). In Oxford Dictionaries. Retrieved form https $/ /$ /en.oxforddictionaries.com/definition/post-truth

Qiu, X., Oliveira, D. F. M., Shirazi, A. S., Flammini, A., Menczer, F. (2017). Limited individual attention and online virality of low-quality information. Nature Human Behavior. 1(0132), p. 1-7. Retrieved from https $/ /$ www.nature.com/articles/s41562-017-0132

Rapoza, K. (2013). Can 'fake news' impact the stock market? Forbes. Retrieved from https $/ /$ www.forbes.com/site s/kenrapoza/2017/02/26/can-fake-news-impact-thestock-market/2/\#41e37d81b45f

Robbins, R. H. (1959). The Encyclopedia of Witchcraft and Demonology. New York: Crown Publishers.

Rouet, J.-F., Favart, M., Britt, M.A., \& Perfetti, C.A. (1997). Studying and using multiple documents in history: Effects of discipline expertise. Cognition and Instruction, $15,85-106$.

Saglam, A. Ç., Çankaya, I., Üçer, H., \& Çetin, M. (2017). The effect of information literacy on teachers' critical thinking disposition. Journal of Education and Learning, 6(3), 31-40. Retrieved from http://ezproxy.fiu.edu/login?url=https://search-proquestcom.ezproxy.fiu.edu/doc view/1913354330?ac countid=10901

Schommer, M. (1990). Effects of beliefs about the nature of knowledge on comprehension. Journal of Educational Psychology, 82(3),498-504. Retrieved from https://doi.org/10.1037/0022-0663.82.3.498

Scotton, J. F., \& Reddick, D. B. (1978). Classroom hoax lesson becomes "too successful." Retrieved from http://ezproxy.fiu.edu/login?url=https://searchproquest-com.ezproxy. fiu.ed u/doc view/63786139?accountid=10901

Shiveley, J. M. (2004). Critical thinking and visiting websites: It must be elementary! Social Studies and the Young Learner, 16(4), 9-12. Retrieved from http:/www.socialstudies.org/sites/default/files/publications/yl/1604/160409.pdf

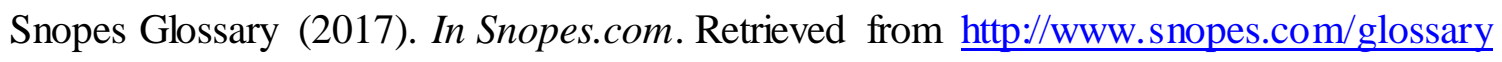


Snyder, T. D., De Brey, C. \& Dillow, S. A. (2016). Digest of education statistics: 2015. NCES 2016-014. National Center for Education Statistics. Retrieved from https $/ /$ nces.ed.gov/programs/digest/d15/ch_7.asp

Spitzer, K. L. (2000). How to use soda pop, "the blair witch project", and other methods to help students learn to evaluate web information critically. Book Report, 18(4), 21-23. Retrieved from http://ezproxy.fiu.edu/login?url=https://search-proquestcom.ezproxy.fiu.edu/doc view/62433865? ac countid=10901

Starnes, B. A. (2006). Even repeated, lies about public education STAY lies. Education Digest: Essential Readings Condensed for Quick Review, 72(4), 13-17. Retrieved from http://ezproxy.fiu.edu/login?url=https://search-proquestcom.ezproxy.fiu.edu/doc view/62031381 ?accountid=10901

Stenovec, T. (2012). Shell arctic ready hoax website by greenpeace takes Internet by storm (IMAGES). Huffington Post. Retrieved from http://www.huffingtonpost.com/2012/07/18/shell-arctic-ready-hoaxgreenpeace_n_1684222.html

Strøms $\varnothing$, H. I., Bråten, I., \& Britt, A. M. (2011). Do students' beliefs about knowledge and knowing predict their judgement of texts' trustworthiness? Educational Psychology, 31(2), 177-206. Retrieved from http://ezproxy.fiu.edu/login?url=https://search-proquestcom.ezproxy.fiu.edu/doc view/854551339?accountid=10901

Tashakkori, A. \& Creswell, J.W. (2007). The new era of mixed methods. Journal of Mixed Methods Research, 1, 3-7. Retrieved from https $/ /$ doi.org/10.1177/2345678906293042

Tate, M., \& Alexander, J. (1996). Teaching critical evaluation skills for world wide web resources. Computers in Libraries, 16(10), 49-55. Retrieved from http://ezproxy.fiu.edu/login?url=https://search-proquestcom.ezproxy.fiu.edu/docview/231086835?accountid=10901

Taylor, A., \& Dalal, H. A. (2017). Gender and information literacy: Evaluation of gender differences in a student survey of information sources. College \& Research Libraries, 78(1), 90-113. Retrieved from http://eds.a.ebscohost.com.ezproxy.fiu.edu/ehost/pdfviewer/pdfviewer? vid=1 \&sid $=6578 \mathrm{~b} 128-4 \mathrm{c} 61-4 \mathrm{~d} 98-8 \mathrm{f} 28-07 \mathrm{ee} 584 \mathrm{e} 1 \mathrm{e} 50 \% 40$ sessionmgr4010

The International Federation of Library Associations and Institutions. (2017). How to spot fake news. Ifla.org. Retrieved from https $/ /$ www.ifla.org/publications/node/11174 
The Real Story of Fake News. (2017). In Merriam-Webster.com. Retrieved from https:/www.merriam-webster.com/word s-at-play/the-real-story-of-fake-news

Thomas S. (2008). Transliteracy and New Media. In: Adams R., Gibson S., Arisona S.M. (eds) Transdisciplinary Digital Art. Sound, Vision and the New Screen. Communications in Computer and Information Science, vol 7. Springer, Berlin, Heidelberg. Retrieved from https://link.springer.com/chapter/10.1007/978-3-54079486-8_10

Trojan Horse. (2017). In Merriam-Webster.com. Retrieved from https://www.merriamwebster.com/dictionary/Trojan\%20horse

Tuominen, K. (2007). Information Literacy 2.0, Signum, 5, 6-12. Retrieved from https:/journal.fi/signum/article/download/3440/3190

Uscinski, J.E., \& Butler, R.W. (2013). The epistemology of fact checking. Critical Review. 25(2), 162-180. Retrieved from https $/ /$ doi.org/10.1080/08913811.2013.843872

Usher, W., \& Skinner, J. (2008). Health websites and reliability components. ACHPER Australia Healthy Lifestyles Journal, 55(4), 31-36. Retrieved from http://ezproxy.fiu.edu/login?url=https://search-proquestcom.ezproxy.fiu.edu/doc view/851225404?accountid=10901

Vandervoort, F. (1995). Can scientific integrity be taught? The Science Teacher, 62(4), 38. Retrieved from http://ezproxy.fiu.edu/login?url=https://search-proquestcom.ezproxy.fiu.edu/doc view/214632464? ac countid=10901

VanSledright, B., Alexander, P., Maggioni, L., Kelly, T., \& Meuwissen, K. (2004). Examining shifts in teachers' epistemologies in the domain of history. Paper presented at the annual meeting of the American Educational Research Association, San Diego, CA.

Vida, I. (2012). The "Great Moon Hoax" of 1835. Hungarian Journal of English and American Studies (HJEAS), 18(1/2), 431-441. Retrieved from http://www.jstor.org.ezproxy.fiu.edu/stable/43488485

Wang, Y. (2016). JebBush.com redirects to Trump, but for a real kick, click on TedCruzForAmerica.com. The Washington Post. Retrieved from

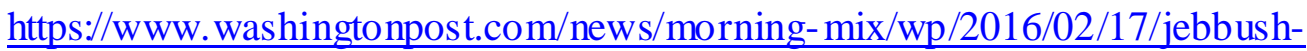
com-redirects-to-trumps-site-but-wait-till-you-see-where-tedcruzforamerica-comgoes/?utm_term=.c5afd755262

Watley (2004). The satire that almost became law. Check Please! Retrieved from http://checkplease.humorfeed.com/issues/0101/2004JuneDHMO.php 
Website. (2017). In Merriam-Webster.com. Retrieved from https//www.merriamwebster.com/dictionary/website

Weiner, J. S. (1955). The Piltdown Forgery. Oxford University Press, London.

Wen, J. R. \& Shih, W. L. (2008). Exploring the information literacy competence standards for elementary and high school teachers. Computers \& Education, 50, 787-806.

Willingham, A. J. (2016). Here's how to outsmart fake news in your facebook feed. CNN. Retrieved from http://www.cnn.com/2016/11/18/tech/how-to-spot-fakemisleading-news-trnd/index.html

Wineburg, S., \& McGrew, S. (2017). Lateral reading: Reading less and learning more when evaluating digital information. Stanford History Education Group, Working Paper No. 2017-A1. Retrieved from https $/ /$ papers.ssrn.com/sol3/papers.cfm?abstract_id=3048994

Winks, R. W. (1995). Lying to ourselves. Humanities, 16(2), 23-28. Retrieved from http://ezproxy.fiu.edu/login?url=https://search-proquestcom.ezproxy.fiu.edu/doc view/62763463 ?accountid=10901

Zapato, L. (2017). Help save the endangered Pacific Northwest tree octopus from extinction. Retrieved from http://www.zapatopi.net/treeoctopus/

Zhang, S., \& Duke, N. K. (2011). The impact of instruction in the WWWDOT framework on students' disposition and ability to evaluate websites as sources of information. Elementary School Journal, 112(1), 132-154. Retrieved from http://ezproxy.fiu.edu/login?url=https://search-proquestcom.ezproxy.fiu.edu/doc view/1018481904?accountid=10901

Zhang, S., Duke, N. K., \& Jiménez, L. M. (2011). The WWWDOT approach to improving students' critical evaluation of websites. The Reading Teacher, 65(2), 150-158.

Zurkowski, P. G. (1974). The information service environment relationships and priorities. related paper no. 5. National Commission on Libraries and Information Science, Washington, DC. National Program for Library and Information Services. Retrieved from http//files.eric.ed.gov/fulltext/ED100391.pdf 
APPENDICES 
APPENDIX A

ONLINE QUESTIONNAIRE 
Please review the website on the link below and select the option that correctly reflects whether you strongly disagree, somewhat disagree, neither agree or disagree, somewhat agree, or strongly agree with the following statements:

click here to view website \#1

\begin{tabular}{|c|c|c|c|c|c|}
\hline & $\begin{array}{l}\text { Strongly } \\
\text { disagree }\end{array}$ & $\begin{array}{c}\text { Somewhat } \\
\text { disagree }\end{array}$ & $\begin{array}{l}\text { Neither } \\
\text { agree or } \\
\text { disagree }\end{array}$ & $\begin{array}{c}\text { Somewhat } \\
\text { agree }\end{array}$ & $\begin{array}{c}\text { Strongly } \\
\text { agree }\end{array}$ \\
\hline $\begin{array}{l}\text { The website is visually } \\
\text { appealing. }\end{array}$ & 0 & 0 & 0 & 0 & 0 \\
\hline $\begin{array}{l}\text { The website is well } \\
\text { organized. }\end{array}$ & 0 & 0 & 0 & 0 & 0 \\
\hline $\begin{array}{l}\text { I trust the content } \\
\text { posted on the } \\
\text { website. }\end{array}$ & 0 & 0 & 0 & 0 & 0 \\
\hline $\begin{array}{l}\text { I plan to visit this } \\
\text { website again in the } \\
\text { future. }\end{array}$ & 0 & 0 & 0 & 0 & 0 \\
\hline $\begin{array}{l}\text { The content on the } \\
\text { website is useful. }\end{array}$ & 0 & 0 & 0 & 0 & 0 \\
\hline
\end{tabular}

Please write a few sentences of your review of the website in the section below: 
Please review the website on the link below and select the option that correctly reflects whether you strongly disagree, somewhat disagree, neither agree or disagree, somewhat agree, or strongly agree with the following statements:

click here to view website \#2

$\begin{array}{lcccc}\text { Strongly } & \text { Somewhat } & \text { Neither } & & \text { agree or } \\ \text { disagree } & \text { disagree } & \begin{array}{c}\text { Somewhat } \\ \text { disagree }\end{array} & \begin{array}{c}\text { Strongly } \\ \text { agree }\end{array}\end{array}$

The website is visually appealing.

The website is well organized.

I trust the content posted on the website.

I plan to visit this website again in the future.

The content on the website is useful.

Please write a few sentences of your review of the website in the section below: 
Please review the website on the link below and select the option that correctly reflects whether you strongly disagree, somewhat disagree, neither agree or disagree, somewhat agree, or strongly agree with the following statements:

click here to view website \#3

$\begin{array}{ccccc}\text { Strongly } & \text { Somewhat } & \begin{array}{c}\text { Neither } \\ \text { agree or } \\ \text { disagree }\end{array} & \begin{array}{c}\text { Somewhat } \\ \text { disagree }\end{array} & \begin{array}{c}\text { Strongly } \\ \text { agree }\end{array}\end{array}$

The website is visually appealing.

The website is well organized.

○

I trust the content posted on the website.

I plan to visit this website again in the future.

The content on the website is useful.

Please write a few sentences of your review of the website in the section below: 
Please review the website on the link below and select the option that correctly reflects whether you strongly disagree, somewhat disagree, neither agree or disagree, somewhat agree, or strongly agree with the following statements:

click here to view website \#4

$\begin{array}{lcccc}\text { Strongly } & \text { Somewhat } & \text { Neither } & & \text { agree or } \\ \text { disagree } & \text { disagree } & \begin{array}{c}\text { Somewhat } \\ \text { disagree }\end{array} & \begin{array}{c}\text { Strongly } \\ \text { agree }\end{array}\end{array}$

The website is visually appealing.

The website is well organized.

I trust the content posted on the website.

I plan to visit this website again in the future.

The content on the website is useful.

O

O

O

$\mathrm{O}$

O

0
O

0

0

.

(1)

O

0

O

0

0

Please write a few sentences of your review of the website in the section below: 
Please select the option that correctly reflects whether you strongly disagree, somewhat disagree, neither agree or disagree, somewhat agree, or strongly agree with the following statements:

\begin{abstract}
important than
whether something

feels true
\end{abstract}

A hunch needs to be confirmed with data

Facts are dictated by those in power

What counts as truth is defined by power

My initial impressions are almost always right

I can usually feel when a claim is true or false even if I can't explain how I know

I trust the facts, not my instincts, to tell me what is true

I need to be able to justify my beliefs with evidence

Scientific conclusions are shaped by politics

Facts depend on their political context

\begin{tabular}{|c|c|c|c|}
\hline $\begin{array}{l}\text { Strongly } \\
\text { disagree }\end{array}$ & $\begin{array}{c}\text { Somewhat } \\
\text { disagree }\end{array}$ & $\begin{array}{c}\text { Somewhat } \\
\text { agree }\end{array}$ & $\begin{array}{c}\text { Strongly } \\
\text { agree }\end{array}$ \\
\hline
\end{tabular}<smiles>[CH-]</smiles><smiles></smiles><smiles>[CH-]CO</smiles><smiles>[CH-]CO</smiles>

O

O

O

O

O

$\mathrm{O}$

O

O 0

$\bigcirc$

$\bigcirc$

O

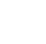


What is your Panther ID?

What is your age group?

$18-24$

25-35

35-45

45-55

above 55

What is your gender?

Male

Female 
What is your ethnicity?

White

Black or African American

American Indian or Alaska Native

Asian

Native Hawaiian or Pacific Islander

Other

What is your education major?

Early Childhood Education

Elementary Education

Physical Education

Recreation and Sport Management

Art Education

Special Education 
APPENDIX B

INTERVIEW QUESTIONS 
1. Which was your favorite website and why?

2. When you become a teacher, would you use any of the websites you evaluated, why or why not?

3. How did you evaluate the websites?

4. Can you explain the process that you used to evaluate the website? What did you do first, second and third?

5. What strategies/methods did you use to evaluate the websites?

6. What tools (survey, rubric, checklist, etc.) did you use to determine whether the information on the website was credible or not?

7. What features did you pay attention to when evaluating the websites?

8. What sources (if any) did you use for determining whether the information on the websites was credible?

9. What red flags did you notice when evaluating the websites' credibility?

10. What led you to accept or disregard the information posted on the websites?

11. What are some ways that you think teachers could learn more about evaluating hoax and credible websites?

12. What are some ways that you think students could learn more about evaluating hoax and credible websites?

13. What are your views concerning truth? What does truth mean to you?

14. What are your beliefs on the nature of knowledge?

15. How do you think your feelings, intuition or political stance affect your beliefs of the credibility of a site?

16. How do you think your beliefs on the nature and source of knowledge or how one comes to know might influence your decision on believing information posted on websites?

17. What are your views concerning whether prospective teachers should be provided with guidance or not about evaluating websites?

18. What resources do you use to verify whether information is credible?

19. What makes information credible for you?

20. What makes something true for you?

21. Do you evaluate things using feelings, intuition or do you base your evaluations on fact and evidence?

22. What is a hoax website for you?

23. Did you notice if any of the websites you evaluated were a hoax? Why or why not?

24. What led you to believe that the content on the website was true or not?

25. How do you feel after evaluating the websites?

26. Do you have any additional thoughts concerning your evaluation of the websites?

27. Do you have any additional thoughts concerning evaluating websites in general?

28. What is your age?

29. What is your gender?

30. What is your ethnicity?

31. What is your education major?

32. Other questions may include clarifying or expanding some of the responses from the questionnaire. 
APPENDIX C

QUALITATIVE THEMATIC TABLE 


\begin{tabular}{|c|c|c|c|c|c|c|c|c|}
\hline Interview \# & Page \# & Line \# & Group & $\begin{array}{c}\text { Trust Level in regards to Hoax } \\
\text { Websites } \\
\text { (Based on Survey) }\end{array}$ & Quote & Sub-themes & Themes 2 & Memo \\
\hline 1 & 1 & 22 & A & Not Trusted Hoaxes & $\begin{array}{l}\text { So to use these websites, I would use a few of them just to show my } \\
\text { students how to detect if they're reading real information or not } \\
\text { because it is i important tow specially that they are talking about fake } \\
\text { news and like random fake articles there's obviously going to be fake } \\
\text { websites as well and try and sell them fake things and take their } \\
\text { information or their money and that's important now to know. }\end{array}$ & Ads/Asking for Money & $\begin{array}{l}\text { Web Evaluation } \\
\text { Strategies }\end{array}$ & \\
\hline 1 & 2 & 20 & A & Not Trusted Hoaxes & $\begin{array}{l}\text { The ads were another thing that I paid attention to. Websites with } \\
\text { ads just want to sell you things. }\end{array}$ & Ads/Asking for Money & $\begin{array}{l}\text { Web Evaluation } \\
\text { Strategies }\end{array}$ & \\
\hline 1 & 2 & 36 & A & Not Trusted Hoaxes & $\begin{array}{l}\text { They were telling you to donate money and start your own } \\
\text { foundation about animals, but they weren't telling you why they're } \\
\text { doing this so there wasn't t really a good reason.. }\end{array}$ & Ads/Asking for Money & $\begin{array}{l}\text { Web Evaluation } \\
\text { Strategies }\end{array}$ & \\
\hline 1 & 2 & 36 & A & Not Trusted Hoaxes & $\begin{array}{l}\text { They were telling you to donate money and start your own } \\
\text { foundation about animals, but they weren't telling you why they're } \\
\text { doing this so there wasn't a really a good reason.. }\end{array}$ & Ads/Asking for Money & $\begin{array}{l}\text { Web Evaluation } \\
\text { Strategies }\end{array}$ & \\
\hline 1 & 3 & 1 & A & Not Trusted Hoaxes & $\begin{array}{l}\text { To disregard it, ads for sure. When people are like showing ads they } \\
\text { just want to sell you stuff or when their first page has links to ask you } \\
\text { for your information that's also the reason why I don't trust some } \\
\text { websites. }\end{array}$ & Ads/Asking for Money & $\begin{array}{l}\text { Web Evaluation } \\
\text { Strategies }\end{array}$ & \\
\hline 5 & 1 & 20 & A & Neutral & $\begin{array}{l}\text { Probably not because some of the websites had advertisement } \\
\text { and stuff and that's always a bad sign.(Use the websites in the } \\
\text { future) }\end{array}$ & Ads/Asking for Money & $\begin{array}{l}\text { Web Evaluation } \\
\text { Strategies }\end{array}$ & \\
\hline 5 & 1 & 25 & A & Neutral & $\begin{array}{l}\text { Ithink l evaluated it off of the looks. Yeah and how they designed it } \\
\text { the organization levels and the advertisements. }\end{array}$ & Ads/Asking for Money & $\begin{array}{l}\text { Web Evaluation } \\
\text { Strategies }\end{array}$ & \\
\hline 5 & 1 & 36 & A & Neutral & $\begin{array}{l}\text { Other times they had supporters or people who got paid for the site, } \\
\text { which is iffy. Why are they paying for the website? }\end{array}$ & Ads/Asking for Money & $\begin{array}{l}\text { Web Evaluation } \\
\text { Strategies }\end{array}$ & \\
\hline 5 & 2 & 39 & A & Neutral & The advertisements... that's pretty much it. (red flags) & Ads/Asking for Money & $\begin{array}{l}\text { Web Evaluation } \\
\text { Strategies }\end{array}$ & \\
\hline 8 & 3 & 15 & B & Not Trusted Hoaxes & \begin{tabular}{|l|} 
So some of the red flags that I noticed with the DHMO websites to me \\
the organization was not very well displayed. To me the information \\
looked really cramped and it had a lot of advertisement which \\
usually to me seem like just like a website that anybody could have \\
easily made up and edit it on their own time and put whatever \\
information they want on there so it tidn't seem like it was \\
sponsored by an actual legitimate like research company or \\
organization that had like actual information to put on the website. \\
\end{tabular} & Ads/Asking for Money & $\begin{array}{l}\text { Web Evaluation } \\
\text { Strategies }\end{array}$ & \\
\hline 8 & 4 & 1 & B & Not Trusted Hoaxes & \begin{tabular}{|l|} 
And then you also mentioned that one had $a$.org and that you \\
trusted it because it was based on an organization. What about the \\
DHMO.org why did you disregard that one even though it had $a$.org? \\
Id disregarded that one because like I said the information seemed \\
like it was easily exited by anybody there was a lot of advertisements \\
there and there was the organization like it was literally one section \\
of the website like the website didn't even fill out the whole screen \\
so it seemed poorly organized in my opinion. \\
\end{tabular} & Ads/Asking for Money & $\begin{array}{l}\text { Web Evaluation } \\
\text { Strategies }\end{array}$ & \\
\hline 8 & 4 & 13 & B & Not Trusted Hoaxes & 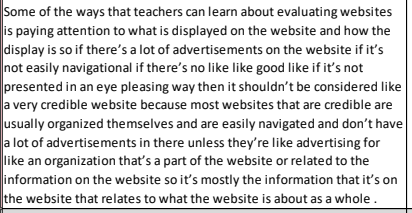 & Ads/Asking for Money & $\begin{array}{l}\text { Web Evaluation } \\
\text { Strategies }\end{array}$ & \\
\hline 10 & 2 & 14 & A & Not Trusted Hoaxes & $\begin{array}{l}\text { Information that I didn't really was unfamiliar with and also if I felt } \\
\text { like there were too many signs of pay here. }\end{array}$ & Ads/Asking for Money & $\begin{array}{l}\text { Web Evaluation } \\
\text { Strategies }\end{array}$ & \\
\hline 10 & 2 & 14 & A & Not Trusted Hoaxes & $\begin{array}{l}\text { Information that I didn't really was unfamiliar with and also if I felt } \\
\text { like there were too many signs of pay here. }\end{array}$ & Ads/Asking for Money & $\begin{array}{l}\text { Web Evaluation } \\
\text { Strategies }\end{array}$ & \\
\hline 10 & 4 & 26 & A & Not Trusted Hoaxes & $\begin{array}{l}\text { A website that basically it's demanding some form of payment } \\
\text { money you know or access to certain information and it doesn't have } \\
\text { alock on it. }\end{array}$ & Ads/Asking for Money & $\begin{array}{l}\text { Web Evaluation } \\
\text { Strategies }\end{array}$ & \\
\hline 13 & 2 & 21 & B & $\begin{array}{l}\text { Trusted One Hoax } \\
\text { but not the other }\end{array}$ & \begin{tabular}{|l|}
$\begin{array}{l}\text { efinitely, some of the websites did look very sketchy just because } \\
\text { again it wasn't simple it had a lot of things popping out. It had a lot of } \\
\text { ads and to me that just doesn't look very trustworthy. }\end{array}$ \\
\end{tabular} & Ads/Asking for Money & $\begin{array}{l}\text { Web Evaluation } \\
\text { Strategies }\end{array}$ & \\
\hline
\end{tabular}




\begin{tabular}{|c|c|c|c|c|c|c|c|c|}
\hline Interview \# & Page \# & Line \# & Group & $\begin{array}{c}\text { Trust Level in regards to Hoax } \\
\text { Websites } \\
\text { (Based on Survey) }\end{array}$ & Quote & Sub-themes & Themes2 & Memo \\
\hline 1 & 4 & 1 & A & Not Trusted Hoaxes & $\begin{array}{l}\text { As far as feel ings, 've always been one to trust my gut and I do } \\
\text { believe that people know when something is wrong. It's human } \\
\text { nature to like have an instinct of something is not going to happen in } \\
\text { a good way. As far as intuition or political stance, I've always been } \\
\text { open-minded sol I don't let that block me I'd rather look up to see if } \\
\text { something is true or not, through other sources that are credible. }\end{array}$ & $\begin{array}{c}\text { Being aware of your own bias and being } \\
\text { open-minded }\end{array} \mid$ & Epistemic Beliefs & \begin{tabular}{|l|} 
for open-minded. Also \\
this quote suggests that \\
this persons does not let \\
her feelings, intuition or \\
political stance affect \\
her decision on \\
believing a website or \\
not. $6 / 8 / 18$ \\
\end{tabular} \\
\hline 1 & 4 & 3 & A & Not Trusted Hoaxes & $\begin{array}{l}\text { As far as intuition or political stance, I've always been open-minded } \\
\text { sol don't let that block me. I'd rather look up to see if something is } \\
\text { true or not through other sources that are credible. }\end{array}$ & $\begin{array}{c}\text { Being aware of your own bias and being } \\
\text { open-minded }\end{array}$ & Epistemic Beliefs & \begin{tabular}{|l|} 
an epistemic belief or a \\
web evaluation \\
strategy? Ithink its an \\
epistemic belief...
\end{tabular} \\
\hline 2 & 3 & 38 & A & $\begin{array}{l}\text { Trusted One Hoax } \\
\text { but not the other }\end{array}$ & $\begin{array}{l}\text { Don't use only Wikipedia, use org or use edu and websites that } \\
\text { we've gone through that we know are trustworthy to show them } \\
\text { these are good websites for the research and not let them just be } \\
\text { biased to one opinion. }\end{array}$ & $\begin{array}{c}\text { Being aware of your own bias and being } \\
\text { open-minded }\end{array}$ & Epistemic Beliefs & Wikipedia \\
\hline 2 & 5 & 11 & $\mathrm{~A}$ & $\begin{array}{l}\text { Trusted One Hoax } \\
\text { but not the other }\end{array}$ & $\begin{array}{l}\text { I mostly use government or governmental websites even though they } \\
\text { are biased, but I also use. EDU websites because that's usually } \\
\text { teaching educational websites and resources that I think that are true } \\
\text { based on many websites that say the same thing continuously to not } \\
\text { be biased or not to be involved with everything else. }\end{array}$ & $\begin{array}{c}\text { Being aware of your own bias and being } \\
\text { open-minded }\end{array}$ & Epistemic Beliefs & \\
\hline 3 & 4 & 25 & A & Trusted Hoaxes & 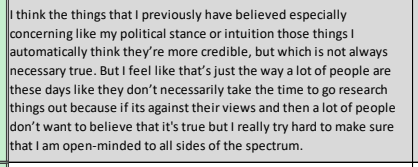 & $\begin{array}{c}\text { Being aware of your own bias and being } \\
\text { open-minded }\end{array}$ & Epistemic Beliefs & \begin{tabular}{|l|} 
This person seems to \\
know that being open- \\
minded is a better \\
choice but it aware of \\
her myside bias $7 / 7 / 18$ \\
\end{tabular} \\
\hline 3 & 5 & 29 & A & Trusted Hoaxes & 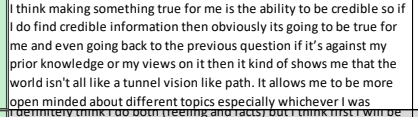 & $\begin{array}{c}\text { Being aware of your own bias and being } \\
\text { open-minded }\end{array}$ & Epistemic Beliefs & \begin{tabular}{|l|} 
open-minded seems \\
related to trusting and \\
this can be trusting hoax \\
or credible website. \\
$6 / 24 / 18$ Look into the \\
"myside bias" which \\
\end{tabular} \\
\hline 3 & 5 & 42 & A & Trusted Hoaxes & 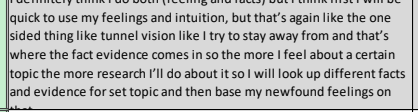 & $\begin{array}{c}\text { Being aware of your own bias and being } \\
\text { open-minded }\end{array}$ & Epistemic Beliefs & $\begin{array}{l}\text { open-minded } \\
\text { metacognition } 6 / 24 / 18\end{array}$ \\
\hline 3 & 6 & 19 & A & Trusted Hoaxes & $\begin{array}{l}\text { In general like I said, I'm definitely going to be more open-minded to } \\
\text { different websites, but it really depends on how I mean I have to look } \\
\text { past that how I feel and like figure out what I need t t know and that } \\
\text { in general it's gonna help me a lot especially teaching me because }\end{array}$ & $\begin{array}{c}\text { Being aware of your own bias and being } \\
\text { open-minded }\end{array}$ & Epistemic Beliefs & $\begin{array}{l}\text { using facts and evidence } \\
\text { instead of feelings } \\
6 / 24 / 18\end{array}$ \\
\hline 3 & 6 & 12 & A & Trusted Hoaxes & $\begin{array}{l}\text { mean it depends.. on what its talking about on the website. It can be } \\
\text { false to one person or be legitimately false so its important to be } \\
\text { open-minded you need to be able to accept other people's views in } \\
\text { make sure that you are looking at more than one side for whatever } \\
\text { you are researching. }\end{array}$ & $\begin{array}{c}\text { Being aware of your own bias and being } \\
\text { open-minded }\end{array}$ & Epistemic Beliefs & \begin{tabular}{|l} 
(trusting a hoax or \\
credible website) \\
subjective view of truth \\
6/24/18
\end{tabular} \\
\hline 3 & 6 & 19 & A & Trusted Hoaxes & 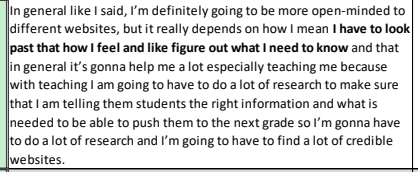 & $\begin{array}{c}\text { Being aware of your own bias and being } \\
\text { open-minded }\end{array}$ & Epistemic Beliefs & $\begin{array}{l}\text { using facts and evidence } \\
\text { instead of feelings } \\
6 / 24 / 18\end{array}$ \\
\hline 7 & 4 & 34 & B & Trusted Hoaxes & $\begin{array}{l}\text { Ithink the same as before just like evidence, facts.. } \\
\text { OK so what about when the evidence or facts do not align with your } \\
\text { beliefs? } \\
\text { Ithink then I would probably have to do further research on the } \\
\text { information because I'm a pretty open-minded person. So, I feel like } \\
\text { if more than three, four research give me the same answer, I } \\
\text { probably would then you know would switch my opinion. I'm not one } \\
\text { to really juststay o ow what I believe in if there's proven facts that } \\
\text { others things have been correct. }\end{array}$ & $\begin{array}{c}\text { Being aware of your own bias and being } \\
\text { open-minded }\end{array}$ & Epistemic Beliefs & $\begin{array}{l}\begin{array}{l}\text { Being open mided if } \\
\text { evidence points in } \\
\text { another direction. }\end{array} \\
\end{array}$ \\
\hline 13 & 3 & 21 & B & $\begin{array}{l}\text { Trusted One Hoax } \\
\text { but not the other }\end{array}$ & $\begin{array}{l}\text { Idefinitely think that some websites are biased so to their beliefs sol } \\
\text { think that when you're reading something you need to keep that in } \\
\text { mind s o if fits a way that you feel about something to remember that I } \\
\text { think to know that there's two sides to everything. }\end{array}$ & $\begin{array}{c}\text { Being aware of your own bias and being } \\
\text { open-minded }\end{array}$ & Epistemic Beliefs & $\begin{array}{l}\text { two sides to everything } \\
\text { as in not letting your } \\
\text { own bias affect decision } \\
7 / 7 / 18\end{array}$ \\
\hline 13 & 3 & 30 & B & $\begin{array}{l}\text { Trusted One Hoax } \\
\text { but not the other }\end{array}$ & 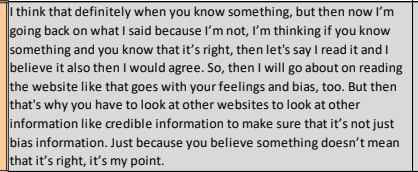 & $\begin{array}{c}\text { Being aware of your own bias and being } \\
\text { open-minded }\end{array}$ & Epistemic Beliefs & $\begin{array}{l}\text { not letting core beliefs } \\
\text { and upbringing affect } \\
\text { whether you believe or } \\
\text { not which is the } \\
\text { opposite of the "myside } \\
\text { bias" concept } 7 / 7 / 18\end{array}$ \\
\hline 16 & 4 & 5 & B & Not Trusted Hoaxes & \begin{tabular}{|l|} 
Well they definitely affect my beliefs or anybody's beliefs on the \\
credibility of a website or anything pretty much because either of \\
those things, like intuition or political stance, gives people a \\
predisposition towards things. So for example, I don't really know \\
much about polititiss in the us, but if I were a Republican and if I were \\
to see a Democrat website, most likely, I would see it as incorrect or \\
false or something else. Definitely all that affects our views because \\
it gives us a predisposition to judge things.
\end{tabular} & $\begin{array}{c}\text { Being aware of your own bias and being } \\
\text { open-minded }\end{array}$ & Epistemic Beliefs & $\begin{array}{l}\text { Being aware of your own } \\
\text { bias and predispositions } \\
\text { is related to being open- } \\
\text { minded. } 7 / 8 / 18\end{array}$ \\
\hline 16 & 4 & 16 & B & Not Trusted Hoaxes & $\begin{array}{l}\text { In the same way, based on whatever you have experienced or you } \\
\text { have seen in your rusrroundings is going to give you a solid idea on } \\
\text { how the world works. In that sense, everenbody has a predidsposition } \\
\text { towards certain things or certain situations, in general. Definitely, the } \\
\text { nature of your surrounding is going to offect how you see the } \\
\text { world. The same thing with students that come from different } \\
\text { backgrounds are going to have different predispositions for certain } \\
\text { information or content areas in the class. I think that is how we might } \\
\text { be affected by our previous knowledge. This is really phillosophical. }\end{array}$ & $\begin{array}{c}\text { Being aware of your own bias and being } \\
\text { open-minded }\end{array}$ & Epistemic Beliefs & $\begin{array}{l}\text { Being aware of your own } \\
\text { bias and predispositions } \\
\text { is related to being open- } \\
\text { minded. } 7 / 8 / 18\end{array}$ \\
\hline 13 & 4 & 13 & B & $\begin{array}{l}\text { Trusted One Hoax } \\
\text { but not the other }\end{array}$ & $\begin{array}{l}\text { Ithink what makes information credible for me is making sure that } \\
\text { there are facts. Like making sure that the website is backed up by the } \\
\text { resources or the bibliography and it shows the sources where they } \\
\text { got their information because you just don't come up with } \\
\text { everything. You have to have sources for that stuff... for what you say. }\end{array}$ & Citations & Epistemic Beliefs & citations \\
\hline & 4 & 1 & A & Not Trusted Hoaxes & $\begin{array}{l}\text { A far as feelings, I've always been one to trust my gut and I do } \\
\text { believe that people know when something is wrong. I't's human } \\
\text { nature to like have an instinct of something is not going to happen in } \\
\text { agood way. As far as intuition or political stance, I've always been } \\
\text { opoen-minded sol don't let that block me I'd rather look up to see if } \\
\text { something is true or not through other sources that are credible. }\end{array}$ & Combination of Feeling and Evidence & Epistemic Beliefs & \\
\hline
\end{tabular}


VITA

\section{JENNIFER V. COCCARO-PONS}

Born, Barranquilla, Colombia

1998-1999

Associate in Arts, Graphic/Commercial Art

Miami Dade Community College

Miami, Florida, USA

1999-2002

Bachelor of Science, Communication

University of Miami

Coral Gables, Florida, USA

2003-2005

Elementary Teacher

Miami-Dade County Public Schools

Miami, Florida, USA

2005-2007

Master of Science, Liberal Studies

Florida International University

Miami, Florida, USA

2010-2018

Doctoral Candidate, Curriculum and Instruction

Florida International University

Miami, Florida, USA

2013-2017

Web Designer, Office of Research Administration

University of Miami

Coral Gables, Florida, USA

2015-2017

Adjunct Faculty, Learning Technologies

Florida International University

Miami, Florida, USA

\section{PUBLICATIONS AND PRESENTATIONS}

Thirunarayanan, M. O., \& Coccaro-Pons, J. (2015, April). Global Information Exchange Project in a Graduate Course. Paper presented at the $26^{\text {th }}$ International Conference on College Teaching and Learning, Ponte Vedra, FL.

Thirunarayanan, M.O. \& Coccaro-Pons, J. (2016). A global information exchange (GIE) project in a graduate course. TechTrends, 60(3): 289-298. 